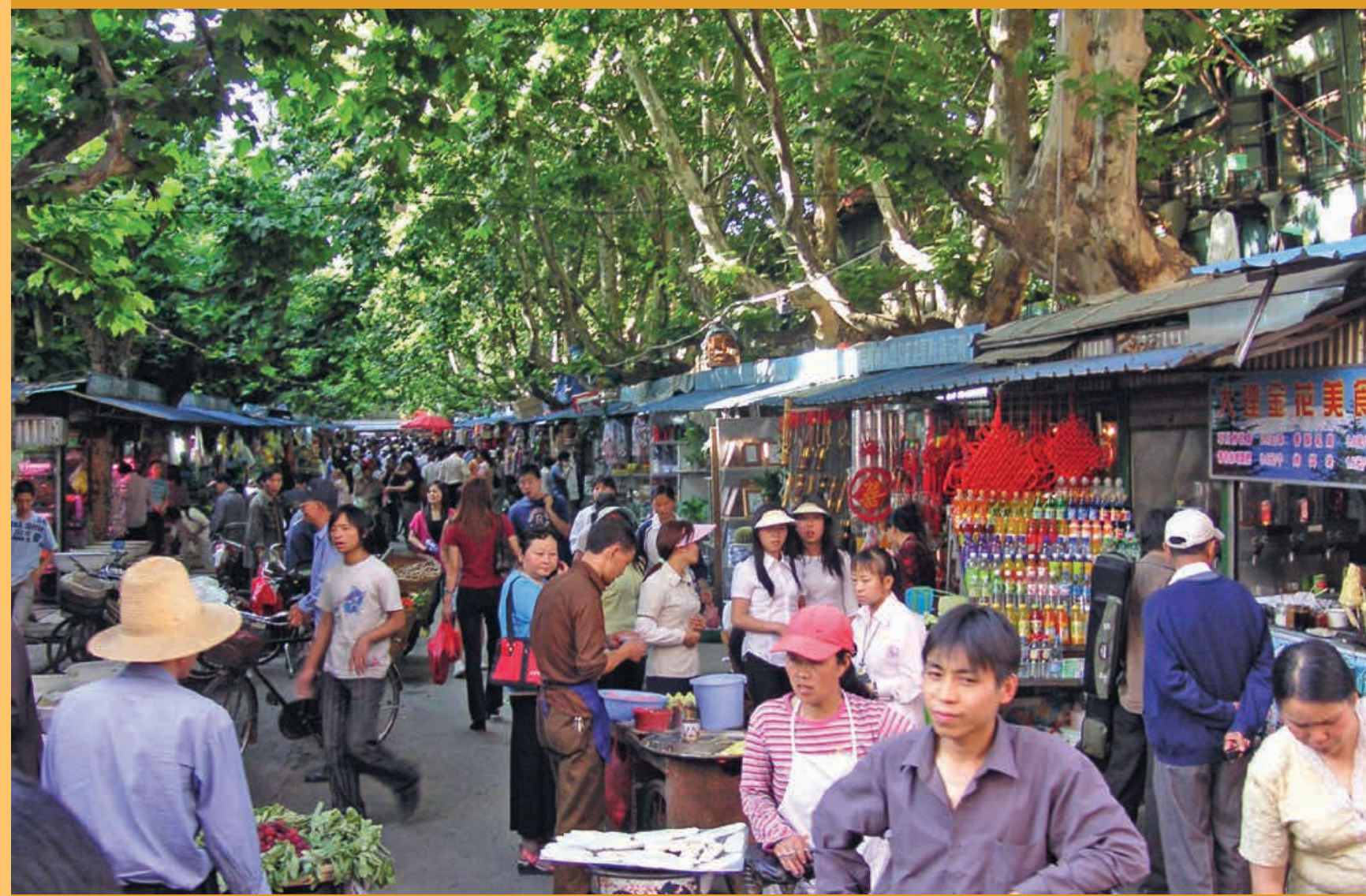

Food Systems for An Urbanizing World 


\section{FOOD SYSTEMS FOR AN URBANIZING WORLD Knowledge Product}

November, 2017

James Tefft, Marketa Jonasova, Ramziath Adjao, Anjali Morgan 
The designations employed and the presentation of material in this information product do not imply the expression of any opinion whatsoever on the part of the Food and Agriculture Organization of the United Nations (FAO) or The World Bank concerning the legal or development status of any country, territory, city or area or of its authorities. The boundaries, colors, denominations, and other information shown on any map in this work do not imply any judgment on the part off FAO or The World Bank concerning the endorsement or acceptance of such boundaries. Neither FAO nor The World Bank guarantees the accuracy of the data included in this work.

The mention of specific companies or products of manufacturers, whether or not these have been. patented, does not imply that these have been endorsed or recommended by FAO or The World Bank in preference to others of a similar nature that are not mentioned. The findings, interpretations and conclusions expressed in this information product are those of the author(s) and do not necessarily reflect the views or policies of FAO or The World Bank, World Bank Board of Executive directors, or the governments and members represented by either institution. FAO and The World Bank encourage the use, reproduction and dissemination of material in this information product. Except where otherwise indicated, material may be copied, downloaded and printed for private study, research and teaching purposes, or for use in non-commercial products or services, provided that appropriate acknowledgement of FAO and The World Bank as source and copyright holders is given and that neither FAO nor The World Bank's endorsement of users' views, products or services is implied in any way. 


\section{Contents}

Acknowledgements vii

Executive Summary ix

1. Introduction 1

1.1 Objectives 3

1.2 Methodology and Approach 4

1.3 Report Organization and Scope 5

2. Urban Food Trends and Drivers 9

2.1 Demographic Changes and Population Movements 10

2.2 Urbanization and Economic Growth 11

2.3 Food Consumption, Nutrition and Health 15

2.3.1 Processed foods 16

2.3.2 Increased consumption of food away from home (FAFH) 16

$\begin{array}{ll}\text { 2.3.3 Nutritional and health impacts } & 17\end{array}$

2.4 Rapid Technological Change and Innovation 18

2.5 Climate Change, Resource Scarcities and Shocks 19

2.6 Localized Development and Strong Stakeholder Engagement 21

2.7 Implications for the Food System 21

3. Urban Food Systems 23

3.1 Traditional, Modern and Informal Food Subsystems 24

3.1.1 Domestic food production $\quad 25$

3.1.2 Urban and peri-urban agriculture (UPA) production 25

$\begin{array}{ll}3.1 .3 \text { Food imports } & 27\end{array}$

3.2 Traditional Food Systems 28

3.2.1 Processors 29

3.2.2 Wholesale markets: Linking rural and urban economies 29

3.2.3 Open or wet markets: Fresh produce 29

3.2.4 Small independent food retailers: Convenience and service $\quad 30$

3.3 Modern Food Systems 30

3.3.1 Food processing: A rapidly growing industry 31

3.3.2 Wholesale markets/transport/logistics/importers 31

3.3.3 Modern retailers: A variety of sizes, formats and locations 32

3.3.4 Acceleration of grocery e-commerce 33

3.3.5 Restaurants 33

3.3.6 New consumer values food subsystem 34

3.3.7 Consumer store preferences: A mixed strategy 34

3.4 Informal System and the Urban Poor 35

3.4.1 Urban food insecurity 36

3.4.2 Informal street vendors: Accessible and economical 37

3.4.3 Community restaurants, food banks and soup kitchens 37

3.4.4 Formal and informal safety nets 38

$\begin{array}{lll}3.4 .5 & \text { The impact of pricing } & 38\end{array}$ 


\section{A Framework to Support Impactful Food Systems for an Urbanizing World}

41

4.1 TRANSFORM Framework 42

4.2 An Emerging Typology of Cities to Tailor Food System Responses 44

4.2.1 Food systems in the evolving urban and peri-urban governance space $\quad 45$

4.2.2 Socio-economic and population criteria 46

$\begin{array}{lll}4.2 .3 & \text { Food system criteria } & 48\end{array}$

4.2.4 Urban food city typology - The first cut $\quad 50$

\section{Enabling Conditions for Future Food Systems 53}

5.1 T: Transformative Institutions 54

5.2 F: Facilitating and Progressive Policies 56

5.2.1 Land use and urban development planning 57

5.2.2 Technology and innovation 59

5.2.3 Rethinking food and agriculture policy priorities and budgets 61

5.3 O: Open Data, Knowledge and Evidence Base $\quad 61$

5.4 R: Resources for Public and Pivate Financing 63

5.5 M: Multistakeholder Governance Mechanisms and Capacity 68

5.5.1 Food system stakeholders and multistakeholder governance mechanisms 68

5.5.2 Political economy $\quad 69$

5.5.3 Capacity development $\quad 71$

5.5.4 Emerging aspects of successful food system governance $\quad 72$

6. Intervention Areas and Key Entry Points 75

6.1 R: Remunerative Jobs and Better Agribusinesses 76

6.1.1 Supporting the informal food sector environment 77

6.1.2 Youth employment 79

6.1.3 Workforce dvelopment 80

6.1.4 Micro, small and medium-scale enterprises (MSMEs) and

6.1.5 Indicative policy, investment, capacity and knowledge interventions by city type 83

6.2 A: Affordability and Accessibility for Food Security 84

6.2.1 Modernizing food supply chains $\quad 85$

6.2.2 Reducing food loss and waste (FLW) along the food supply chain 87

6.2.3 Potential actions to reduce FLW 88

6.2.4 Food security: Social protection for the vulnerable urban poor 90

6.2.5 Indicative policy, investment, capacity and knowledge interventions by city type 92

6.3 N: Nutritious, Diverse, Quality and Safe Food 92

6.3.1 Potential policies towards more nutritious, diverse and quality diets 93

6.3.2 Public and private partnerships for nutritious food 96

6.3.3 Improving nutrition through urban and peri-urban
horticulture production

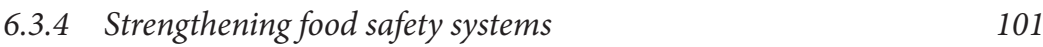


6.3.5 Indicative policy, investment, capacity and knowledge interventions by city type $\quad 105$

6.4 S: Sustainable, Resilient Agriculture and Food Systems 106

6.4.1 Environmental challenges and climate change 107

6.4.2 Non-linear resource flows 107

6.4.3 Closed loop food system practices 110

6.4.4 The rise of urban forests 111

6.4.5 Indicative policy, investment, capacity and knowledge interventions by city type 111

7. Moving Forward in Support of Urban Food 113

$\begin{array}{lll}7.1 & \text { A Brief Recap } & 114\end{array}$

7.2 Indicative Policy and Programme Entry Points 117

7.2.1 Incentives for multisector approaches 119

$\begin{array}{ll}7.3 & \text { Next Steps in the Process } \\ & 120\end{array}$

7.3.1 Development of a food system toolkit $\quad 120$

7.3.2 Experiential learning and city-to-city exchanges 121

7.3.3 Demand-driven analysis 121

7.4 Global Leadership and Aligning to the Urban Agenda 123

\section{$\begin{array}{ll}\text { 8. Annexes } & 127\end{array}$}

8.1 Indicative Policy and Action Points that Multistakeholders

Can Utilize to Address each Outcome Area 127

8.2 Indicative Project Operations (supplement to Table 7.1) 132

Endnotes

133

\section{List of Figures}

Figure 2.1 Driving Forces Shaping Future Food Systems 10

Figure 2.2 Evolving Global Urban Population by Ciy Type 11

Figure 2.3 Changes in Value Added by Income and Manufacturing Industries, 1963-2014

Figure 2.4 Changes in Employment by Income and Manufacturing Industries, 1963 to 2014

Figure 2.5 Growth in Per Capita Consumption of Processed Food Products in Asia: 1999 to $2017 \quad 16$

Figure 2.6 Share of Household Food Expenditures on Food Consumed Away from Home $\quad 17$

Figure 3.1 Evolving Food Systems: Modern, Traditional and Informal 24

Figure 3.2 Share of Urban and Peri-Urban Land in Total Global Agriculture Land 26

Figure 3.3 Food Retail Market Shares: Modern vs. Traditional 35

Figure 3.4 Prevalence of Food Insecurity among Urban and Rural Populations $\quad 36$

Figure 4.1 A Food System Framework 43

Figure 4.2 An Emerging Typology of City-Regions to Tailor Food System Interventions $\quad 51$ 
Figure 5.1 Urban Food System Actors and Issues

Figure 6.1 Composition of Jobs in the Food System In Low-, Middle-, and High-Income Countries $\quad 77$

Figure 6.2 Food Policies on Nutrition 94

$\begin{array}{lll}\text { Figure } 6.3 & \text { Food-Water-Energy Nexus } & 109\end{array}$

\section{List of Tables}

Table 2.1 Strong Growth in Farming and Off-Farm Food System Jobs in Africa $\quad 14$

Table 3.1 Types of Urban and Peri-Urban Agriculture 27

Table 5.1 Indicative Actions for Establishing "Enabling Conditions” 73

Table 6.1 Remunerative Jobs and Better Agribusiness: Indicative Policy, Investment, Capacity and Knowledge Interventions by City Type 84

Table 6.2 Affordability and Accessibility for Food Security: Indicative Policy, Investment, Capacity and Knowledge Interventions by City Type 92

Table 6.3 Nutritious, Diverse, Quality and Safe Food: Indicative Policy, Investment, Capacity and Knowledge Interventions by City Type 106

Table 6.4 Sustainable, Resilient Agriculture and Food Systems: Indicative Policy, Investment, Capacity and Knowledge Interventions by City Type

Table 7.1 Urban Food Entry Points by Intervention Type and Main Client/Partner

\section{List of Boxes}

Box 1.1 Food Systems 2

Box 2.1 The Challenge of Defining Cities in An Evolving Rural-Urban Space 12

Box 3.1 Gender and Women in UPA 28

Box 4.1 City-Region Food Systems $\quad 45$

Box 5.1 Fostering Municipal Food System Connections across City Agencies and with the Community $\quad 57$

Box 5.2 Supporting the Diverse Types of Urban and Peri-Urban Agriculture in Beijing, China $\quad 59$

Box 5.3 Belo Horizonte: Local Political Commitment and Diverse Funding 64

Box 5.4 Innovative Urban Food Financing 66

Box 5.5 Peru's Informal Sector Political Activism 70

Box 6.1 Formalizing the Informal: Singapore's Hawker Centres 78

Box 6.2 Universities in the Lead on Urban Food 80

Box 6.3 Retraining Workers in Singapore 81

Box 6.4 Food Waste Reduction, Recovery and Treatment 89

Box 6.5 Lessons from Denmark's “Fat Tax” 95

Box 6.6 Refugee Cash Transfers Generate Strong Economic Benefit to Local Communities $\quad 98$

Box 6.7 Havana, Cuba: Meeting the Vegetable Availability Challenge 99

Box 6.8 Ireland's Origin Green 109 


\section{Acknowledgements}

"Food Systems for an Urbanizing World" is the outcome of a collaborative effort between the World Bank (WB) Global Practice for Food and Agriculture and the Food and Agriculture Organization of the United Nations (FAO).

The knowledge product was prepared under the overall strategic guidance of Juergen Voegele (Senior Director, Agriculture and Food Global Practice (AGR GP); Ethel Sennhauser (Director, AGR GP) provided intellectual leadership guiding its formulation. Overall technical and operational guidance and management was provided by Preeti Ahuja (Practice Manager, AGR GP, Latin America and Caribbean Region of the World Bank, GFA04). Steven Jaffee (Lead Agriculture Economist, AGR GP, East Asia and Pacific Region of the World Bank, GFA02) contributed technical advice throughout the various iterations of the report.

The Knowledge Product was written by a team led by James Tefft (Task Team Leader, AGR GP, Global Engagements Unit (GFAGE)/FAO Investment Center), and comprising Marketa Jonasova (Co-Task Team Leader, GFAGE), Ramziath Adjao (Young Professional, South Asia Region of the World Bank, GFA12), and Anjali Morgan (Consultant, GFAGE). Other team members contributing to the report are Asa Giertz (Senior Agricultural Specialist, Africa Region of the World Bank, GFA13), Friederike Mikulcak (GFAGE), Leah Germer (Consultant, GFAGE), Fang Zhang (Consultant, GFAGE) and Alva Kretschmer (GFAGE). The team would like to thank Shunalini Sarkar and Fang Zhang for the design of graphics, figures, and infographics.

Three technical contributions on urban agriculture, urban food systems, and urban nutrition and health were provided by FAO, respectively by Makiko Taguchi (Agriculture Officer), Caroline Ledant (Consultant) and Jia $\mathrm{Ni}$ (Consultant); Jorge M. Fonseca (Nutrition and Food System Officer), Domonkos Oze (Consultant) and Ana Puhač (Consultant); and Janice Meerman (Consultant) and Rosa Rolle (Senior Enterprise Development Officer). Marielle Dubbeling (Director, RUAF Foundation) provided technical input and guidance throughout the elaboration of the report.

The team would like to extend its gratitude to the external peer reviewers for their helpful and insightful feedback: Marielle Dubbeling (Director, RUAF Foundation), Rob Vos (Director, Agricultural Development Economics Division, FAO), and Makiko Taguchi (Agriculture Officer, Plant Production and Protection Division, FAO).

The team is also grateful for internal comments received from Ziauddin Hyder (Sr. Nutrition Specialist, Health Nutrition \& Population Global Practice, GHN01), Jean Saint-Geours (Economist, Trade \& Competitiveness Global Practice, GTCCS), Megha Mukim (Sr. Urban Economist, Social, Urban, Rural \& Resilience Global Practice, GSU19), Mary Kathryn Hollifield (Lead Agriculture Economist Agriculture and Food Global Practice, GFADR), Sanna Liisa Taivalmaa (Senior Gender Specialist, GFAGE) and Roy Parizat (Senior Private Sector Specialist, Trade \& Competitiveness Global Practice, GTCCS). 
The team is equally appreciative of comments provided by FAO Investment Center colleagues: Ida Christensen (Technical Advisor), Dino Francescutti (Senior Economist), Frans Goossens (Senior Economist), Chase Palmeri (Country Programme Manager), Nuno Santos (Economist) and Alexandra Sokolova (Economist).

The team also benefited from guidance provided during the process by an informal advisory team consisting of Madhur Gautam (Lead Economist, Agriculture and Food Global Practice, South Asia Region of the World Bank, GFA12), Victor Vergara (Lead Urban Specialist, Independent Evaluation Group, IEGSD), Lorraine Ronchi (Lead Economist, Trade \& Competitiveness, GTCCS), Eugene Moses (Strategy Officer, International Finance Corporation, CMGAF) and Parmesh Shah (Lead Rural Development Specialist, AGR GP, South Asia Region of the World Bank, GFA07). 


\section{Executive Summary}

\section{Introduction}

Rapid urbanization of the planet is changing the way we think about food systems. Two percent of the global population lived in urban areas in 1900, 50 percent in 2017 and a projected 67 percent in 2050. No longer are we just concerned about feeding everyone in the world. The types of foods we eat, where we eat them and the way they are grown, processed and delivered to consumers has wide-reaching implications for the nutrition and health of people, for jobs that all societies need and for the long-term sustainability of the planet.

Our increasingly urbanizing world carries tremendous implications for food systems and for their evolution, management and performance. Urban food issues are a critical dimension of an integrated urban-rural development agenda, contributing to multiple outcomes that are key to meeting the World Bank Group's twin goals of boosting shared prosperity and reducing extreme poverty. Specifically, what happens in the food system is increasingly understood as a key dimension of the many challenges facing most governments: creating more and better jobs; addressing climate change and resource scarcity; improving nutrition and health; and ensuring food security. In other words, the long-term, agro-ecological sustainability of the food system, its resilience to shocks, its ability to assure access to affordable food for all people, the quality, safety and nutritional value of diets and the agrifood sector's capacity to create viable agribusinesses and decent jobs are critically important outcomes for the food system, with implications for the larger economy and societal goals.

Food systems issues have historically been addressed at national and provincial levels; to date, they have not figured prominently among the priorities addressed by municipalities and metropolitan districts. This is starting to change. Interest in urban food systems and the increasing engagement of cities and metropolitan districts in food issues are growing rapidly, due in large part to the admission of the signficant role cities play in the urban food production and consumption paradigm, where decentralized cooperation can sustainably help to fight against poverty and hunger in our cities. Today, it is imperative to launch the process of more deeply and systematically understanding and addressing the issues and needs arising from the shifting geography of the food system, considering the supply and demand dimensions of urban and peri-urban areas as a critical component of the global rural-urban transformation phenomenon.

To address this rapidly evolving food environment and changing institutional landscape, the World Bank's Agriculture Global Practice has initiated a process of reflection, analysis and discussion on how the World Bank, in partnership with others, can most effectively support diverse public, private and civil society actors in their efforts to advance a transformative agenda in support of urban food systems. This report, "Food Systems for an Urbanizing World," represents 
the first step in the process. Based on a desk review of the wide range of literature related to urban food issues, food systems and urban and peri-urban agriculture, the report examines available evidence and innovative initiatives as the basis for proposing a narrative, a conceptual framework and the broad parameters and priorities for efforts to improve urban food systems.

This broad survey piece has been challenged by a dearth of comparable and relevant data and information, particularly empirical evidence on policy or programme/project impacts, and the lack of fiscal/financial and economic analysis. More granular analysis in subsequent phases will require data collection and focused studies that are guided by city, country and specific sector interests and priorities. This executive summary highlights the salient findings of this report.

\section{Diverse Food Systems Responding to Rising Global Food Demand}

Urbanization offers tremendous opportunities for the US $\$ 7$ trillion global food sector, with rising incomes and a growing middle class providing a rapidly growing market for women and men to work and earn their livelihoods in the agriculture, manufacturing and service components of the food system.

The report has identified three overlapping and rapidly evolving segments or channels of the food system: a traditional system featuring urban wholesale markets, open or wet retail markets and small, independent (family-run) retail stores; an informal channel that caters to the urban poor through the use of informal food vendors and restaurants and a variety of formal and informal safety nets; and a modern channel characterized by modernized wholesale and food safety systems, capital-intensive food processing, integrated cold chains and food service firms, state-of-the-art logistics, private branding, labelling and packaging, and modern retail and restaurants.

Urban food systems are challenged to modernize in ways that support many consumers' continued preference for open markets, small retail stores, informal vendors and the integration of modern retail and e-commerce into their shopping experience. Investment, updated policy frameworks and institutional reorganization are needed to modernize and transform current critical food system functions into more competitive and resource-efficient (with low greenhouse gas emissions) functions. They include wholesale systems, market information and intelligence, food quality and safety, cold chains, transport and logistics, processing, and waste reuse. Sourcing food from rural production areas and using imports and urban and peri-urban agriculture (horticulture) can strengthen food security and resilience to potential shocks.

Informal food vendors and restaurants play a critical food security role in catering to the urban poor. Food access for the urban poor is strongly conditioned by access to housing, transport and time, in addition to income. Urban food insecurity in low-income countries, estimated by the Food Insecurity Experience Scale of the Food and Agriculture Organization of the United Nations, is higher (50\%) than levels in rural areas (43\%). In urban slums, 


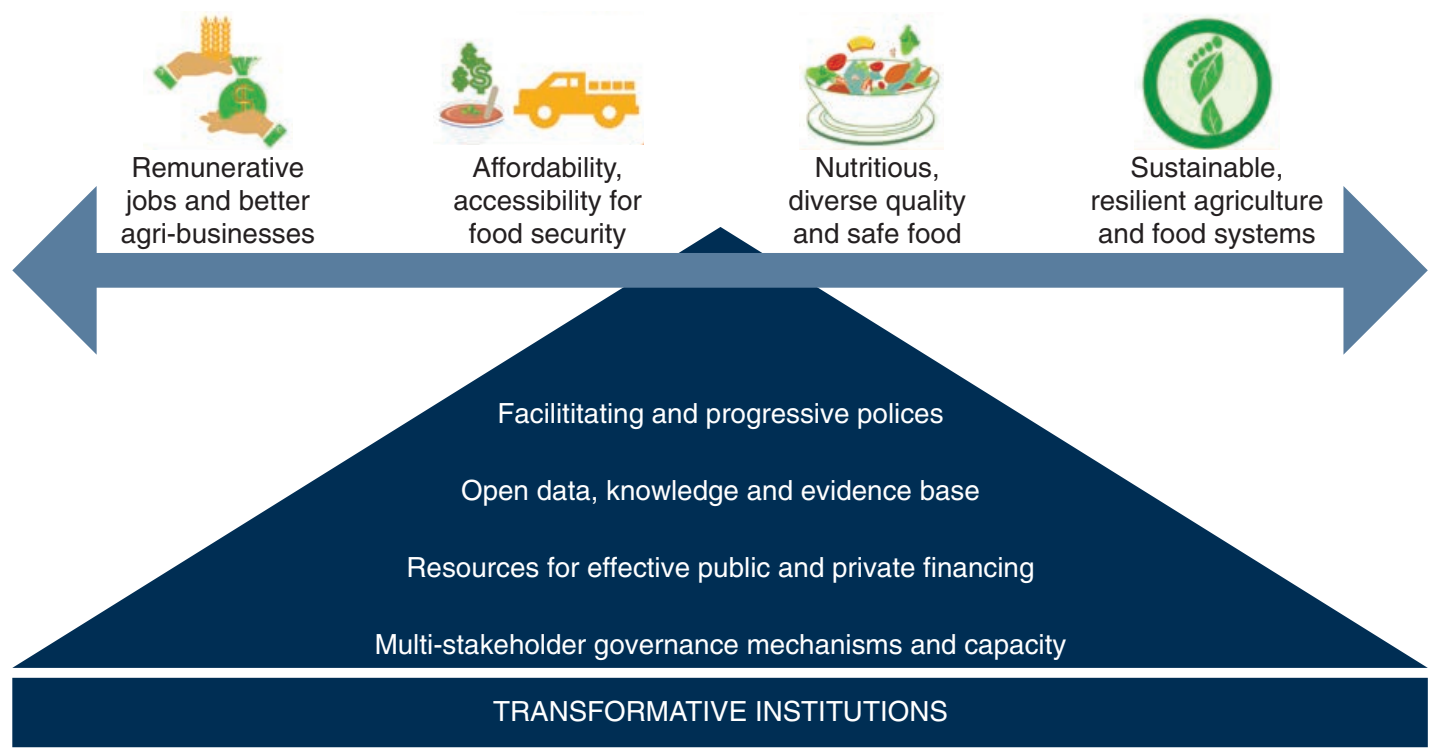

other studies estimate food insecurity at up to 90 percent. Informal safety net systems and innovative food banks contribute to boost food access for the urban poor in many cities.

\section{TRANSFORM - A Framework for Future Food Systems}

Positioning food systems to address the future challenges and opportunities will require a transformation in how we think about future goals and interventions to improve their performance. First, there is need for a transformation in the food system focus from one that has been traditionally centred on producing a sufficient quantity of food to one that strives to achieve the four interlinked outcomes:

- Remunerative jobs and better agribusinesses;

- Affordability and accessibility for food security;

- Nutritious, diverse, quality and safe food;

- Sustainable, resilient agriculture and food systems.

Achieving these interlinked outcomes would represent a quadruple win for the food system, which is in line with a vision of a food-smart city. Second, there is need to place more focus on the evolving institutional, policy and governance dimensions related to the growing role of municipal and metropolitan district governments and of private and civil society stakeholders engaged in urban food issues. This focus on the urban or downstream dimension of food systems should be viewed as an important complement to the agricultural and rural aspects in the ongoing rural-urban transformation. 
Finally, urban food issues and dimensions are inherently multisectoral, thus requiring greater attention to diverse, but often complementary, inputs from multiple sectors and actors, ensuring they are properly prioritized, planned, financed and implemented. Together, these elements underscore the important transformation that needs to take place in food systems.

These "transformations" in the food system are articulated by the TRANSFORM conceptual framework put forth by this report. The TRANSFORM food system outcomes (i.e. "RANS") can be viewed as goalposts through which to achieve poverty reduction and shared prosperity. Achieving progress in these outcome areas will be strongly contingent on the ability of countries and cities to establish a set of enabling conditions or "enablers" that are essential for effectively prioritizing, planning, designing and assuring accountable implementation of policies, programmes and investment: Transformative institutions (T); Facilitating and progressive policies (F); Open data, knowledge and evidence base (O); Resources for effective public and private financing (R); Multistakeholder governance mechanisms and capacity (M).

Stewarding these changes in the food system and in actions at the municipal level will require transformative institutions $(\mathrm{T})$ to lead the process, particularly as food issues have historically been addressed by agriculture ministries and focused around rural production issues. A locus in the form of a responsible authority, alongside mechanisms for multisectoral and stakeholder coordination and integration of food issues into urban development plans and budgets are necessary in the new urban food space. Stronger roles for municipal and metropolitan governments may augur well for pragmatic, problem-solving approaches that draw the requisite sector expertise and contributions to urban food interventions, the majority of which will be implemented by private sector and civil society actors. National-level ministries may also need to consider transformative reforms to more effectively contribute to emerging municipal agendas and those centred on "food," not just agriculture.

The enabling conditions are equally important to helping to transform food systems. The development of facilitating and progressive policies (F) and regulatory frameworks-including aspects related to urban planning with attention to food system needs, land use, tenure and technological innovation-are significant. Public, private and civil society actors need open access (O) to accurate, reliable and timely data and knowledge; use of Big Data and citizen science will require enhanced capacities for processing, understanding and using information. The effective mobilization and deployment of public and private resources (R)-including fiscal decentralization, adherence to a transparent municipal budgetary process and prudent and accountable financial management-are equally critical for financing programmes at scale and attracting private capital towards financially viable investment opportunities. The required transformation in institutions, policies and processes will require strong local leadership, the development of effective governance and accountability mechanisms, and strengthening of human and institutional capacity at these levels of government and of the diverse local stakeholders (M).

This report also proposes a provisional city typology framework to be revised and ultimately used in association with the TRANSFORM framework 
to help practitioners and policy-makers in tailoring programme and policy recommendations to types of cities with similar socio-economic, demographic and food system characteristics:

- Agrocities (agriculture towns and cities with under 1 million people);

- Secondary cities of 1 to 10 million;

- Megacities and conurbations with over 10 million people;

- Future Food-Smart cities and neighbourhoods.

An approach embracing both municipalities and their larger metropolitan districts appears to offer a pragmatic way forward, combining municipal specificity, procedures and budget with the breadth and wider political mandate of a metropolitan or city-region perspective. This provisional typology recognizes that the structure and conduct of food systems are strongly influenced by overall city wealth, size and density in addition to the specific characteristics of the food system, including the relative importance of traditional, modern and informal food marketing channels. As the knowledge base is improved, a revised, more nuanced typology will help to orient policy, programmatic and investment interventions to the specific socio-economic, demographic and food system characteristics of different types of cities.

\section{An Indicative Set of Key Food System Interventions}

In the context of the TRANSFORM framework and city typology, this report suggests a select number of indicative policy, institutional, technological, investment and capacity building measures and actions to be considered in programmes that contribute to the achievement of these food system outcomes. These intervention areas for each TRANSFORM outcome are meant to provide an initial structure for thinking about support to public, private and civil society stakeholders supported by empirical examples and available evidence. Subsequent phases will naturally need to carry out consultations with municipal and national government complemented by in-depth economic and financial analysis as the basis for formulating specific projects in these diverse areas.

As governments and diverse stakeholders come together to develop programmes and prioritize actions to address problems and accomplish goals, it is important to underline that there are multiple angles, entry points and opportunities for addressing aspects of a problem; there is not one silver bullet, one sector, one programme or one level of government to address an issue and attain results. It is also neither a linear process nor a "one action-one outcome" process; a given intervention can contribute to multiple outcome areas within the TRANSFORM framework.

- The first outcome area relates to the creation of more and better jobs and the development of agrifood businesses, through the support of the 
informal food sector, a focus on youth and women's employment, workforce development, micro-, small- and medium-scale enterprises and entrepreneurship. Getting the incentive and regulatory environment right is critical for mobilizing private sector investment, which is primed to make the domestic food economy and intraregional market a real engine of sustainable, inclusive growth.

- Improving food security through greater affordability and accessibility of food will require policy, investments, innovations and capacity building for efficient, modernized food supply chains, reducing food loss and waste, and establishing targeted, food-friendly social protection programmes for vulnerable urban populations.

- Improving the availability of and access to nutritious, diverse, quality and safe food can be addressed by policies to promote the consumption of healthy foods; facilitating innovative partnerships (e.g. with restaurants) and institutional procurement of nutritious food; strengthening food safety systems to prevent food-borne diseases; and increasing the availability and accessibility of fruits and vegetables through innovative supply sources.

- A sustainable, resilient agriculture and food system will require every system function to significantly reduce its carbon footprint through the adoption of new and improved methods, innovations and technologies such as closed-loop urban food systems or urban forestry, which help to reduce emissions and protect the land and water supply.

The interventions are premised on strong collaboration and complementarity among public, private and civil society actors and recognize the interconnectedness and interdependence of urban and rural areas as part of the same evolving social and economic processes. Opportunities for both men and women, young and old, are critical to their success. Although the discussion is oriented towards municipal and metropolitan district actions, certain interventions may be more appropriate at community, national, subregional or global levels. The success of the suggested food interventions will often depend on their systematic integration into comprehensive urban planning and budgeting processes (as part of the enabling conditions) accompanied by relevant policy and investment actions in other sectors, particularly with respect to physical and financial infrastructure, and an enabling macroeconomic and business environment. Attention to areas like labour, housing, health, education and social protection are also of paramount importance.

\section{Thinking about Programme Delivery}

For each outcome area, there exist several potential delivery mechanisms for initiating work around urban food system issues. They provide different opportunities for mobilizing stakeholders, emphasizing particular aspects, accessing financial resources and responding to priorities. At this early stage in the development of urban food programmes, it will be important to 
maintain a certain degree of flexibility and agility in responding to potential requests for support and assistance, each involving different entry points, programmatic focus and clients. Potential project areas include:

- Municipal and metropolitan district governments may be interested in establishing or strengthening the institutional and governance architecture for food system interventions (i.e. enabling conditions), serving as the basis for a comprehensive urban food programme.

- Agriculture Ministries may be interested in an urban market component for a project centred on market access or value addition or strengthening an urban and peri-urban production programme, probably in collaboration with Ministries of Environment and Water.

- National governments, whether in Agriculture Ministries, Food Security Secretariats or at an even higher policy level, may wish to upgrade national food strategies, policies and plans, requiring assistance to effectively incorporate the urban food dimension into new frameworks.

- Private sector programmes that support small- and medium-scale agrifood enterprises, entrepreneurship or financing for urban-based interventions may offer many ways to contribute to a food system agenda.

- An urban food component could be extremely relevant and included in an urban development project or programme.

- There are a myriad of other potential sector entry points for action, whether food-specific or related to another sector perspective. For example, health sector programmes centred on overweight/obesity issues or micronutrient deficiencies could integrate food system interventions that address dimensions of the given problem.

Irrespective of the entry point, lead institution or actor, it is important to underscore the multisectoral nature of food system issues, the critical contributions and synergies derived from inputs from diverse sectors, and the importance of a systems perspective afforded by the interlinked outcome areas articulated in the TRANSFORM framework.

Translating this knowledge product into operational projects and programmes will require action in several areas: technical assistance and advisory services; demand-driven analytics and investment project design; peer learning, knowledge sharing and capacity development; and partnerships for innovative projects and programmes. Global networks of cities that are currently engaged in urban food issues have consistently emphasized and continue to prioritize the need for action supported by demand-driven technical assistance. Most interventions at city and metropolitan district levels will need to be preceded by a participatory urban food assessment to provide an initial diagnostic of the urban food system. A future agenda will also include development of an operational toolkit that provides more granular, evidence-driven guidance to orient technical assistance and programme design of potential interventions.

Project work will need to be supported by a knowledge agenda driven by experiential learning from cities that have advanced in the design and 
implementation of food system interventions. A global knowledge facility based on city-to-city peer learning and capacity development for urban food practitioners could be linked to technical assistance that generates empirical evidence from existing interventions and projects. Partnership with existing global city food networks and their technical partners assures continuity, facilitates access to existing technical expertise and experienced practitioners, and keeps the process focused on client needs and priorities.

While many countries and cities wish to receive technical support, policy assistance and advisory services, it is also clear that advancing the urban food agenda towards a more refined operational footing will require a stronger evidence base upon which to design and implement project and programme actions. The short-term data and analytical focus should be centred on what is required to formulate financially, technically and socially valid projects. Collaborative analytical partnerships on issues for which there is a groundswell of interest and commitment offer great potential for action-oriented policy research that feeds into programme development. Undertaking rapid impact evaluations of promising urban food interventions can produce more rigorous quantitative and qualitative information on project technology, costs, effective institutional arrangements and capacity support needed to produce results, to replicate and to scale up. Use of crowdsourcing techniques and citizen science can offer opportunities for inclusive, practitioner-based approaches.

Diverse partnerships with city networks, experienced technical partners and diverse private sector and civil society actors can help to advance a transformative, pragmatic food system agenda that is consistent with Sustainable Development Goals and World Bank goals. For all institutions involved, efforts must be made to strengthen institutional mechanisms and develop incentives for implementing collaborative approaches and multisector programmes and projects. Innovative partnerships at global, national and municipal levels with diverse private sector and civil society actors are also key to advancing a programme and tapping into innovation, expertise and private capital that will drive urban food investment. These include restaurant chefs, architects and real estate developers, global food business incubators, university agribusiness departments, food market associations, Big Data companies and civil society groups in informal urban settlements, to name a few. Developing creative ways (e.g. secondments) to access seasoned professionals and practitioners from diverse backgrounds is critical for infusing programmes with dynamism and the requisite level of competence and experience.

\section{Conclusion}

The time is ripe to strengthen engagement on urban food issues. This report provides a broad overview of this diverse and rapidly evolving area of work. It proposes the TRANSFORM conceptual framework and city typology as a guiding approach and suggests a set of indicative interventions and delivery instruments to be further operationalized in a demand-driven approach in subsequent phases. Partnerships are crucial at all levels between diverse 
sectors and the large number of public sector institutions, private sector and civil society who have a vested interest and innovative ideas to help advance food systems. Tapping into the groundswell of stakeholder momentum, knowledge and local expertise and providing a space for their continued engagement and leadership will help to advance a transformative, pragmatic urban food agenda in support of more sustainable and resilient, more affordable and accessible, safer, nutritious, and inclusive urban and peri-urban food systems. 



\section{Introduction}

Food has always been the most essential of economic goods. Scholarship, advocacy, policies and investments over the last century have been primarily focused on agricultural production and the rural economy. This focus was natural and justified, given that most people-including most poor people-lived in rural areas and their welfare depended on agriculture. Results have been positive as agriculture growth has had a larger impact on poverty reduction than growth from outside the agriculture sector (e.g. 3.5 and 2.7 times more effective, respectively, in China and Latin America). ${ }^{1}$ But the world is rapidly becoming urban, moving from 2 percent urban in 1900 to 50 percent today and a projected 67 percent in 2050. ${ }^{2}$ The Population Division of the Department of Economic and Social Affairs of the United Nations estimates that more than 90 percent of future urban population growth will be in low- and middle-income countries. ${ }^{3}$ Moreover, it is estimated that the world will need to produce up to 50 percent more food to nourish the close to 10 billion world population by 2050 . Today, it is imperative to launch the process of more deeply and systematically understanding and addressing the issues and needs arising from the shifting geography of the food system, considering the supply and demand dimensions of urban and peri-urban areas as a critical component of the global rural-urban transformation phenomenon.

Several important trends have led to a new focus on the food system, its sustainability and resilience, its potential to create viable jobs and livelihoods, and the basis for access to affordable, safe and nutritious food. Globalization, urbanization, a rising middle class, automation and rapid technological innovation have all contributed to strong economic growth in the service sector but the world is also facing growing inequality, fragility, conflict and violence, and challenges to job creation and shared prosperity. Recent estimates provided by UN-Habitat in 2014 show that almost 900 million, mostly poor, residents live in slums and the proportion of the urban population living in slums in the developing world is about 30 percent. ${ }^{4}$ The food system currently employs or provides livelihoods for over 1.3 billion people in the world (not including the millions working in the informal urban food economy), representing one of the largest employers of men and 


\section{BOX 1.1 Food Systems}

Food systems encompass the entire range of activities involved in the production, processing, marketing, consumption and disposal of goods that originate from agriculture, forestry or fisheries, including the inputs needed and the outputs generated at each of these steps. Food systems also involve the people and institutions that initiate or inhibit change in the systems as well as the sociopolitical, economic and technological environment in which these activities take place.

Source: FAO (Food and Agriculture Organization of the United Nations). 2013. The state of food and agriculture: Food systems for better nutrition. Accessed June 30, 2017. http://www.fao.org/docrep/018/i3300e/i3300e00.htm.

women. ${ }^{5}$ Even today, over 800 million people are food-insecure, while some 2 billion suffer from micronutrient deficiencies. On the other hand, over one-third of adults are overweight or obese. In addition, the type of food being produced, distributed and consumed has been changing across the world and has been a contributor to the growing prevalence of non-communicable diseases, food-borne diseases, poor health and rising health care costs. The food system is moreover a primary climate change driver, contributing some 30 percent of greenhouse gas (GHG) emissions related to agricultural production alone.

As the world becomes increasingly urban, what people in towns and cities eat and where and how they source their food, will have strong implications for rural, peri-urban and urban areas and a strong influence on the food system overall. How the world addresses urban food issues will strongly affect future GHG emissions, weather patterns and climate change. Feeding growing urban populations in the future will require that food systems be more productive and competitive, capable of sustainably producing affordable, adequate, safe, diverse and nutritious foods. With the billions of adults suffering from diet-related morbidity or food insecurity, largely in urban areas, access to nutritious, affordable food is a critical input to improved human health and welfare and to a productive society capable of sustained, inclusive economic growth. Policies and practices related to food production, processing and distribution to urban markets will also strongly affect climate change and the use of nonrenewable resources, as well as the health of the planet. Although a vast number of poor people will continue to live in rural areas, the numbers of poor people in urban areas, including slums, "inner" cities and refugee camps are expected to remain staggeringly high unless concerted action on many fronts is taken and sustained. Cities need to create jobs for billions of people, with a large share among them consisting of poor, under-resourced and under- or unskilled workers; the food system-including light manufacturing, services and primary production-can serve as one of the largest employers and sources of inclusive growth and poverty reduction in all types of economies and cities. 
Food is everyone's business; it concerns all. Business as usual will not be sufficient as the interoperability of actions and actors around the food system is necessary for sustainability, productivity and progress. More systematic consideration of the vital, dynamic and growing urban segment of food systems will naturally focus attention on the downstream, value-addition portions of value chains, helping to enhance their productivity and competitiveness, which in turn will drive growth, incomes and poverty reduction in rural and urban areas. This will help revitalize rural, urban and peri-urban producers' economic activity, giving greater attention to the important issues of changing consumer food demand, market access and value chain competitiveness. Systematic efforts will also consider diverse food and ecosystem products and services that increase resilience and contribute to a better quality of life in rapidly evolving urban landscapes and in the increasingly blurring continuum between peri-urban and peri-rural areas. Finally, a more proactive approach will include systematically integrating food issues into multisectoral and multi-actor actions. More than ever, ensuring environmentally, socially and economically sustainable, resilient, affordable, safe, nutritious and inclusive food systems will depend on consistent and well-aligned policy, institutional, technological and investment actions from other sectors, ministries and actors-public and private.

\subsection{Objectives}

The report seeks to examine the key issues within a framework of interlinked outcome areas that will affect the future of the food system in urban and peri-urban areas and suggest impactful pathways on which to focus future programmes. It represents the first step in the process of determining how the World Bank, in partnership with others, could assist national governments, municipalities and metropolitan districts to address urban food issues. This report aims to set the broad parameters of an approach and propose a narrative as to how this could happen. A firm grounding in the World Bank's twin goals of ending extreme poverty and promoting shared prosperity-including in International Development Association countries-positions urban food as an integral component within the Food and Agriculture Global Practice's programme of work. It represents a fusion between the second Sustainable Development Goal (SDG 2) to "End hunger, achieve food security and improved nutrition, and promote sustainable agriculture" and SDG 11 to "Make cities inclusive, safe, resilient and sustainable," ${ }^{\text {wh }}$ wile at the same contributing to several other SDGs.

It is in this context that this report presents the TRANSFORM conceptual framework as an instrument for addressing these interdependent challenges. This framework posits that future food systems must be focused on delivering impact in four interlinked outcome areas: Remunerative jobs and better agribusiness; Affordability and accessibility for food security; Nutritious, diverse, quality and safe food; and Sustainable, resilient agriculture and food systems. 
These represent the centre of the framework (i.e. RANS). Achieving progress in these outcome areas will be strongly conditioned by Transformative institutions and four other enabling conditions: Facilitating and progressive policies; Open data, knowledge and evidence base; Resources for effective public and private financing; and Multistakeholder governance mechanisms and capacity (i.e. FORM). Gender-differentiated considerations and approaches are essential in order to maximize the contributions of both women and men.

\subsection{Methodology and Approach}

The report is intended as a think piece for use by World Bank Group staff. It aims to serve as a foundation upon which practical operational knowledge and tools related to the urban and peri-urban dimensions of food systems can be subsequently developed. Given the relative newness of the field and lack of consensus on the potential directions that country and city-level support should take, the World Bank has adopted an iterative and phased "peel the onion" approach. During this first phase, the report takes stock of the current situation, examines available evidence and suggests priorities for potential actionable areas. Subsequent steps will build on this initial broad diagnostic, delving into further analytical detail and the development of operational instruments to guide practitioners in the design and implementation of future actions. As such, this report may be of value to external parties.

Given the interdependent and growing food-water-energy nexus affecting the billions of people living in secondary towns, suburban areas and cities, the World Bank's work on urban food systems must fundamentally be guided by a poverty perspective and a clear focus on improving the welfare of the bottom 40 percent of the population. Insofar as many of the challenges and outcomes discussed here concern a wide variety of towns and cities of diverse socio-economic levels, however, this initial report includes a review of innovative actions being taken by cities and countries throughout the world. In other words, it attempts to learn from the good and better practices globallywhether cities are rich or poor, located in the north, south, east or west. As all cities are challenged to varying degrees by food issues, particularly with respect to improving the livelihoods and food security of the urban poor, the traditional dichotomy between high-income and low-income countries is not germane at this stage in the process.

This work is based primarily on a desk review of the wide range of literature on urban food issues and urban and peri-urban agriculture (UPA). Given the aim to produce a guiding narrative and framework, this review is purposely broad. Based on a concept note, internal and external peer reviewers provided comments and recommendations. The work was also facilitated by three technical contributions related to urban agriculture, urban food systems, and urban nutrition and health that were provided by the Food and Agriculture Organization of the United Nations. ${ }^{7}$ Although in-depth analyses of World Bank data sets was not undertaken for the purposes of this report, complementary diagnostic work on closing some of the gaps in urban food systems 
data approaches has been initiated to better understand the nexus between the urban poor and associated food systems.

This review and the associated approach and methodology were clearly affected by the dearth of consistent, comparable and relevant data and information, particularly in terms of time series, empirical evidence on policy or programme/project results and impacts, and related fiscal/financial and economic analysis. This is an important finding, as empirical data and evidence are the basis of effective decision-making. The absence of robust evidence and quantitative results may challenge the reader. As noted, subsequent phases will seek to address these data and analysis challenges, including information related to investment costs and potential returns of potential programme interventions, for which there is currently a scarcity of reliable information.

\subsection{Report Organization and Scope}

The report is organized into seven chapters, as follows, with additional text supported by data in the annexes:

- This first chapter sets out the context for the report, presents the objectives, outlines the methodology and approach, and briefly introduces the scope and organization.

- Chapter 2 looks at the key drivers and underlying trends that are already shaping the agenda or will influence the future of urban food issues.

- Chapter 3 pulls together relevant data and information to describe the structure and performance of the three interrelated channels in urban food system - traditional, modern and informal - the latter catering primarily to the urban poor.

- Chapter 4 introduces the TRANSFORM framework of the interlinked food system outcome areas related to job creation, affordability and accessibility, security and nutrition, and sustainability and resilience. It also discusses an initial typology of cities based on demographic and food system criteria with which to begin to consider priority interventions.

- Chapter 5 discusses the enabling conditions of the TRANSFORM framework: Transformative institutions; Facilitating and progressive policies; Open data, knowledge and evidence base; Resources for effective public and private financing; and Multistakeholder governance mechanisms and capacity.

- Chapter 6 examines four broad areas of intervention to achieve results in the interlinked outcome areas: Remunerative jobs and better agribusinesses; Affordability and accessibility for food security; Nutritious, diverse, quality and safe food; and Sustainable, resilient agriculture and food systems. An initial set of indicative interventions and entry points are presented for each area, with further refinement and precision to be determined by analysis and consultation in subsequent phases. 
- Chapter 7 synthesizes the salient findings and proposes a streamlined and succinct approach for advancing this important agenda, including potential instruments and programme sequencing, key information and data gaps, and partnership opportunities.

\section{Mina: Carbon-Neutral Living in Ecopia}

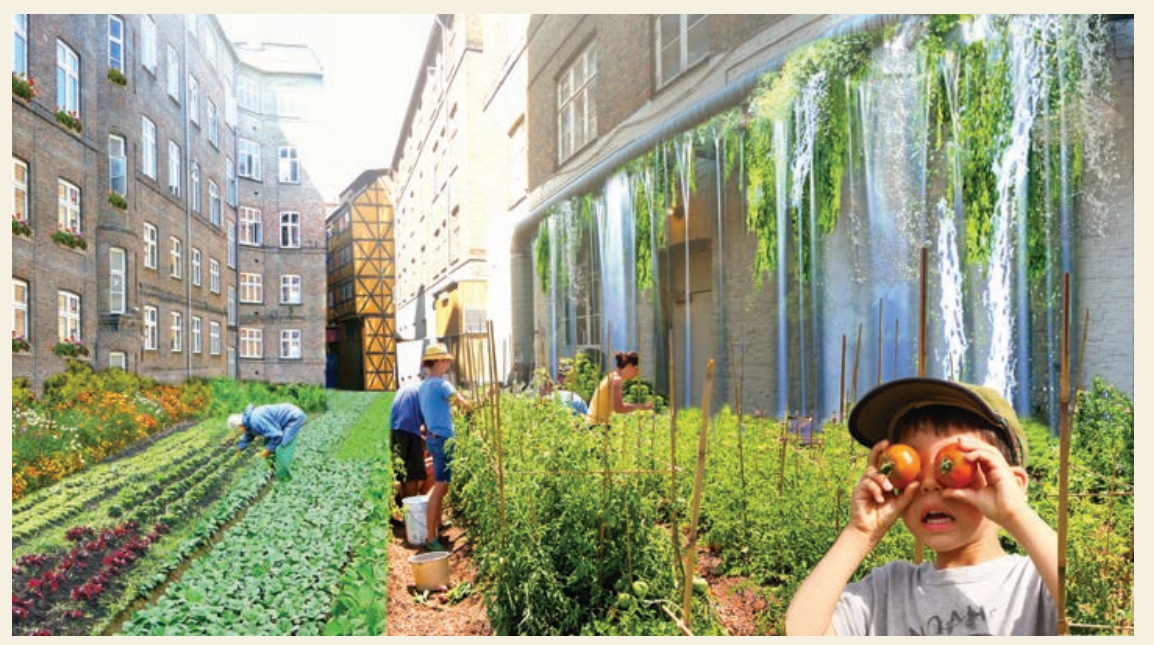

(C) Mark Stevens/Flickr. Further permission required for reuse.

Mina moved to Ecopia in 2044 in hopes of finding a community that supported her lifestyle. Mina loves to eat beans and lentils, but still likes an occasional Eco Burger, her favorite of the second generation of cell-cultured, lab-produced meat burgers; they ooze red juice when her robot cooks them on her solar-powered grill. She eats chicken kebabs from time to time that she buys at her neighbourhood vendor centre, but feels it usually isn't worth using her allocation of ClimateNeutral (CN) points on costly animal protein.

You see, what attracted Mina to Ecopia is the city's carbon-neutral food policy that had been piloted and subsequently scaled up over the previous decade. The opportunity to make money by trading her monthly allocation of animal protein credits on the city's eco-nut virtual market was plenty motivating. All food products are assigned a climate and sustainable resource use rating based on the greenhouse gas (GHG) emissions and resources used to produce, transport, process and market the item and dispose of any waste. Every citizen's monthly CN point allocation is credited to their arm-embedded $\mathrm{CN}$ card chip, which enables consumers to purchase those food items with a positive $\mathrm{CN}$ score (or negative depending on how you look at it). CN points can be used in either stores or restaurants. Mina's preference for climate-neutral foods (which are zero $\mathrm{CN}$ points), allows her to sell her $\mathrm{CN}$ points to people who consume more animal protein. She never feels that 


\section{Mina: Carbon-Neutral Living in Ecopia (continued)}

she is depriving herself of any food, given that the joint venture food innovation labs have mastered the science of naturally creating such tasty lab meat with jerk, Szechuan, French or Senegalese flavouring.

The money she saves from the sale of her $\mathrm{CN}$ points helps pay the mortgage on her SmartPart, her fashionable, sensor-laden, resource-neutral apartment in Ecopia's Smart Park. Fortunately, Mina, like all residents, receives tax breaks on her climate-neutral SmartPart. Mina was also fortunate to have studied sensor engineering and her knowledge of all the sensors used throughout the SmartPart complexes is in high demand. She still can't believe that she is paid to oversee and repair the sensor systems used throughout the Smart Park; it is truly the best application of the Internet of Food Things. She works a full work week of 25 hours, giving her enough time to help neighbours with their waterless microgardens that use agar-agar gel as a growing medium. Mina likes the feel of dirt, however, so she still grows her trellises of green peas and $\mathrm{CO}_{2}$-loving plants.

The most challenging sensors are those used for linking the grey water re-use and treatment system with the community gardens and aeroponic vertical farming greenhouse system that produce the most flavorful greens and peppers. I forgot to mention that Ecopia is one of the urban areas that come closest to a closed-loop, zero waste food system, established through a comprehensive incentive and regulatory framework that ensures that almost every resource is recovered, reused or recycled.

Plastics are banned in Ecopia, but Mina loves the new next-generation food packaging, which is food-based and melts or dissolves in water after use, which Ecopia's Biomimicry Lab helped create. She is also proud that Ecopia is known as one of the cleanest and coolest cities around-figuratively and temperature-wise. You see, Ecopia is built with the newest generation of green infrastructure, including integrated storm water and rainwater harvesting systems, rain gardens, green roofs and permeable pavements, all of which help to recharge the aquifer.

The municipal government, civil society, real estate developers, architects, utility companies and other private sector actors have formalized a partnership to design, build and operate the city. It was only when they agreed to a long-term collaboration that tied private sector profits to total implementation and resource efficiency and stipulated use of local labour and small businesses that things really took off. Fortunately, surplus water and energy sales to other cities are so profitable that Ecopia's innovative community profit-sharing schemes are reinvesting in development of sister cities across the globe. Mina is excited about Ecopia’s role in shaping the future of the earth.

Read about Elio on page 39

Note: The three Avatar stories presented in this report were written with a view to share some ideas and spur some thought about urban food issues in the future. They do not in any shape or form represent the World Bank vision for future food systems. 



\section{2}

\section{Urban Food Trends and Drivers}

\section{Key Messages}

- Rapid urbanization is a global phenomenon, but is especially occurring in Africa and Asia, where 90 percent of future urban growth will occur.

- As national income rises, the food sector experiences value-added growth and job creation, but may be affected by new technologies that spur job dislocation.

- A growing demand for meat and dairy products, convenient, processed foods and meals consumed outside the home is contributing to the rising over-nutrition epidemic on the one hand and micro-nutrient deficiency on the other-factors that are increasing health care costs and leading to new demands on the food system.

- Climate change demands sustainable, resource-efficient food systems in the face of rising temperatures, land use change and water scarcity, threating food security today and the ability to feed a growing population.

- At a time when involuntary human displacement is occurring at record levels, local actors and governments can lead innovative solutions to a range of food and nutrition security challenges.

Throughout the history of agriculture and socio-economic development, the rural-urban nexus has witnessed strong cross-fertilization and movements of resources, capabilities, contracts and information. Over the past several decades, however, the movement of humans, goods and services is increasingly directed towards urban centres. This chapter looks at a number of key exogenous factors and evolving trends that have been driving structural changes in the overall food system and will affect its response to challenges of sustainability, affordability, nutrition and inclusiveness (Figure 2.1). 


\section{FIGURE 2.1 Driving Forces Shaping Future Food Systems}

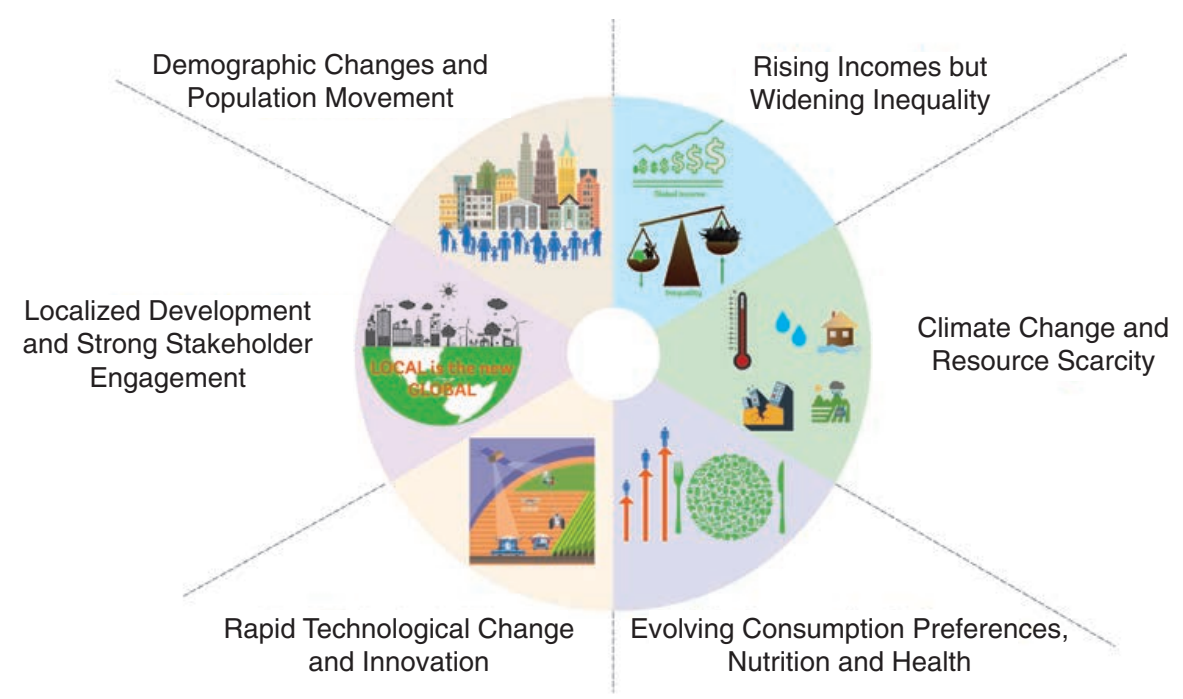

\subsection{Demographic Changes and Population Movements}

At the forefront of today's significant changes are population growth, urbanization, migration (voluntary and involuntary) and youth bulges in several countries but aging populations elsewhere-forces that are expected to drive up global food demand by an estimated 50-60 percent by 2050 .

Current projections foresee the world population increasing from 7.4 billion people in 2016 to well over 9 billion by $2050 .{ }^{8}$ Over 50 percent of this growth will take place in sub-Saharan Africa, while about 25 percent will occur in South Asia. ${ }^{9}$ The current rate of urbanization globally is about 1 percent, driven primarily by rural to urban migration. ${ }^{10}$ Today, half the world lives in urban areas. By 2050, that percentage will be two-thirds, with Africa and Asia accounting for 90 percent of the increase. ${ }^{11}$

Some 20 percent of migrants live in the 20 largest cities in the world. The year 2015 witnessed the highest levels of involuntary, forced displacement globally since World War II; a staggering 65 million people were forcibly displaced worldwide because of political or socio-economic drivers, conflict, generalized violence or other human rights issues. That year, approximately 6 out of 10 refugees lived in urban areas, altering the state of play of many urban food systems.

The population age structure is also changing. In both North and sub-Saharan Africa, close to 70 percent of the population is less than 30 years old today, creating a demographic dividend whereby large cohorts of young Africans are reaching working age. In some fragile countries, almost three-quarters of the population is under 30. In contrast, however, the world's population of people aged 60 and over will rise from 12 percent today to 22 percent in $2050 .{ }^{12}$ 
FIGURE 2.2 Evolving Global Urban Population by City Type

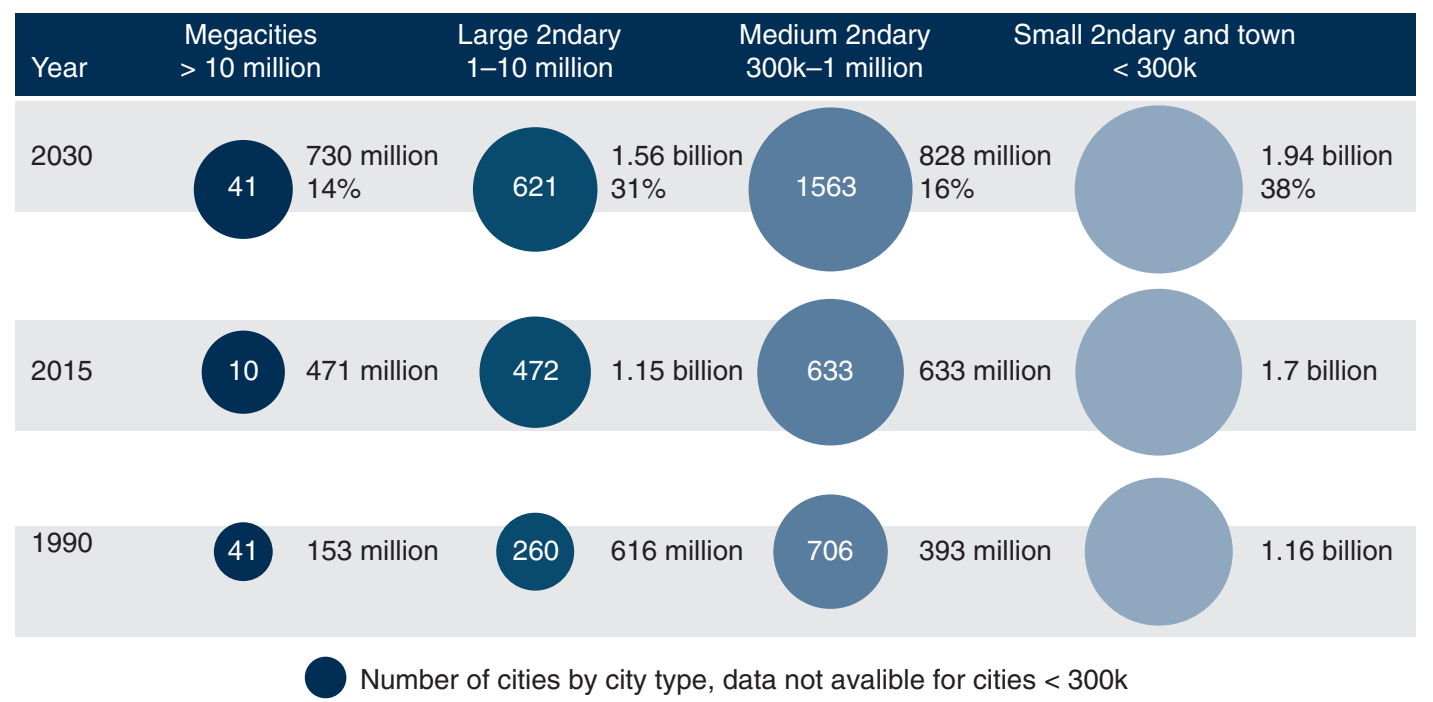

153 million: total urban population by city type $14 \%$ : share of 2030 urban population by city type

Data source: United Nations. World Urbanization Prospects.

The world will also see a rise in the number of megacities and cities with between 1 and 10 million residents (Figure 2.2), which has implications for urban land areas. In certain regions, urban land areas are growing faster than the population, leading to rising levels of low-density urban centres. ${ }^{13}$ Overall, this has promoted urban expansion into peri-urban areas, with faster population growth on the peripheries of major cities and higher population densities in the low-income settlements on the edges of larger urban centres. ${ }^{14}$ Today, an estimated one billion people globally live in informal settlements or slums. ${ }^{15}$ By 2030, this number will increase to 2 billion, the majority of whom will be in Africa and Asia. ${ }^{16}$

\subsection{Urbanization and Economic Growth}

Urbanization and economic growth are generally mutually reinforcing. Urbanization fosters innovation, economies of scale and agglomeration effects, including more efficient labour markets, lower transaction costs and knowledge spillovers that in turn lead to economic growth. ${ }^{17}$ Living in an urban area is positively associated with economic well-being. Except in sub-Saharan Africa, overall poverty declines as the share of people living in cities rises. ${ }^{18}$ Yet the share of poor people living in urban areas has also been rising, often more rapidly than the overall population. Survey-based estimates of income inequality show that global inequality is very high (Gini coefficient ${ }^{19}$ of 0.701 ), and this figure increases when adjusted for the top 1 percent of household incomes. 


\section{BOX 2.1 The Challenge of Defining Cities in An Evolving Rural-Urban Space}

Each country defines "urban" and "rural", "city" and "town" by using diverse administrative, economic and population criteria that are suitable to the national context. No standardized international criteria exist for determining the boundaries of a city or for defining urban and rural populations. "City proper" refers to a city based on an administrative boundary while "urban agglomeration" delineates boundaries based on a contiguous urban or built-up area. A "metropolitan area" considers the degree of economic and social interconnectedness (e.g. interlinked commerce, commuting) of nearby areas to determine boundaries. This report uses data from the United Nations World Urbanization Prospects 2014 (WUP) publication, which adheres to the "urban agglomeration" concept of cities. "City proper" and "metropolitan area" are used by WUP as needed to assemble a consistent series of population estimates over time.

This report uses WUP population data to group cities into four categories: fewer than 300 000; 300000 to 1 million; 1 million to 10 million; more than 10 million.

Source: United Nations. 2016. The world's cities in 2016. Accessed May 20, 2017. http://www.un.org/en/development/ desa/population/publications/pdf/urbanization/the_worlds_cities_in_2016_data_booklet.pdf.

Small or medium-sized "secondary" towns and cities tend to contribute more to poverty reduction than larger cities (due to the generation of higher non-farm employment for the poor and the lower cost of living). A growing middle class and expanding labour force are driving changes in food markets that may further accelerate this trend. ${ }^{20}$

Growing labour forces, especially in Africa and Asia, and the potential demographic dividend, provide an ideal opportunity for inclusive growth. An estimated 200 million people are currently unemployed in the world, however, and over 45 percent of total employment is considered to be "vulnerable employment." An estimated 1.5 billion working-age women and young people have "dropped out" of the labour market globally, and an estimated 400 million more young people will be looking to join the labour market before 2030. ${ }^{21}$ Cashing in on the demographic dividend will require considerable commitment and investment to establish the requisite conditions and incentives for employers to hire people who are joining the job market, especially as 75 percent of jobs are created by the private sector and an estimated 80 percent are found in cities. ${ }^{22}$

United Nations Industrial Development Organization (UNIDO) analysis (see Figures 2.3 and 2.4) shows that the food and beverage industry is the only labour-intensive, low-tech industry that sustains value-added growth as countries develop to upper-middle and high incomes. This growth is attributable to the food industry's relatively higher value-added and sustained employment growth, resulting in sustained labour productivity 
gains at all income levels. ${ }^{23}$ The food and beverage industry is a major and stable source of employment for all countries regardless of income levels. At very low-income, pre-industrialization levels, food and beverage is one of the three industries which dominate the manufacturing sector; it is largely labour-intensive, with growth rates that are not much lower than those of emerging capital-intensive industries. As countries become richer, there is

\section{FIGURE 2.3 Changes in Value Added by Income and Manufacturing Industries, 1963-2014}

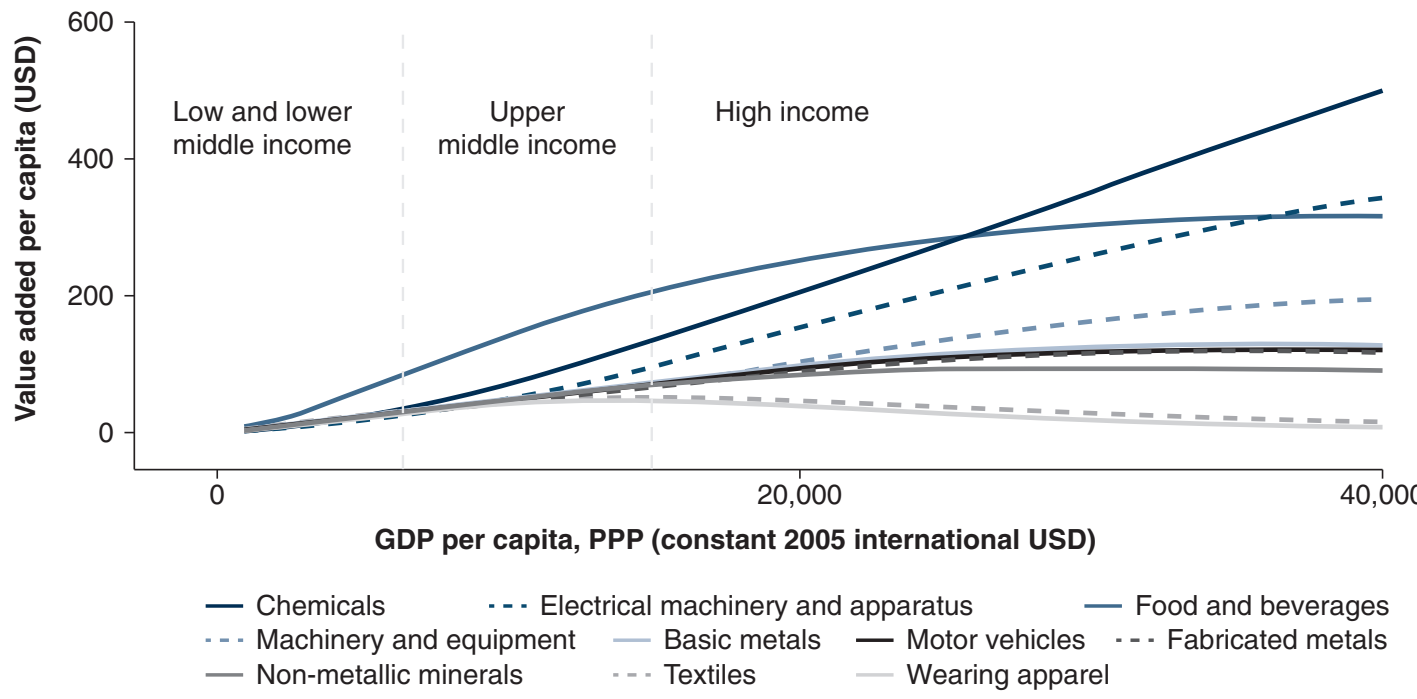

FIGURE 2.4 Changes in Employment by Income and Manufacturing Industries, 1963 to 2014

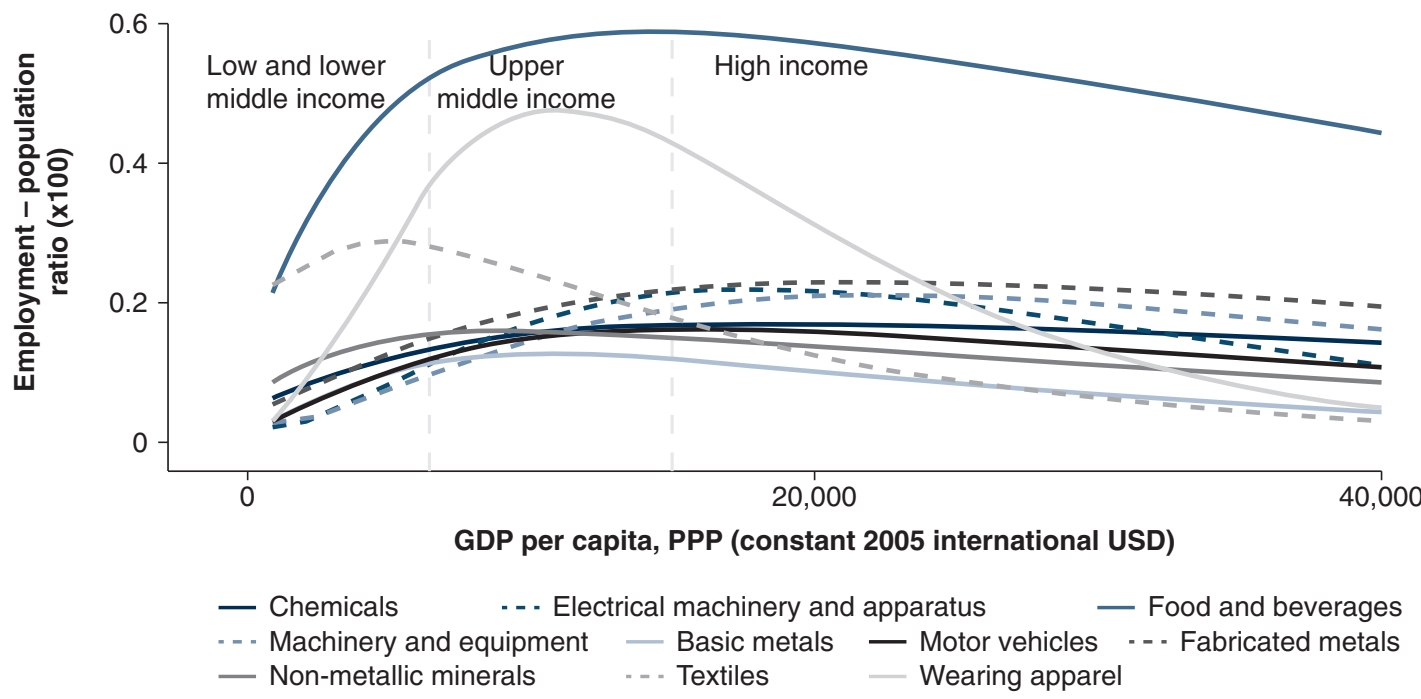

Source: UNIDO (2014). (Ibid) 
a shift from labour-intensive to capital-intensive industries as the former tends to slow down and latter grows rapidly and adds more value. At very high national income levels, most labour-intensive industries have declined, except for the food and beverage industry. The food and beverage industry, along with textiles and wearing-apparel industries, is one of the three major sources of manufacturing employment, with no other industries coming close to the peak employment levels of these industries at any income level. The immense potential impacts of technological advancement-both positive and negative-will need to be carefully analysed as food systems evolve. $^{24}$

Recent Tanzanian data confirm the potential for job growth in high quality food manufacturing. Analysis shows that food manufacturing in Tanzania offers the highest output per worker and the second-highest rate of growth in output per worker, and accounts for 5 percent of all new jobs. ${ }^{25}$ The strong job-creating function of the food system is further evident in the urban parts of East Africa, where approximately 60 percent of all urban jobs are affiliated with the food sector. ${ }^{26}$

In Nigeria, Rwanda and Tanzania, job growth in the off-farm portion of the food system has increased more rapidly in percentage terms than farming, albeit from a lower base and thus with a smaller contribution to the total number of new jobs. Between 2016 and 2021, the off-farm food system is projected to contribute between 18 and 22 percent of job growth over the next five years in Nigeria and Tanzania but only 11 percent in Rwanda. ${ }^{27}$

In cities in the United States of America, food service job growth is also more than double the overall rate of growth (5.1\% vs. $2.3 \%)$, with 2.2 jobs created in food processing, service and retail for every US\$100,000 in food sales. ${ }^{28}$ In the Cleveland, Ohio metropolitan area (United States), analyses show that sourcing 25 percent of the metropolitan area's food demand with local production could create over 25,000 new jobs, contributing to strong local growth, higher local tax collection and improved nutrition and health outcomes and a lower regional carbon footprint. ${ }^{29}$

TABLE 2.1 Strong Growth in Farming and Off-Farm Food System Jobs in Africa

\begin{tabular}{|c|c|c|c|c|c|c|c|c|c|}
\hline & \multicolumn{3}{|c|}{$\begin{array}{c}\text { Share of labour force } \\
\text { by sector }\end{array}$} & \multicolumn{3}{|c|}{$\begin{array}{l}\text { Share of all new } \\
\text { job creation }\end{array}$} & \multicolumn{3}{|c|}{$\begin{array}{l}\text { Estimated share of future job } \\
\text { growth (2016-2021) }\end{array}$} \\
\hline & Farming & $\begin{array}{l}\text { Off-farm } \\
\text { food } \\
\text { system }\end{array}$ & $\begin{array}{l}\text { Non- } \\
\text { food } \\
\text { system }\end{array}$ & Farming & $\begin{array}{l}\text { Off-farm } \\
\text { food } \\
\text { system }\end{array}$ & $\begin{array}{l}\text { Non- } \\
\text { food } \\
\text { system }\end{array}$ & Farming & $\begin{array}{l}\text { Off-farm } \\
\text { food } \\
\text { sys. }\end{array}$ & $\begin{array}{l}\text { Non- } \\
\text { food } \\
\text { system }\end{array}$ \\
\hline Nigeria & $34 \%$ & $23 \%$ & $43 \%$ & $59 \%$ & $40 \%$ & $1 \%$ & $36 \%$ & $18 \%$ & $46 \%$ \\
\hline Rwanda & $53 \%$ & $8 \%$ & $37 \%$ & $52 \%$ & $16 \%$ & $32 \%$ & $33 \%$ & $11 \%$ & $56 \%$ \\
\hline Tanzania & $47 \%$ & $17 \%$ & $35 \%$ & $33 \%$ & $11 \%$ & $57 \%$ & $32 \%$ & $20 \%$ & $48 \%$ \\
\hline
\end{tabular}

Source: Allen et al., Agrifood youth employment.

Note: The percentages are based on full time equivalent (FTE) terms that take into account the relative amount of time spent on the job; seasonal jobs like farming generally have lower shares of FTE.

The periods for the labour shares are: Nigeria, 2013; Tanzania, 2013; and Rwanda, 2011. The periods for the shares of job creation are: Nigeria, 2011-2013; Tanzania, 2011-2013; and Rwanda, 2006-2011. 


\subsection{Food Consumption, Nutrition and Health}

Over the last 50 years, the agriculture sector globally has done a tremendous job of making more food available to more people. However, the Food and Agriculture Organization of the United Nations (FAO) projects that agriculture in 2050 will require up to 50 percent more food, feed and biofuel than it did in 2012 (i.e. to feed 9.7 billion people in 2050); ${ }^{30}$ this estimated need could be significantly lowered by improved reductions in food loss and waste (see Chapter 6.2.2).

The socio-economic trends affecting consumer preferences and lifestyles are driving significant changes in dietary choices and food consumption. Although changing food consumption patterns are a global phenomenon, their origins are largely urban and most significant in urban areas.

Despite progress, the diets of the urban poor can be deficient in terms of calories, diversity and nutrients. Poor households tend to prioritize calories over quality-spending scarce resources on more affordable, calorie-dense, micronutrient-poor food groups with high levels of fat, sugar and salt. As incomes rise, there is a general shift in consumption from carbohydrate-rich staples to a more energy-dense diet consisting of refined grains/carbohydrates, vegetable oils, animal products and sugar. ${ }^{31}$

Greater disposable income, changing lifestyles and new consumer preferences are leading to a higher demand for convenience and a greater consumption of packaged, processed and ultraprocessed food, more frequent meals and snacking, and a greater percentage of meals eaten outside the home (Figure 3.5) - a large proportion of which is "fast food" and involves fried and processed food. ${ }^{32}$ Previous consumption differences between urban and rural residents are also narrowing. ${ }^{33,34}$

While income level affects overall consumer demand for food, choosing what to buy is influenced by taste, price, convenience and consumer perceptions of and trust in product quality, which involves notions of safety, appearance, cleanliness and freshness. ${ }^{35} \mathrm{~A}$ growing number of consumers-especially those with middle and higher incomes and those who use digital media-are giving greater importance to a set of value- and aspirational-driven preferences, including health and wellness, social impact, animal welfare and shopping experience. ${ }^{36}$ These dimensions relate to the increasing personalization of food consumption and purchasing behaviour, as consumer-citizens consider the nutrition, health and wellness, sustainability and equity impacts of their actions. In many countries, and among higher income groups, these preferences are manifested through demand for local food and short value chains with direct contact with producers, including those who provide food through e-commerce (i.e. first-hand traceability).

\subsubsection{Processed Foods}

Consumption of packaged and processed products is growing up to five times faster in low-income than in high-income countries (Figure 2.5) ${ }^{37}$ and is higher in larger cities. This trend is partly due to the fact they are produced to 
be hyper-palatable, highly available through distribution outlets, widely advertised and convenient to consumers. Per capita retail sales (a proxy for consumption) of ultraprocessed snack food in low- and middle-income countries across the world grew at an annual rate of 5.45 percent between 1998 and 2012, reaching 7.7 percent and 9.9 percent, respectively, for frozen products and soft drinks. ${ }^{38}$ The trend towards increased consumer expenditure on processed food (i.e. consumption) is equally present in Africa, where processed food represents 27 to 58 percent of all food expenditure in seven African countries, the large majority of which is more minimally processed food (NOVA food processing group 1), not the ultraprocessed products. ${ }^{39}$

\section{FIGURE 2.5 Growth in Per Capita Consumption of Processed Food Products in Asia: 1999 to 2017}

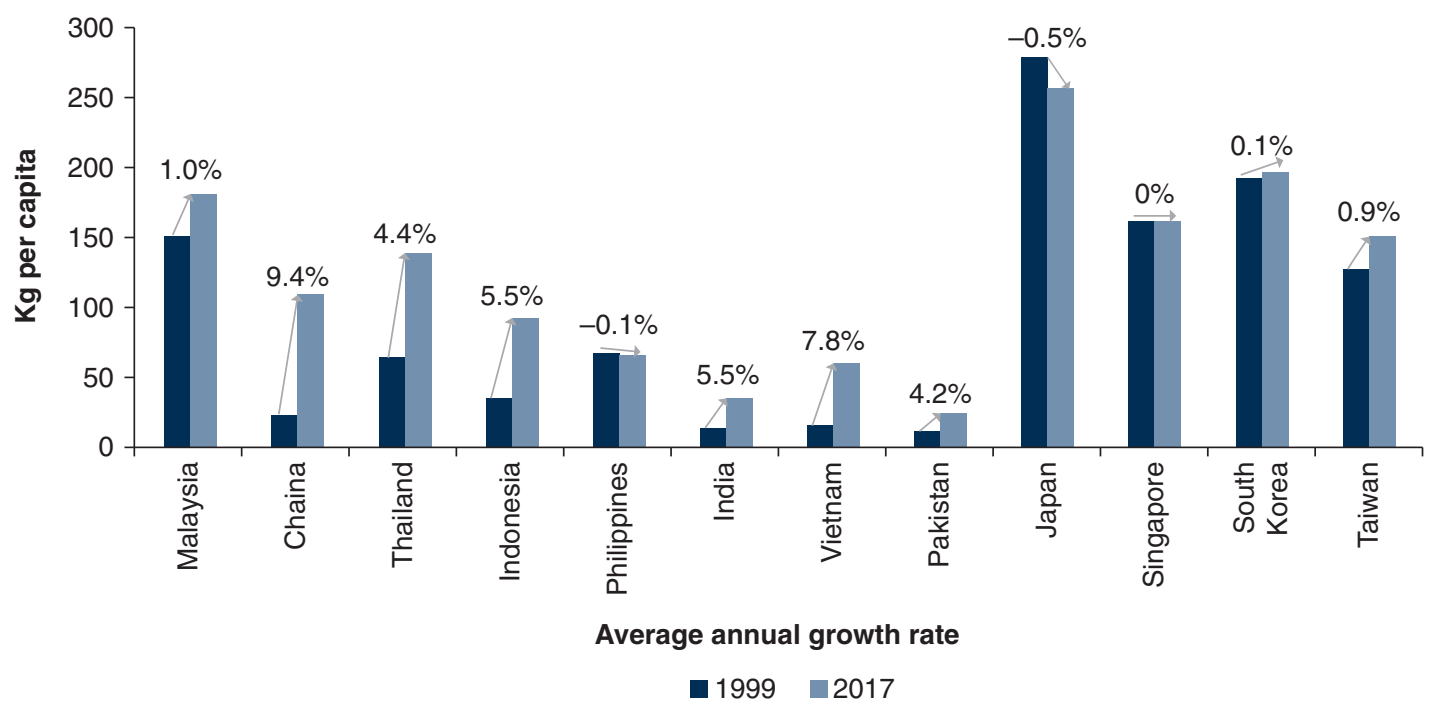

Source: Baker, P., \& Friel, S. 2014. Processed foods and the nutrition transition: evidence from Asia. Obesity Reviews, 15(7), 564-577.

\subsubsection{Increased Consumption of Food Away from Home (FAFH)}

City dwellers throughout the world are consuming an increasingly large share of their daily food consumption away from home, especially as income rises. Food away from home (FAFH) refers to prepared food and beverages purchased for consumption outside the home, whether in informal, traditional or modern markets, stores or restaurants. Figure 2.6 presents a broad cross-section of cities' and countries' shares of household food expenditures on FAFH. A large share of FAFH is processed food. Street food represents an important source of FAFH in many cities, particularly for low-income consumers.

In Nigeria and Tanzania, FAFH generates the most rapid and largest growth of any type of food as well as the fastest growth in output per sector, suggesting more attractive wages or returns to self-employment. Further, continued growth in FAFH has strong employment implications, especially for women, 
who represent 90 and 71 percent of all full-time equivalent employment in the sector in Nigeria and Tanzania, respectively. ${ }^{40}$

\subsubsection{Nutritional and Health Impacts}

Six of the top 11 risk factors driving the global burden of disease are related to diet. ${ }^{41}$ High levels of saturated fats, trans fats, refined carbohydrates, sugar-sweetened beverages, and red or processed meats are established risk factors for cardiovascular disease. ${ }^{42,43}$ Excessive salt or sodium consumption is even more telling. In a 2010 study representing almost three-quarters of adults in the world, average global sodium consumption averaged 3.95 grams per day, almost double the World Health Organization (WHO) recommended level of 2.0 grams per day.

The quantity of food consumed is also a determining factor for nutrition and health outcomes. Per capita calorie consumption exceeds average daily energy requirements in regions containing half of the world's population. Together with reduced physical activity, this excess calorie consumption means that the number of overweight and obese adults is projected to increase from 1.33 billion in 2005 to 3.28 billion in $2030 .{ }^{44}$ Young adults in low-income countries are gaining weight faster on average than those in industrial countries. ${ }^{45}$ The alarming speed of this "nutrition transition" has contributed to substantial increases in nutrition-related non-communicable diseases, which were estimated in 2010 to contribute to 3-4 million deaths. ${ }^{46}$ In non-highincome countries, these phenomena are particularly prominent among poorer segments of the population in urban areas, where physical activity is limited due to certain areas of cities being unwalkable and there has also been

\section{FIGURE 2.6 Share of Household Food Expenditures on Food Consumed Away from Home}

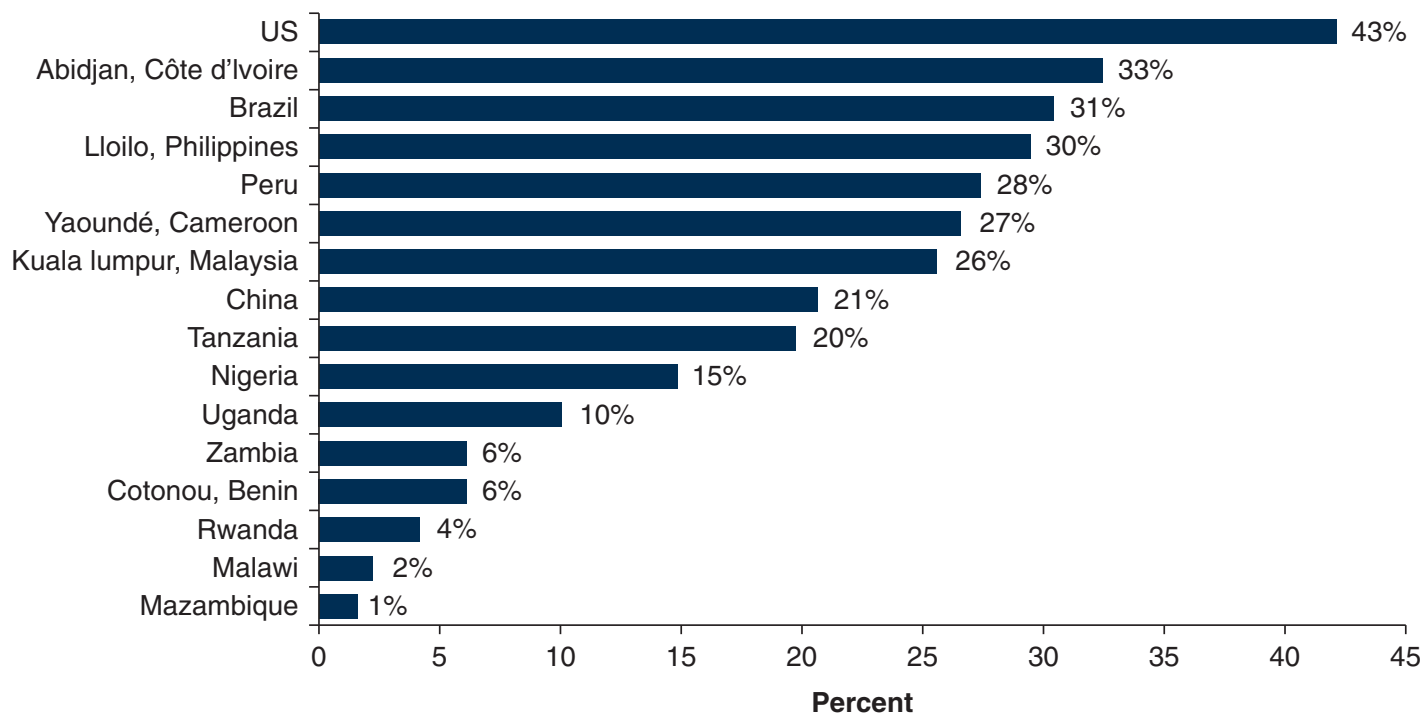

Sources: Allen et al., Agrifood youth employment. 
a rise in non-physical work and increased out-of-home eating. Despite these facts, some 800 million people go to bed hungry each day and approximately one in three stunted children live in urban areas, rising to 54 percent of children in low-income families. ${ }^{47}$

Unsafe food can also contribute to acute episodes of ill health. Every year 600 million people fall ill from eating contaminated food and 420000 people die as a result. ${ }^{48}$ Food-borne diseases caused by bacteria, viruses, parasites, toxins and chemicals represent growing public health burdens. ${ }^{49}$ In addition, the associated global costs are consequential. Over the last six decades, zoonotic pathogens caused more than 65 percent of emerging infectious disease events, costing over US $\$ 20$ billion and an additional estimated US $\$ 200$ billion in indirect losses to affected economies. ${ }^{50}$

In this context, the health sector bears the cost of (or benefits from-depending on one's perspective) the negative nutrition and health externalities created by the current food system. Annual direct costs for the treatment of overweight- or obesity-related conditions and for undernutrition (including stunting, wasting and micronutrient deficiencies) are estimated to be US\$1-2 trillion per year. ${ }^{51}$ Additional costs are borne by families in the form of higher medical bills, lost income due to illness, reduced school performance and lower lifetime earnings due to cognitive impairment. ${ }^{52}$ Over the next 20 years, non-communicable diseases will cost more than US $\$ 30$ trillion. They are expected to increase substantially in low- and middle-income countries. ${ }^{53}$

\subsection{Rapid Technological Change and Innovation}

The exponential and continual changes and innovations driven by cellular, digital, data and information and communication technologies (ICTs) are the "new normal" and will need to be integrated for sustainable, diversified and resilient productivity growth to meet future food demands and to improve efficiency, food quality and safety both on-farm and off-farm. In the immediate future, six technologies appear positioned to influence the shape of urban food systems: continued ICT development and applications; automation and artificial intelligence; Smart Cities; agrifood technologies; renewable energy/water resources and other resource recycling; and Big Data and analytics. New technologies will potentially eliminate certain jobs or tasks, particularly lower-skilled ones that use hands and muscle power, while at the same time creating new jobs or tasks at high skill levels reflecting cognitive ability. The relationship between technology needed for a productive and competitive food system and job creation represents both a major challenge and opportunity for countries.

Greater automation and the use of robotics will expand to carry out diverse functions throughout the food system, including the use of machine learning, ${ }^{54}$ $3 \mathrm{D}$ printers, drones, wearable/mobile technology and sensors. These technologies will be able to perform both repetitive, manual work as well as highly specialized, skilled work using artificial intelligence. For example, sensors and machine learning for driverless, autonomous trucks could reduce logistical costs and help reduce urban traffic congestion, while nanotechnology and 
mobile technology could monitor, detect and issue real-time alerts for salmonella or listeria outbreaks in a cold chain. Population growth and rapid urbanization in the developing world will require massive investment in infrastructure and services over the next several decades, providing a big opportunity for Smart Cities or neighbourhoods to expand food-friendly infrastructure and urban agriculture.

Food technology is rapidly advancing in the use of biotechnology, synthetic biology and nanotechnology. Cellulose ethanol represents a future second-generation biofuel derived from agriculture and forest residues as well as from municipal waste, while anaerobic digesters process organic material to produce renewable biogas energy (and methane and carbon dioxide) and fertilizers. Whether or not these technologies are considered favourably, they will be used by certain actors, institutions and countries to improve productivity, increase profitability and gain a competitive edge-particularly the larger private actors in global food chains.

\subsection{Climate Change, Resource Scarcities and Shocks}

Production and consumption patterns are not climate-neutral. An estimated one-fifth of GHG emissions are generated by agriculture, forestry and land use change ${ }^{55}$ while urbanization accounts for about 80 percent of global GHG emissions and strongly influences demand for non-renewable resources such as land, water and energy. ${ }^{56}$ The food system is at the heart of the food-water-energy nexus, confronted with a warming planet, more extreme weather events and sea level rise, thus requiring more systems and collaborative multisector and multistakeholder approaches. The impact on the production side of the food system has been relatively well analysed, with agronomic yields projected to fall by approximately 7 percent and water scarcity resulting in less productive pastures. ${ }^{57}$

Post-production functions of the food system represent approximately 6 percent of GHG emissions, ${ }^{58}$ with refrigeration being the largest energy-intensive component. ${ }^{59}$ They also consume 21 percent of the world's available energy. ${ }^{60}$ The carbon footprint of food produced and not eaten is estimated at 3.3 gigatonnes of $\mathrm{CO}_{2}$ equivalent-a wasted resource from human consumption, environmental sustainability and economic efficiency perspectives. In high-income countries with highly developed cold chain, transport, processing and retailing systems, the downstream portion of the food system collectively emits as much GHG as the production stages, a worrying omen for middle- and lower-income countries with rapidly developing urban food systems. ${ }^{61}$ To keep the increase in global temperature below the crucial ceiling of $2^{\circ}$ Celsius, emissions must be reduced by as much as 70 percent by $2050.6^{62}$

Urban growth and expanding towns and cities strongly influence demand for limited or scarce resources such as land, water and energy. Urbanization contributes to climatic change, modifies hydrologic and biogeochemical cycles and changes precipitation patterns, ${ }^{63}$ increases pollution ${ }^{64}$ and reduces biodiversity. ${ }^{65}$ 
Direct loss in vegetation biomass from areas with high probability of urban expansion is predicted to contribute about 5 percent of total emissions from tropical deforestation and land use change. ${ }^{66}$ These changes also have a strong influence on urban dwellers' vulnerability to environmental stress; ${ }^{67}$ many of these individuals are highly dependent on natural resources.

Reduced freshwater availability and competition from energy and agriculture could reduce water availability in cities by two-thirds between 2015 and 2050; the problem will be exacerbated by water pollution, aging and inadequate water infrastructure and inadequate water regulation. ${ }^{68}$

Land represents another scarce resource in the urban and peri-urban areas of many city-regions and metropolitan districts. The massive need for housing, public and office spaces, and transport services over the next 40 years will challenge all actors to find innovative solutions. By 2030, built-up areas are forecast to nearly triple in size over the 2000 footprint, an increase of $1.2 \mathrm{mil}$ lion square kilometres.

Food is an equally critically important resource that cannot be wasted. An estimated one-third of food produced for human consumption is never eaten. ${ }^{69}$ Food loss and waste (FLW) occurs along the entire food supply chain-from production and processing to transport and distribution, retail and consumption. Most FLW in lower-income countries occurs at production and post-harvest levels while in middle- and high-income countries, FLW is concentrated at distribution and consumption. ${ }^{70}$ In Australia, Europe, New Zealand and North America, more than 60 percent of FLW occurs during the market and consumption stages - in supermarkets, food and drink retailers, households, restaurants and caterers. ${ }^{71,72} \mathrm{FLW}$ results in US $\$ 940$ billion per year in lost revenue ${ }^{73}$ and accounts for nearly a quarter of the water used for agriculture ${ }^{74}$ and an estimated 8 percent of global anthropogenic GHG emissions. ${ }^{75}$ Each year, an estimated 30 percent of cereals, $40-50$ percent of root crops, fruits and vegetables, 20 percent of oil seeds, meat and dairy, and 35 percent of fish are lost or wasted. ${ }^{76,77}$ Animal diseases claim about 20 percent of direct livestock losses globally-a significant contribution to FLW. Finally, food waste represents between 23 and 67 percent of municipal solid waste in regions across the world. ${ }^{78}$

All these driving forces can introduce several risks or shocks to the overarching environment in which urban food systems will develop and actors operate. The risks include but are not limited to climate stress, economic factors, pandemics, political instability and civil conflict. As it is largely the poor who are more vulnerable when exposed to these risks, there is greater threat to the disruption of their lives, leading to food insecurity and the loss of income, assets and opportunities. ${ }^{79}$ Naturally, the climate change phenomenon has the potential to negatively affect producers, private companies, municipal and regional governments, and countries as well as the performance of the food system. It will be increasingly important to develop effective and predictable instruments to respond to these shocks and to address the needs of vulnerable communities and households without distorting incentives or increasing uncertainty in the economic environment required to achieve longer-term development goals. 


\subsection{Localized Development and Strong Stakeholder Engagement}

Finally, there is a groundswell of local food initiatives and action by communities, towns and cities throughout the world that have been supported by a rising number and diversity of non-state actors. This growing localization of food policies and grassroots nature of urban programmes addresses a variety of issues related to food, agriculture, environmental quality and sustainability, nutrition and employment in the communities. Some municipal initiatives have evolved from advocacy coalitions arising from diverse food movements; others are driven by political commitment or were viewed as part of municipalities' mandate to provide services to their citizens. ${ }^{80}$

The vibrant, highly innovative civil society sector is assuming a diversity of roles, ranging from facilitators, conveners and innovators to advocates, social change mobilizers and providers of service to producers and microentrepreneurs. Partnerships and alliances with government, business and other civil service organizations, combined with the strategic use of social media, are helping to redefine how business is conducted and information is shared. However, the spatial expansion of urban agglomerations beyond traditional municipal boundaries poses several challenges related to cross-jurisdictional governance and urban planning and service delivery across city-regions. ${ }^{81}$ While multicity agglomerations (continuous belts of urbanization) provide opportunities for greater agglomeration economies, they will need good city planning mechanisms, sound land policies and institutional coordination. The downsides of concentration include congestion, pollution and growth of slums.

\subsection{Implications for the Food System}

The external driving forces presented in this chapter exert significant influence on the structure and performance of food systems and will continue to shape their future evolution, particularly in urban areas; this analysis was not intended to capture the diversity of factors influencing rural areas. While each driver has been discussed individually, when considered together, this complex set of forces presents food system actors with the following interconnected challenges and opportunities. First, food systems will be called on to produce and deliver significantly larger quantities of food to growing urban populations in various types of cities; to provide a growing diversity of food products available in increasingly convenient forms and places; and to assure that food is safe and nutritious for people of all incomes. Second, these tasks must be done more efficiently, using scarce land, water and energy resources, while generating a smaller climate footprint. Innovation and new technology will be critical to improved food system productivity and competitiveness to provide more affordable healthy food, but not at the expense of job loss in one of the biggest economic sectors. Finally, the groundswell of interest and initiative from municipal and metropolitan governments and diverse private and 
civil society stakeholders will drive local food policy and investment actions, for which strong capacity and coordination with national governments and multiple sectors will be required.

This report focuses largely on the urban dimension of the food system. Considering these drivers and trends, complementary analysis may also be useful in many countries to consider their effect (along with other factors) on the agriculture sector and rural economy. This analysis may include the influence on the evolving structure and scale of agriculture, the capital and labour intensity of production systems, and the gender and generational aspects as well as the implications of these trends for achieving TRANSFORM framework outcomes in agriculture and rural areas. 


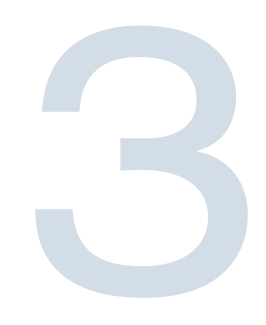

\section{Urban Food Systems}

\section{Key Messages}

- Food systems are not homogeneous but are composed of rapidly evolving and overlapping traditional, modern and informal subsystems.

- Countries and cities will continue to obtain food from varied sources, long and short domestic supply chains and imports. Diverse urban and peri-urban (as well as rural) agriculture systems supply urban markets, particularly for horticulture.

- Supermarkets, restaurants, e-commerce and "new value" consumers are spurring innovation and modernization of supply chain management and logistics.

- Fresh food, convenience and a range of retail services attract consumers to open (wet) markets and small independent retailers, which exist alongside modern supermarkets.

- Informal sector food vendors and restaurants cater to the urban poor. Food access is conditioned by housing, transport and time, in addition to income.

- Urban food insecurity in low-income countries is higher than in rural areas, rising to over 70 percent in urban slums. Informal safety nets help to boost food access.

Over the last 60 years, the food system has evolved and transformed in response to the interlinked trends of urbanization, a growing middle class, increased female participation in the labour force, technological advances and changing consumer preferences and consumption patterns. This chapter builds on the preceding discussion to provide a broad overview of how the food system is structured and evolving, and the large number of formal and informal actors and businesses that are positioning themselves to respond to evolving consumer demand and growing food market opportunities. 


\subsection{Traditional, Modern and Informal Food Subsystems}

There are three types of food systems that predominate in urban and peri-urban areas: a traditional food system; a rapidly emerging modern and globalized food system; and an informal food system, catering mostly to low-income urban people (Figure 3.1). All three systems exist to varying degrees in most types of cities, overlapping and sharing certain functions, each with value and responding to diverse aspects of consumer food demand. However, they are heterogeneous with respect to actors, organization and functioning. Food systems may vary considerably by crop or food product, country or city type and also by the policies, institutions, technology, investment and capacities that shape actor incentives and determine performance.

In order to respond to the growing demand for food in urban areas, municipalities and metropolitan districts source food from a combination of long and short domestic supply chains and food imports. Below we briefly discuss each.

\section{FIGURE 3.1 Evolving Food Systems: Modern, Traditional and Informal}

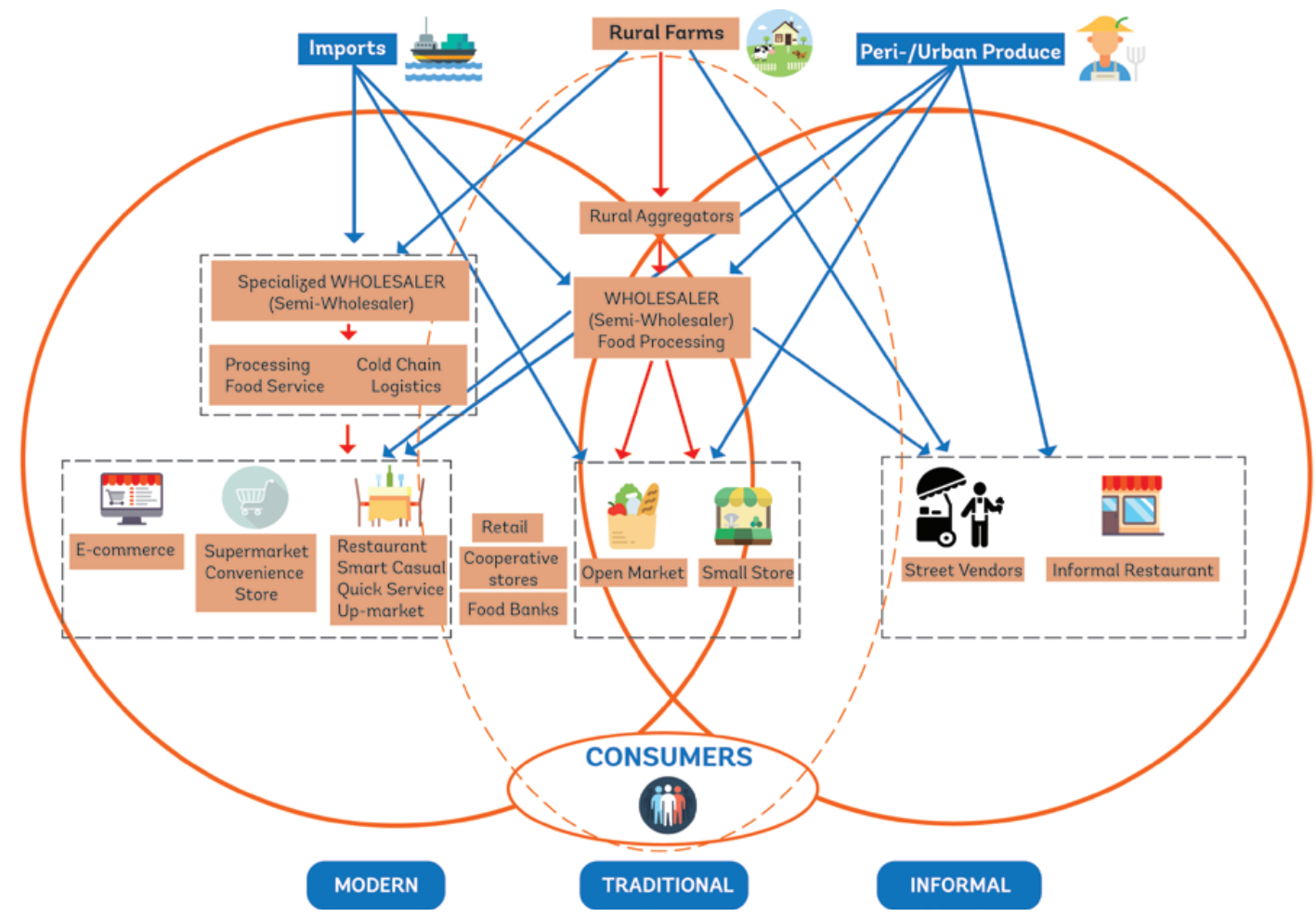

\subsubsection{Domestic Food Production}

How municipalities and metropolitan districts source their food needs will be specifically determined by the composition and evolution of food consumption, the relative productivity and competitiveness of domestic, regional and global food systems, and national values and priorities articulated in strategies 
and policies that facilitate and/or impose costs on domestic production and import systems. In Asia and in West Africa, 95 percent of the food consumed is domestically produced, and two-thirds to three-fourths of this demand is driven by urban needs. ${ }^{82}$ Some urban consumers may prefer to purchase local food through shorter supply chains. Access to a diversity of food sources and supply chains enhances flexibility in responding to evolving and differentiated preferences by type of consumer and in maintaining a more resilient urban food system.

Urbanization and changes in dietary patterns are also contributing to major transformations in domestic value chains, particularly the midstream portions that include processing, storage, wholesaling and logistics. These changes have positively affected the rural non-farm economy, particularly in rural areas within a certain radius of cities where the urban demand pull is more pronounced. ${ }^{83}$ Agriculture production is also becoming increasingly differentiated, with a large share of smallholder farmers who are net food buyers and only sell part of what they produce, while those closer to markets, along transport corridors and in agriculturally dynamic zones have become increasingly specialized and linked to agribusiness. ${ }^{84}$

Public investment in rural transport and wholesale market infrastructure has contributed to the spatial lengthening of food value chains that are needed to supply growing urban agglomerations in parts of the world. The midstream portions of food value chains have also contributed to an increase in food produced, processed and distributed in longer or more distant value chains. Improved transport systems extend market catchment areas that supply urban centres; investment in larger-scale food processing plants has also enabled economies of scale and location of facilities further from cities and storage systems have equally helped to decentralize value chains. ${ }^{85}$

\subsubsection{Urban and Peri-Urban Agriculture (UPA) Production}

Despite the trend towards longer domestic value chains, agricultural production continues to be extensively practiced in urban and peri-urban areas throughout the world. Urban and peri-urban agriculture (UPA) has historically taken place in relative proximity to or within urban areas, with cities historically sited in areas with the highest-quality land. Urban agriculture accounts for 15 percent of the total agricultural land in the world, although it extends to 40 percent of all cropland when peri-urban production areas within 20 kilometres of cities are included (see Figure 3.2). Some 60 percent of all irrigated cropland is located within this 20 -kilometre band while 35 percent of rain-fed croplands are located within this 20-kilometre urban periphery. Rain-fed systems predominate in sub-Saharan Africa, while irrigated production is prevalent in the more densely populated or water-scarce areas of North Africa and South and East Asia. ${ }^{86}$

Although rural production and food imports may provide the overwhelming quantity of food currently consumed by urban consumers, the groundswell of interest in and intensification of the various forms of UPA portend 
significant opportunities for its further expansion in a diversity of contexts, including for displaced people, humanitarian emergencies and protracted crises. In many cities throughout Asia, urban and peri-urban horticulture production supplies up to 90 percent of the vegetables consumed in cities, particularly green leafy varieties. And recent technological innovations in UPA also suggest a growing role for UPA as a leader and an incubator of highly productive, more resource-efficient (i.e. water, energy and land) production.

\section{FIGURE 3.2 Share of Urban and Peri-Urban Land in Total Global Agriculture Land}
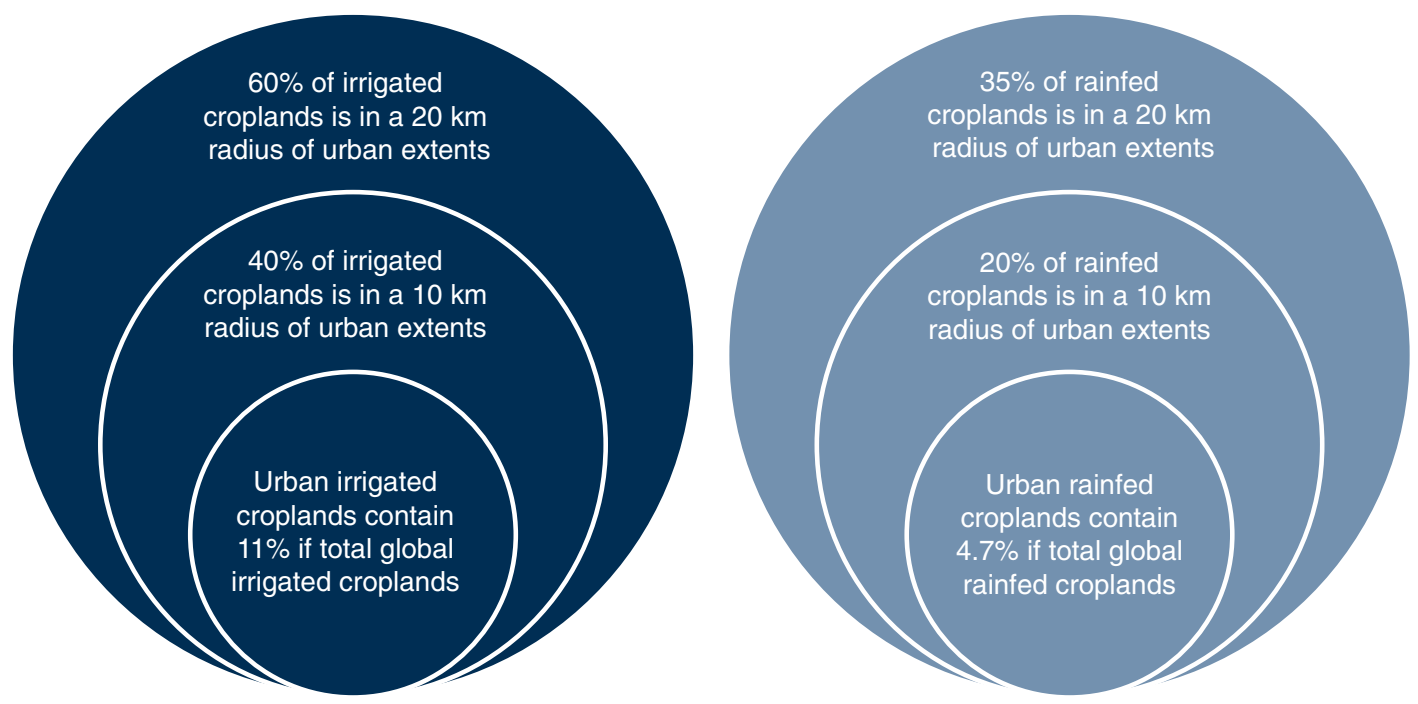

Source: Thebo, A. L., Pay Drechsel, and E. F. Lambin. 2014. Global assessment of urban and peri-urban agriculture: irrigated and rainfed croplands. Environmental Research Letters, 9(11), 114002.

The types of UPA are diverse and ever-changing (See Table 3.1). Systems can be characterized in multiple ways including by their growing medium (soil, soilless, pellets, gel-based), water source (rain-fed, irrigated, mist), natural or artificial light (LED, reflectors), outdoor or indoor systems, type of product (s) produced or animals raised, location (urban or peri-urban, rooftop, balcony, underground, vacant plots, in buildings), growing container (shipping container, burlap bag, plastic bottles, reusable cloth, ground), degree of environmental control, ownership (individual, family, community, business), scale of operation, input use (compost, fertilizer, pesticide, nutrient solution) and system technology (hydroponics, aeroponics, aquaponics, vertical). While UPA in low-income countries today generally ranges from the more "traditional" small family plots to medium-sized community farms to even larger-scale commercial operations, technological applications are increasingly redefining UPA to meet competition for resources or address constraints related to scarce and high-priced land and more efficient water usage, leading to intensification and innovation. 
TABLE 3.1 Types of Urban and Peri-Urban Agriculture

\begin{tabular}{|c|c|c|c|c|c|c|}
\hline Type & Location & $\begin{array}{l}\text { Growing } \\
\text { container }\end{array}$ & $\begin{array}{l}\text { Growing } \\
\text { medium }\end{array}$ & Technology & Labor & Products \\
\hline \multicolumn{7}{|c|}{ Small-medium scale gardening, primarily for self-consumption } \\
\hline $\begin{array}{l}\text { Open-field } \\
\text { garden } \\
\text { Family, } \\
\text { Allotment, } \\
\text { Squatter, } \\
\text { Community }\end{array}$ & $\begin{array}{l}\text { Peri-urban } \\
\text { Vacant plots }\end{array}$ & $\begin{array}{l}\text { Ground, Box, } \\
\text { Shacks }\end{array}$ & Soil & & Family & $\begin{array}{l}\text { Vegetables, } \\
\text { orchards, flowers } \\
\text { and herbs, } \\
\text { seedlings, livestock }\end{array}$ \\
\hline $\begin{array}{l}\text { Constrained } \\
\text { space }\end{array}$ & $\begin{array}{l}\text { Rooftop, } \\
\text { Balcony, } \\
\text { Camps, } \\
\text { Indoor }\end{array}$ & $\begin{array}{l}\text { Bags, Bottles, } \\
\text { Containers } \\
\text { Trays }\end{array}$ & $\begin{array}{l}\text { Soil, Pellets, } \\
\text { Rocks }\end{array}$ & $\begin{array}{l}\text { Hydroponics } \\
\text { Aero-ponics } \\
\text { Vertical }\end{array}$ & Family & $\begin{array}{l}\text { Vegetables, some } \\
\text { fruits, some grains } \\
\text { and legumes }\end{array}$ \\
\hline $\begin{array}{l}\text { Institutional } \\
\text { garden }\end{array}$ & $\begin{array}{l}\text { Schools, } \\
\text { Churches } \\
\text { Hospitals } \\
\text { Prisons }\end{array}$ & Ground, Box & Soil & & $\begin{array}{l}\text { Student } \\
\text { Military } \\
\text { Civil servants } \\
\text { Prisoners }\end{array}$ & $\begin{array}{l}\text { Fruits, vegetables, } \\
\text { Flowers, herbs, } \\
\text { seedings, livestock }\end{array}$ \\
\hline \multicolumn{7}{|c|}{ Medium-large scale farming, primarily for commercial operation } \\
\hline $\begin{array}{l}\text { Multi-functional } \\
\text { farms } \\
\text { Agro-tourism } \\
\text { Aquaculture } \\
\text { Tree }\end{array}$ & Peri-urban & $\begin{array}{l}\text { Ground, } \\
\text { Ponds, } \\
\text { Greenhouse }\end{array}$ & $\begin{array}{l}\text { Ground, } \\
\text { Soil, Water, } \\
\text { ponds }\end{array}$ & $\begin{array}{l}\text { Aqua-ponics, } \\
\text { Irrigation }\end{array}$ & Salary & $\begin{array}{l}\text { Trees, tourism, } \\
\text { horticulture, social } \\
\text { livestock, fish, } \\
\text { education, } \\
\text { research }\end{array}$ \\
\hline $\begin{array}{l}\text { Open-field } \\
\text { commercial } \\
\text { farms }\end{array}$ & $\begin{array}{l}\text { Urban } \\
\text { Peri-urban }\end{array}$ & Ground & $\begin{array}{l}\text { Ground, } \\
\text { Soil, Water }\end{array}$ & Irrigation & $\begin{array}{l}\text { Salary } \\
\text { Family }\end{array}$ & $\begin{array}{l}\text { Crops, livestock, } \\
\text { nuts, nursery } \\
\text { beds, composting, } \\
\text { seeds, composting }\end{array}$ \\
\hline Green-house & $\begin{array}{l}\text { Industrial } \\
\text { buildings }\end{array}$ & Ground & $\begin{array}{l}\text { Perlite, } \\
\text { Vermiculite, } \\
\text { Soil Moist }\end{array}$ & $\begin{array}{l}\text { Climate } \\
\text { controlled } \\
\text { Hydroponics } \\
\text { Aero-ponics }\end{array}$ & Salary & Horticulture, hops \\
\hline Rooftop & Urban & $\begin{array}{l}\text { Light weight } \\
\text { container, } \\
\text { Greenhouse }\end{array}$ & $\begin{array}{l}\text { Soil } \\
\text { nutrients }\end{array}$ & & Salary & $\begin{array}{l}\text { Horticulture } \\
\text { Shallow root crops }\end{array}$ \\
\hline Indoor farms & $\begin{array}{l}\text { Buildings } \\
\text { Vertical } \\
\text { Underground }\end{array}$ & $\begin{array}{l}\text { Trays, Box, } \\
\text { Container }\end{array}$ & $\begin{array}{l}\text { Pellets, Soil, } \\
\text { Rocks }\end{array}$ & $\begin{array}{l}\text { LED light } \\
\text { Hydroponics } \\
\text { Aero-ponics } \\
\text { Vertical }\end{array}$ & Salary & $\begin{array}{l}\text { Vegetables, fruits, } \\
\text { herbs }\end{array}$ \\
\hline
\end{tabular}

\subsubsection{Food Imports}

Irrespective of the country, trade in agricultural and food products has generally played an instrumental role in helping nations to feed their populations and assure national food security. An estimated one in every six people in the world rely on food imports to feed themselves today, a critical food source for many countries and urban populations, particularly in coastal cities ${ }^{87}$ Food imports will continue to supply many countries with key food staples for the foreseeable future. ${ }^{88}$ Trade allows countries to import food that is produced under different climatic conditions and in different seasons, to acquire diverse food products not normally found locally, and to access less costly food than what is produced domestically. Although global markets are less volatile than domestic markets and food imports exert downward pressure on consumer 


\section{BOX 3.1 Gender and Women in UPA}

Nearly 65 percent of the world's urban farmers are women, but they tend to predominate in subsistence farming; men play a greater role in urban food production for commercial purposes. Urban agriculture as an occupation is convenient for many women as it can be practiced close to home and can be practiced at different scales and with various capital, technology and input intensities; it also enables many women to effectively combine their multiple roles in child care, food security, income generation and environmental management. Sometimes it represents the only alternative for wage labour for women who lack access to formal employment due to limited education and training or sociocultural factors that limit their mobility. Women's engagement in sack gardening in the Kibera slums of Nairobi, for example, underscores their important role in improving food security for low-income families and in strengthening social capital.

Addressing the requirements for female producers to engage in commercial urban production is a major challenge, particularly with respect to access to land, financing and technical support and the requisite enabling political and social empowerment of women. Despite the challenges to practicing urban agriculture, it has a huge potential to improve the socio-economic status and empowerment of women.

Source: Van Veenhuizen, René, ed. 2006. Cities farming for the future: Urban agriculture for green and productive cities. IDRC.

prices, a high degree of reliance on food imports may leave countries vulnerable to trading partner policies and market shocks. ${ }^{89}$

Global food trade represents an estimated 26 percent of world gross agricultural production (based on farmgate prices) and an estimated 20 percent of global calories. Wheat, soybean and maize account for 50 percent of calorie exports and 21 percent of the value. ${ }^{90}$ Countries with the largest economies are the largest food importers (China, Germany, Japan, United States of America, etc.) while city-states like Singapore import 90 percent of their food needs. The Middle East and North Africa (MENA) region imports 80 percent of its vegetable oil, 70 percent of its sugar and more than 50 percent of wheat, its main staple. Sub-Saharan Africa's increasing trend in food imports includes 50 percent of vegetable oil, 36 percent of poultry meat and 23 percent of sugar. ${ }^{91}$ Rising Asian demand for animal protein may continue to exert strong demand for maize and soy imports to supply feed industries. ${ }^{92}$ Different types of food preparations and ingredients used in food processing are also extensively traded and are growing annually by more than 7 percent, commensurate with the growing consumption of processed food. ${ }^{93}$ 


\subsection{Traditional Food Systems}

Traditional urban food systems are characterized by vibrant urban wholesale markets that are connected to rural areas through a diverse group of ruralbased traders (assemblers, aggregators, etc.) and various scales of wholesalers (including smaller "semi"-wholesalers) who are in agriculture-based towns and small cities. Traditional urban food systems predominate in many cities in Africa and Asia but continue to thrive throughout the world despite the growing presence of diverse types of modern channels. Below we briefly describe the many modalities and functions of a traditional urban food system.

\subsubsection{Processors}

Local processing firms have responded to growing food demand through aggressive local investment over the last few decades, resulting in more standardized products that are sold through a common distribution system (e.g. milled cereals, dairy, processed meat and fish, and condiments). ${ }^{94}$ The food processing subsector is dominated by SMEs and microprocessors, complemented by some large, industrial-scale operations, many of which are foreign-owned. ${ }^{95}$ Food processing has been more organically decentralized compared with other manufacturing, and is often located in small towns and in small and medium-sized secondary cities with adequate infrastructurewhere it is situated closer to raw materials and has strong potential for reducing poverty through backward and forward linkages with both the farm and non-farm sectors. ${ }^{96}$

\subsubsection{Wholesale Markets: Linking Rural and Urban Economies}

Urban wholesale and rural assembly markets play a key role in carrying out the functions that link rural producers and the agricultural economy with the downstream functions of the urban supply chain. In agriculture-based towns and small cities, secondary wholesale markets provide the entry point for rural traders and smallholders ${ }^{97}$ to connect with transporters and traders who, in turn, assure the link with larger urban markets.

Terminal wholesalers in larger urban centres service diverse retailers and domestic consumers or assemble produce for exports. Located in dedicated structures or in a more dispersed manner in the vicinity of open markets, wholesale markets are generally operated by public or private entities that manage the space, oversee and regulate the market and collect fees. ${ }^{98}$ Wholesalers receive food from a variety of sources, including in bulk shipments from other regional wholesalers who aggregate from small producers, farmers' cooperatives, contracted producers, food companies and state farms before transportation to urban centres. ${ }^{99}$ Bulk marketing arrangements can also take the form of contract farming or "outgrower schemes," with the buyer generally providing the product and price specifications against which a farmer is to deliver in the future. 


\subsubsection{Open or Wet Markets: Fresh Produce}

Open or wet markets, together with small, independent family-run stores, represent the two main retail options for urban consumers in the traditional food system. Prevalent in low- and middle-income countries, these types of markets seem to be regaining their footing in high-income countries as well, such as in the form of neighbourhood farmers' markets. Open markets generally involve the retail sale of fresh food in covered, open buildings or open-air stalls. They are typically managed by public authorities such as municipalities or public-private companies, who collect fees from vendors for space rental, garbage disposal, utilities, security and facility maintenance. ${ }^{100}$ They usually have a dominant position in sales of staple goods, fresh fruits and vegetables, and fresh and frozen meat and fish, including in developing countries with high market penetration of modern retail. Many consumers also purchase fruits and vegetables at local kiosks, specialized stands or small independent retail shops (see below), most of which stock their goods from the same open markets. ${ }^{101}$ Open markets appeal to urban consumers for many reasons: the ability to buy and consume the freshest produce without refrigeration; ${ }^{102}$ proximity to home or office; lower prices; and usually a greater variety than modern retail stores. ${ }^{103}$ They also provide an opportunity to taste and inspect unpackaged staples, enhancing consumer trust. These advantages often outweigh concerns about congestion, poor hygiene, lack of product presentation, or a stressful shopping experience. ${ }^{104}$

\subsubsection{Small Independent Food Retailers: Convenience and Service}

Small family-run businesses are a fixture of neighbourhoods throughout the world-known locally as kiranas, dukas, hanoots, warung, spazas, and so on. These retail outlets are more informal, no-frills/low-cost enterprises, using family labour, maintaining low inventories and often paying no taxes or license fees. ${ }^{105}$ They generally sell a wide variety of packaged products and a limited selection of fresh produce as well as providing a range of services that make them attractive to urban consumers: location convenience; often lower and negotiated prices; unlabeled products; sales on credit; phone orders and home delivery; customized personal service; flexible hours; and easy return/exchange systems, in addition to an ability to flexibly respond to consumer demand-e.g. selling one egg or a dozen, two slices of bread or a loaf. These services compensate for limited selection and quantity (including often a lack of frozen products due to erratic electricity) and the lack of cleanliness, quality and helpfulness that can be found in some stores. ${ }^{106}$

\subsection{Modern Food Systems}

Modern urban food systems, given all the variants and actors at play, are characterized by modernized wholesale and food safety systems, capital-intensive food processing, integrated cold chains and food service firms, state-of-the-art 
logistics, private branding, labelling and packaging, modern retail and restaurants, and global integration. Wholesale operations may be more specialized than traditional food systems, operate at larger scales and make extensive use of supply contracts with larger commercial producers. They may source food from both long and short domestic food supply chains and food imports as well as direct purchases between consumer and producer. Modern retail comes in a variety of forms and scales, including a rapidly growing segment that is responding to the demand of middle- and high-income consumers for food products and experiences that address an evolving set of value- and aspirational-driven preferences, including health and wellness, social impact, animal welfare and shopping experience. ${ }^{107}$

Within this modern food system component, systems will differ according to the relative importance of specialized wholesale operations and procurement systems, the level of development of food service businesses that serve restaurants, and the presence of third party logistics firms that support food businesses to strengthen the efficiencies of their internal operations. This sector is also characterized by strong foreign direct investment and engagement of multinational food companies throughout all functions of the food system (wholesale, processing, retail, food service and restaurants). In fact, multinational food companies have achieved the same level of market penetration in middle-income countries as that achieved in high income countries. ${ }^{108}$ Local government and institutional procurement (e.g. schools, hospitals, offices, prisons) also plays a role in the modern food system that can represent a large share of the urban food market and influence various desired food system outcomes.

\subsubsection{Food Processing: A Rapidly Growing Industry}

Sustained investment in modern food processing has contributed to improving the availability and safety of food as well as the reduction of FLW in many countries. Technologies to freeze, pasteurize, vacuum-seal and dry food are among the techniques contributing to this trend, helping to improve efficiencies, reduce costs and meet diverse quality, food safety and phytosanitary standards. ${ }^{109}$ These advances in food processing in Asia and Africa, particularly for more minimally processed products (i.e. cleaned, milled, etc.), help to explain the growing percentage of processed foods in consumer food baskets (in Asia: $58 \%$ of low processed products, $42 \%$ for highly processed; in East and Southern Africa: 70\% of middle class consumer purchases). ${ }^{110}$

Modern processing firms are also large importers of diverse ingredients and food preparations that are needed as inputs to produce food products, explaining the steady growth in this import segment. Large processing firms have also initiated direct marketing to modern retail. ${ }^{111}$ The current capability and state of processing and logistics enterprises is considered inadequate, however, to meet future urbanization needs. ${ }^{112}$ The overall productivity of food processing could potentially rise by an estimated 60 percent or so in low-income countries through operational improvements, such as lean manufacturing and bigger processing facilities to take advantage of scale effects. ${ }^{113}$ However, it is the smaller and nimbler food processing companies that have 
been the leaders in responding to consumer demand in the new values food channel, particularly in the organic, natural and functional food segments.

\subsubsection{Wholesale Markets/transport/logistics/importers}

As economies grow and evolve, centralized procurement systems, the use of specialized wholesalers, preferred supplier systems, contracts and private quality standards, integrated packing, grading, processing, cold chain systems and transport generally follow. ${ }^{114}$ Centralized procurement systems that supply large volumes and meet relatively stringent private standards have helped to improve efficiency and reduce transaction costs as well as offering consistent quality and competitive prices to consumers. ${ }^{115}$ These innovations, moreover, have often reduced the number and role of traditional wholesalers in some countries, which makes it difficult for independent supermarkets and small regional chains to compete as modern retailers. Some modern systems are also leveraging traditional distribution networks involving formal and informal actors to distribute processed and packaged food products in rural areas. ${ }^{116}$

However, modern transportation, cold chains, logistics and warehousing remain insufficiently undeveloped in many urban food systems, notably in low-income countries. Reducing urban congestion, pollution and transport costs will require close collaboration between public and private stakeholders to determine and assess future options and improve efficiencies for last-mile logistics. More investment in refrigerated warehousing and modern logistics for efficient supply chain management will increasingly be needed as food systems modernize and respond to evolving consumer demands, contributing to improved food safety and the delivery of fresh products to retail stores, restaurants and consumers. For this to happen, increased investment in renewable power generation is critical to stabilize power supplies and lower energy costs, along with attention to other utilities and infrastructure.

Importers also often operate as wholesalers, retailers and owners of supermarkets. Food import value chains have also been consolidated and shortened, with retailers sourcing directly from importers, who maintain warehouses, cold stores and distribution points in multiple urban locations. Importers may also directly supply some of the larger traditional retail stores as part of their distribution and promotion strategies. Foreign multinational companies have also invested heavily in streamlining food import procedures and food safety systems to expedite the import process for their products.

\subsubsection{Modern Retailers: A Variety of Sizes, Formats and Locations}

The modernization of the food system has been heavily focused on modern retail with innovations in supply chain management and logistics. It has typically been initiated in larger cities and focused on wealthier consumers before expanding, often through franchises, to the middle and lower-middle classes and to small cities and towns. The food system has targeted the sale of processed, packaged products and dried goods, along with some imported fresh fruits and vegetables and minimally processed meats. 
Modern grocery retailing is generally a self-service format, appreciated for its comfort, hygiene, retail space, parking, and often entertainment and other services in addition to a wide assortment of quality food products of diverse brands. ${ }^{117}$ Modern retail is also diversifying with a variety of new formats, whether as small grocery stores in service stations, modern mini-markets or small-footprint grocery stores in lower-income residential neighbourhoods or at bus stops. ${ }^{118}$ In many cities, the presence of modern retail is pushing some traditional retailers to abandon over-the-counter service for self-service formats, while some neighbourhood shops are adding value by cleaning and cutting vegetables for working households. ${ }^{119}$

Market penetration of modern retail has advanced to varying degrees, but it has also been affected by a variety of factors: consumer preferences for shopping in open markets and small independent "traditional" retailers; consumer income, access to refrigerators, vehicle ownership and proximity to stores; government restrictions and duties on imports; small retail margins; the unavailability or high cost of rental space; complex and stringent labour laws and constraints on direct sourcing from farmers; and limits on foreign investments. ${ }^{120}$ Future growth in modern food retailing will be shaped by addressing several factors currently at play, including: the unavailability and high cost of real estate; lack of consumer access to transport; scarcity of skilled human resources for management, operations and food services; unreliable supplies of electricity that discourage consumers from purchasing refrigerators; undeveloped domestic supply chains with inadequate quality control; a lack of preferred suppliers; and problems of quality, presentation, packaging and product consistency, ${ }^{121}$ as well as newer formats introduced by technology.

\subsubsection{Acceleration of Grocery e-Commerce}

Grocery e-commerce is online shopping, which has the potential to develop into a dynamic growth sector. China is the leader in business-to-consumer shopping, with annual online grocery sales of US $\$ 41$ billion, projected to increase to US $\$ 178$ billion by 2020 . The United Kingdom is second, with a US\$15 billion market. In responding to consumers' demand for convenience, price and quality, e-commerce and restaurants are also increasingly addressing demand for more regional products. The future development and expansion of e-commerce will be shaped by increased Internet access and smartphone penetration, by the development of innovative, cost-effective delivery, logistics, and warehouse infrastructure for congested urban settings, and by an appropriate regulatory environment. Whether e-retail operations are effectively established as an e-retail arm of a traditional grocery, a freight delivery company, a new dedicated e-grocery company, or some other yet-to-be developed business model, it is clear that e-commerce will face tough competition from traditional retail outlets that provide quick, responsive and trustworthy services to demanding consumers. ${ }^{122}$ However, e-commerce food companies can provide many advantages to food entrepreneurs for selling new products minus the fixed costs of a storefront. 


\subsubsection{Restaurants}

The urban food service and restaurant subsector is also evolving to offer a variety of formats to urban consumers who are eating an increasingly large proportion of meals away from home. Restaurant options include a variety of quick-service or fast-food restaurants, slightly upscale fast-casual restaurants, mobile vendors, street food stalls or kiosks, and small traditional and conventional casual and up-market restaurants. Modern quick-service and fast-food casual restaurants are rapidly expanding, as they provide a consistent product prepared in improved hygienic conditions with higher standards for food safety. Pleasing restaurant décor and ambiance appeals to middle-class consumers' demand for both entertainment and reflections of their status as a function of their changing urban lifestyles. ${ }^{123}$ Restaurant food is sourced both domestically and through imports, the former generally procured from preferred suppliers to guarantee quality and consistency of supply. Foreign direct investment has played a major role in expanding the appearance of all varieties of restaurants-quick-service, smart-casual, upscale-in all parts of the world, usually accompanied with integrated supply chain and food service development needed to provide the familiar chains with the consistency, regularity and quality required for these businesses.

\subsubsection{New Consumer Values Food Subsystem}

An emerging and fast-growing segment of the modern system is driven by consumers, especially urban consumers, who embody a diverse set of new values and aspirations that guide their purchasing decisions and consumption patterns (Section 2.3). Largely (but not exclusively) middle- or higher-income consumers have grown more concerned with safety, health and wellness, sustainability and equity issues, or with their personal shopping experience, and these new value chains, private food companies and modern retail stores (or revamped parts of existing stores) are responding to this high growth market. They are doing this by introducing new products, relabelling, refocusing on product safety, avoiding certain ingredients (e.g. trans fats) or supporting local or global producers. Some modern retailers are even using their own "private" labels to market food that is made by a contract manufacturer. Growing demand for more nutritious food includes products that are minimally processed, high in fibre, heart-healthy, non-GMO, locally-produced, "slow", natural or organic. ${ }^{124}$

In many countries, particularly among middle- and higher-income groups, these preferences are often manifested through demand for local food supplied by short value chains and direct contact with producers, including those who provide food through e-commerce (i.e. first-hand traceability). Food wholesalers and modern retailers in numerous countries are working to supply local and seasonal food to mainstream retailers, catering companies and online stores. The municipality of Rosario in the province of Santa Fé in Argentina has facilitated the provision of locally grown horticulture products directly to hotels associated with the city hotel association. The provincial government of Santa Fé also developed a "Product of My Area" (Producto de Mi Tierra) logo and label, indicating the location and quality of food 
production; producers receive a 20 percent premium for sustainably produced food. However, many local food initiatives, in seeking to achieve multiple TRANSFORM outcomes (i.e. affordable, fresh nutritious food, jobs and low food miles), are often challenged by volume requirements, logistics and quality criteria that may limit participation of local producers. ${ }^{125}$

\subsubsection{Consumer Store Preferences: A Mixed Strategy}

Faced with this array of retail and restaurant options, most consumers at all income levels adopt a mixed or multichannel shopping strategy to meet their food needs. They may visit a supermarket once a week or month to make bulk purchases or to take advantage of the large assortment and low prices for key staples, complemented by daily or weekly visits to open markets or neighbourhood retail stores or the use of mobile vendors to purchase fresh produce and other necessities. ${ }^{126}$ Higher-income urban households allocate a larger share to modern retail but still spend twice as much at traditional food outlets.

\section{FIGURE 3.3 Food Retail Market Shares: Modern vs. Traditional}

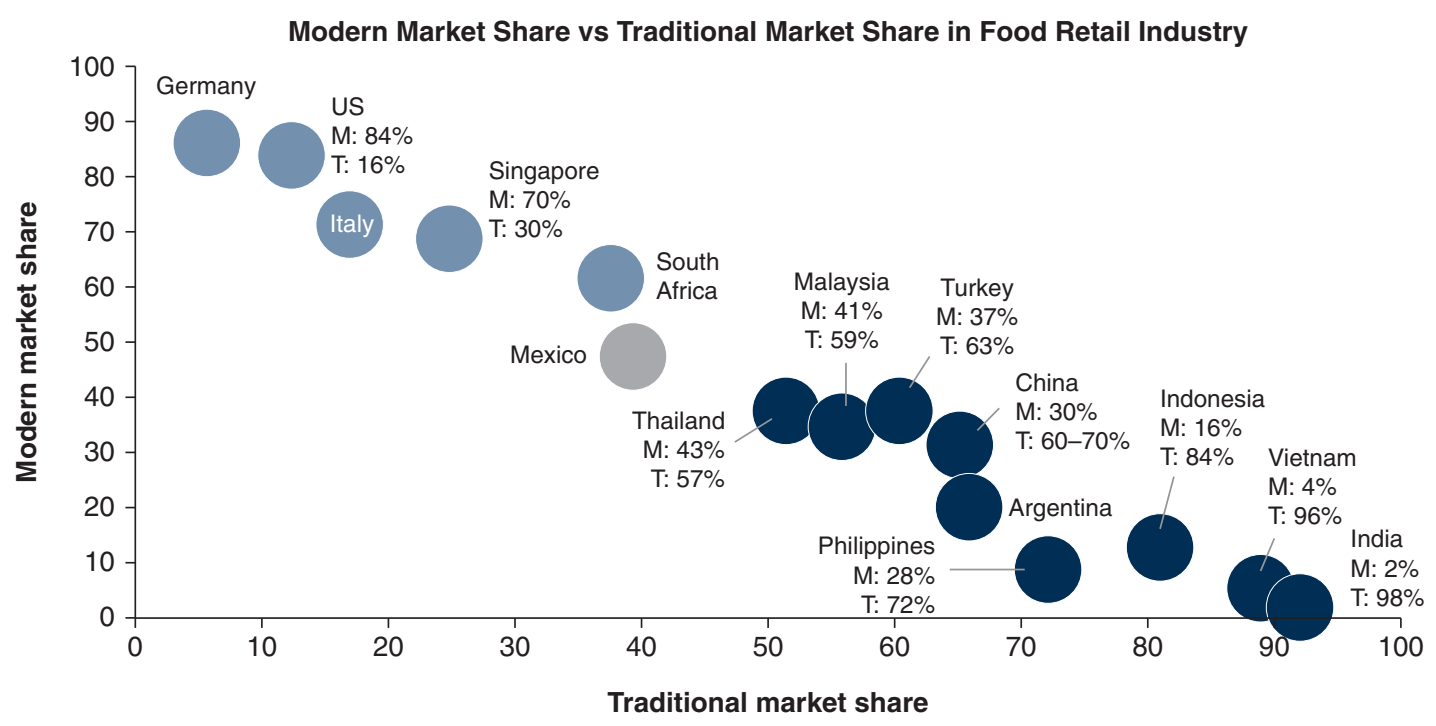

M: Modern market share

$\mathrm{T}$ : Traditional market share

Source: DBS Group Research. 2015. Industry focus: Asian grocery retail report. Accessed June 1, 2017. https://www.dbs.com.sg/ treasures/aics/pdfController.page?pdfpath=/content/article/pdf/AlO/150722_insights_whetting_asean_appetite.pdf; Delgado, Juan. 2015. Market structure, growth and competition in the supermarket sector in Latin America; Agriculture and Agri-food Canada. Modern grocery retailing in the United States. International Markets Bureau Market Indicator Report. Accessed June 1, 2017. http://www.agr. gc.ca/resources/prod/Internet-Internet/MISB-DGSIM/ATS-SEA/PDF/6365-eng.pdf; Yurdagul, Bulent and Neerav Agarwal. 2015. Turkish food retail. HSBC Global Research. Accessed June 1, 2017. http://f.bigpara.com/20151126_Turkish\%20Consumers_HSBC.pdf; Battersby, Jane, and Stephen Peyton. 2014. The geography of supermarkets in Cape Town: Supermarket expansion and food access. Urban Forum 25, no.2: 153-164. Springer Netherlands, 2014; Zhang et al., Transformation of urban.

Food retail market share data (Figure 3.3) show a mixed division between the traditional sector-including open/wet markets and small independent retail stores-and the large variety of modern retail, headlined by supermarkets. Modern retail has made significant inroads in many countries but has not advanced as rapidly as some had predicted. Open markets and small, 
independent retail stores in the traditional system continue to claim a large share of retail market, representing more than 80 percent in India, Indonesia and Vietnam. Regular availability of quality and affordable fresh fruits and vegetables in open markets, as well as the convenience and services of small, independent neighbourhood stores, are two of the most important features that have helped the traditional sector to retain a competitive advantage.

\subsection{Informal System and the Urban Poor}

The informal food system represents a third subsystem that caters predominantly to the urban poor through informal food vendors and restaurants that are not generally registered businesses. It is largely cash-based and characterized by small volume retail transactions involving both domestic and imported food products sourced from open or wet retail markets or wholesale markets in the traditional system. Some vendors may extend credit to regular customers. It also includes informal safety nets that poor households use to secure food including food transfers from family members in rural areas and through sharing with neighbours.

FIGURE 3.4 Prevalence of Food Insecurity Among Urban and Rural Populations

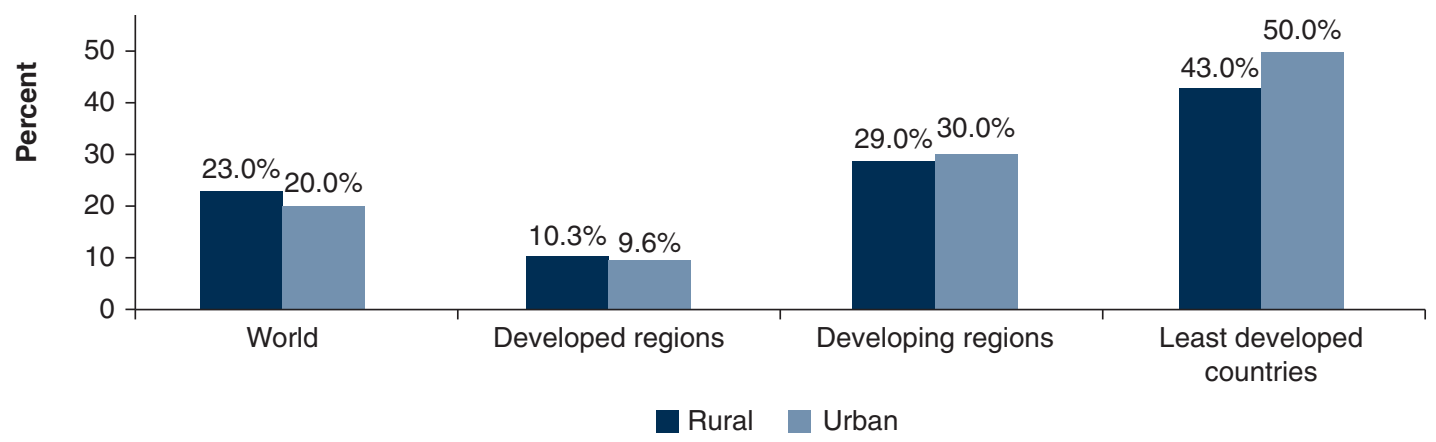

Source: FAO's Voices of the Hungry (2016).

\subsubsection{Urban Food Insecurity}

According to the FAO's Food Insecurity Experience Scale (FIES) ${ }^{127}$ survey in 146 countries, 50 percent of urban populations in the least-developed countries are food-insecure, compared with 43 percent in rural areas ${ }^{128}$ (Figure 3.4). Among informal urban settlements around the world, however, the prevalence of food insecurity reaches 70-95 percent of the population. ${ }^{129}$ Food insecurity often particularly touches recent rural migrants and female-centred households. ${ }^{130}$

Although the urban poor use diverse strategies to obtain food, they depend - more than any others-on informal market vendors, open markets and small traditional retail outlets. A large portion of the world's urban population lives in informal settlements on the urban periphery, ranging from 20 percent in Latin America to 55 percent in sub-Saharan Africa, and rising to 65 percent for all low-income countries. In these neighbourhoods, informal food vendors and restaurants predominate. 
The urban poor are generally limited to shopping at nearby stores, which often have a small selection of food items and an even smaller choice of nutritious products. ${ }^{131}$ In areas without food stores or adequate transportation systems, people depend more on the informal sector and purchase prepared food more frequently. ${ }^{132}$ In countries with high market penetration of modern retail, the urban poor may purchase some food at modern retail outlets but significantly less so than higher-income households. ${ }^{133}$ Shopping decisions of the urban poor are also strongly conditioned by such factors as the difficulty and cost of transporting large volumes of food from supermarkets, the lack of storage and refrigeration, the cost of electricity or cooking gas, and the lack of time or hygienic areas to prepare food. High levels of mobility and long-distance commuting also push the urban poor to get their food from informal vendors. ${ }^{134}$

\subsubsection{Informal Street Vendors: Accessible and Economical}

Informal street vendors or hawkers sell a large share of the food consumed by the urban poor, whether through retail sales of small units or by the large number of vendors, kiosks, stands, pushcarts and small restaurants selling prepared food on sidewalks/roadsides. They operate primarily in the open air in makeshift structures, bringing all their business materials to their place of sale. In informal settlements, vendors may be sheltered from the harassment experienced in cities and will very often not pay rent or transport.

Both men and women work as informal street food vendors. Many of them are poorly educated and are recent rural migrants. ${ }^{135}$ Food vending generally demands higher investment but is often more profitable than other informal trades. ${ }^{136}$ Street vendors have knowledge of local conditions and develop close relations with customers who depend on trust to overcome lack of food safety enforcement. They source the food they prepare or sell from supermarkets, wholesalers, fresh produce markets and local farmers. ${ }^{137}$ Street food vendors often operate on the margins of society in a profession that is often viewed negatively as a nuisance and safety hazard and that is subject to random harassment. ${ }^{138,139}$ Many vendors may be aware of hygiene and healthy practices but are challenged by daily exposure to health hazards from poor sanitation, drainage, lack of waste collection and poor access to clean water. This environment and the absence of food safety enforcement lead customers to carefully determine the most trustworthy food vendors.

\subsubsection{Community Restaurants, Food Banks and Soup Kitchens}

Several options are used in cities across the world to distribute subsidized or free food and meals to the urban poor. Cities in Brazil and Mexico have successfully developed government-run, community dining rooms to serve nutritious meals prepared with locally sourced food at subsidized prices. Food banks and soup kitchens have also been effectively used throughout the world, particularly in North America and Europe, to distribute available, unused food to those in need. Largely managed by diverse civil society and faith-based organizations, food banks use diverse models to collect surplus food from grocery stores, farms and manufacturers and redistribute it to 
families within the local community. ${ }^{140}$ France's food bank network has benefited from a 2016 law that requires supermarkets to donate food that is approaching its expiration date. Food banks are increasingly focused on securing fresh produce to distribute to those in need, while providing classes on how to make nutritious meals with the distributed food.

\subsubsection{Formal and Informal Safety Nets}

In addition to the retail purchases of food, some poor urban households receive food from their rural-based families or from neighbours. In some cities, half to three-quarters of the urban poor in informal settlements receive food transfers from their rural-based families engaged in agriculture. ${ }^{141}$ Others have access to food by producing their own food, from their own food vending business, or through direct consumption of food away from home. ${ }^{142}$

Some countries also provide food to the urban poor at subsidized prices in government-managed stores or cooperatives as part of government food programmes. Approximately half of India's urban population is entitled to five kilograms of subsidized food grain, for example, as decreed by the National Food Security Act of 2013. ${ }^{143}$ In some countries, however, the government has not been able to respect food commitments to all targeted beneficiaries due to insufficient product availability, shop closings or corruption. Differential access to social and physical infrastructure, along with low incomes, affect the poor's access to and consumption of affordable, safe and nutritious food and help to explain a lack of urban household food security. ${ }^{144}$ Poor urban residents who spend 46 to 66 percent of their income on food are likely to be food-insecure, with the highest prevalence located in informal settlements on the urban periphery. ${ }^{145}$ Given the high share of household income spent on food, food prices are a determining factor in household food security.

Equally important actions to consider are the many different innovative social protection programmes and municipal policies that recognize and provide support services for the vulnerable and the poorest households, including refugees, displaced populations and the associated host communities, as well as workers in the informal space. Urban food policy and regulations must recognize the forms and roles played by the informal sector, as well as non-state actors providing these socio-economic support services and safety net programmes, and develop appropriate measures to facilitate and support these actors while ensuring adequate standards and without jeopardizing economic or environmental sustainability.

\subsubsection{The Impact of Pricing}

A limited number of food price analyses reveal that prices vary between open markets, traditional small outlets, modern retail outfits and informal vendorsdepending on the country, type of product, product quality, store location, intensity of competition and quantity purchased. In India, modern retailers sell basic foods at the same or lower prices than traditional retail, ${ }^{146}$ while in Madagascar, food prices in modern retail are 40 to 90 percent higher than those in traditional retail markets ${ }^{147}$ (although the quality may be higher too). 
Government-supported outlets are generally cheaper for some products than traditional outlets, after controlling for quality. ${ }^{148}$ In a competitive food retail environment with fairly small retail margins, some supermarkets may not try to lower prices to attract middle-class customers, knowing that consumers are attracted to multiple attributes of modern retail, including the convenience of one-stop shopping. ${ }^{149}$ Meanwhile, processed foods are often cheaper than fresh produce, as they are generally manufactured from cheaper ingredients that have long shelf lives, they are easy to store/transport, and the costs of inputs are lower.

Better understanding of the spatial dimension of food prices is important for monitoring the performance of urban food systems, particularly as neighbourhood location and access, type of retail market, quantities transacted and the level of market concentration and competition may affect their level and volatility. Since the urban poor may spend up to 50 percent or more of their household budget on food expenditure, they are particularly vulneable to price volatility that may limit access to quality food.

\section{Entr'acte - Elio: Food at the Heart of Bergerak's Urban Transformation}

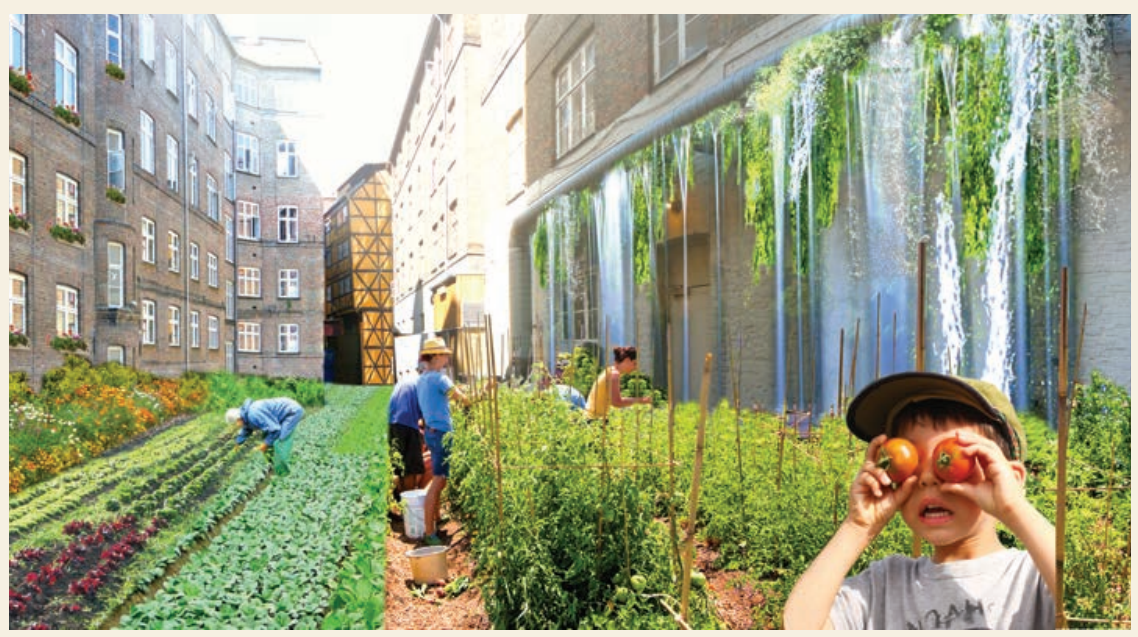

(C) Mark Stevens/Flickr. Further permission required for reuse.

In 2050, the conurbation of Bergerak was in the last stage of Urban Transform, an urban renewal and resilience programme implemented in sync with a nutritious food and healthy lifestyle initiative. Bergerak's governor initiated the programme in 2035 to modernize the city's eroding infrastructure, to mitigate the impact of flooding, to diversify the economy and to eliminate the scourge of obesity and the array of associated diseases.

Elio's low-income neighbourhood had been among the first target communities of the programme 15 years ago, when the streets flooded every time it rained and almost all of his six-year-old friends were obese. Families in his neighbourhood couldn't afford to widen doorways in their homes or install elevators to accommodate their expanding girth as was happening in the wealthier parts of Bergerak. Faced with declining productivity, exorbitant health care costs and huge annual

(continued on next page) 


\section{Entr'acte - Elio: Food at the Heart of Bergerak's Urban Transformation (continued)}

costs to repair flood damage, civic and private sector leaders joined with the governor to design, finance and implement the Urban Transform programme.

The "Eat Fit" nutrition component included: providing nutritious, locally sourced organic foods in schools and public institutions; limiting salt, sugar and saturated fat in food; providing incentives for food businesses and restaurants to transition to healthier foods; and replacing unhealthy food advertising with Eat Fit promotions. All Elio and his friends knew was that they loved the nu-food or nutritious food.

Urban Transform was designed and planned through a green, food and economic diversification lens. With dwindling demand for traditional natural resources, Bergerak leaders rebuilt the transportation and energy infrastructure and restructured sanitation and storm water systems to contribute to a more resilient and economically dynamic, green city. The conurbation reprioritized its budget and secured climate financing to initiate the programme. Its success was assured through innovative incentives for infrastructure and property development that assured longterm engagement of the private sector and helped to create a sustainable tax base.

Over the course of his childhood, Elio's world had been transformed with parks, forests, sports fields and the latest urban and peri-urban agriculture commingled with new housing, all irrigated with treated waste and storm water that used to flood his house. He had also met other friends at his new school since the city had successfully out-competed other cities to attract climate and conflict refugees whom they needed to ensure a stable work force for future economic growth.

By the time Elio finished University, neighbourhood food markets and stores were provisioned by urban food producers as well as by the underground metrorail network that transported food from the wholesale food market and Metro Food, the agrifood processing park located about 15 kilometres outside the city. Elio's first job was with a food processing/gene awakening firm that used fourth-generation epigenetics and 3D printing to produce on-demand food items whose nutrient and vitamin composition was determined through a 24/7 individual nutrition monitor sensor system; the shape of the $3 \mathrm{D}$ food and flavour preferences were selected by the consumer. The job paid well, offered free lunches and excellent health and life insurance, and paid you a higher salary if you ate nutritious foods and kept your body mass index and nutrient profile at recommended levels based on food-based dietary guidelines. Companies and employees loved the higher productivity and lower health costs from a healthier workforce.

Some of Elio's friends worked at the new metrorail and the agrifood park, which were powered by the newest generation of biofuel, derived from municipal waste and converted to energy in a grid of decentralized Waste More bio plants. Waste was in such high demand that companies paid households for their waste. With most freight moving underground or through drone delivery to rooftop dronepads, Bergerak had less concrete, no congestion and cleaner air.

Looking out over the playground at his childhood neighbourhood school, Elio didn't see one obese child running around the playground. All he could see was green trees, grassy areas and clear skies.

Read about Lola on page 125 


\section{A Framework to Support Impactful Food Systems for an Urbanizing World}

\section{Key Messages}

- The TRANSFORM framework proposes a set of interlinked outcome areas to which interventions in food systems would contribute:

- Remunerative jobs and better agribusinesses

- Affordability and accessibility for food security

- Nutritious, diverse, quality and safe food

- Sustainable, resilient agriculture and food systems

- Achievement in these regards are contingent on a set of enabling conditions:

- Transformative institutions

- Facilitating and progressive policies

- Open data, knowledge and evidence base

- Resources for effective public and private financing

- Multistakeholder governance mechanisms and capacity

- An initial typology of four city groupings is provided to help tailor programme and policy recommendations:

- agriculture towns and cities under 1 million people;

- secondary cities of 1 to 10 million;

- megacities and conurbations with over 10 million people;

- future food-smart cities and neighbourhoods.

Thus far, this report has identified several driving forces and key trends that will shape the overarching context in which food systems operate and the challenges they will face in the future. It has also discussed how these converging demographic, socio-economic, agroclimatic, environmental and technological factors have been driving structural changes in the organization and 
performance of the food system, ultimately shaping its future direction. This chapter introduces the TRANSFORM food system framework of interlinked institutional capabilities, enabling conditions and the attendant outcome areas in agriculture and food systems. It also proposes a first cut of a city typology (to be further refined in later analytical phases) that could be used to help develop and target food system interventions for specific types of city.

\subsection{TRANSFORM Framework}

Climate change, food security, good nutrition and health, and inclusive economic growth and jobs represent the overarching challenges that future food systems must address. Given their crucial importance and deep linkages to poverty reduction and shared prosperity, these challenges provide the basis for identifying a set of four interlinked outcome areas to which food systems may aspire and future interventions can be viewed, analysed, prioritized and ultimately designed, implemented and measured, utilizing all or several components of the TRANSFORM framework:

- Remunerative jobs and better agribusinesses refers to an inclusive food system that creates opportunity, employment and enterprise for all segments of the population, distributing equitably the dividends of increased prosperity.

- Affordability and accessibility for food security relates to the ability of the food system to provide food such that it is accessible and obtainable at reasonable prices to an individual or family everywhere, every day.

- Nutritious, diverse, quality and safe food refers to diverse and balanced diets and safe, good food that does not expose the consumer to any risk of illness and in fact provides the body with the necessary nutrients.

- Sustainable, resilient agriculture and food systems rest on the three prongs of sustainable productivity, resilience and emissions mitigation. It is the ability to continuously support productive, adaptive agriculture and food systems with a low/minimum carbon footprint.

These four interlinked outcome areas represent the centre of the TRANSFORM framework (i.e. representing the letters "R A N S") (Figure 4.1) and a quadruple win for the food system. They designate a shift or a transformation in the food system focus from one that has been traditionally centred on producing and delivering a sufficient quantity of food for urban populations to one that underscores the growing and critical importance of these critical dimensions: the long-term, agro-ecological viability and sustainability of the food system; its resilience to shocks; its ability to assure access to food for all; the quality, safety and nutrition of diets for healthy lives; and the opportunities provided by the agrifood sector for meaningful and remunerative businesses and jobs. They also represent the vision and foundation on which to develop a food-smart city. 


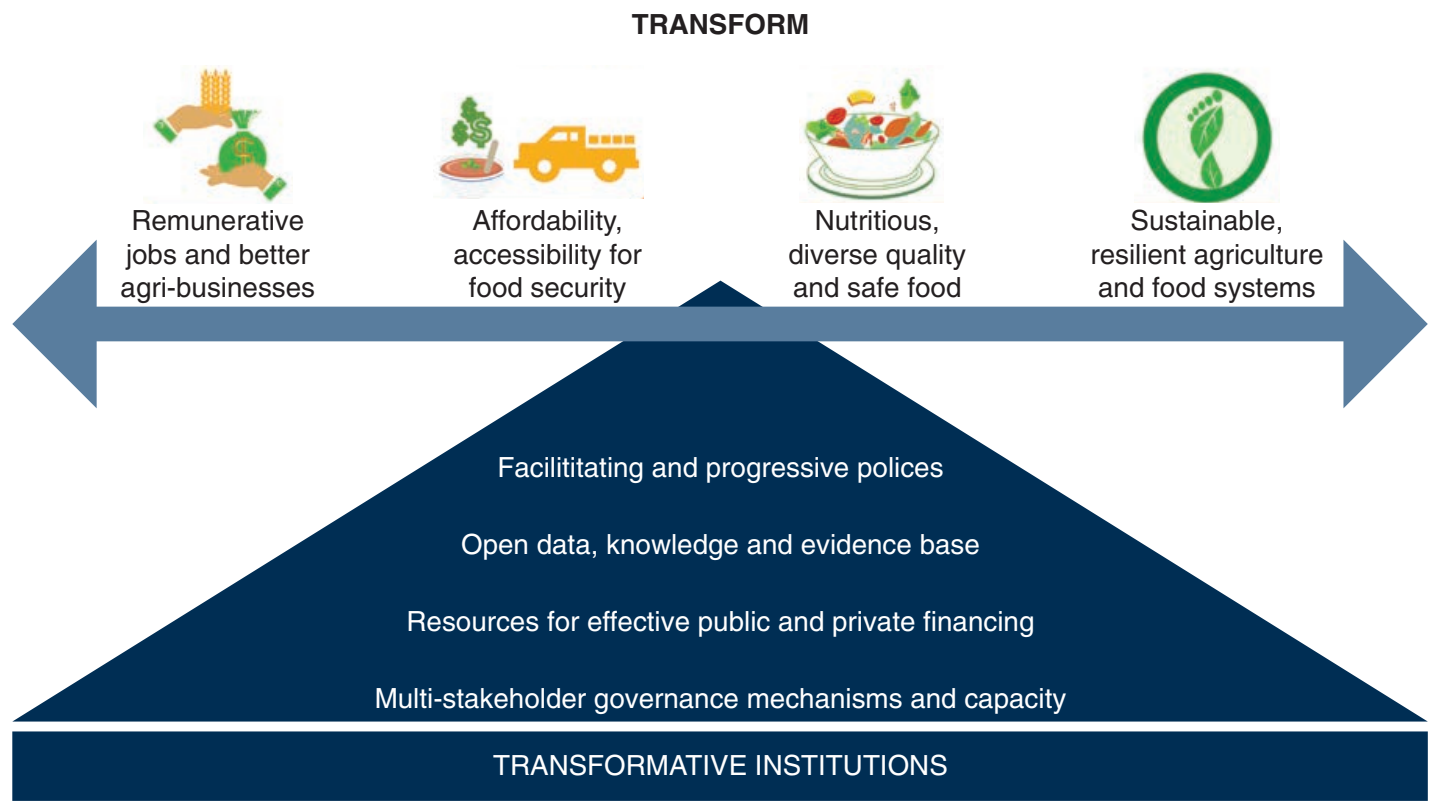

In an increasingly interconnected and interdependent world, these challenges play out at multiple levels-global, regional, national, district, municipal and community. Although they are strongly influenced by the actions of individuals as consumers, they raise an equally important set of questions related to our roles and actions as members of communities, residents of cities, citizens of our countries and inhabitants of the planet. Naturally, these changes and processes will exert a strong influence on rural areas as the largest source of food in the food system and as the other half of the evolving rural-urban continuum and transformation.

Achieving progress in these outcome areas will be strongly contingent on the ability of countries and cities to establish a set of enabling conditions or "enablers" that are essential for effectively prioritizing, planning, designing and assuring accountable implementation of policies, programmes and investment.

Transformative institutions (the " $T$ " in TRANSFORM) represent the cornerstone of the enabling conditions. This enabler addresses the fundamental need to rethink and iteratively restructure the institutions, processes and mechanisms to effectively address the future food system challenges facing communities, municipalities, metropolitan districts and provincial and national governments. Transformative institutions, with their champions, commitment and facilitation are key to leveraging the other four enablers (i.e. FORM), which in turn are central to delivering the four interlinked outcome areas (RANS). 
Facilitating and progressive policies: Addressing food sector issues within decentralized levels of governance (e.g. municipal or metropolitan districts), combined with a competing number of technical sectors and diverse stakeholders, offers a formidable challenge to how policies and programmes will be designed and implemented.

Open data, knowledge and evidence base: Investment in data and analysis and open and transparent processes to access information will be essential for improving the evidence base required to plan, prioritize, design and track interventions in these relatively new areas.

Resources for effective public and private financing: The mobilization and commitment of public financing to fund key public goods at municipal, metropolitan, provincial and national levels must be complemented by policies and incentives to attract private capital towards financially viable investment opportunities.

Multistakeholder governance mechanisms and capacity: The required transformation in institutions, policies and processes will require strong local leadership, the development of effective governance and accountability mechanisms, and strengthening human and institutional capacity at these levels of government and of the diverse local stakeholders.

The following chapters discuss in more detail the TRANSFORM framework from an operational perspective. Chapter 5 examines the enabling conditions. Chapter 6 then proposes four broad intervention areas to be considered for achieving results across the interlinked food system outcome areas.

\subsection{An Emerging Typology of Cities to Tailor Food System Responses}

Contextualized understanding of the specific challenges and drivers of agrifood systems with respect to cities, urban and peri-urban areas and the crafting of viable solutions are a sine qua non for progressing effectively on this agenda-whether in terms of defining policies, designing investments or simply benchmarking and monitoring trends and changes. The development of a typology of cities can assist in this task of orienting food system interventions to groupings of cities that share similar characteristics. While many efforts have been made to identify globally representative city profiles based on specific variables (e.g. demographics, resource base, geography, agro-ecological conditions, climatic features), attempts to design a universally applicable/ multipurpose typology of cities and metropolitan areas are ongoing. The development of a more robust typology will inevitably improve as attention focuses on food systems and an improved data and evidence base enables a more refined analysis of the differentiating features and TRANSFORM 
outcomes. This section briefly examines some of the complexities in definitions of rapidly evolving cities. It then discusses a set of demographic/ socio-economic and food system criteria as the basis for a future city typology. Given the lack of available data needed to feed this typology, these criteria can be refined further and applied more meaningfully as relevant data become available in the future.

\subsubsection{Food Systems in the Evolving Urban and Peri-Urban Governance Space}

The absence of standard international criteria to define "urban" and "rural", "city" and "town", and "urban agglomeration" and "metropolitan area" (Chapter 2, Box 2.1), together with the rapidly changing urban and peri-urban space in most regions of the world (in addition to incomplete data and lack of an analytical base), makes it quite difficult to determine $a$ priori the types or profiles of cities and towns for targeting specific recommended interventions. ${ }^{150}$ But food issues are not easily circumscribed within convenient, static boundaries of one municipal district or provincial government. Just as built-up urban areas spill over administrative municipal boundaries into adjoining jurisdictions, so do food system issues transcend the multiple levels of decentralized government within the dynamic urban, peri-urban and rural space. The increasing use of the term "city-region" stems from the recognition that urban food issues must often be addressed from a larger regional or territorial perspective that encompasses the dynamic urban/peri-urban and rural space and multiple jurisdictions in which food systems operate. ${ }^{151}$

Developing a city typology is partly conditioned by potential programme entry points and implementation steps; these decisions will be strongly influenced by the specific context, priority issues to be addressed, and the political

\section{BOX 4.1 City-Region Food Systems}

A city-region food system is a concept that refers to a "complex network of actors, processes and relationships related to food production, processing, marketing and consumption that exist in a given geographical region and includes a more or less concentrated urban centre and its surrounding peri- urban and rural hinterland-a regional landscape across which flows of people, goods and ecosystem services are managed" (FAO 2013). In practice, operationalizing city-regions has been challenged by the complexity of defining boundaries, the relatively low priority accorded to food issues in urban planning processes (e.g. natural resource management), gaps and overlap in institutional mandates of and linkages between government units and the lack of functional multistakeholder platforms.

Source: Forster, T., F. Egal, A. Getz-Escudero, M. Dubbeling and H. Renting. 2015. Milan urban food policy pact: Selected good practices from cities. Fondazione Giangiacomo Fektrinelli, Italy. Accessed June 1, 2017. http://www. foodpolicymilano.org/en/ebook-good-practice-en/. 
interest and calculus of the participating units of government. An approach embracing both municipalities and their larger metropolitan districts would appear to offer a pragmatic way forward that combines the municipal specificity, procedures and budget with the breadth and wider political mandate of a metropolitan or city-region perspective. A "metropolitan district" is roughly consistent with the United Nation's statistical focus on urban agglomerations, which delineate boundaries based on a contiguous urban or built-up area. It is also consistent with the poverty focus of future programmes, as many low-income settlements are often located in the urban periphery far from the city centre. Finally, the metropolitan district focus is consistent with the observation that some cities are growing out, rather than up, with lower population density spread out over a larger area.

This municipality/metropolitan district approach is also consistent with experiences in many parts of the world. China, for example, has used three city-region mechanism types for economic development purposes: administrative annexation for "metropolitanization"; strategic regional plans to consolidate urban clusters and to coordinate infrastructure development; and regional institutions for intercity coordination. ${ }^{152}$ The challenge of intergovernment coordination is considerable in many large cities. In the municipality of Nanjing in the Nanjing Metropolitan Region of China, for example, there exist over 400 entities divided into four hierarchical administrative levels: the municipal (shi); eleven districts (qu); 100 subdistricts (jiedao); and 307 communities (juweihui or cunweihui) - each community with one or more neighbourhoods (shequ or xiaoqu). ${ }^{153}$ This institutional complexity at subnational levels of government underscores the importance of addressing the enabling conditions (Chapter 5), particularly transformative institutions (T).

\subsubsection{Socio-Economic and Population Criteria}

Cities across both middle- and low-income countries will be the focus of relevant urban food system interventions; this target is consistent with the World Bank's mandate. The socio-economic level of cities represents a first criterion by which to classify cities. However, a comprehensive data or indicator set does not currently exist that would enable one to systematically classify cities by their per capita income or its distribution across the population. Income estimates exist for many of the world's largest cities but are lacking for most small- and medium-sized towns and cities. It is therefore difficult to classify most of the world's cities by income level. Similarly, data to estimate Gini indexes of income inequality within municipalities and metropolitan districts are equally sparse. The application of existing methods or development of new indicators to estimate the level and distribution of income in cities represents an area of work in subsequent phases.

As the evolution, structure and performance of such food systems are intimately linked to the process of urbanization, the population or demographic profile of urban agglomerations represents a second key criterion for grouping cities. Based on United Nations (UN) population data and trends presented in Chapter 2, we have initially identified three large groupings of cities: 
small cities and towns with under 1 million inhabitants; medium and large secondary cities with 1 to 10 million inhabitants; megacities and conurbations with more than 10 million inhabitants. Conurbations are urban agglomerations in which built-up areas of cities, suburbs and towns have expanded, swallowing up once peri-urban areas, effectively merging together and blurring the lines between city boundaries. Conurbations are naturally more amenable to a metropolitan district and city-region approach.

As cities with less than 1 million inhabitants will continue to represent more than 50 percent of urban dwellers in 2050, some countries are developing specific strategies for these towns and smaller cities. Many countries, including Brazil, China, India, Indonesia and a few nations in West Africa have initiated the development of agricultural or "agropolitan" regions, working to strengthen the linkages between these towns and cities and their surrounding rural areas. In Latin America, for example, Monteria is among the small cities in the northeast region of Columbia benefitting from the development of city-region territories that address the needs of local smallholders as well as new export markets. ${ }^{154}$

As additional city-level analysis is undertaken in subsequent phases of this urban food analytical programme, further refinement to population and socio-economic criteria could be envisioned. Cities could be further disaggregated by city size (e.g. less than 300000 inhabitants, 300000 to 1 million, 1 to 5 million, 5 to 10 million, greater than 10 million). Additional factors could include: population densities within urban agglomerations; the level and distribution of income within cities; the number of households living in informal, low-income settlements; the number of municipal and submunicipal administrative jurisdictions within urban agglomerations; criteria to assess transport infrastructure that differentiates cities by their access to a port, navigable river or railroad, which are key to food marketing and trade; and criteria on the business and macroeconomic climate.

The growing recognition that new cities and neighbourhoods will need to be constructed to absorb the increasing number of urban dwellers will provide an opportunity for developing food-smart urban areas. Irrespective of their size, these future cities or communities will undoubtedly require new thinking on the set of policies, institutions, capacities and investment required for their development. Future food-smart cities therefore represent a fourth category for this emerging typology.

A specific set of urban food interventions may also need to be envisaged for urban areas housing many displaced people and refugees or those located in countries in protracted crisis or their neighbours. ${ }^{155}$ Six in every ten displaced people reside in urban settings. ${ }^{156}$ Additional reflection and analysis will need to be carried out to advance thinking on interventions that benefit both the displaced and host populations.

Although subsequent discussions of key programme interventions (Chapters 5 and 6) will suggest examples of potential interventions for each city type, further refinement of the socio-economic and demographic criteria will require a much more detailed evidence base driven largely by consultation and diagnosis with city officials. 


\subsubsection{Food System Criteria}

The previous chapters have underscored the complexity and diversity of food systems, which are continuously and rapidly changing as they are subjected to important external influences such as population growth, climate change and urbanization. These different factors need to be considered when analysing food systems at national and local levels and identifying paths for increasing their positive impact on TRANSFORM outcomes. Food system variables related to the structure and performance of the food system represent a third set of criteria to classify municipalities, eventually helping to orient potential interventions that address specific challenges relevant to different types of cities. In an ideal, data-abundant world, these indicators would be inspired by the TRANSFORM framework outcomes since the issues of remunerative jobs, affordability and accessibility, nutritious food, and sustainable and resilient systems represent key performance indicators for future food systems.

The current paucity of food system-related data, however, makes it difficult to operationalize the indicators needed to effectively classify cities. This section briefly discusses some second-best, operationally feasible ways to categorize cities with minimal data collection and analysis. It then presents an indicative list of indicators that would logically help to guide urban food assessments that cities could undertake as a first step in helping to identify the priority issues to address in future interventions.

Identifying whether a town or city exists in an agriculture production area represents a useful first indicator to determine urban areas in which large assembly or wholesale markets provide a key link to rural areas and serve an important economic role in the rural non-farm economy. These towns or cities may be prioritized in actions that look to improve market access and efficiency or seek to strengthen agrifood processing in close proximity to the key agriculture commodity inputs. The agriculture priority would differentiate certain cities from those located in zones with minimal agriculture production (e.g. natural resource extraction areas), which may have different food system priorities.

The geographic location of a city and access to transportation networks (ocean, river, modern highway) represent a second criterion that will affect the type, origins and affordability of food consumed by residents and contribute to shaping the sustainability and climate footprint of the food system ( $\mathrm{S}$ in TRANSFORM). An estimated 40 percent of the world's population lives within 100 kilometres of the coast and three-quarters of the world's megacities are located by the sea. ${ }^{157}$ These cities, particularly those on the coast, may find it easier and more affordable to access food from regional and global markets than to source from national production. City location also affects food system resilience. Those with easy access to multiple sources of food supply (national, regional or global) may be more resilient to many shocks, compared with those dependent on food imports and potential supply or price shocks in global markets. Coastal cities may also be exposed to risks from rising sea levels. ${ }^{158}$ 
As discussed in Chapter 3, every city or town in the world includes, to varying degrees, elements of traditional, modern and informal food channels or subsystems. Determining the relative share of food sales-by value or volume, and potentially by major food types that flow through each channel -represents a third criterion for which some data are available (see Figure 3.3) or for which a rough estimate could be determined. Understanding whether 80 percent of food is sold in traditional retail channels or whether 50 percent of food sales depends on informal channels will have strong implications for the types of interventions that could improve performance (e.g. modernizing wholesale markets for fresh fruits and vegetables). Determining the percentage and location of consumers who are dependent on the informal food sector will unfortunately require more specific analyses. This criterion is intimately linked to all four TRANSFORM outcomes.

For many of the other variables that could help to characterize a city by food system criteria, data are not readily available. For these indicators, analysis of existing secondary survey data, rapid appraisals or surveys, and innovative crowdsourcing or Big Data techniques would be required to produce the relevant information, construct the indicator and categorize cities. In most cases, this work would probably be carried out as part of an urban food assessment (see Chapter 7) that most cities will need to undertake as the starting point for their engagement in urban food issues. Key indicators in this category include:

- the FAO FIES to estimate the prevalence of urban food insecurity;

- use of the World Bank Living Standards Measurement Study (LSMS) household survey data for spatial analysis of urban poverty complemented by use of rapid poverty assessment tools;

- analysis of budget-consumption surveys to classify the structure of consumer food demand for different groups (based on income, age, gender, etc.), identifying the relative importance of food consumed away from home and processed food in overall diet composition and the places of purchase;

- rapid appraisals to determine retail market coverage in all city neighbourhoods and to appraise the availability and affordability of nutritious, safe food (i.e. identification of food deserts);

- rapid appraisals of food sector businesses including informal sector actors;

- analysis of consumer price and market information databases for food products;

- analysis of demographic health survey data (or other nutrition surveys) to undertake spatial analyses of the prevalence of malnutrition in urban centres.

In this early stage of understanding and analysis of urban food systems, it is primarily through rapid urban food assessments that the local specificity and context will be determined. Many other indicators for which there are minimal data (e.g. an estimate of a city food system's climate footprint) will necessarily require more in-depth analyses that would logically precede project formulation and establishment of monitoring baselines. 


\subsubsection{Urban Food City Typology - The First cut}

At this initial phase of reflection and analysis, and in light of the paucity of data on key food system characteristics for the large majority of cities in the world, an initial set of four city types are proposed:

- C1: Agriculture towns or small cities with under 1 million inhabitants

- C2: Medium and large secondary cities with 1-10 million inhabitants

- C3: Megacities and conurbations with more than 10 million inhabitants

- Cn: Future food-smart cities or neighbourhoods yet to be built

This typology combines an initial demographic layer followed by a provisional food system layer that is under development. The typology is intended to assist programme development by suggesting a set of interventions (related to the TRANSFORM framework) that are applicable to a group of cities with similar socio-economic/demographic and food system characteristics. Although it would have been possible to denote a larger number of city types, disaggregating secondary cities further by the predominant food retail channel (modern or traditional) and population density, there is a certain value in simplifying this first city typology and thus maintaining a reduced number of city types in this early stage of development.

As such, these city types ( $\mathrm{C} 1$ to $\mathrm{Cn}$ ) represent urban areas with significant demographic differences as well as substantial variation in their current food systems and arguably their future needs. As explained, agriculture towns or cities have smaller but fast-growing populations and are in agriculture production areas with a key role in the rural economy. Type $\mathrm{C} 2$ groups medium and large secondary cities together, some densely populated while others are growing outward, both challenged to modernize food system architecture and strengthen food businesses to cater to the needs of diverse consumers. The global megacities (C3) generally have more mature economies, with larger numbers of both middle class and low-income consumers, served by vibrant modern, traditional and informal food systems that are challenged to operate in congested environments, many of them in need of upgrading. Finally, as mentioned, the need for new neighbourhoods and cities to house expanding urban populations presents municipal governments and stakeholders with opportunities to plan, design and construct modern, foodsmart cities ( $\mathrm{Cn}$ ), ones whose food systems are poised to achieve the four interlinked outcomes. In these diverse city types, the relative importance or prioritization of TRANSFORM outcomes may also differ (e.g. affordability and accessibility may be a higher priority in large secondary cities and megacities). Further, the most effective project entry points (see section 7.2) may differ between types of cities. For example, the integration of food system interventions in urban development projects may be suited to large secondary cities and megacities, while agriculture value chain projects may be appropriate for small agriculture cities (C1). 
FIGURE 4.2 An Emerging Typology of City-Regions to Tailor Food System Interventions

City Typologies

- C1: Agriculture towns and small cities under 1 million inhabitants

- C2: Medium and large secondary cities with 1-10 million inhabitants

- C3: Mega-cities and conurbations with more than 10 million inhabitants

- Cn: Future food-smart cities or neighborhoods yet to built
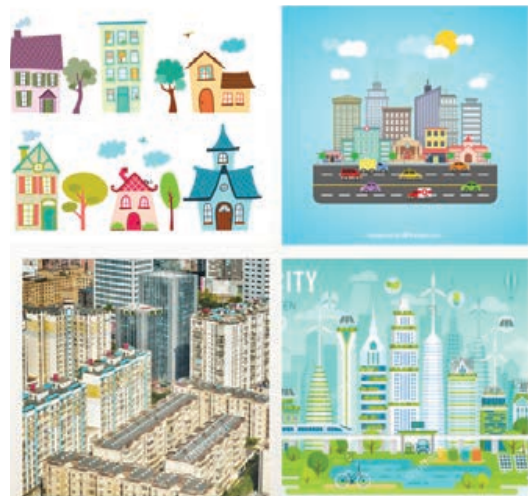

As noted above, subsequent data collection and analysis on urban poverty and demographic profiles, wholesale and retail market infrastructure, relative market shares of traditional, modern and informal food subsystems, food waste intensities, governance structures, stakeholder structures and institutional and human capacity levels, to name a few, will contribute to the development of a more refined and nuanced typology of cities in subsequent phases. 



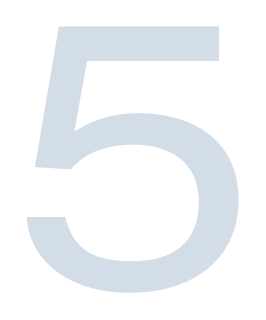

\section{Enabling Conditions for Future Food Systems}

\section{Key Messages}

- Vibrant, sustainable and inclusive urban food systems will depend on a set of enabling factors that offer the essential conditions for successful interventions and investments.

- A fundamental transformation in how institutions, policies and investment are determined, prioritized, designed and accountably implemented is key to effective urban food interventions.

- A locus in the form of a responsible authority, alongside mechanisms for multisectoral and stakeholders' coordination and integration of food issues into urban development plans and budgets, are necessary in the new urban food space.

- The development of facilitating and progressive policy and regulatory frameworks, including aspects related to urban planning with attention to food system needs, land use, tenure and technological innovation, is necessary.

- Public, private and civil society actors need open access to accurate, reliable and timely data and knowledge; use of Big Data and citizen science will require enhanced capacities for processing, understanding and using information.

- The effective mobilization and deployment of public and private resources, including fiscal decentralization, adherence to a transparent municipal budgetary process and prudent and accountable financial management are critical for supporting policies that work and financing programmes at scale.

Thinking and doing something about food issues in cities, towns, metropolitan areas and regional districts is a relatively recent development. Issues related to food have historically been addressed at federal or regional/provincial levels. But that is changing rapidly. A growing number of cities across the world are already working to improve urban food systems. Municipal and 
metropolitan district food-related initiatives stem from several origins: visionary leaders in government and civil society committed to one or several food issues; devolution of responsibilities to decentralized levels of governance; and/or a lack of attention and institutional capacity for addressing urban food issues at national levels. In all situations, successful interventions depend on informed leadership that views food as part of the essential infrastructure of vibrant, sustainable and inclusive cities.

This does not imply that there is not a role for other levels of government to engage in urban food issues. On the contrary, one of the key challenges for countries, municipalities, metropolitan districts and provincial levels of government consists of determining how or what each level of government can most effectively contribute to address certain urban food issues. In some cases (e.g. norms and standards), the most appropriate level of intervention may be regional, where regional integration institutions are responsible for policy and regulations governing regional trade.

Food, like nutrition, is an issue that cuts between ministerial or department lines, with multiple dimensions touching a large number of sectors and institutional mandates. In many countries, food issues have historically been addressed by agriculture ministries, but almost exclusively from a rural perspective; other dimensions have been managed by ministries of health, commerce, livestock, environment or social affairs, to name a few.

Urban food systems, as viewed from the TRANSFORM framework, involve several levels of government, multiple sectors, many stakeholders and new processes and capacities, which in most situations do not yet exist (or are insufficiently developed) at the municipal or district levels. The effective prioritization, planning and design, funding and accountable implementation of technical interventions will depend on the ability of municipalities and metropolitan districts to address and subsequently establish a set of enabling conditions for successful action.

This chapter discusses five conditions or "enablers" that will be critical to the advancement of urban food systems: Transformative institutions and four other enabling conditions: Facilitating and progressive policies; Open data, knowledge and evidence base; Resources for effective public and private financing; and Multistakeholder governance mechanisms and capacity (i.e. FORM). Developing and strengthening these enabling conditions will be the starting point for many cities' and towns' engagement in urban food systems.

\subsection{T: Transformative Institutions}

Delivering successful food policy and institutional strengthening measures and programme interventions in cities at scale will invariably require strong

political commitment to ensure effective prioritization, establishment of the necessary institutions and governance (and stakeholder) mechanisms, capacity strengthening, sequencing, and integration into urban planning and subnational and national budgeting. This is no small task as it basically 
requires a fundamental transformation in how institutions, policies and investment will be determined, prioritized, designed and accountably implemented.

The enormous demographic and structural shifts occurring with rapid urbanization across the globe imply that demand for food, housing, transport, utilities and services in cities will accelerate and augment greatly over the next several decades. This provides an exciting opportunity for governments to design, build and manage food-smart neighbourhoods, communities and new cities. As policies pertinent to food systems influence, and are in turn deeply influenced by, a host of other urban challenges and policies-in domains ranging from poverty, housing, health, social protection, water and sanitation, land use planning, environment, transport, energy, trade and more-public, private, research and civic stakeholders will need to come together to deliver a comprehensive, interdisciplinary and interinstitutional approach. ${ }^{159}$

The institutional challenges to address food issues at the municipal level are great. Municipalities or metropolitan districts will likely need to create a responsible authority to lead work on urban food issues. This structure will need a clear mandate, clear lines of authority, capable staff, adequate budget line and sustained political support. For many municipalities located in a larger metropolitan area, regional districts or conurbations, it may be more appropriate from food system, political, governance and financial perspectives, to establish a joint food unit at a higher district level of governance. City-region or metropolitan district approaches may be more effective for addressing many food issues that require cross-jurisdictional, collaborative planning, programming and financing of actions across a larger urban space. They may be better placed to address issues arising from the physical expansion of built-up areas that push cities beyond their traditional administrative boundaries into other jurisdictions. They may be more resilient to changes in municipal governments and shifts in budget allocation, thereby helping to institutionalize food programmes in district policies and budgets; budgets can also be shared across municipalities. This metropolitan or regional district approach is also consistent with the emerging concept of city-regions, which is strongly grounded in the principles of many urban food movements to promote green urban landscapes, local food and short value chains. Further, working at this higher, district level enables municipalities to more effectively develop programmes that embrace the urban periphery where most urban agriculture takes place (i.e. local food shed).

Irrespective of the level of decentralized governance at which urban food interventions are initiated, it will be important to establish and iteratively improve mechanisms for both vertical and horizontal coordination across sectors and stakeholders and with various levels of government. The institutional modalities of urban food planning and implementation will need to clearly specify roles and responsibilities and to clarify linkages between municipal and district food policy efforts with provincial and federal agencies and line ministries. The clarification of the institutional mandate and specific 
responsibilities, and sustained political support for their application, cannot be too heavily emphasized. Debilitating conflicts can easily develop within and between various levels of government (e.g. between municipal agencies and national ministries) due to ambiguous mandates and minimal accountability for their application. As many issues fall between agency or ministerial lines, developing effective mechanisms to share responsibility and assure accountable implementation becomes very important.

It is equally important to clearly articulate the pathways through which food issues can be integrated into urban development plans and budgets. In these ways, city-region food systems can be embedded within the wider municipal, provincial and federal policy context. Integrated and coordinated action may be equally advisable to take advantage of and resolve issues arising in conurbations-regions where several cities and large towns have merged to form one continuous urban area. Multijurisdictional coordination and rural-urban connectivity are also essential in corridor initiatives.

Beyond the establishment of some type of food coordination unit at municipal or district level, it is also important to develop sound mechanisms and transparent procedures for mobilizing sector agencies and line ministries that will be called on to design and implement specific components of a food programme. In this regard, there is a need to clarify the roles and responsibilities, build capacity and systems and empower local governments in designing and implementing contextually relevant policies and programmes. Given the complexity of this institutional transformation, municipalities, metropolitan districts and national governments will need to draw upon existing resources and knowledge of other cities involved in similar processes, benefiting from good practices and knowledge transfer and leveraging resources via North-South, South-South and Triangular cooperation.

\subsection{F: Facilitating and Progressive Policies}

Beyond the need for significant evolution in the institutional framework to effectively engage in work on urban food systems, developing transformative, facilitating and progressive policies represents a second enabling condition for future engagement in this area. The urban and peri-urban space of rapidly evolving food systems represents a relatively new area for which policy and regulatory frameworks remain at an embryonic stage. Engagement in this policy space will need to consider both the specificity of the urban context as well as its interconnectedness with rural areas and agriculture and rural development policy. The urban food policy agenda must also find effective ways to address the policy and regulatory issues within the multiple sectors that will need to contribute to food system issues. Three issues serve to illustrate the need for facilitating and progressive policies in urban food systems: land use and urban development planning; technology and innovations; and rethinking food and agriculture policy priorities and budgets. 


\section{BOX 5.1 Fostering Municipal Food System Connections Across City Agencies and With The Communit}

The Toronto Food Policy Council's Food Strategy ${ }^{\star}$ is a food systems-focused initiative that brings city, businesses and civil society organizations together around food-related issues. The Food Strategy finds and implements innovative ways to achieve multiple objectives on food, taking an "action research" approach to incubate and pilot creative projects and bring them to scale by leveraging resources from partner agencies. Initiatives have included "Healthy Corner Stores," "Mobile Good Food Markets," and a "Toronto Urban Agriculture Programme."

The Baltimore Food Policy Initiative (BFPI) is an intergovernmental collaboration between multiple government departments and agencies and the Johns Hopkins Center for a Livable Future to address food system policies, strategies and programmes. With strong stakeholder commitment and a balanced governance structure, BFPI: created extensive awareness around the inequity of food deserts and local food issues; developed 10+ city food plans; helped develop an Urban Agricultural Plan; and passed an urban farm tax credit and a land-leasing initiative for urban farmers.

Source: Hoekstra, Femke, and Lauren Baker. 2016. Integrated Food Planning across Urban and Rural Areas. In: Dubbeling, M., C. Bucatariu, G. Santini, C. Vogt and K. Eisenbeiß. 2016. City region food systems and food waste reduction - Linking rural and urban areas for sustainable and resilient development. GIZ, RUAF Foundation and UN FAO. Accessed August 1, 2017. http://www.ruaf.org/projects/city-region-food-systems-and-food-waste-management-linkingurban-and-rural-areas.

\subsubsection{Land Use and Urban Development Planning}

For urban food systems to flourish and deliver multiple benefits, most cities in the world will need to review and update the prevailing legal and institutional frameworks on land policy, land use, property rights, and planning and management and to reconcile rural and urban tenure systems in the urban periphery. Finding workable solutions in evolving and multijurisdictional peri-urban spaces will require clear legislation and strong institutions to meet the needs of urban populations.

Particular attention may need to be focused on urban zoning codes that: allow crop production or food processing by right or conditional use permits in all zoning districts; preserve agricultural land, forest land, and critical watersheds; stipulate community-based rights with protection from eviction or exclusion; and include specific standards regarding details such as signage, parking and walkways, public space, fencing, height requirements on greenhouses and hoop houses, farmstalls and composting bins. ${ }^{160}$ Box 5.2 illustrates how Beijing designated certain parts of the city for the practice of different types of UPA.

Empowering residents of informal settlements with secure tenure rights should be a part of efforts to create more sustainable, livable cities. Some settlements may be authorized but simply lack infrastructure and services, or they may find that a land transaction has not been recorded in a land registry. Land 


\section{BOX 5.2 Supporting the Diverse Types of Urban and Peri-Urban Agriculture in Beijing, China}

The Beijing Municipal Government integrated urban agriculture is in its 11th Five-Year (2006-2010) Plan to increase the city's food self-sufficiency ratio from 25 to 35 percent. This plan divides the city by agriculture zone:

1. The Intra-Urban Agriculture Zone (in red) is a moderate

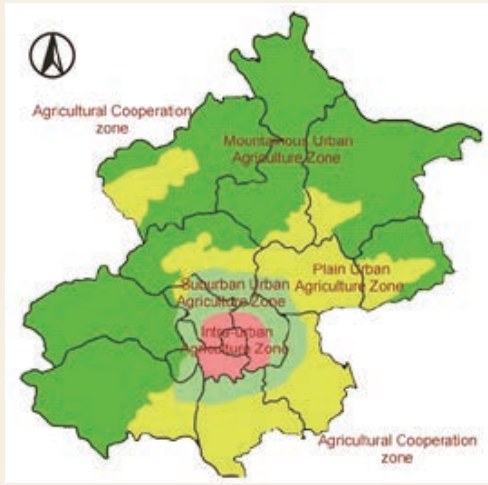
urban agriculture development zone focusing on gardening and landscaping.

2. The Suburban Urban Agriculture Zone (in light green) is a transitional area between agriculture production and urban life, specializing in recreational agriculture and precision agriculture and utilizing smart technologies such as moisture monitoring for automatic irrigation.

3. The Plain Urban Agriculture Zone (in yellow) represents the major food production zone of Beijing, with more land and better conditions for modern agricultural production and processing.

4. The Mountainous Urban Agriculture Zone (in dark green) includes environmentally friendly production such as organic and circular agriculture and is focused on special fruits and ecological protection.

5. The Agriculture Cooperation Zone, located in neighbouring provinces, emphasizes relationships with cooperatives to improve local food security and ensure quality food delivery.

Owing to the high value addition of urban agriculture, farmland is preserved and used, with short transportation distances allowing delivery of local fresh food, which integrates clean, specialized green production with natural resource management and agrotourism. And with more visitors to peri-urban areas, restaurants and other commercial outlets have emerged.

Source: Zhu, Xi. 2016. Planning for agriculture: An exploratory research on urban agriculture from the Chinese planning perspective. Wageningen University. Accessed June 1, 2017. http://edepot.wur.nl/392716.

leasing could be a potential option for cash-poor households, including internally displaced persons, to obtain land. ${ }^{161}$ Low-tech enumerations and hightech approaches (for example, crowdsourcing land information using Habitat's Social Tenure Domain Model) may help reduce land registration costs.

In light of rising urban land costs, competing land titles and unavailability of public land in urban centres, creative solutions will need to be found for 
identifying available land on which new wholesale and open markets will need to be built in cities throughout the world. ${ }^{162}$ Given the lack of a crystal ball to foresee exactly how food systems will evolve, at a minimum, urban food planning will need to embrace flexibility in terms of designating the public space that will be needed by cities ${ }^{163,164}$ in the future for markets, transportation, parks, UPA, forestry and ecosystem services, water and sanitation systems, and restaurant and vendor food courts, to name a few. Making the necessary provision of public space (i.e. land) for these critical public goods will be required for the future development of urban food systems. Bringing a spatial food system perspective into urban planning will push planners to understand where people live, where they work, and where they eat and shop, thereby helping to identify the most useful interventions to improve peoples' lives.

Innovative partnerships between public agencies, real estate developers, architects and civil society - supported by a catalysing incentive and regulatory environment-will be needed to ensure the integration of UPA and green food system architecture into future urban housing developments and planning for urban renovation and new construction. The volume of urban construction for housing, office space and transport over the next 40 years is estimated to roughly equal the entire volume of such construction to date in world history, which augurs well for planning and development of food-smart green cities. ${ }^{165}$ Transparent and enforceable land tenure legislation is equally important to the preservation of urban and peri-urban ecosystems critical to management of scarce water resources, preservation of biodiversity and flood protection.

\subsubsection{Technology and Innovation}

Technological and institutional innovation stems largely from the creation of a policy and incentive environment that is conducive to the development of new ideas and to the entrepreneurship that helps to translate them into reality. New technologies as well as institutional and policy innovations offer potential to advance quickly to accelerate productivity growth and to close socio-economic gaps and advance inclusive socio-economic development. Throughout the food system, innovation and new technology-whether ICT applications, automation and artificial intelligence, agrifood technologies, renewable energy/water resources or Big Data and analytics-will require appropriate policies, standards and institutions to incentivize the necessary investments.

Many technologies are capital-intensive and labour-saving; they contribute to efficiency gains through automation, resulting in the elimination of specific tasks or jobs. Inversely, new technologies may provide opportunities for creating new jobs (e.g. sensors). Governments must often strike a balance between the establishment of appropriate incentives for innovation and investment in these technologies and an enforceable regulatory environment to ensure compliance with municipal and larger societal goals (e.g. increase employment, improve human welfare).

Making the step from policy design to implementation will be strongly contingent on dynamic institutions that can help to steward the process. They may include scientific advisory councils, public-private technology boards to 
oversee and regulate technologies, education partnerships to contribute to skills development of food sector workers and professionals, or food innovation labs that assist small and medium-scale businesses and entrepreneurs to translate ideas into concrete initiatives. Market analysis, food product development, processing technologies and food safety are critical elements to address in this process. National agriculture research organizations and other technology-focused institutions should be involved in the urban food processes, particularly as the articulated priorities may help to orient research and development programmes (e.g. urban horticulture production).

Policy development must increasingly include opportunities for diverse stakeholders to contribute to the process, participating in the analysis, position papers/viewpoints and advocacy that underpin policy formulation. For technology and innovation to serve as a driving force for positive change in food systems, diverse stakeholders in private sector and civil society must also become more aware of and knowledgeable about the specific characteristics and available evidence regarding the positive and negative attributes of new technology and innovations.

New ICTs provide opportunities to expand citizen science, or the involvement of the public in scientific research and collaboration between civil society, practitioners and the scientific community. Along with the potential for enhancing local variability in scientific research, citizen science can help to sensitize civil society on questions affecting their lives and increase their scientific literacy. New social learning and multidisciplinary approaches focused on merging top-down with local, experiential knowledge offer promise for developing innovative, practical solutions to diverse challenges. Communicating this information to citizens and consumers is an important prerequisite to the eventual demand for and use of products that contain new technologies.

Perhaps most importantly, new ICTs, social media and crowdsourcing approaches could stimulate young or fresh minds to come up with the disruptive innovation that propels progress, changing the trajectory of innovation and moving people and cities to a higher level of achievement.

\subsubsection{Rethinking Food and Agriculture Policy Priorities and Budgets}

Addressing issues related to future urban food systems will inevitably give rise to a host of additional policy questions for many sectors, including the implications of future urban food systems for the agriculture sector and rural economy. As national and municipal food system goals become defined, discussion will inevitably turn to the prioritization and allocation of government budgets. For example, numerous countries invest a large share of national resources in food and input subsidy programmes under the auspices of improving food security. Reassessing priorities and approaches with respect to consumer-driven urban food goals could provide a space and interest for countries to more thoroughly reexamine current agricultural, food and trade programmes and policies; to reflect on the roles and mix of food sources (rural, urban, import) to achieve national food security; to assess how they 
are using budgets to contribute to their national or municipal goals; and to analyse incentives of national actors creating diverse and oft-competing policy and regulatory frameworks (e.g. agriculture and trade policies on food security). It could also help countries think about the set of measures and the instruments to use in response to short-term socio-economic and agroclimatic shocks in a way that is coherent with (and does not distort) the overall agrifood environment, sector programmes and long-term actor incentives.

The interrelationship between agriculture and larger food systems also merits greater reflection as policy effects spill over from one to the other. For example, since countries with high rates of agricultural productivity growth experience more rapid exit of labour out of farming as well as higher growth in labour productivity in the non-agriculture sector, the policies and programmes affecting agriculture productivity growth will affect expansion in job opportunities. ${ }^{166}$ In rapidly urbanizing countries with economically dynamic cities, there may be risks that rural areas are left behind as food needs are sourced from imports through temperature-controlled global supply chains, with implications for rural poverty and agriculture development, not to mention dietary patterns. ${ }^{167}$ The changing food environment presents many challenges to food and agriculture policy.

\subsection{O: Open Data, Knowledge and Evidence Base}

The development of facilitating and progressive policies, the effective functioning of multistakeholder governance, and the following discussion on designing and implementing food system interventions all depend on the availability of and access to accurate, reliable and timely data and knowledge. Although there is a current lack of rigorous, valid data and an evidence base for many of the urban food issues discussed in this report, the current data and information revolution underway will quickly change the discussion to one of prioritizing, organizing, processing, interpreting and accessing the projected large volumes of data to be available in the future. This is the essence of the third enabling condition: open data, knowledge and evidence base.

Every day, over 2.5 quintillion bytes of data are produced in the world. By 2020 , the data world will possess 44 zettabytes, ${ }^{168}$ or 44 trillion gigabytes of data, with 1.7 megabytes produced every second for every human being on the planet. ${ }^{169}$ Data come from the constantly evolving Internet of Things: climate sensors, packaged perishable food, Internet surfing, posts to social media sites, digital pictures and videos, purchase transaction records, car sensors and cell phone global positioning system (GPS) signals to name a few. The Smart Cities of tomorrow, of which there will be an estimated 88 by 2025, will be harnessing technologies such as information technology and sensors, ${ }^{170}$ to improve the quality of life of residents, manage available resources in an economically sustainable manner and reduce environmental pollution. ${ }^{171}$ In fact, Smart City technologies will grow to an industry worth US $\$ 27.5$ billion by 2023 .

The quantity of data being produced is increasing so rapidly that the Big Data of today will be the small data of tomorrow. Big Data refers to the 
unprecedented fluxes of data that stream in and out of computational systems. ${ }^{172}$ Most of these data are sent to powerful computers for analysis and use. Many firms in the modern food system invest in systems or pay for data for internal cost and control and/or diverse analyses of food demand and consumer preferences. John Deere, for example, fits all of its tractors with sensors that continuously stream and aggregate data about soil and crop conditions; farmers can subscribe for access that can help them decide when and where to plant crops. Likewise, Big Data for cities can be generated through sensor systems within urban infrastructure and moving objects such as cars. It can also be user-generated through social media, human computation tasks and citizen science projects. The possibilities are endless and evolving and offer a great opportunity for evidence-based decision-making.

Open data are accessible public data that people, companies, and organizations can use to launch new ventures, analyse patterns and trends, make datadriven decisions and solve complex problems. In contrast to a large share of Big Data owned by private companies, open data are characterized by public availability and free access, ease of use, and the fact that they can be reused. Open data are defined by their use, and are only as good as the analysis and true data transparency policies on which they rely. ${ }^{173}$ Every urban food stakeholder will depend to some extent on access to data and their analyses for use in decision-making. Policy and programme planning and design and metrics for accountable implementation and results represent two of the many priority areas for which open access data are required.

Food systems are highly complex networks that will require Big Data analytics as a backbone to operate effectively and sustainably in the future. Urban food strategies and actions should be derived from and underpinned by an evidence-based understanding of the food system at city scale and from tracking and analysing associated outcomes for different groups, all of which have the potential to bring enormous social, economic and environmental benefits. Achieving this detailed understanding, however, will depend on significant investments in urbanized agribusiness data systems; on specific socio-economic, demographic, financial, technical and institutional analyses that present policy and investment options; and on increased capacities of municipal officials and diverse stakeholders to effectively assimilate and use the information in decision-making. Carrying out this analysis and explaining the implications to stakeholders will require innovative partnerships involving local academic or research institutions, private sector and non-governmental organizations. Chapter 6 identifies priority data needs in each programmatic area-most notably, comprehensive assessments of UPA production systems and rigorous impact evaluations of the myriad urban food system actions that have been implemented. Big Data analytics offers the opportunity to contribute to these assessments to improve the food system, thereby providing a substantial return on investment.

To get a better understanding of the effectiveness of the policy and investment measures and distribution of benefits to different groups, there is also a strong need for the comparative evaluation of the impacts of city-region food policies, strategies, plans or programmes, as well as the development of strong 
metrics. Many policies and programmes do not contain measurable goals and results frameworks, making it difficult to monitor implementation for results. The use of keystone indicators or a small number of relevant metrics could strengthen the results focus. It is well known that what is measured is what gets acted on. One example is the metric related to "the strength of responsive local credit sources", which would provide an indication of whether wealth remains in a community. Likewise, quantitative benchmarks complemented with rich qualitative detail on effective political and institutional processes and governance mechanisms are useful both for internal/local stakeholders and for external actors, including other cities. ${ }^{174}$ Agreement around quantitative targets with clear baselines and time frames for each intervention goal mobilizes stakeholders around a concrete vision, focuses monitoring and is the basis for shared accountability.

The use of Big Data analytics offers the user many options: from the availability and use of diverse data sources to the provision of analytical tools for modelling complex systems to evaluating policy and programme options to direct public and private programmes, policies and investments.

\subsection{R: Resources for Public and Pivate Financing}

The decentralization process underway across countries over the past century has seen a transfer of responsibilities to local authorities, without always being accompanied by the adequate transfer of resources or efforts to build a financially sustainable base for carrying out assigned or organically evolving roles of local governments. The mobilization of public and private resources, effective fiscal decentralization, adherence to an effective, open and visible municipal budgetary process, and transparent, prudent and accountable financial management are critical for translating urban food system ambitions into policies that work and financing programmes at scale. As with other urban services, a solid, sustainable fiscal base consisting of an effective mix (and collection) of revenue sources-including diverse taxes, user fees, intergovernmental transfers and charges on developers and public-private partnerships (PPPs) - must be balanced with an appropriate incentive environment for private investment. Measures that strengthen their creditworthiness will help give cities access to capital markets. ${ }^{175}$

Public funding can help improve credit access for urban producers and entrepreneurs, particularly for women and resource-poor actors. As women comprise over 40 percent of the agricultural labor force worldwide as farmers, entrepreneurs, and labors, and are playing significant roles in agribusiness supply chains, ${ }^{176}$ investing in women along agribusiness value chains can maximize their contribution to the sector. ${ }^{177}$ A government guarantee fund can induce financial institutions to establish special credit schemes for urban producers or make them eligible for informal sector funds. City councils in many cities allocate resources to support infrastructure development, training, start-up kits and marketing for their food systems. ${ }^{178}$ Many municipal and metropolitan governments will need assistance to develop financing 


\section{BOX 5.3 Belo Horizonte: Local Political Commitment and Diverse Funding}

Since 1993, when the mayor of Belo Horizonte, Brazil, declared food to be a right for all people, the municipal government, in partnership with the private sector, civil society and provincial and national governments, established the Municipal Secretariat for Food and Nutrition Security (SMASAN) to coordinate a set of policies and interventions to support urban communities' access to healthy and nutritious food. The programme consists of six areas: subsidized food sales; food assistance; food market regulation; support to urban agriculture; education for food consumption; and jobs.

The SMASAN formed a partnership with the federal government, serving as a model for Brazil's Zero Hunger strategy and family grant, school meals and food procurement programmes. With an annual budget of US\$27 million, representing less than 2 percent of the annual municipal budget, and 180 staff members (including 30 nutritionists), Belo Horizonte has benefitted from diverse partnerships and state-funded programmes to improve access to nutritious food for over 300000 citizens.

Source: Rocha, Cecilia. 2016. Belo Horizonte: the Opportunities and Challenges of Urban Food Security Policy. Cecilia was the Director of the project Building Capacity in Food Security in Brazil (2004-2010), funded by the Canadian International Development Agency.

strategies and access finance for urban food programmes. While a variety of financing options are available, many cities and towns will probably need to take advantage of grants and subsidized lending mechanisms to improve their capacity before graduating to borrowing through special mechanisms and eventually on more market-based terms. Food-related infrastructure investment could potentially tap into other diverse financing instruments such as a municipal development fund (e.g. the Philippines), development bank (e.g. South Africa) or future flow financing secured by anticipated future revenues and pooled finance schemes (e.g. Mexico). ${ }^{179}$

A wide variety of financing options are available to assist with the capital needs of start-ups and emerging or mature food system enterprises, matching the capital source to the stage of growth and scale of business. Moreover, innovative financial services and applications are improving access to finance, but appropriate regulations, supervision and controls need to be put in place to allow financial institutions, mobile operators and retailers to effectively offer new services and explore new partnership models. ${ }^{180}$ Private foundations, federal or local funding sources, and food system investors can leverage additional resources, including programme-related investments in charitable activities that offer the potential return of capital within an established time frame. Impact investment or crowdfunding investors, who bridge philanthropy and venture capital, select companies in which to invest based on the social or environmental impact of a business. For example, Slow Money 


\section{BOX 5.4 Innovative Urban Food Financing}

- Participatory budgeting in Rosario, Argentina.

- Certificates of donation in Medellin, Colombia, which allow producers, agroprocessors, and retailers to receive tax exemptions.

- Financial incentives for waste recycling by exchanging waste for safe and nutritious food in Curitiba, Brazil.

- Quito, Ecuador's water protection fund (FONAG) pools contributions from water utility (1.5\% of total water sales) and a percentage of consumer and private business water bills to improve management and protection of Quito's watersheds.

- The Toronto Food Strategy (Canada) could attract funding from charitable foundations and the provincial government for multiple initiatives.

- The City of Vancouver's Food Policy Council (Canada) partners with the Vancouver Foundation to share the cost of green initiatives and food projects. Public links and funding contribute to positive project impact.

Source: Dubbeling et al., City-region food systems.

catalyses investments in local, sustainable and organic food and farming enterprises by providing a forum for food and farming communities. ${ }^{181}$ Governments can stimulate the multiplier effect of core financing of food initiatives.

Collateral-based lending may limit access for many small-scale or start-up/ early stage enterprises that have little collateral or whose cash flow is constrained. Start-ups may gain access to seed capital only to be subsequently blocked by access to capital needed to grow. In addition, lack of understanding of more complex financing instruments and the use of financial intermediaries to assist firms add both expense and time to the financing process. Equity capital is not readily accessible to many food-related enterprises (except for agriculture technology enterprises and value-added food manufacturers) and may not be advisable, given the firm-investor mismatch regarding the expected rate of return, growth rates and investor margins. Often a food enterprise may need risk capital to grow, but in smaller amounts and at lower returns than are usually available. Centralizing information on financing options along with mentorship programmes and a favorable tax policy may help SMEs and entrepreneurs and may mobilize capital to the food system.

SMEs are less likely to secure bank loans than large firms, relying instead on personal savings to launch and initially run their enterprises. Fifty percent of formal SMEs do not have access to formal credit in low-income countries, while 70 percent of micro, small and medium-scale enterprises (MSMEs) in emerging markets lack access to credit, a situation most pronounced in Africa and Asia. The current credit gap for formal SMEs is estimated at US\$1.2 trillion, rising to US\$2.6 trillion for both formal and informal SMEs. Bringing informal SMEs into the formal sector can have 
considerable advantages for both the enterprise-through improved access to credit and government services-and the overall economy-through higher tax revenues and improved regulation. There is, however, a general lack of proven methods within financing for SMEs to graduate to the next level. There is a potential role for mobilization of diaspora investments and other innovative forms of financing, including impact investment financing, franchising models, digital solutions, and crowdfunding. ${ }^{182}$

Remittances from migrant workers constitute a key source of finance for low-income countries; in 2013, they stood at more than US $\$ 410$ billion, more than three times the size of official development assistance. ${ }^{183}$ For many economies, remittance inflows exceed 10 percent of gross domestic product (GDP). During the recent global financial crisis, remittances also proved much less volatile than other sources of finance, such as bank loans or portfolio investment. Remittances can therefore play an important role in pulling and keeping millions out of poverty. Given the difficulty of borrowing in developing countries, remittances can substitute for a lack of financial development and hence promote growth. ${ }^{184}$ Reducing barriers to migration and ensuring better access to financial services for migrants should therefore represent a key element of any policy to encourage remittances. These results are in line with the explicit commitment of international institutions and G-20 governments "to reduce the average cost of transferring remittances from 10 percent to 5 percent by 2014."

Experiences with PPP agriculture investment funds (AIFs) indicate that agribusinesses with proven track records and risk-return patterns are attractive to investors who seek development impact and financial return. ${ }^{185}$ SMEs and producer organizations usually require extensive capacity development support from AIFs via grants for technical assistance. Careful analysis is also needed to prioritize how and where to invest in value chains. The enabling environment is an important prerequisite to attract AIF financing and to generate returns. Public agencies can also help to strengthen SME capacity, reduce reliance on fixed collateral by introducing a secured transaction register that includes movable assets, mitigate financial institutions' risk perception for financing SMEs and provide public support for investments that spur innovations and new technology. ${ }^{186}$

Credit bureaus offer another option for improving access to finance for entrepreneurs, but they only exist in 50 percent of countries, generally those with high entrance barriers to the banking sector. ${ }^{187}$ Improving access to financing helped small businesses in Mexico to stay in operation and increased employment and income. ${ }^{188}$ In Afghanistan, the recent establishment of the Public Credit Registry to determine the creditworthiness of borrowers significantly improved access to financing for SMEs, while in Liberia the creation of a collateral registry in 2014 enabled farmers and entrepreneurs to securitize and use movable assets to borrow money; US\$227 million in loans were registered in less than one year. ${ }^{189}$

Several UPA-related financing pilots have proved successful and are ready to be scaled up: municipal guarantee schemes; public and household procurement of local food; crop insurance schemes; and securing tenure through temporary occupancy licenses to access microcredits. Financing institutions 
may also consider a UPA financing window or its inclusion in other funding streams. ${ }^{190}$ Traditional rural agricultural grant schemes could be amended to include urban producers, as has been done in Brazil and India. Other policy measures include: improved information on producers' repayment capacity; producer training in business skills, preparation of business plans and recordkeeping; assistance to producer groups in preparing loan applications; municipal guarantee schemes to financial institutions willing to provide loans to small-scale urban producers; insurance to protect against agroclimatic shocks; and quantification of credit demand among small urban producers.

Finally, access to diverse sources of climate financing may provide opportunities for municipal governments to catalyse action in urban food systems, particularly with respect to their environmental sustainability and reduced climate footprint. They may be particularly relevant for transport, energy and closed-loop resource processes (Section 6.4) in the food system, helping in the formulation of projects and leveraging the contributions of other actors.

\subsection{M: Multistakeholder Governance Mechanisms and Capacity}

\subsubsection{Food System Stakeholders and Multistakeholder Governance Mechanisms}

Most municipalities and metropolitan districts have also found it useful to establish some type of multistakeholder coordination mechanism to assist in the planning, implementation and governance of food system programmes. ${ }^{191}$ They may take a variety of forms and be called a variety of names, such as a food council, stakeholder coordination platform or food actor network. While mandates may vary, multistakeholder mechanisms have generally been used to ensure stakeholder participation and programme buy-in, which is necessary for ensuring demand- and evidence-driven design of policies and programmes, mobilization of requisite financing envelopes and accountable and impactful delivery.

A stakeholder network or council may consist of producers, supply chain actors, non-governmental organizations, citizen groups, advocacy groups, local leaders, town planners, economic development organizations and others. Figure 5.1 depicts the large number of issues and actors comprising Canada's fairly mature urban food environment. As urban food issues embrace a wide variety of issues, different programme components will naturally attract different actors grouped around common goals that reflect their interests, values, positions, perspectives, knowledge base, goals and levels of power. Understanding the myriad of potential stakeholders involved or interested in a particular food issue is an important first step for determining potential alliances, advocacy, lobbying strategies or partnerships.

Better governance and need-focused policies and programmes require the systematic and regular engagement of a range of pertinent rural and urban actors, including the poor and vulnerable populations. Although information-sharing represents an important function of these units, more successful 
platforms and councils engage stakeholders in joint planning and implementation or as a body advocating for food policy on behalf of communities, proposing policies and devising programmes that are mission-aligned, community-oriented and politically viable. A robust performance management framework in combination with a democratically anchored implementation process could set the stage for a prosperous city-region food system economy.

Belo Horizonte in Brazil, Baltimore in the United States of America, Singapore and Toronto and Vancouver in Canada, are but a few of the forward-looking cities that have introduced a participatory political process and developed strong, innovative municipal institutions and mechanisms to

\section{FIGURE 5.1 Urban Food System Actors and Issues}

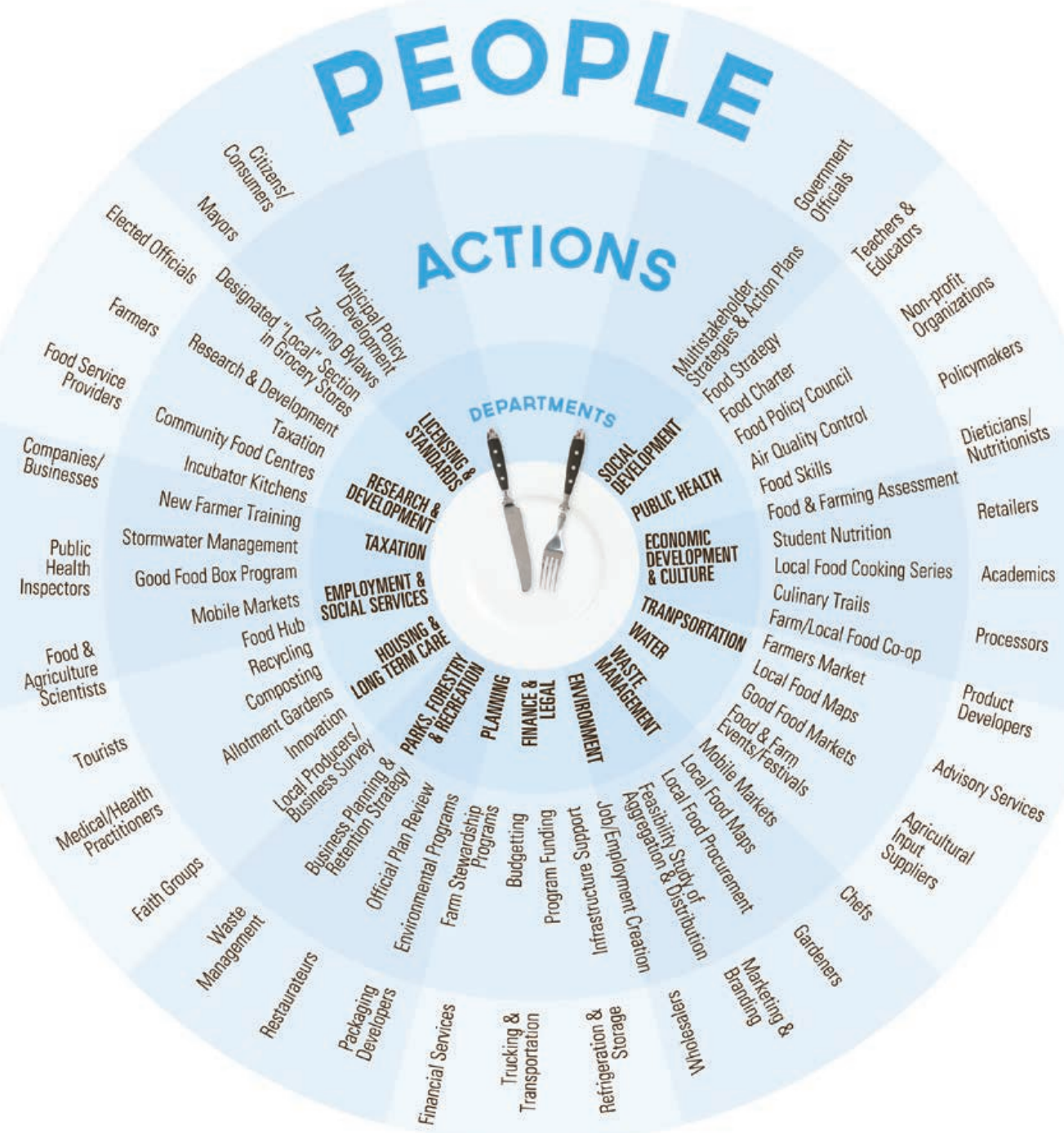

Source: MacRae, Rod, and Kendal Donahue. 2013. Municipal food policy entrepreneurs: A preliminary analysis of how Canadian cities and regional districts are involved in food system change. Toronto Food Policy Council. 
initiate, shepherd and effectively govern urban food programmes. In Amman, Jordan, urban agriculture and food strategies are mainstreamed through municipal structures, programmes, plans and budgets, and are also built around engagement with multistakeholder partnerships. ${ }^{192}$

\subsubsection{Political Economy}

Achieving strong results in the interlinked food system outcome areas will require all interested public, private and civil society actors to harness a certain amount of political savvy and institutional agility for effectively navigating and succeeding in this new urban food space. These skills will be particularly important for the food units mandated to lead municipal or metropolitan district food initiatives, starting with the integration of a food perspective in urban development plans. They will also need to be conscious of the importance and value of developing relationships with federal and provincial level authorities and sector experts, recognizing that they are relatively new actors treading into policy and programme waters that have well-established actors and "turf."

Establishment of multi-actor coalitions is often critical for advancing programme priorities, securing buy-in, accessing budgets and achieving goals. The relationships and political clout of each stakeholder group provide different opportunities for leveraging the political space. Larger numbers of stakeholders, consumers and citizens, united behind a common position and narrative, also have power to advance their interests onto the agendas of policy-makers and influence their course of action, particularly at local levels (e.g. joint public/private/civil society management structures for urban wholesale markets). Alliances of diverse actors may also open channels to alternative programmatic or policy entry points, as each stakeholder has different interests, relationships and ideas for accessing decision-makers and those who may wield power. These coalitions are particularly important in influencing the prioritization and administration of public resources. For example, those who work to improve access to healthy food for the urban poor may find opportunities to achieve goals in alliances with public and private actors working to build urban housing, transportation or commercial retail developments.

Incisive political economy analysis and a certain amount of creativity are critical for all actors as they seek to develop strategies for advancing their interests. Understanding who benefits and who may suffer from policy or programmatic options is often important for political strategizing. A mayor of one political persuasion may not receive the necessary financial or policy support for a municipal initiative from an opposing political figure at the national level. Open data platforms and the instantaneous availability of information through social media increase transparency and level the playing field for many stakeholders and thus their ability to hold others accountable. Finding effective approaches for aligning consumer and business interests with longer-term citizen goals (e.g. addressing climate change) or joining forces between different thematic groups (e.g. nutrition/health and climate change) may help to advance specific causes and achieve their different goals. 


\section{BOX 5.5 Peru's Informal Sector Political Activism}

More than 140 informal worker leaders from Lima and other cities in Peru convened the first meeting of informal workers in November 2016 to create a common platform of demands and proposals to put forward to the 2016 presidential candidates. They invited chief advisors of two political parties to hear their views on employment, the right to work and the necessary instruments to improve the situation of informal workers. They also presented their demands for legal recognition, street vending permits, application of occupational health and safety regulations and access to social protection and capacity building. They also requested more regular formal dialogue, underscoring the political power of the informal sector in which 70 percent of Peruvian workers are employed.

Source: Abizaid, Olga. 2017. Informal workers in Peru present their demands and proposals to political parties. World UrbanCampaign.AccessedJune1,2017.http://www.worldurbancampaign.org/wiego-informal-workers-peru-present-theirdemands-and-proposals-political-parties.

Many stakeholders, such as associations of informal food sector actors or advocates for those living in informal settlements, may require support to improve their capacities.

\subsubsection{Capacity Development}

Strengthening human and institutional capacity is arguably the most critical of the enabling conditions for the advancement of urban food initiatives and specific interventions, particularly among the diverse stakeholders and new government actors that will start to engage in this area. Capacity building will need to focus on the effective functioning of municipal and district food units and multistakeholder platforms to advance the skills and capabilities of the actors engaged in technical programmes. Investment in social capital is a critical complement to hard infrastructure, as it is often the soft infrastructure that carries out the difficult tasks, catalysing their success.

A capacity development plan and programmes will stem from the institutional mandate, roles and responsibilities and activities to implement to achieve the identified outcomes in the agreed results frameworks. As the capacity needs and knowledge gaps for working on urban food issues are daunting, it is critical to prioritize and sequence a plan and programmes so that both male and female actors have the requisite skills to move the agenda forward and the agility to change direction as needed.

Beyond formal training, capacities will ostensibly be developed by learning on the job and from trial and error. Capacity development that is associated with peer learning and identification of good practices will allow various stakeholders to enhance their capabilities to design and execute actions that have been effectively implemented in other cities.

Considering the World Bank's twin goals of poverty reduction and shared prosperity, and the primacy of the inclusiveness dimension in the food 
system framework, the majority of programmes will need to be carried out in concert with key stakeholders and ultimate beneficiaries. Many capacity development programmes will need to be preceded by awareness-raising activities that impart the knowledge needed to understand the context and subsequently develop a shared understanding of aspects of urban food problems and potential solutions. This task is arguably one of the most important because informed leadership represents the first step for moving ahead.

Capacity development can play an important role in several areas. It can help stakeholders to develop a common language for programme prioritization and goals, design and implementation. Given the importance but also the dearth of data and analysis for empirically guided, project-cycle decision-making and accountability processes, stakeholders will need a diagnostic capacity to analyse and understand issues. It will also be increasingly important to develop capabilities to use digital data and to understand information and knowledge products that will be created with the enormous amount of data generated by ICT and the Internet of Things in the future. These skills may be helpful in determining potential programme entry points and potential pathways for achieving outcomes. Stakeholder skills will also need to be strengthened in issues related to budget, planning, monitoring and accountability. Stakeholder training in political economy issues is equally important for stakeholders to become effective in the political arena. For example, strengthening capabilities to identify and form operational coalitions, to determine potential conflicts of interest and solutions for their resolution, to use data and analysis to develop policy positions, and to effectively negotiate in the political space and leverage power are particularly useful skills to develop.

Finally, and naturally within each intervention area, capacity development will be a central focus of all programmes for all stakeholders and stakeholder organizations, with respect to technical, financial and organizational capacities as well as political engagement, often in gender-specific ways.

Innovative ICTs offer new ways to communicate and share information and knowledge and strengthen capacities of many people in diverse locations, effectively marrying the global with the local. The city-city networks and South-South/East-West/South-North cooperation frameworks should be mobilized to contribute to this process, linking capacity development to knowledge exchange so that stakeholders can act on what they learn.

\subsubsection{Emerging Aspects of Successful Food System Governance}

Successful programmes underscore the importance of several critical governance factors:

- Adequate high-level political commitment alongside the political engagement of mayors and municipal councils in urban food issues;

- Strong engagement by civil society and private sector actors and an effective mechanism for participation in decision-making processes; 
- Participatory processes that give voice to the urban poor for addressing the food challenges of poor and marginalized residents, notably in informal settlements, slums or refugee camps;

- Pragmatic approaches for devolving responsibilities to communities, neighbourhoods or submunicipal jurisdictions, and for collaborating with national authorities, policies and programmes;

- Joint food system assessment, an analysis of a city's food strengths, weaknesses, opportunities, and threats (SWOT), and design of a holistic food strategy with actionable components;

- Recognition that local governments, which may be more responsive and multisectoral, still require inputs from national sectoral ministries. Health, education, water, transport, energy or social affairs sectors may provide some effective entry points;

- A municipal implementation unit to coordinate and oversee programme design and delivery, ensuring that the means exist for technical inputs to be delivered from relevant technical and sectoral specialists;

- A coherent, transparent results framework supported by monitoring procedures to track programme implementation;

- Frequent communications with stakeholders and citizens via multiple channels regarding plans, challenges and results;

- An enabling fiscal and regulatory environment to mobilize the requisite public and private resources for programme implementation;

- Substantial investment in improving the capacities, skills and knowledge of municipal officials as well as civil society and private sector stakeholders who will be expected to contribute to the design, management, delivery and oversight of interventions. 
TABLE 5.1 Indicative Actions for Establishing "Enabling Conditions"

\begin{tabular}{|c|c|c|c|}
\hline Enablers & Start with & Mature stage & $\begin{array}{l}\text { Considerations for the } \\
\text { future }\end{array}$ \\
\hline $\begin{array}{l}\text { Transformative } \\
\text { institutions }\end{array}$ & $\begin{array}{l}\text { - Food systems assessments } \\
\text { and plans/conditions for } \\
\text { food systems governance } \\
\text { - Clarification of jurisdictional } \\
\text { mandates related to food } \\
\text { systems } \\
\text { - Stakeholder analysis of } \\
\text { - } \text { ongoing projects } \\
\text { - } \text { food security interventions } \\
\text { - } \text { Policies for informal sector } \\
\text { Governance devolution }\end{array}$ & $\begin{array}{l}\text { - } \quad \text { Elimination of regulatory barriers } \\
\text { to local food entry and expansion } \\
\text { - } \text { sours on local manufacturing or } \\
\text { - Cross-jurisdictional food systems } \\
\text { policy, linkages to provincial and } \\
\text { national food and other policy } \\
\text { domains } \\
\text { - Food systems instruments-a } \\
\text { food strategy or plan, with small } \\
\text { doable initiatives and projects } \\
\text { that connect several public sector } \\
\text { institution departments }\end{array}$ & $\begin{array}{l}\text { - Institutionalizing food } \\
\text { systems in government } \\
\text { structures } \\
\text { - Support to other cities }\end{array}$ \\
\hline $\begin{array}{l}\text { Facilitating and } \\
\text { progressive } \\
\text { policies }\end{array}$ & $\begin{array}{l}\text { Food systems urban } \\
\text { planning and capacity } \\
\text { building } \\
\text { - } \text { (In)formal food retailing } \\
\text { options for low-income } \\
\text { access to affordable, } \\
\text { nutritious and safe food } \\
\text { - Examining approaches to } \\
\text { improve tenure security: } \\
\text { protection from eviction or } \\
\text { exclusion and community- } \\
\text { based rights } \\
\text { - Agricultural land review, } \\
\text { including use of open } \\
\text { spaces, competition over } \\
\text { land resources and potential } \\
\text { for diverse land use. } \\
\text { - Providing support to UPA } \\
\text { Incentives and regulations } \\
\text { for innovation }\end{array}$ & $\begin{array}{l}\text { - Addressing different tenure } \\
\text { systems with incentives for } \\
\text { peri-urban areas as urban areas } \\
\text { expand (e.g. temporal user-right } \\
\text { agreements) } \\
\text { - } \text { Local government capacity } \\
\text { building to improve the design } \\
\text { and implementation of zoning } \\
\text { plans to bridge and facilitate } \\
\text { urban and peri-urban linkages } \\
\text { - Securing tenure rights for } \\
\text { informal settlements } \\
\text { - Institutions for fostering } \\
\text { technology and innovation } \\
\text { - Regulations governing local food } \\
\text { production and sale } \\
\text { Advocacy/awareness raising }\end{array}$ & $\begin{array}{l}\text { - Legislation for urban } \\
\text { agriculture } \\
\text { - Food systems elements } \\
\text { integration into land } \\
\text { use plans and zoning } \\
\text { codes and housing } \\
\text { programmes } \\
\text { - Innovative models of } \\
\text { alternative food systems } \\
\text { New distribution models } \\
\text { and food hubs for } \\
\text { smallholders and SMEs }\end{array}$ \\
\hline $\begin{array}{l}\text { Open data, } \\
\text { knowledge and } \\
\text { evidence base }\end{array}$ & $\begin{array}{l}\text { - Food system data } \\
\text { - } \text { Metrics } \\
\text { - } \text { Marketing Information } \\
\text { - Kystem/market intelligence } \\
\text { - Knowledge for governance }\end{array}$ & $\begin{array}{l}\text { - } \text { Aggregation infrastructure } \\
\text { platforms } \\
\text { - } \text { Logistics platforms } \\
\text { - } \text { Monitoring of spatial distribution } \\
\text { of food system subsectors }\end{array}$ & $\begin{array}{l}\text { - } \text { Big Data } \\
\text { - } \text { Agricultural census } \\
\text { linked to real-time } \\
\text { monitoring platform } \\
\text { - Benchmarking analysis } \\
\text { - Facilitation platforms }\end{array}$ \\
\hline $\begin{array}{l}\text { Resources for } \\
\text { effective public } \\
\text { and private } \\
\text { financing }\end{array}$ & $\begin{array}{l}\text { - } \text { - } \text { Food SMEcipal financing support } \\
\text { partners } \\
\text { - Fiscal policy } \\
\text { - Public seed funding }\end{array}$ & $\begin{array}{l}\text { - UPA financing } \\
\text { - } \text { Public-private partnerships (PPP) } \\
\text { - } \text { Incen urban food infrastructure } \\
\text { enterprises } \\
\text { - } \text { Multicity joint financing } \\
\text { - Incentives for start-up } \\
\text { enterprises }\end{array}$ & $\begin{array}{l}\text { - Innovative financing } \\
\text { (e.g. social investment } \\
\text { vehicles, municipal } \\
\text { guarantee schemes) } \\
\text { - PPP for urban food } \\
\text { infrastructure }\end{array}$ \\
\hline
\end{tabular}


TABLE 5.1 Indicative Actions for Establishing "Enabling Conditions" (continued)

\section{Enablers}

Multistakeholder

governance

mechanisms and

capacity

\section{Start with}

- Government awareness and - Alignment with national policy staff training on urban food systems

- Stakeholder mechanisms (e.g. informal food policy councils)

- Food system stakeholders capacity building (e.g. street traders and food processors in food safety)

- Political economy assessment by jurisdiction and stakeholder

- Regulatory gap assessment /policy review

- Supportive policy instruments

- Pre-competitive collaboration

\section{Mature stage} system governance through local authority policies and stakeholders for coordination satisfy city region markets

- Changes to cropping and agricultural techniques

- Addressing risks of ceding

- Encouraging investment in infrastructure or abuse by powerful buyers
Considerations for the future and international agreements or adjustment of these agreements

- Operationalizing city-region food programmes with defined lead

- Restructuring farm systems to power to city-region institutions

- Cooperation with rural authorities

- Addressing risk of elite capture
- Local food system policies and

programmes embedded in larger city-region development objectives (e.g. climate change)

- Inclusive and multistakeholder governance arrangements and a government authority with the responsibility, capacity and power to bring multisectoral solutions

- Institutional home for food mandate

- Coordination agreements between various levels of government (larger city and surrounding municipalities; cities and higher-level governments)

- Well-structured and transparent trading forum/brokering services to match production to demand 


\section{6}

\section{Intervention Areas and Key Entry Points}

\section{Key Messages}

- The first outcome area relates to the creation of more and better jobs and the development of agrifood businesses, through: support of the informal food sector; youth and women's employment; workforce development; and MSMEs and entrepreneurship.

- Improving food security via better affordability and accessibility of food will require policy, investments, innovations and capacity building for: constructing efficient, modernized food supply chains; reducing FLW; and establishing targeted, food-friendly social protection programmes for vulnerable urban populations.

- Improving the availability of and access to nutritious, diverse, quality and safe food can be addressed by: policies to promote the consumption of healthy foods; facilitating innovative partnerships (e.g. with restaurants) and institutional procurement of nutritious food; strengthening food safety systems to prevent food-borne diseases; and increasing the availability and accessibility of fruits and vegetables through innovative supply sources.

- A sustainable, resilient agriculture and food system will need every function to significantly reduce its carbon footprint through: adoption of new and improved methods, innovations and technologies; and innovations such as closed-loop urban food systems or urban forestry that help to reduce emissions and protect the land and water supply.

Four broad intervention areas can be considered by cities, towns, metropolitan areas and countries as part of a strategy to position future food systems. These interventions are intended to achieve progress and deliver results in the interlinked set of TRANSFORM outcome areas: 
- Remunerative jobs and better agribusinesses

- Affordability and accessibility for food security

- Nutritious, diverse, quality and safe food

- Sustainable, resilient agriculture and food systems

The following sections propose a select number of indicative policy, institutional, technological, investment and capacity building measures and actions to be considered in programmes that contribute to the achievement of these food system outcomes. The following discussion of the interventions in each outcome area is meant to provide an initial structure for thinking about potential interventions, supported by empirical examples and available evidence. Subsequent phases will naturally need to carry out in-depth economic and financial analyses as the basis for formulating specific projects in these diverse areas.

Emerging experience shows that these actions can contribute to the interlinked food system outcome areas as well as to poverty reduction and shared economic prosperity. The suggested interventions may contribute to multiple outcomes. For example, interventions related to urban and peri-urban production of fruits and vegetables (presented in the section on "Nutritious, diverse, quality and safe food") will contribute to jobs, improved affordability and sustainable agriculture, in addition to boosting the supply of diverse, nutritious food.

The interventions are premised on strong collaboration and complementarity among public, private, and civil society actors and recognize the interconnectedness and interdependence of urban and rural areas as part of the same evolving social and economic processes. Opportunities for both men and women, young and old, are critical to their success. Although the discussion is oriented towards municipal and metropolitan district actions, certain interventions may be more appropriate at community, national, subregional or global levels. The success of the suggested food interventions will often depend on their systematic integration into comprehensive urban planning and budgeting processes (as part of the enabling conditions) accompanied by relevant policy and investment actions in other sectors, particularly with respect to physical and financial infrastructure and an enabling macroeconomic and business environment. Attention to areas like labour, housing, health, education and social protection are also of paramount importance.

\subsection{R: Remunerative Jobs and Better Agribusinesses}

Globally, more than 2 billion people depend on the 500 million smallholder farms worldwide for their livelihoods. ${ }^{193}$ Beyond the farm, agrifood systems are often the largest employer in many countries and cities, employing men and women as producers and processors, manufacturers, storage handlers, transporters and retailers, as food service and restaurant workers, as well as in food recovery and waste management (Figure 6.1). As per capita incomes increase and dietary patterns shift, the demand for jobs in these off-farm segments will grow. ${ }^{194}$ The World Bank's Future of Food: Shaping the Food System 
to Deliver Jobs (2017) shows that as per capita incomes rise, the share of food manufacturing and services jobs tends to increase relative to farming, often accounting for a large share of the initial growth in the manufacturing and services sectors, and thereby in overall structural transformation (Figure 6.1); this analysis is consistent with analysis presented in section 2.2. ${ }^{195}$

FIGURE 6.1 Composition of Jobs in the Food System In Low-, Middle-, and High-Income Countries

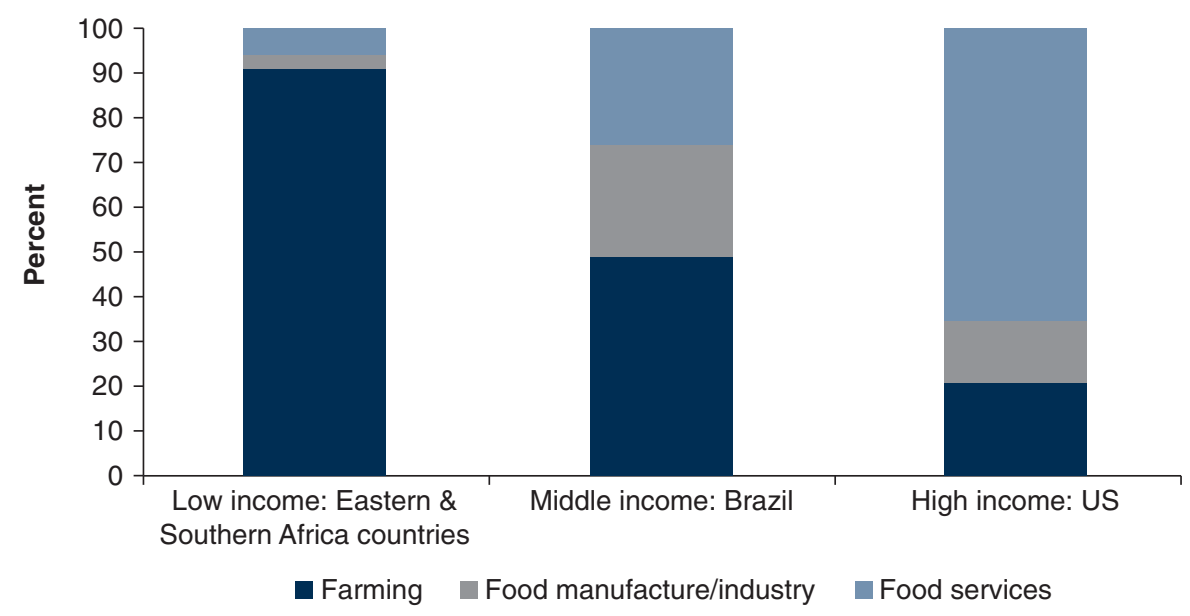

Source: Tschirley, David L., Jason Snyder, Michael Dolislager, Thomas Reardon, Steven Haggblade, Joseph Goeb, Lulama Traub, Francis Ejobi, and Ferdi Meyer. 2015. Africa's unfolding diet transformation: Implications for agri-food system employment. Journal of Agribusiness in Developing and Emerging Economies 5(2): 102-36; Rodrigues Moreira, Vilmar, Ricardo Kureski, and Claudimar Pereira da Veiga. 2016. Assessment of the economic structure of Brazilian agribusiness. The Scientific World Journal.

Note: Farming includes farms [16\%], and forestry, fishing and related activities [5\%].

Facilitating the development of future agribusinesses and sustained job creation for youth, women and men will require support and action in four specific areas: the informal sector; youth employment; workforce development; and MSMEs and entrepreneurship. Supporting these measures will especially require engagement with the private sector.

\subsubsection{Supporting the Informal Food Sector Environment}

The informal food sector plays important food provisioning and livelihood roles in informal settlements, as noted in Chapter 3. Street food-one of the most prevalent and visible examples of the informal food sector-can also enhance the quality of urban public space when it is properly managed. In this diverse sector, selling both raw and prepared foodstuffs in public spaces and in home-based retailing environments is an important livelihood, often benefitting women. ${ }^{196}$ From a consumer standpoint, informal food markets can provide nutritious, low-cost food. ${ }^{197}$ But they are often not recognized, are the object of harassment and have not been well-supported, and most lack the infrastructure (proper food storage facilities, adequate water and sanitation, and trash collection) to provide a safe and clean environment and hygienic services. ${ }^{198}$ The informal food economy will remain critical in cities well into the future, as the urban poor often do not have other options for procuring food. They may also not be aware of their 


\section{BOX 6.1 Formalizing the Informal: Singapore's Hawker Centres}

- In the 1960s some 40000 hawkers were active in the streets and along the Singapore River, selling food and other low-cost goods and services. There were serious food safety and environmental concerns.

- A licensing and inspection scheme was introduced, but the core strategy aimed to relocate vendors to hawker centres, 54 of which were built in the late 1970s and an additional 59 in the early 1980s.

- During the 1980s and 1990s a policy of "regulate and educate" was phased in to improve hygiene practices. Some centres were phased out as land was developed for other purposes, yet there was growing recognition that hawker centres were also playing an important community function of social interaction.

- In 2001, US\$420 million was allocated to a Hawker Centre Upgrading Programme involving many improvements in infrastructure. Some centres were completely rebuilt and most incorporated central freezers and cleaning areas. By 2014, 109 centres had been upgraded, accommodating some 6000 vendors.

- In 2016, two hawker stalls were awarded a Michelin Star for excellence. Hawker centres continue to have loyal local customers and they have also been an attraction for tourists.

Source: Ghani, Azhar. 2011. A recipe for success: How Singapore hawker centres came to be. Institute of Policy Studies 3, 1-15.

rights to certain legal and social protections and worker benefits or how to get them. ${ }^{199}$ There are equally important agendas related to decent wages and safe labour conditions and standards, including for migrant labour.

As a large-scale informal sector contributes to tax loss, low wages, lower productivity of companies and a lack of credit and pensions, governments need to address informality, including measures to reduce the burden of registration, taxation and regulation on new businesses. Technology can also make the formal sector attractive by giving registered firms access to credit through digital records. ${ }^{200}$ Six policy considerations for the informal sector stand out:

- Official government recognition and inclusion of the informal sector in policy documents, supported by institutions with clear lines of authority and oversight;

- Support for targeted social protection programmes that enhance livelihoods in the sector, ${ }^{201}$ focused on gender-specific support;

- Attention to the needs of informal sector actors in market modernization programmes so as not to exclude them or price them out of market stalls;

- Strengthened municipal-level capacity and a public budget for targeted programmes;

- Municipal policies that create an enabling environment for more-established informal enterprises; ${ }^{202}$ 
- Application of the International Labour Organization's Recommendation 204 concerning the transition from the informal to the formal economy. ${ }^{203}$

\subsubsection{Youth Employment}

Jobs for young people remain a top policy concern as many countries look to cash in their demographic dividend by developing the diversely skilled workforce needed to increase labour productivity and drive inclusive growth. The growing domestic consumer food market offers tremendous opportunity for local (and private) investment in the agrifood system and has the proven potential to drive broad-based growth and job creation in all supply chain segments-agriculture, manufacturing and services. ${ }^{204}$

Translating potential into reality, however, will require substantial investment in educational and skills development capacity to train millions of new job market entrants, estimated at 700 million young people in Africa over the next 30 years. ${ }^{205}$ Rapid scaling-up of effective skills development and training programmes is needed for the 500 million unemployed young people worldwide, potentially through innovative social protection. ${ }^{206}$

Colleges, universities, vocational and technical training institutes, and secondary schools will all need to strengthen their curricula and programmes to equip young men and women to work as the next generation of food scientists, managers, technicians, analysts and food service workers. Collaboration with agrifood companies assures that graduates will complete programmes with the requisite skills to work in the sector.

Promoting self-employment and entrepreneurship can help some young people in both formal and informal sectors. This can be facilitated through training, mentoring, start-up grants and help with business registration, and can be introduced in secondary school curricula related to business, finance and economics. Access to land and capital are major constraints for young people in many countries. The following are key recommendations for youth-related job development programmes: ${ }^{207}$

- Focus on areas expected to generate more, better and inclusive jobs, such as value chains that service the expanding FAFH, food manufacturing and horticulture sectors.

- Develop and implement comprehensive youth employment strategies and implementation plans, with funding allocated to programmes to be coordinated across ministries and levels of government. These programmes should include appropriate metrics and monitoring systems. The YouthPOL database provides information on youth employment policies and legislation.

- Support targeted social protection programmes that enhance youth skills and livelihoods in the sector.

- Accelerate the application of ICTs and other advanced technologies to agrifood system problems, training programmes, and innovation centres (e.g. KLab ${ }^{208}$ in Kigali, Rwanda).

- Expand cost-effective agrifood system training programmes, improve curricula and increase private sector engagement in training programmes 
(internship, apprentice and incubator programmes). Set training standards and strengthen municipal capacities and accountability measures to ensure programme quality control.

- Take advantage of global partnerships between academic institutions for collaborative curriculum development and training as well as rapidly developing, free, Internet-based training options. An existing free online course on urban enterprise development was developed last year by several higher education institutes in Europe and the RUAF Foundation.

- Ensure that SME clusters can get up-to-date training, technologies, and market information, and identify and implement options for addressing policy and regulatory barriers. Young people should have access to such specialized training.

\subsubsection{Workforce Dvelopment}

New technology and innovations are creating opportunities for income gains and higher skilled jobs in the agrifood system. ${ }^{209}$ Competitive and operationally viable food industries that employ these innovations cannot develop further without a critical mass of managers, technical experts, entrepreneurs, and well-trained, technically skilled employees to work in a diversity of professions and jobs in agriculture, manufacturing and service sectors of the agrifood system. In addition, well-educated youth and women trained in business development and vocational skills are likely to benefit from the increasing knowledge intensity of the agrifood system, with significant opportunities in high-value agriculture and associated agroprocessing and value addition. ${ }^{210}$

A vibrant, sustainable food system needs both a dynamic education system and workforce development to ensure that there are properly trained and educated male and female workers whose skills are regularly updated. Stronger partnerships with private sector firms are crucial for developing

\section{BOX 6.2 Universities in the Lead on Urban Food}

The College of Agriculture, Urban Sustainability, and Environmental Sciences at the University of the District of Columbia has developed Urban Food Hubs in Washington, DC to test ways to strengthen small-scale urban food systems. The hubs include: high-efficiency food production sites using bio-intensive aquaponics and hydroponic production techniques; commercial kitchens that serve as business incubators and training facilities for food processing and local food value addition; waste reduction and water reuse approaches; innovative fresh food distribution systems that include farmers' markets, food trucks and partnerships with restaurants and food retail. This innovative model is extremely relevant in a city riddled with food deserts and where 88 percent of the 520 food retailers do not offer fresh produce.

Source: University of the District of Columbia. Vision, mission, goals, Accessed June 1, 2017. https://www.udc.edu/ causes/causes/about-causes/. 


\section{BOX 6.3 Retraining Workers in Singapore}

Singapore's government is pushing for a culture of lifelong learning to build a newly trained class of workers. The SkillsFuture initiative subsidizes and pays for a full range of courses to create "industry transformation maps." Some programmes cater to the needs of those who lack basic skills while professional conversion programmes offer subsidized training to people switching to new specialized careers. Programmes bring together individuals, employers and providers of education; many employers, especially smaller ones, can benefit, as these programmes signal their skills needs to the workforce at large.

Source: SkillsFuture. Accessed June 1, 2017. http://www.skillsfuture.sg/.

the requisite skills for the variety of occupations in the sector. Conducting a food systems strategic plan and an industry analysis is a prerequisite for informing food systems workforce development needs. Linking the educational and training solution to the business or market solution helps to prioritize critical skill and job needs required to drive business performance. ${ }^{211}$ Upgrading workers' skills will ultimately facilitate food system transformation and promote growth in food value chains in response to consumer demand. ${ }^{212}$

Coordination of internships and apprenticeships is also important to adequately train and educate as well as to meet the needs of food producers and agrifood system workers. Municipal agencies may facilitate and coordinate a registered apprentice programme or an employer-sponsored training programme that includes both supervised work experience and instruction in several occupations.

Cities must be able to maximize and leverage the new age of ICT into education and training curricula for new and experienced agrifood system entrepreneurs so that they can fully participate in an increasingly mobile and digital-based economy. Connectivity-via Internet or mobile phones-can bring valuable market information and financial services. And with more than 75 percent of the world having access to a cell phone and 3.2 billion people using the Internet, ICT is changing the way people govern and do businesstransforming public service delivery and democratizing innovation. ${ }^{213}$

\subsubsection{Micro, Small and Medium-Scale Enterprises (MSMEs) and Entrepreneurship}

MSMEs play a major role in most economies and often dominate the agrifood sector, particularly in small rural towns. ${ }^{214}$ There are between 365 million and 445 million MSMEs in emerging markets. Formal SMEs from all sectors contribute approximately 50 percent of total employment and up to 33 percent of national income in emerging economies. Most formal jobs are with SMEs, which also create four out of five new positions. 


\subsubsection{MSME Policy Environment}

In many contexts, municipalities, metropolitan districts and national governments may want to use the initiation of food system work to strategically review and potentially recalibrate the policies and institutional mechanisms related to MSMEs. A collaborative review and update of existing labour laws, incentives, regulations and institutional oversight mechanisms by public, private and civil society organizations is essential for future investment and job creation in the agrifood system. Examining potential tradeoffs in policy decisions related to the scale of food processing firms (e.g. effects of scale on product affordability, scale and job creation) and their relative capital- or labour-intensity is equally important. Finally, assuring equal access to services and support for male- and female-owned food businesses is critical to developing inclusive food systems.

In many parts of the world, it has been largely at the MSME level that food system innovation has taken place. With consolidation and increased investment by large-scale food companies in the food systems' modern sector, however, there is increasing competitive pressure on many smaller actors. In many cases, micro or small enterprises may barely cover operating costs and retain only a small market share but still make a positive contribution to employment and livelihoods. ${ }^{215}$ Their productivity and competitiveness could be improved with focused assistance, helping firms to meet evolving consumer food demand that requires increasing sophistication in product development and marketing.

The competitiveness of e-commerce food businesses provides significant opportunities to food MSMEs, particularly as it precludes the need for a brick and mortar store presence. Greater attention will need to be centred on the cost of doing business for all food MSMEs, including in the emerging e-commerce industry.

Regulation reform often includes procedures to register a business, which may then allow informal entrepreneurs to join the formal sector, making it easier to gain access to markets and services. While business registration is often useful to cut red tape and foster competition, it may not spur much SME growth, as evidenced in Mexico, where after registration 80 percent of the informal businesses remained informal. ${ }^{216}$

Tax policy will play a large role for SMEs. On the one hand, tax policies that constitute increases, complex regulations or a lack of tax policy awareness-raising can be an encumbrance on a business's ability to sustain itself and to expand. ${ }^{217}$ On the other hand, a new tax regime in Georgia, which instituted zero tax for firms with revenue below a certain threshold, led to an increase of approximately 40 percent in the number of firms that registered with the tax authority for the first time. But while many governments implement similar special tax regimes for SMEs, with simplified procedures and sometimes lower tax rates, the tax code could also encourage firms to stay small. ${ }^{218}$

\subsubsection{MSME Support Options}

Extensive training in skills to improve business performance and harmonize business practices such as accounting, marketing and financial planning has

been widely conducted throughout the world. Unfortunately, the impact on 
business practices and performance has been modest. The provision of consulting services has been more successful. As discussed in the section on youth employment, all food start-ups and many MSMEs require assistance in developing businesses lines, bringing products to market and sustaining their growth. In addition to capital and a supportive business ecosystem, entrepreneurs and MSMEs need mentoring. Business development requires mentoring for the entire gamut of issues and functions faced by food companies. Many business incubators and accelerators are challenged to facilitate access to the diverse skills and advice required by both young and mature food business (e.g. inputs, outputs, seed capital/growth capital, quality control, regulatory environment, product development). Development of a global food business mentoring facility that provides virtual and physical mentoring for food entrepreneurs and MSMEs could potentially address this insufficiency in the number, variety and specificity of mentors available to help food companies in many countries. A food MSME or entrepreneur incubator or accelerator would not be limited to a small pool of potential mentors in a country.

Cities or countries may also want to consider the establishment or strengthening of food science innovation labs to assist food SMEs and entrepreneurs in product development and training or technical assistance on labelling, traceability and safe natural processing for nutritious, healthy packaged food. These labs could be linked to regulations governing the content of processed food and the options for MSMEs to respect these measures.

Another key issue in support of SMEs is the need to think of new business models for urban food systems. The specific nature and diversity of business strategies in urban food production need to be more flexible than business strategies in "rural" agriculture due to the particular features of urban and peri-urban contexts. These include land being not easily available and also expensive, the need to be close to the customers and the need to develop new networks of suppliers, customers, business partners and facilitators. ${ }^{219}$

\subsubsection{Indicative Policy, Investment, Capacity and Knowledge Interventions by City Type}

Table 6.1 presents, by city type, a list of indicative interventions to support this first key area, remunerative jobs and better agribusinesses. Policy, investment and capacity-enhancing interventions are likely to differ significantly by city type. For example, small cities and towns in agriculture regions could strengthen their focus on agrifood processing as their proximity to raw material increases their cost competitiveness. ${ }^{220}$ Certain suggestions, such as the MSME Mentoring Facility, may be well-suited to a regional or global level. Many of the proposed interventions depend strongly on inputs from other sectors, most notably a stable supply of energy, transport and labour policies.

As this urban food system work is in its early stages of development, there is insufficient granularity in the analysis and an incomplete, updated understanding of city priorities that would allow us to suggest a complete list of intervention areas by each type of city. It is for this reason that a base package of interventions is proposed, potentially applicable to each city type. Subsequent 
analysis and consultation in forthcoming phases will contribute to refining this table. The table also indicates the critical inputs from other sectors that are needed to complement the suggested intervention areas.

TABLE 6.1 Remunerative Jobs and Better Agribusiness: Indicative Policy, Investment, Capacity and Knowledge Interventions by City Type

\begin{tabular}{|c|c|c|c|c|}
\hline Base package & $\begin{array}{l}\text { C1: Agrocities: } \\
\text { agriculture-based } \\
\text { towns or small } \\
\text { cities with under } 1 \\
\text { million inhabitants }\end{array}$ & $\begin{array}{l}\text { C2: Growing } \\
\text { secondary } \\
\text { cities of } \\
1-10 \text { million } \\
\text { inhabitants }\end{array}$ & $\begin{array}{l}\text { C3: Megacities } \\
\text { and conurbations } \\
\text { with more than } 10 \\
\text { million inhabitants }\end{array}$ & $\begin{array}{l}\text { Cn: Food-Smart } \\
\text { cities: Future cities } \\
\text { or neighbourhoods } \\
\text { yet to be built }\end{array}$ \\
\hline $\begin{array}{l}\text { - } \text { Informal sector policy } \\
\text { - } \text { and support } \\
\text { business environment } \\
\text { - } \text { Food systems education } \\
\text { and skills partnerships } \\
\text { - } \text { Global SME/food } \\
\text { entrepreneur technical } \\
\text { mentoring facility } \\
\text { - Social protection } \\
\text { programmes to } \\
\text { enhance youth skills and } \\
\text { livelihoods }\end{array}$ & $\begin{array}{l}\text { - Productive } \\
\text { alliances for } \\
\text { sustainable } \\
\text { rural-urban value } \\
\text { chains } \\
\text { - } \text { Agrifood } \\
\text { processing parks } \\
\text { or other territorial } \\
\text { agro-industry } \\
\text { investment tools }\end{array}$ & \multicolumn{2}{|c|}{$\begin{array}{l}\text { - Focus on effective distribution } \\
\text { - } \quad \text { Adaptesale and retail development } \\
\text { and zoning codes to enable } \\
\text { rooftop gardening, greenhouses } \\
\text { and other commercial agriculture } \\
\text { - Support to enable food MSMEs } \\
\text { to improve the nutritious quality of } \\
\text { food products } \\
\text { - Entrepreneurship incubators }\end{array}$} & $\begin{array}{l}\text { - } \text { PPP development } \\
\text { along the food } \\
\text { system } \\
\text { - Education via ICT } \\
\text { - Innovative } \\
\text { partnerships } \\
\text { with academic } \\
\text { institutions, } \\
\text { NGOs, and others } \\
\text { - Entrepreneurship } \\
\text { incubators }\end{array}$ \\
\hline
\end{tabular}

Critical inputs and policy from other sectors required for interventions to be effective:

- Enhanced labour regulations

- Electricity grids or other renewable energy infrastructures

- Water and sanitation services enhanced

- Land administration and policy

- Education policy

- Commerce and finance policies

\subsection{A: Affordability and Accessibility for Food Security}

Providing the significant volume of food needed to feed a world population of 9 billion plus, and especially the burgeoning urban populations-projected to be more than 7 billion people in 2050-will involve an immense operational and logistical effort. It will also involve vast productivity and enhanced performance at several levels to make sure food is affordable, safe and of good quality, and accessible to all, including urban dwellers belonging to lower-income quintiles or living in slums or other underserved areas. Getting the incentives, policy and regulatory environment right is critical for enabling private enterprise and mobilizing private sector investment in the food and agriculture sector. Properly designed and implemented, an enabling institutional environment will prime the domestic food economy and stimulate intraregional and export markets, offering the basis for broad-based, sustainable and inclusive growth. Relevant policy actions, investments, innovations and capacity building will need to centre on: modernizing food supply chains; reducing FLW along the food supply chain; food security; and social protection for vulnerable urban poor. 


\subsubsection{Modernizing Food Supply Chains}

This intervention area includes a range of actions that are centred on improvements to supply chains, to improve their efficiency, productivity and safety needed to handle increasing food volumes and to improve affordability and accessibility of food for all consumers through improved performance of all three urban food marketing channels (i.e. traditional, modern, informal). Upgrading or modernizing wholesale markets represents a critical priority for improving performance of all three urban food channels, which will continue to function for the foreseeable future, providing diverse services to different segments of consumer food demand. In line with the TRANSFORM framework's interlinked outcome areas, these actions must be equally focused on improving availability of nutritious food, strengthening resilience and becoming more carbon-efficient, and contributing to greater inclusiveness through generation of jobs and food system livelihoods. Prioritizing food system-specific public investments and facilitating private investments in food processing, climate-smart transport and logistics, and wholesale and retail sectors-which account for 50-70 percent of food prices in urban marketsare critical for productivity growth to keep food affordable. ${ }^{221}$ Sufficient supply of low-cost food, in turn, is deemed essential for expanding employment opportunities throughout the economy. ${ }^{222}$

The modernization of urban food markets and their governance mechanisms, including wholesale markets through PPPs, are a key element for improving food system performance, given their role as the junction between rural and urban actors (see Chapter 3). Beyond the assembly, sale and purchase of fresh food, modern wholesale markets provide space for market actors to add value (e.g. washing, sorting, packaging, storage, logistics) demanded by restaurants and modern retail. They assist with waste reduction and recycling, hygiene, green energies and improved management. ${ }^{223}$ In addition to securing real estate, complementary public actions include measures to improve logistical efficiency for traffic flow and the loading and unloading of goods, in combination with better garbage collection, sewage service and other hygiene improvements. ${ }^{224}$ An inclusive perspective impels governments to assure that small-scale retailers or wholesalers are not priced out of the upgraded facilities. ${ }^{225}$ Public-private efforts underway in Paris to promote low-cost, climate-friendly urban freight measures, including use of urban rail and the integration of freight into land-use planning, represent the type of action that will need to be replicated and accelerated in many congested urban centres. ${ }^{226}$ In terms of food retail facilities, improvements in the overall business environment (such as contract enforcement, access to financing and ease of doing business) ${ }^{227}$ will benefit all actors.

Agrifood processing parks or other territorial approaches to agro-industry investment (e.g. agrocorridors, clusters, special economic zones, incubators $)^{228}$ developed in rural towns or the urban periphery of larger cities can generate multiple benefits from agglomeration economies and positive clustering of SMEs, which represent 75 percent of the food industry. The benefits include an enabling environment for interfirm cooperation, the diffusion 
of innovations and a means to efficiently channel public support to increase competitiveness. ${ }^{229}$ Increasing the number of firms in the same industry and concentrating them in the same area reduces their costs and increases the total factor productivity for those producing the same product. ${ }^{230}$ The clustering economies or critical mass effect applies to microenterprises in close proximity to larger or lead firms. ${ }^{231}$ As firm growth is linked more to market expansion than to market share, ${ }^{232}$ it is possible to envision non-competitive mentoring in which a large food company assists SMEs and potential entrepreneurs in areas like product or brand development and marketing. These diverse instruments, which couple infrastructure investments with trade and regulatory policy reforms and sectoral development plans, ${ }^{233}$ provide opportunities linking the delivery of critical public goods with investment from private food system actors.

Regular availability and affordability of power generation is critical to the sector's development, particularly for food processing and cold chains. Complementary investment in the power sector will require electrification planning, an enabling incentive and regulatory environment (including for green power) and institutional and financial capacity. ${ }^{234}$ Improving the availability and accessibility of cold chain infrastructure for food businesses, including informal sector actors, improves profitability and contributes to reduced FLW and a smaller carbon footprint. ${ }^{235}$

Future food price and market policy will need to closely monitor competition issues and the regulations that govern urban food systems, paying close attention to market concentration (the number of firms and their respective shares of total market volume), scale economies and effect on prices. ${ }^{236}$ In Asia, for example, there is evidence that competition is increasing in grocery retail but not in manufacturing and food service sectors. ${ }^{237}$ Issues related to private labels, exclusive supply and purchasing agreements, cartels, barriers to entry and single branding also give rise to competition concerns. ${ }^{238}$

An adaptation of the "Productive Alliance" model, effectively implemented in several countries in Latin America and the Caribbean region, may provide integrated solutions in small, agriculture-based cities and towns. These involve smallholder producers, one or more buyers, and the public sector, connected through a business plan that stipulates capital and producer services needed to upgrade capacities and skills to access markets as well as financing through public grants and matching contributions by producers and/or buyers. ${ }^{239}$ Upstream and downstream vertical integration or even horizontal integration at specific stages of a supply chain can result in potential outcomes ranging over the spectrum from increased efficiencies and profitability to market failure. National and city/regional enabling environment-policies, institutions, regulatory framework and incentives-is key to their effective functioning.

Understanding the nuances of evolving consumer food demand market through a market intelligence facility could be an important public-private service to SMEs to strengthen their competitive position relative to well-informed global competitors. Similar ventures are needed for urban food market information systems, whose positive impact in rural areas is well established. Market 
information systems have been shown to lead to a more equitable distribution of bargaining power within the food system, to improve market efficiency through better private decision-making and to improve the design and implementation of government programmes and technology development. ${ }^{240}$

As cities conduct urban food system assessments through the TRANSFORM lens, attention may need to be focused on identifying ways to source more food from smallholder producers and SMEs (inclusiveness), to offer more nutritious/healthy food choices and to diversify food sources for greater resilience (including local procurement). More function-specific assessments (e.g. transport and delivery) or market channel and carbon footprint assessments can provide information for public and private stakeholders to prioritize and design future actions.

\subsubsection{Reducing Food Loss and Waste (FLW) Along the Food Supply Chain}

Almost all urban areas experience high levels of food waste-and this will rise as populations in cities rise. Furthermore, evidence indicates that cities in low-income countries may in fact have higher rates of food waste than those in industrial countries, mainly due to a lack of infrastructure to address FLW along the value chain. ${ }^{241}$ While food waste reduction presents significant challenges, addressing waste issues also provides an opportunity for growing cities to reduce their carbon emissions, curb deforestation and mitigate water withdrawals caused by agriculture as well as being part of a broader strategy to ensure a nutritious and affordable food supply. Momentum is indeed building for local governments to explore innovative methods of managing and reducing food waste.

Quantitative and qualitative research and analysis undertaken by the World Resources Institute (WRI) finds that actions to reduce FLW yield high cost-benefit ratios for municipalities, households and private food companies-with higher ratios seen in actions closer to consumption. For every $£ 1$ invested by London boroughs to reduce household food waste, $£ 8$ was saved. The cost-benefit ratio was even higher, at 92:1, when the financial benefits to households located in the boroughs were included. In a sample of 700 companies across 17 countries, half of the businesses earned greater than a 14-fold financial return on investment. ${ }^{242}$

\subsubsection{Integrating FLW Solutions}

Successful approaches to reduce urban FLW can be found across the globe, generating important economic, social and climate co-benefits. For example, UPA has significant potential to reduce urban FLW, particularly for perishable food, through reduced time and distance for transport, distribution and retail, and through direct producer to consumer transactions. UPA can also absorb sources of urban waste, such as storm water and household wastewater, which can be reused for irrigation, thereby generating significant cost savings for the producer. ${ }^{243}$ Another growing practice is the use of restaurant waste for electricity generation to reduce the amount of food 
waste deposited in landfills and the associated GHG emissions. Food banks, which for decades have been key actors in FLW reduction initiatives, are expanding and using innovative forms of engagement, including targeting discarded food still fit for consumption, involving school feeding programmes and creating jobs. ${ }^{244}$ In 2016, France passed a law to ban supermarkets from throwing away or destroying unsold food, requiring them to donate it to charities and food banks. ${ }^{245}$ Social enterprises are also taking on the very definition of "fit for consumption" by promoting "ugly foods," aiming to reduce the amount of food discarded for failing to meet retail standards for appearance. ${ }^{246}$

As most FLW in lower-income countries occurs at production and post-harvest, the greatest potential for food waste reduction in developing and emerging economics may be in market-led investment in infrastructure related to storage, transport, cold chains and distribution, together with technological skill development and targeted support. The greatest potential for reducing food waste in high-income countries generally involves retail, food service and the consumer level. ${ }^{247}$ Some examples of the treatment of FLW by various countries and cities of the world are given in Box 6.4.

\subsubsection{Potential Actions to Reduce FLW}

Efforts to reduce FLW, either at the company level or for specific functions in a food supply chain, will usually start with the collection of reliable data and careful diagnosis of the quantity of waste or loss generated by different levels of a supply chain or the food system. This stronger empirical base provides the basis for stakeholders to identify strategies and potential interventions to address the causes of FLW. ${ }^{248}$ The recently developed Food Loss and Waste Accounting and Reporting Standard (or FLW Standard) fills a critical need for guidelines on what and how o measure FLW in a consistent and transparent manner. ${ }^{249}$

Recent diagnoses in Kenya's desert banana sector quantified the following losses in the supply chain: 5 percent in collection and handling induced by soil contamination and sun; 20 percent by ripening at high temperature and oxygen levels; 10 percent by improper loading, offloading and insufficient protection in transport; and 10 percent from spoilage due to high temperature. Accordingly, proposed solutions to reduce losses include: training to supply chain actors in proper handling procedures and quality control; investment in pre-cooling facilities in wholesale markets and ripening chambers; assessment of the potential for value-added processing; and integration of post-harvest pest/disease management plans. ${ }^{250}$ This level of analytical detail will need to exist as a critical prerequisite for all interventions.

Given the widely varying nature of FLW within food chains worldwide, approaches to reducing urban FLW must be tailored to the local context and specific food chain actors. An emerging body of evidence is illustrating how specific causes of FLW at different stages of the food chain call for different actions. These results, together with the FLW Standard and new guidance 


\section{BOX 6.4 Food Waste Reduction, Recovery and Treatment}

- The city of Curitiba, Brazil implements an innovative programme to collect solid waste directly from its citizens. By trading in recyclable materials, citizens in the Cambio Verde programme can in turn receive fresh produce from the peri-urban and rural metropolitan areas or purchase such produce at 30 percent cheaper prices.

- Balangoda, Sri Lanka's Municipal Solid Waste compost plants, located in semi-urban and rural areas, facilitate waste reuse in agriculture with farming areas closely located to them.

- Since 2001, Linkoping, Sweden has used 3422 tonnes of food waste from public canteens and restaurants to produce 12.65 Gwh of biogas that serves 7 percent of the local fuel market for vehicles. The plant also generates 3422 tonnes of biofertilizer.

- The Riga, Latvia Getlini landfill, with over 40 percent food waste, produces gas that generates "green" energy as well as heat for greenhouses that produce tomatoes, which in turn supply supermarkets in the winter off-season.

- In Australia, the retail and food processing sectors have partnered with food recovery organizations to save more than 72 million meals for the community that would otherwise have gone to landfill in 2014-2015.

- In the Republic of Korea, 17 biogas facilities and 4 sewage sludge-drying fuel facilities are estimated to turn 188000 tonnes of organic waste into biofuels every year. The Republic of Korea's smart disposal system, which uses scales built into disposal bins and radio frequency identification (RFID) chips to measure food waste generated by each user, has helped 145000 users reduce their food waste by 30 percent.

- Hong Kong, where urban dwellers generate around 3900 tonnes of food waste every day, launched the Food Wise campaign at the district level in 2013. Over 320 organizations from public, private and civil society sectors signed a charter to encourage food waste reduction.

- The United Kingdom's Waste and Resources Action Programme, together with food manufacturers and retailers, launched the campaign "Love Food Hate Waste" in which more than 300 local authorities participate to reduce food waste.

- Public and private sector actors in Accra, Ghana partnered in the development of a factory that uses human and other organic waste to develop safe, nutrient-rich compost.

Source: FAO, Global food losses; Gianfelici, F., L. Lancon, C. Bucatariu, M. Dubbeling, G. Santini, and Sudarshana Fernando. 2016. Composting urban organic waste into agricultural inputs: Balangoda, Sri Lanka; Symbi Interreg Europe. 2017. Global practice guide and benchmarking guidelines on ecosystems of byproduct and energy exchanges. Accessed June 1, 2017. https://www.interregeurope.eu/fileadmin/user_upload/tx_tevprojects/library/file_1502280065.pdf; The World Bank. 2016. Financing landfill gas project in developing countries. Accessed June 1, 2017. http://documents. worldbank.org/curated/en/591471490358551160/Financing-landfill-gas-projects-in-developing-countries; Australian Government. Department of the Environment and Energy. 2016. Working together to reduce food waste in Australia. Accessed June 1, 2017. http://www.environment.gov.au/protection/national-waste-policy/food-waste; Innovation Seeds. 2017. South Korea's food waste reduction policies. Accessed August 1, 2017. http://www.innovationseeds.eu/policy-library/core-articles/south-koreas-food-waste-reduction-policies.kl; Hong Kong Environmental Bureau. 2014. A food waste \& yard waste plan for Hong Kong. Accessed June 1, 2017. http://legco.gov.hk/yr13-14/english/panels/ea/papers/ ea0224cb1-956-1-e.pdf; WRAP. 2012. Household food and drink waste in the United Kingdom. Accessed June 1, 2017. http://www.wrap.org.uk/sites/files/wrap/hhfdw-2012-main.pdf.pdf; CGIAR (Consultative Group on International Agricultural Research). 2017. New compost plant to aid the greening of Ghana's economy by recycling waste and delivering a safe, nutrient-rich fertilizer for food production. Accessed June 1, 2017. https://wle.cgiar.org/press-releasenew-compost-plant-aid-greening-ghana $\% \mathrm{E} 2 \% 80 \% 99$ s-economy-recycling-waste-and-delivering-safe. 
material (e.g. World Resource Institute, FAO, Save Food, CFS High Level Panel of Experts), provide the necessary basis for advancing this work. An array of potential intervention options may serve as a starting point to guide individual actors, public and private organizations in reducing FLW in urban areas:

- Ensure a holistic approach to FLW solution integration by stage of the food supply chain;

- Apply the FLW Standard and set targets and plans of action to achieve them;

- Mainstream FLW reduction strategies within sectoral policies;

- Improve the enabling environment for reducing FLW by, for example, removing regulatory barriers related to food labelling and donations;

- Introduce social awareness campaigns to promote FLW reduction;

- Streamline date labelling on food packaging (e.g. sell by, use by, best before);

- Introduce programmes to train key actors along the food supply chain on best practices in packaging, processing, post-harvest handling and distribution;

- Invest in or incentivize investments in infrastructure, cooling and cold chain technology to reduce FLW during packaging, transport, storage, distribution and retail, assuring access for small-scale actors;

- Provide incentives for investments in systems to redistribute nutritious food and/or reuse discarded food-for instance, composting or the use of biodigesters for anaerobic digestion;

- Enhance research and extension capacities to improve understanding of the technical and context-specific dimensions of FLW;

- Improve data collection and knowledge-sharing on FLW by food supply chain.

\subsubsection{Food Security: Social Protection for the Vulnerable Urban Poor}

Food subsidies, diverse types of social protection programmes, and specific nutrition and food security programmes are all used by municipal and national governments to address the specific welfare and food needs of vulnerable urban populations-male and female, young and old. National food subsidy programmes are widely used in India, Indonesia, the Near East and North Africa to provide select food items to vulnerable urban (and rural) populations at below-market prices.

Social protection programmes involve many instruments (such as cash and food transfers, insurance, social services, child benefits and public works) to achieve diverse objectives that include protecting households from the negative impacts of shocks, helping build resilience to shocks and stresses, addressing the underlying causes of crises, and lessening household vulnerability by strengthening economic and productive capacities. They are increasingly used with humanitarian assistance as a response to saving 
lives and livelihoods while also enhancing the capacity of households to respond, cope with, and withstand threats and protracted crises. ${ }^{251}$ National governments also need to work closely with municipal and city/regional authorities as well as NGOs, bilateral and UN agencies to secure adequate food and water and ensure improved nutritional status of the displaced, while ensuring that host communities are not adversely affected.

Although food- and nutrition-specific social protection programmes have not been widely used in urban areas, Belo Horizonte in Brazil has successfully implemented a comprehensive rights-based programme and set of policies to assure the food security of the urban poor. Innovative programme aspects include direct farmer-to-consumer fresh produce sales at set low prices in poor neighbourhoods and municipal markets, establishment of "people's restaurants" that provide subsidized meals of locally grown food to 12000 people a day ( $85 \%$ of whom are poor), nutrition education, locally grown school lunches, community gardens, widely disseminated food market price information system and the innovative use of food waste.

Mexico City's Community Dining Rooms programme, also based on right-to-food principles, had established 352 restaurants in low-income neighbourhoods by 2016, providing 56500 nutritious meals daily at affordable and stable prices. Community Dining Rooms are operated jointly by local government, academic institutions, civil society and the private sector, and offer training and employment to vulnerable women, seniors and those with disabilities. Toronto, Canada has developed a set of innovative market-oriented interventions to improve the availability and affordability of fresh nutritious food. ${ }^{252}$ The Egyptian Food Bank serves as a link between individual and institutional donors, to feed the poor and needy across Egypt, with the mission of "Ending Hunger in Egypt by 2020". In 2014, it had reached 2 million families. ${ }^{253}$

Development of urban, food-based, social protection programmes will require more careful analysis of these diverse programmes being used to address urban food insecurity and hunger, and assessment of their potential integration into current safety net and social protection systems and institutional structures. Some countries are also using price stabilization schemes, government and cooperative stores and food price subsidy schemes that strive to ensure access to certain food items at affordable prices for the urban poor. Their coverage, targeting and effectiveness need to be more closely examined relative to diverse social protection mechanisms, and particularly with respect to their large share of government budgets.

\subsubsection{Indicative Policy, Investment, Capacity and Knowledge Interventions by City Type}

Table 6.2 presents, by city type, a list of indicative interventions to support this second key area, affordability and accessibility for food security. Policy, investment and capacity-enhancing interventions are likely to differ significantly by city type. 
TABLE 6.2 Affordability and Accessibility for Food Security: Indicative Policy, Investment, Capacity and Knowledge Interventions by City Type

\begin{tabular}{|c|c|c|c|c|}
\hline Base package & $\begin{array}{l}\text { C1: Agrocities: Agriculture- } \\
\text { based towns or small } \\
\text { cities with under } 1 \text { million } \\
\text { inhabitants }\end{array}$ & $\begin{array}{l}\text { C2: } \\
\text { Growing } \\
\text { secondary } \\
\text { cities of } \\
1-10 \text { million } \\
\text { inhabitants }\end{array}$ & $\begin{array}{l}\text { C3: Megacities } \\
\text { and } \\
\text { conurbations } \\
\text { with more } \\
\text { than } 10 \text { million } \\
\text { inhabitants }\end{array}$ & $\begin{array}{l}\text { Cn: Food- } \\
\text { Smart cities: } \\
\text { Future cities or } \\
\text { neighbourhoods } \\
\text { yet to be built }\end{array}$ \\
\hline $\begin{array}{l}\text { - } \text { Modernized food } \\
\text { market infrastructure } \\
\text { - } \text { Supply chain and } \\
\text { plan and support } \\
\text { facility } \\
\text { - FLW accounting and } \\
\text { reporting } \\
\text { - Capacity building of } \\
\text { supply chain actors } \\
\text { - Food security } \\
\text { response } \\
\text { programmes } \\
\text { Innovative food- } \\
\text { based social } \\
\text { protection } \\
\text { programmes for } \\
\text { urban poor and food- } \\
\text { insecure }\end{array}$ & 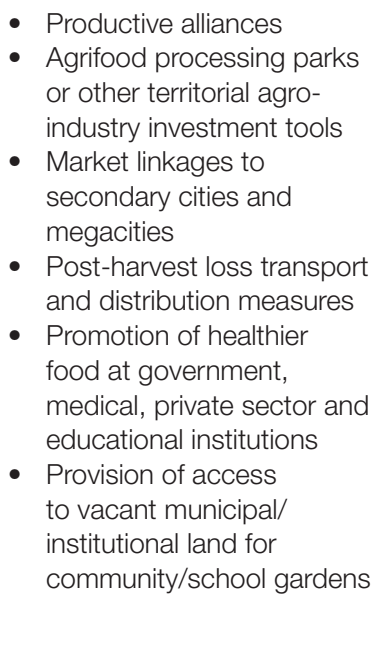 & $\begin{array}{ll}\text { - } & \text { Transport Ic } \\
\text { - } & \text { Covelopme } \\
\text { - } & \text { Intracity foc } \\
\text { - } & \text { review/plan } \\
\text { - } & \text { in slumsiew/pla } \\
\text { - Food to en } \\
\text { - Facilitated } \\
\text { producers } \\
\text { land (e.g. la } \\
\text { incentives) }\end{array}$ & $\begin{array}{l}\text { istics/food hubs } \\
\text { frastructure } \\
\text { availability } \\
\text { for food systems } \\
\text { gy infrastructure } \\
\text { cess for poor } \\
\text { private vacant } \\
\text { d banks, tax }\end{array}$ & $\begin{array}{l}\text { - Rail/drone, } \\
\text { climate- friendly } \\
\text { transport system } \\
\text { - Food-friendly real } \\
\text { estate } \\
\text { - Advanced } \\
\text { traceability } \\
\text { methods (e.g. } \\
\text { nanotechnology) } \\
\text { - Adaptation } \\
\text { of building } \\
\text { regulations and } \\
\text { zoning codes to } \\
\text { enable rooftop } \\
\text { gardening, } \\
\text { greenhouses and } \\
\text { other commercial } \\
\text { agriculture }\end{array}$ \\
\hline \multicolumn{5}{|c|}{$\begin{array}{l}\text { Critical inputs and policy from other sectors required for interventions to be effective: } \\
\text { - Power generation or renewable energy infrastructure } \\
\text { - Transport and information technology } \\
\text { - Broadband Internet } \\
\text { - Enhanced water and sanitation services } \\
\text { - Health and safety standards development }\end{array}$} \\
\hline
\end{tabular}

\subsection{N: Nutritious, Diverse, Quality and Safe Food}

There is overwhelming evidence that the world's current food system does not contribute to nutritious diets for an increasingly large segment of the population. ${ }^{254} \mathrm{~A}$ healthier food system has substantial potential for reducing the incidence of cardiovascular disease. ${ }^{255}$ Assuming the improvements discussed so far lead to the increased availability and affordability of more nutritious foods in cities, it is also important to increase their share in consumption. It is also increasingly evident that a growing number of people living in towns and cities are food-insecure.

Food supply chain interventions (Section 6.2) that improve the affordability of nutritious food are arguably the most important actions to improve urban food security, given the large share of household budgets allocated to food purchases. Increasing access to income through food system jobs (Section 6.1) is another important action to improve food security and nutritious diets. Beyond these measures, enhancing access to quality health services, potable water, sanitation and education, housing and public transport represent important complementary measures to improve food security and nutritional outcomes, most notably for the poor and marginalized. The 
importance of delivering and assuring access to these instruments highlights again the critical contributions required from other sectors.

This section discusses four interrelated actions to improve food security and increase the availability of nutritious, diverse, quality and safe food:

- Upgrading the policy and regulatory environment to promote the consumption of nutritious, diversified and quality diets and food and decrease consumption of unhealthy food;

- Facilitating innovative partnerships and institutional procurement of nutritious food by public and private actors;

- Promoting and supporting the production of fruits and vegetables in urban and peri-urban areas;

- Strengthening food safety systems.

These intervention areas should naturally be part of a comprehensive programme of food action, progressive learning and evaluation by a range of sectors and actors at community, municipal, national, regional and global levels.

\subsubsection{Potential Policies towards More Nutritious, Diverse and Quality Diets}

Changing consumption patterns towards more nutritious diets is not easy. People are drawn to food that is seemingly more pleasurable-with more sugar, salt and fat-and easier to prepare. ${ }^{256}$ There is overwhelming evidence that processed food and beverages containing high levels of sugar, salt and saturated fats contribute to the growing prevalence of overweight and obesity that leads to rapid increases in non-communicable disease and ill health. The food people choose to eat is strongly influenced by income and relative prices, by sociocultural environments, by lifestyles and by the social value placed on consumption of certain foods. Purchase decisions and consumption choices are equally conditioned by regular exposure to advertising and other environmental stimuli that trigger more automatic, non-cognitive actions, largely unaccompanied by conscious reflection. ${ }^{257}$ Therefore, many interventions targeting individual behaviour change based on knowledge alone have largely been ineffectual. The availability of highly processed, nutrient-deficit foods at lower cost, which are often more readily accessible, served in convenient portions and more prominently displayed-all features associated with food swamps ${ }^{258}$ and food deserts in several developed countries-are being imported wholesale into the developing world, with access to such foods deemed to be a sign of growing prosperity.

Each of these factors is related to policy decisions affecting the incentive and regulatory environment that guides the behaviour of economic actors and consumers (Figure 6.2). It is well established that improved nutrition and health outcomes will require actions to address both the demand and supply aspects of the problem. "If people made healthier choices, the food systems 
would have greater incentives to produce healthier items. At the same time, a healthier food supply enables individuals to make healthier choices." 259 Certain analyses have concluded that regulation of the food industry is the only viable option for addressing nutritional challenges in the food system, given that private sector voluntary self-regulation or PPPs have proven to be ineffective in achieving positive change. ${ }^{260}$

There is clearly a need for more rigorous policy impact evaluations of the small number of nutritional measures that have been implemented by cities and countries. Existing evidence suggests that a mix of voluntary and non-voluntary measures is needed to improve access to and promote

\section{FIGURE 6.2 Food Policies on Nutrition}

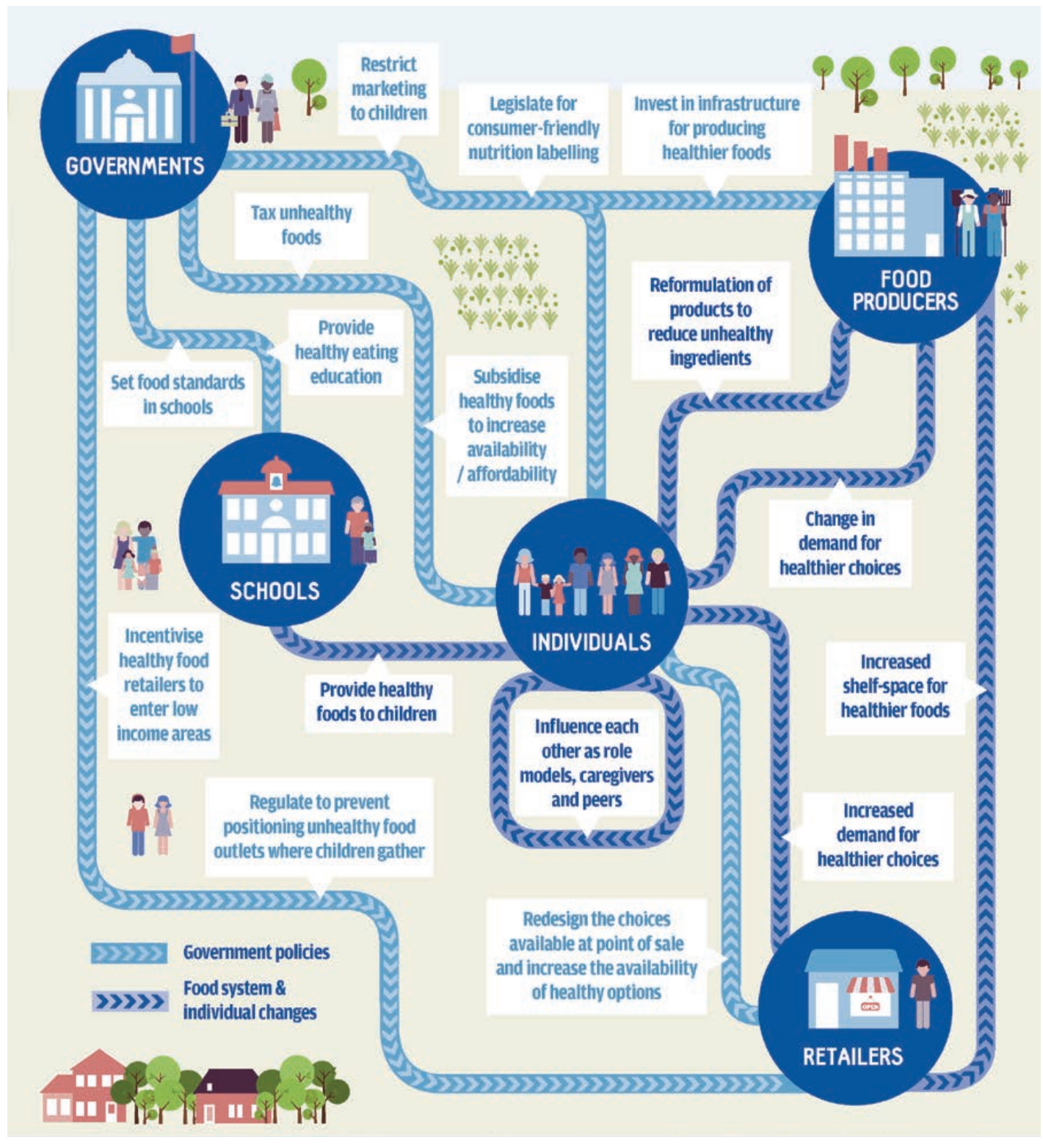

Source: The Lancet. 2015. Obesity. Accessed June 1, 2017. http://www.thelancet.com/series/obesity-2015. 
consumption of affordable, nutritious food in addition to increasing the relative cost of and reducing exposure to and consumption of unhealthy, nutrient-poor food. ${ }^{261}$

Potential policy measures can take multiple forms with diverse entry points: taxes on food with a high fat content (see Box 6.5 on Denmark's experience); ${ }^{262}$ advertising and marketing restrictions on nutrient-poor food, both through media and in retail stores; simple, uniform and understandable food labelling measures with regulations on nutrients, clear expiration dates, front of packet labels or traffic light labelling to indicate good nutrition (green) or poor nutrition (red); zoning restrictions on fast-food restaurants; food standards on fatty food imports or sugar and sodium levels; policies on product formulation; and use of particular processing techniques. Strong accountability mechanisms to track and enforce application are also needed. Many of these operational measures are well developed in several recent reports and frameworks (e.g. World Cancer Research Fund International's Nourishing Framework; ICN2 Framework for Action; Global Panel Foresight Report; FAO toolkit on nutrition-sensitive agriculture) ${ }^{263}$

In addition to city- or country-specific actions to improve the availability of and access to nutritious, healthy foods and, inversely, to reduce (or eliminate) the availability of and access to nutrient-poor, unhealthy food, there is also a need to deal with incentives affecting global food supply closer to its production, ${ }^{264}$ particularly for commodities used in the production of nutrient-poor, processed products.

Policy levers that affect incentives to produce, market, process and consume nutritious foods, on the other hand, have been less widely used but merit additional analysis and efforts to design, test, evaluate and implement them at scale. Possible measures include: the sale of nutritious food at affordable prices; mandatory food vendor sales of nutritious food in low-income neighbourhoods; no/low sales tax on healthier food; food traceability requirements for food chains; discount programmes for nutritious food purchases;

\section{BOX 6.5 Lessons from Denmark's "Fat Tax"}

In 2011, Denmark introduced the world's first tax on saturated fats: 16 Danish kroner $(\$ 2.90)$ per kilo of saturated fat in meat, dairy, animal fat, oils, margarine, butter blends and processed products containing these ingredients. Fifteen months after its adoption, the fat tax was abolished. Analysis highlights several points. It was highly criticized for being poorly designed. Support and popularity for the measure waned over time. Politicians considered the fat tax as a funding source rather a public health issue. Massive influence (viz opposition) by industry stakeholders was not balanced with inputs from public health professionals.

Source: Bødker, Malene, Charlotta Pisinger, Ulla Toft, and Torben Jørgensen. 2015. The rise and fall of the world's first fat tax. Health policy 119(6): 737-742. 
and incentives, support and standards for food fortification across the production and processing spectrum.

Important precedents exist for the reduction of salt and trans fats in food. Publicly facilitated in 2001, the United Kingdom phased in a salt reduction programme in food industry firms, which was supported by targets, improved labelling and consumer awareness, and resulted in a 70 percent reduction in salt content of some foods and a 15 percent reduction in 24-hour urinary sodium. ${ }^{265}$ Equally encouraging is the 13-30 percent drop in global trans fat consumption for all income levels between 1990 and $2013 .{ }^{266}$ Identifying effective measures to increase consumption of nutritious food is increasingly important, particularly for fruits and vegetables, for which current daily consumption is as low as 66 percent below recommended levels (Section 2.3). ${ }^{267}$

Recommendations to set prices of nutritious food 20-50 percent below market levels require information and mechanisms to target the right beneficiaries, careful financial management of the fiscal implications of the subsidy element and attention to design aspects relating to phase-out provisions.

Initiating stakeholder discussions on food-based dietary guidelines is a low-key, non-threatening way to approach a vast number of urban food issues, particularly those related to a healthy diet, ${ }^{268}$ food quality and safety. Developing new guidelines or updating existing ones ${ }^{269}$ and determining what constitutes a nutritious, healthy diet in cities may provide a clear dietary vision and the food compass needed to set in motion an integrated group of policy, regulatory, institutional and investment measures in support of a more nutritious food system. Brazil recently developed food- and mealbased dietary guidelines, based on principles and consideration of cultural, socio-economic, environmental, biological and behavioural dimensions. ${ }^{270}$

Municipal and national governments may find greater policy traction to address these issues from a health entry point by designing incentive and regulatory measures that address risk factors for non-communicable diseases (such as diabetes), many of which will inevitably lead to food system interventions.

\subsubsection{Public and Private Partnerships for Nutritious Food}

Policy and regulatory actions can be effectively complemented by direct interventions by public institutions, restaurants and other private sector actors to procure and serve more nutritious food. Public schools, hospitals, the civil service and the military serve millions of meals every day. A growing number of examples highlight the positive impacts of establishing nutritious food standards for and transforming the public catering services to serve nutritious food. Numerous school systems in Brazil, Greece, Italy, Japan, Greece and the Republic of Korea have successful initiatives to serve nutritious food in school canteens, ${ }^{271}$ while small vegetable gardens maintained by schoolchildren in several countries are teaching them the value of 
fresh plant-based diets. Local sourcing adds a powerful growth and employment-generating benefit for local food systems and helps sustain freshness and quality while reducing carbon footprint via short(er) value chains. Similar measures, stimulated by appropriate policies and incentives, could be instituted in many public institutions that prepare and serve meals, serving as an example to the larger community.

Working with food processors, private restaurants, chefs and food vendors is equally important, given the growing number of pre-prepared meals or food consumed outside the home. When people source their meals from outside the home, they cede control over the quality, to some extent the type, and even the quantity of food eaten; commercially prepared food often contains high levels of fat, salt and sugar. The percent of daily calories consumed by children in fast food is rising throughout the world, jumping in the United States from 4 percent in 1977 to 14 percent in 2013. Singapore's Healthy Food initiative and the Healthy Carts programme in Jakarta are two innovative programmes to promote and facilitate provision of nutritious food by private actors. Sourcing of quality ingredients, and preparation and consumption of nutritious and convenient food could encourage local chefs, food science labs, food processors, restaurants and street food vendors to develop healthier and sanitary local food options, to train in their preparation, and to promote their marketing and consumption. Convenient, quality local foods are often preferred but unavailable and are at times uncompetitive with cheaper food imports.

Innovative use of social media and large mass media and social marketing campaigns are critical components of any efforts to influence perceptions, behaviours and preferences that guide food choices. More comprehensive nutritious food campaigns will naturally need an integrated set of coherent actions at multiple levels and-in addition to agriculturethese will involve education, health, water, energy and trade sectors to promote nutritious food and discourage unhealthy alternatives. Encouraging nutritious food at schools and tertiary educational institutions could involve a multitude of measures, including mandatory nutrition education, physical education and new, nutritious and sustainable food curricula.

Certain cities with politically committed mayors and city councils, and effective partnerships with civil society food movements (such as the "slow food" movement $)^{272}$ and the private sector may also be positioned to address the rising consumption of animal protein that is associated with increased risk of non-communicable diseases and production of twice the level of GHG emissions as plant-based diets. Advances with laboratory-grown meat offer promise for stemming the global march towards higher meat consumption and the attendant health issues and rising emissions. Creative solutions would need to overcome numerous hurdles: overcoming public intolerance of any seeming intrusion on consumers' right to choose; the cultural and aspirational significance of meat in many societies; private sector resistance; people's ambivalence about climate change; and government uncertainty regarding the acceptability and expected outcomes of 
interventions to change what people eat. ${ }^{273}$ Emerging anecdotal evidence suggests that younger generations are more open to dietary change.

\subsubsection{Improving Nutrition through Urban and Peri-Urban Horticulture Production}

UPA is widely practised throughout the world in diverse forms, locations and scales depending on the city and country (Section 3.1.2). UPA contributes to food system jobs, livelihoods and businesses (Section 6.1), which can be expanded in the future to become a more dynamic engine of inclusive growth. UPA plays a crucial role in providing livelihoods and improving the food security of households in protracted crises as well as those who are refugees and internally displaced persons fleeing conflict or extreme weather events. There are a myriad of UPA examples that have been documented by RUAF in fragile areas: Kakuma refugee camp (Kenya); slums within the greater Freetown area (Sierra Leone); Monrovia (Liberia); Kirkuk (Iraq); Harare (Zimbabwe); the food security and livelihoods programmes in Acholiland (Northern Uganda) and Jijiga (Ethiopia); and gardening documented in United Nations High Commissioner for Refugees (UNHCR) refugee camps.

UPA also provides critical environmental and ecosystem services-including climate change mitigation and adaptation, reduction of urban heat islands, biodiversity protection and flood protection-thereby strengthening household, community and city resilience and fostering cohesive community development. Finally, UPA represents a key cog in the food-water-energy nexus, with significant potential for resource recycling and reuse and energy production in closed loop systems.

In the context of this discussion on actions to improve food security and quality and nutritious food, and considering the extremely low levels of fruit and vegetable consumption throughout the world, UPA can play a pivotal role in increasing the availability and the affordability of fresh, safe horticultural

\section{BOX 6.6 Refugee Cash Transfers Generate Strong Economic Benefit to Local Communities}

Rwanda and Uganda have developed strategies to maximize the positive impact of refugees on the food system and local economy. Every dollar received by refugees in cash transfer programmes generates US $\$ 1.51$ to US $\$ 1.95$ in economic benefits to the host local community, compared to a US $\$ 1.20$ real income increase when food rations are distributed. When accompanied with access to land, cash provides strong incentives for local food production, which enables households to contribute to the food system and build livelihoods.

Source: Taylor, J. Edward, Mateusz J. Filipski, Mohamad Alloush, Anubhab Gupta, Ruben Irvin Rojas Valdes, and Ernesto Gonzalez-Estrada. 2016. Economic impact of refugees. Proceedings of the National Academy of Sciences 113(27), 7449-7453. 
products to consumers in all cities. As discussed in this report, increased consumption of fruits and vegetables represents an important component of improved human nutrition and health.

UPA produces a large share of the food consumed in many cities-e.g. 20 percent in Mexico City, particularly fresh fruit and vegetables; 80 percent of green leafy vegetables in Nanjing, China; and 55 percent of vegetables and 90 percent of green leafy vegetables in Shanghai. Systematic, rigorous estimates of urban agriculture's prevalence are not available, though multicountry analysis suggests that country-level participation rates in UPA range from 11 to 69 percent. $^{274}$

UPA has proved to be a valuable source of both food and income to vulnerable urban households, with profitable, more commercially oriented systems serving as a dynamic engine of job creation and income growth. ${ }^{275}$ Labourintensive market gardening is estimated to create one job per 110 square metres in addition to those generated by backward and forward linkages (inputs, marketing and value addition). ${ }^{276}$

Urban and peri-urban production of fruits and vegetables can, in all its diversity, serve as a future innovator of resource-efficient production, which will be instrumental for all agriculture systems and indispensable to increasingly resource-challenged (i.e. for land, water, energy) cities throughout the world. Modern, innovative forms of UPA (e.g. hydroponics, aeroponics) can produce vegetables with one-twentieth the volume of water and one-half the growing time as conventional production. ${ }^{277}$ The diversity of UPA models provides opportunities for both capital- and labour-intensive production systems.

Despite increasing recognition of the notable successes and impacts, UPA is rarely included in urban planning in many parts of the world. ${ }^{278}$ In fact,

\section{BOX 6.7 Havana, Cuba: Meeting the Vegetable Availability Challenge}

Between 1997 and 2009, Havana, Cuba increased vegetable production by 1325 percent, from 20000 to 285166 tonnes, the equivalent of 330 grams per capita per day, which surpassed the government's commitment to produce 300 grams per capita per day (the WHO recommended level) for the city's 2141993 inhabitants. Upon establishing a comprehensive policy, regulatory and legal framework, the government initiated successful pilots, changed unfavourable perceptions within government, and improved human resource and economic incentives to encourage involvement of skilled government and stakeholder experts. Their multifaceted UPA programme includes diverse systems (e.g. livestock, forestry, crops) supported by services that include nurseries, pesticide labs, composting, veterinary and inputs. An estimated 22700 jobs were created.

Source: Santandreu, Alain. 2010. Havana, Cuba urban agriculture policy. IPES Promotion of sustainable development case study. 
many urban officials frown upon urban agriculture, viewing it as a backward, informal activity to be eliminated or, at most, tolerated. For UPA to flourish and provide multiple benefits to cities, it must first become integrated into urban planning with clear policies, incentives, and transparent, enforceable regulations and mechanisms regarding zoning, land use and land tenure. It will also require significant institutional evolution and capacity development, whether in new municipal or metropolitan district agencies or new divisions in Ministries of Agriculture, Water or the Environment at national level. Expansion or intensification of UPA and particularly the use of new technologies will need to be supported by curricula, skills development, support systems and innovative partnerships that contribute to the development of and access to appropriate technology and input industry.

Given the scarce evidence base, more rigorous agronomic and socio-economic analyses of diverse horticulture production systems and technologies will be needed at different scales and in different settings, appropriate for both low-asset producers and cutting-edge innovators. UPA provides a unique opportunity to develop and test productive, profitable, resource-efficient technology for implementation at scale in different city settings. UPA reviews must also assess new technologies and ventures from a sustainable resource use and GHG perspective, as different systems have different climate and resource footprints. Assessment of the adequacy of seed varieties is equally required to determine priorities for intensified public horticulture research and to plan coordinated national, subregional, and global collaboration efforts. Given the high opportunity costs of urban land, proposals for future investments will need to carefully assess the nuances of consumer food market demand as well as the opportunity cost of land and the options for mitigating risks or identifying innovative modalities such as vertical farming and leveraging discarded/abandoned spaces.

To implement UPA more widely, many cities will need to address soil contamination from heavy metals and other pollutants. ${ }^{279}$ Establishing or strengthening the technical and political capacities of urban producer organizations will also be required for them to deliver services. Well-functioning producer organizations can negotiate access to credit and contracts with food retailers as well as assume roles in farmer training and extension and in product quality control/certification. Strengthening the organization and political knowledge of urban producers and MSMEs can enhance their voice and ability to advocate effectively for their interests in urban planning and decision-making, such as secure land tenure and access to water. ${ }^{280}$ UPA reviews also need to assess the advisability of, risks associated with, and regulations needed for animal production systems, particularly considering pandemic risks.

\subsubsection{Strengthening Food Safety Systems}

Growing public concern and engagement has contributed to great strides in improved food safety. Despite this progress, contaminated food still sickens an estimated 600 million people a year and causes many deaths. Regionally, 
the highest burden of food-borne disease is found in the global South, particularly in Africa and South Asia. ${ }^{281}$ Modern food safety systems comprise a diversity of institutions, policy and regulatory frameworks, and various instruments and approaches to ensure food safety in both formal and informal sectors. This section discusses actions related to food safety regulation and standards, informal sector food actors, animal health and welfare and assistance to food SMEs.

\subsubsection{Food Safety Standards and Regulation}

Food safety regulation and mitigation are responsibilities shared by the public and private sectors. Food safety is essentially a "public good", as safe food is a basic requirement of any food system to ensure trust in the food supply. Due to the presence of externalities, informational asymmetries and public good characteristics, markets alone will generally not provide the socially desirable amount of food safety.

The public mandate is increasingly centred on providing an enabling environment through creating a proper legislative and policy framework, providing incentives to empower the private sector to deliver safe food, promoting good practices and offering compliance support. Public authorities also need to implement a well-designed and balanced control and enforcement system to ensure that food is safe, while building customer confidence and avoiding undue interference with market functions. Effectively fulfilling these roles requires a network of well-trained and accountable food inspectors, coordinated science- and risk-based food safety surveillance plans, recognized laboratory networks (public and private) providing timely and quality-assured tests, and risk communication capacity and strategies.

Upgrading or modernizing food safety systems, procedures and capacities represents a key priority area of work for urban food systems. Many food supply chains in low- and middle-income countries lack appropriate agricultural, manufacturing and hygiene practices and do not apply rigorous food safety standards. This upgrading task becomes increasingly important considering the ongoing transformation in the food system, changing consumption patterns (e.g. animal protein, FAFH, processed products), the increasing volume and diversity of food moving into urban centres, the growing number and diversity of formal and informal actors engaged in the food system and the threats from diverse food-borne pathogens (e.g. zoonotic disease, parasites, microbes, adulterants). Food safety systems will need to invest in measures to strengthen the preventive and monitoring aspects as well as their procedures and capacities for emergency response to specific outbreaks.

Strengthening national systems to conform with internationals standards as set out by CODEX Alimentarius (or "Food Code"), the International Organization for Standardization (ISO), the World Organisation for Animal Health (OIE), General Principles of Food Hygiene, and Hazard Analysis of Critical Control Points (HACCPs) as well as other voluntary and private standards (e.g. Good Agricultural Practices (GAPs), Global Food Safety 
Initiative (GFSI)) represents a key starting point. Determining the appropriate mix and relative importance of public and private standards is an important area of concern for many countries and municipalities, particularly as third-party private certification of certain food products may not include food consumed by the urban poor. Economically motivated adulteration $^{282}$ (EMA) is a threat to the integrity of the food supply chain, with potential impacts ranging from loss of consumer trust to brand reputation damage to food safety. An improved understanding of adulteration and maturation of approaches to assess and combat EMA are critical to modern food safety and defense. While food safety has been a predominant area of concern for export-oriented supply chains, it is increasingly important for issue affecting the competitiveness of domestic supply chains seeking to market food products to consumers concerned about the quality and safety of their food.

Urban food systems will need to pay attention to assessing food-borne hazards and safety issues in open markets (e.g. particularly for live animals), environmental contaminants in UPA (e.g. heavy metals) and in the growing food service and restaurant sectors, both formal and informal. Investments to ensure the availability of and access to clean water, electricity and sanitation represent a priority investment to improved food safety and hygiene.

Prioritizing areas on which to focus (e.g. regulation, investments)—which institutional and human capacities to develop and which partnerships to strengthen-will depend on an improved evidence base of the current food safety situation, identification of food system hazards and an evaluation process of food safety practices. Carrying out a food system food safety assessment (or supply chain audits) by utilizing FAO guidelines, for example, will be an important first step for many cities and countries to generate the requisite information to determine food safety interventions. ${ }^{283}$ Indeed, in order to bring about sustained food safety system investments, there is a need to strengthen the economic case for ongoing and substantive future expenditures across the public and private sectors. ${ }^{284}$

Strengthening capacity and systems for the rigorous application of food safety management (e.g. the ISO 22000, a standard developed by the International Organization for Standardization) is a whole- chain approach to food safety. It is not just for food processors, but goes all the way from the farm to the fork, including packaging and ingredient suppliers, caterers, storage and distribution facilities, and chemical and machinery manufacturers and it can be applied to primary producers such as farms. International Food Standard (IFS) is another rigorous international approach dealing with quality and food safety for retailer- (and wholesaler-) branded food products. ${ }^{285}$ Food safety management is also important for strengthening and enforcing regulations related to food adulteration and food fraud. Together these actions represent essential measures to gain consumer confidence and positively alter perceptions of product quality and safety and subsequently allow for greater competition in domestic, regional and international markets. Strengthening the functioning of collaborative mechanisms between food industry, 
government and civil society is a key step in the design and implementation of modernization programmes. ${ }^{286}$

Public-private collaboration to upgrade food labelling regulations represents another key area of work that is linked to effective food safety systems. The application of international standards for labelling is growing increasingly important considering the increasing consumption of processed and packaged foods. Traceability systems that follow the movement of a food through production, processing and distribution are extensively used by global food supply chains (e.g. GFSI). ${ }^{287}, 288$ While current food labelling procedures may not guarantee that food is authentic, of good quality, and safe, diverse traceability instruments (e.g. RFID, holograms, barcodes, chips) can contribute to better informed consumers and food system actors. However, traceability instruments can only succeed if they are built on global standards across the entire food supply chain, utilizing adaptive technologies, and there is communication between industry actors. ${ }^{289}$ Real-time, sophisticated technology-driven systems, however, may be too costly for many food system actors in low-income countries. Use of nanotechnology (e.g. colour changes in packaging to indicate spoiled food) may need to be better understood and assessed by countries to determine its future role and broad acceptance by consumers.

The conduct of food safety risk assessments (e.g. using WHO tools) provides a basis for cities or countries to judge the potential harm of food products to human health. ${ }^{290}$ Shanghai was the first municipality in China to conduct food risk assessments, beginning with the investigation of pesticide residue on farm produce and the use of illegal additives in local tonics. ${ }^{291}$ Shanghai has also been keen on spurring consumer-led advocacy on food safety issues, establishing a public hotline for food safety inquiries, violations and complaints, which generated over 90000 calls in 2015 .

\subsubsection{Food Safety and the Informal Sector}

Street food represents a growing part of urban food consumption-by some estimates, approximately 2.5 billion people, many of whom live in informal settlements, eat street food every day. ${ }^{292}$ Likewise, street food preparation and food vending provides a regular source of income for millions of men and women who generally have a low asset base and limited education or skills. ${ }^{293}$ While there is an obvious socio-economic importance of street food and the informal food economy, assuring safe and hygienic food is often a problem. ${ }^{294}$ In fact, most food-borne disease in low-income countries result from the consumption of perishable food sold in these informal markets. And foodborne illness is likely to increase as the result of massive increases in the consumption of at-risk foods such as livestock, dairy, fish products and relatively perishable produce. ${ }^{295}$ The improper use of additives such as colouring agents and preservatives, food adulteration, and exposure to other contaminants are additional street food hazards. ${ }^{296}$

Unclear government policy towards the informal sector often inhibits an effective regulatory environment to monitor and prevent food hazards. 
Policies on street vending and oversight of informal food preparation and retail outlets remain unclear and often contradictory. In some countries, street vending is defined as illegal but vendors must still pay taxes or be registered. Oftentimes, street vendors are forced to bear the extra expense of bribing local authorities just to remain in business. ${ }^{297}$

Furthermore, food safety hazards and practices within informal food marketing channels are not assessed on a regular basis, despite the great importance of these channels for the food supply to the poor and often to the more general population. Thus, while many policy-makers and other stakeholders in developing countries recognize that there are gaps and other shortcomings in prevailing food safety systems, less well understood are the socio-economic impacts of such system weaknesses-and, importantly, the size of the potential benefits from remedial or forward-looking investments.

Initiatives aimed at training informal value chain actors have achieved limited success, as many itinerant vendors receive little to no training in food hygiene or sanitation and must work under difficult and unsanitary conditions. Some local authorities have taken the initiative to improve street food vending. A South Africa Department of Health initiative developed an Informal Food Trading Programme to promote safe food handling among street food vendors, with an implementation strategy that included registering vendors and allocating sales space. ${ }^{298}$

In addition to clarifying government policy towards the informal sector, many of the suggested intervention issues mentioned in the preceding section on food safety standards and regulations will need to be examined through an informal food system lens, leading to a specific set of actions that target actors, their needs and threats to this important economic sector.

\subsubsection{Animal Health, Welfare and Food Safety}

Animal health is inextricably linked to animal welfare, as animals that are treated well are more resistant to diseases, and thus there is a lower risk of transmission to humans. Improvements in animal welfare have the potential to reduce stress-induced immunosuppression, the incidence of infectious disease on farms, the shedding of human pathogens by farm animals and the use of antibiotics. In addition, improving animal welfare is associated with better quality and higher returns for producers. ${ }^{299}$ The welfare of animals produced for food is also becoming increasingly viewed as an important ethical concern for consumers and actors throughout the food system.

Continued development of HACCP-based approaches to animal welfare could contribute to smoother integration of animal welfare and food safety standards. ${ }^{300,301}$ There is not, however, an internationally agreed upon standard for animal welfare schemes. The lack of standardization may hinder demand for and trade in products from animals reared per specified levels of welfare. Defining a credible best practice framework for animal welfare certification schemes represents an important first step that could benefit many 
countries. Schemes may aim to provide assurance on minimum levels of welfare or may aim to promote welfare improvement within their scheme membership. ${ }^{302}$

Animal diseases are also a threat to public health. Without proper handling during the rearing of livestock or proper handling of the products themselves, livestock-derived foods can pose huge risks to human health. Tuberculosis, rabies, brucellosis and Rift Valley Fever are just a few of the well-known infectious diseases sourced from animals. Globally, a mere 13 zoonotic diseases are responsible for 2.2 million human deaths and 2.4 billion illnesses each year. ${ }^{303}$ Strengthening the capacity and procedures of food safety institutions and personnel is hugely important in order to monitor and respond to zoonotic disease, including in live animal markets in urban areas.

The overuse of antibiotics as growth promoters in livestock production is an important factor in the acceleration of anti-microbial resistance (AMR). AMR occurs when microorganisms are exposed to antibiotics and other antimicrobial drugs often enough to become resistant to them. Approximately 75 percent of these antibiotics are excreted un-metabolized and dispersed into the environment. AMR is already having an impact on our ability to treat tuberculosis, malaria and other diseases in humans, and is increasingly viewed as a critical global threat to human health. As animal and human health are increasingly interconnected, food systems need to invest in strengthening collaborative multisector approaches for preventing, preparing for and responding to infectious disease. ${ }^{304}$

\subsubsection{Micro, Small and Medium Scale Enterprises (MSMEs) and Food Safety}

Challenges remain for small enterprises to ensure food safety, including being unable to pay the high compliance costs and ensuring that such costs do not mean that poor consumers will not be able to afford nutritious foods. Policies and programmes need to bolster food safety measures among MSMEs based on modern equipment, modern sanitation and refrigeration facilities, training on food safety and hygiene standards, and behavioural change. ${ }^{305}$ Cities or countries may also want to consider the establishment or strengthening of food science innovation labs to assist in product development, technology assessment, and training or technical assistance to MSMEs and food entrepreneurs challenged to develop solutions related to labelling, traceability and safe, more natural processing for nutritious, healthy, packaged food.

\subsubsection{Indicative Policy, Investment, Capacity and Knowledge Interventions by City Type}

Table 6.3 presents by city type a list of indicative interventions to support this third key area: nutritious, diverse, quality and safe food. Policy, investment and capacity-enhancing interventions may likely differ by city type. 
TABLE 6.3 Nutritious, Diverse, Quality and Safe Food: Indicative Policy, Investment, Capacity and Knowledge Interventions by City Type

\begin{tabular}{|c|c|c|c|}
\hline Base package & $\begin{array}{l}\text { C1: Agrocities: } \\
\text { Agriculture-based } \\
\text { towns or small cities } \\
\text { with under } 1 \text { million } \\
\text { inhabitants }\end{array}$ & $\begin{array}{l}\text { C3: Megacities } \\
\text { and } \\
\text { conurbations } \\
\text { with more } \\
\text { than } 10 \text { million } \\
\text { inhabitants }\end{array}$ & $\begin{array}{l}\text { Cn: Food-Smart } \\
\text { cities: Future cities } \\
\text { or neighbourhoods } \\
\text { yet to be built }\end{array}$ \\
\hline $\begin{array}{l}\text { - Food policy, plan and } \\
\text { review on nutrition } \\
\text { - } \text { Development of } \\
\text { dietary guidelines } \\
\text { - } \text { Development of } \\
\text { nutrition standards } \\
\text { - } \text { Development of food } \\
\text { safety institutions } \\
\text { and management } \\
\text { systems; update on } \\
\text { processes, norms } \\
\text { and standards; audits } \\
\text { performed } \\
\text { - Nutrition agenda for } \\
\text { street vendors } \\
\text { Municipal land access } \\
\text { for community/school } \\
\text { garden } \\
\text { - HPA support facility } \\
\text { Horticulture research }\end{array}$ & $\begin{array}{l}\text { Development } \\
\text { of peri-urban } \\
\text { production systems } \\
\text { - Nutritious food } \\
\text { programmes in } \\
\text { schools } \\
\text { - Provision of } \\
\text { affordable, healthy } \\
\text { food outlets in } \\
\text { low income and } \\
\text { underserved areas }\end{array}$ & $\begin{array}{l}\text { - Nutritious food programmes } \\
\text { agenda with restaurants, retail, } \\
\text { civil service and other innovative } \\
\text { partnerships } \\
\text { - UPA institutional support } \\
\text { mechanisms } \\
\text { - Treated wastewater/UPA } \\
\text { integration } \\
\text { - } \text { Affordable and healthy food } \\
\text { outlets in low-income and } \\
\text { underserved areas } \\
\text { - Prevention of overconcentration } \\
\text { of hot food takeaway shops, } \\
\text { fast-food eateries, liquor and } \\
\text { convenience stores in residential } \\
\text { areas and around schools and } \\
\text { youth facilities } \\
\text { Regulations on sugar, sodium } \\
\text { and fat content } \\
\text { Zoning/regulations on location of } \\
\text { fast food around schools, youth } \\
\text { facilities, etc. }\end{array}$ & $\begin{array}{l}\text { - Integrated UPA } \\
\text { development in new } \\
\text { housing and urban } \\
\text { settings } \\
\text { - Quality food } \\
\text { programmes in new } \\
\text { schools } \\
\text { - Provision of healthy } \\
\text { foods promoted at } \\
\text { supermarkets, small } \\
\text { grocery stores and } \\
\text { restaurants } \\
\text { Agro-enterprises } \\
\text { in the region } \\
\text { stimulated to } \\
\text { improve the } \\
\text { nutritious quality of } \\
\text { the food products } \\
\text { they provide }\end{array}$ \\
\hline \multicolumn{4}{|c|}{$\begin{array}{l}\text { Critical inputs and policy from other sectors required for interventions to be effective: } \\
\text { - Health policy and standards development } \\
\text { - Education policy and curricula development } \\
\text { - Water, sanitation, and housing services enhanced } \\
\text { - Communication policy (e.g. television, radio) } \\
\text { - Social and community affairs considered }\end{array}$} \\
\hline
\end{tabular}

\subsection{S: Sustainable, Resilient Agriculture and Food Systems}

Every food system function-whether production, processing, packaging, refrigeration, transport, preparation or distribution - can and must significantly reduce its carbon footprint through adoption of new and improved methods, innovations and technologies. Unsustainable practices can lead to deleterious impacts arising from biodiversity and habitat loss, soil erosion and degradation, water, soil and air pollution and wasteful resource consumption-natural or human-induced. Informed decisions on potential incentives and regulations for new technologies will require more detailed information on food products' carbon footprints and technology assessments including feasibility and cost-benefit analyses. Carbon labelling on food products and considerable education would give consumers the market power to decide on better products and production processes. Some type of environmental cost-based pricing, in which market prices include environmental costs and benefits, represents an option, but implications, especially for the poor consumers, must be properly addressed. 


\subsubsection{Environmental Challenges and Climate Change}

Environmental and climate change-related challenges are complex. However, the ways in which cities influence and are influenced by environmental vagaries and climate change are relatively less explored. ${ }^{306}$ Municipalities will need to strengthen urban food systems' resilience to the rising frequency of diverse agroclimatic and associated socio-economic shocks and sustainably manage the risks arising from extreme weather phenomena. While cities cover only 2 percent of global land area, they account for 70 percent of GHG emissions. ${ }^{307}$ Urban carbon dioxide $\left(\mathrm{CO}_{2}\right)$ emissions depend on several factors such as geographic location, population size, density, urban economy and residents' consumption patterns. GHG emissions occur at every stage of the food system-and to better estimate food system emissions, disaggregated data analysis needs to be undertaken. ${ }^{308}$

Urban areas are exposed to multiple effects of climate change, including higher temperatures, rising sea levels, rainfall variability, and more frequent and severe floods, droughts, storms and heat waves. Approximately 360 million urban residents live in coastal areas less than 10 metres above sea level, with 78 million of these living in China alone. ${ }^{309}$ Climate change is also aggravating the urban heat island effect-the increase in daily mean temperature in built-up areas. This effect results in higher energy demand for cooling, impairs air and water quality and worsens public health. The urban poor are disproportionately affected by both extreme weather events, such as droughts and floods, and by climate change in general, as they often live in informal settlements on steep hillsides, in low-lying coastal zones, or in poorly drained areas. UN Habitat counts 3351 cities with such areas worldwide, 64 percent of which are in low-income countries. ${ }^{310}$ In addition to living in vulnerable areas, the urban poor are especially vulnerable to natural disasters due to their weak adaptive and coping capacities stemming from malnutrition, poor health or poor access to water and sanitation. ${ }^{311}$

Climate and environmental impacts are important criteria to consider in policy, regulatory, and investment decision-making related to both short and long supply chains and to e-commerce; individualized delivery models in e-retail must be assessed for climate and congestion impacts. Public, private sector and civil society partnerships can help craft appropriate policies and regulations that could include zoning and opening hours, sourcing requirements, and food waste and environmental standards. ${ }^{312}$

\subsubsection{Non-Linear Resource Flows}

A "circular economy," "closed loop" production in food systems, and an enhanced "food-energy-water nexus" in the agrifood systems space provide opportunities for climate-smart and innovative solutions (Figure 6.2). ${ }^{313,314}$ Urban areas worldwide face multiple environmental challenges, with a key one being the transition from a linear to a circular model of resource flow. Traditional farming tends to rely on practices that capture and recycle wastes such as livestock manure, crop residues, and wastewater, enabling a "circular" flow of resources. A more modern rendition in the form of "closed loop" 
farming (e.g., widely being practiced in Ireland) is based on the principles of capturing and recycling nutrients and organic matter, deploying this back into the soil for maintaining nitrogen and carbon levels in the soil as the basis for sustainable farming. These same principles can be applied to urban food systems.

Many modern cities tend to exhibit a more linear resource flow, in which refuse, wastewater, and sewage are discarded in landfills and waterbodies rather than captured and reused. ${ }^{315}$ Localized water sources such as groundwater, urban drains, streams, or wastewater in cities of low- to medium-income countries are often severely contaminated due to the concentration of settlement with rudimentary sanitation services and unregulated industrial effluents. ${ }^{316}$ As urban and peri-urban farmers often irrigate their plants from untreated municipal sewage, health risks for both farmers and consumers increase substantially. ${ }^{317}$

Industrial and commercial solid wastes can be extremely hazardous to the environment and human health, leaching toxic chemicals into surface and groundwater through runoff. ${ }^{318}$ Given the rapid urbanization, environmental threats and climate change-driven resource scarcity expected to occur going forward, agriculture and the agrifood system will need to adopt innovative approaches and technologies to capture and reuse wastes efficiently.

When handled with care, the productive reuse of urban organic wastes as compost or for thermal energy production for production, storage or processing functions, as well as of wastewater for irrigation, reduces methane emissions from landfills and energy use in fertilizer production. ${ }^{319}$ Composted organic waste allows the urban farmer to reduce fertilizer application and prevent problems related to the contamination of groundwater. Diverting storm water to urban agricultural systems through rainwater harvesting can be another efficient source of irrigation. ${ }^{320}$ Urban agriculture can hence enable synergic and cyclical processes between urban domestic and industrial sectors, as well as agriculture with multiple economic and environmental benefits. ${ }^{321}$ The European Union could save an estimated US\$520-630 billion per year under an advanced circular economy scenario in which all net materials are reused. ${ }^{322}$

An enabling policy environment to guide and incentivize a circular or closed loop urban economy will play a critical role in attaining food security and environmental and resource sustainability. Key intervention options include the development and dissemination of knowledge products and tools for urban waste reuse across actors and sectors; integrated waste and wastewater management at the municipal level based on participatory governance, cost-benefit analyses, and environmental risk assessments; new financing arrangements such as PPPs; and strengthened water quality and waste disposal regulations. ${ }^{323}$

The "food-energy-water nexus" is another climate-smart and innovative approach that governments and other actors are taking (See Figure 6.3). Although urban food, energy and water have long been studied and managed as independent sectors, a range of approaches are now available that capitalize on linkages among them within an interlinked ecosystem. ${ }^{324}$ When applied to specific situations and problems, such an approach helps to understand and identify the tradeoffs and synergies in the key interactions between 


\section{FIGURE 6.3 Food-Water-Energy Nexus}

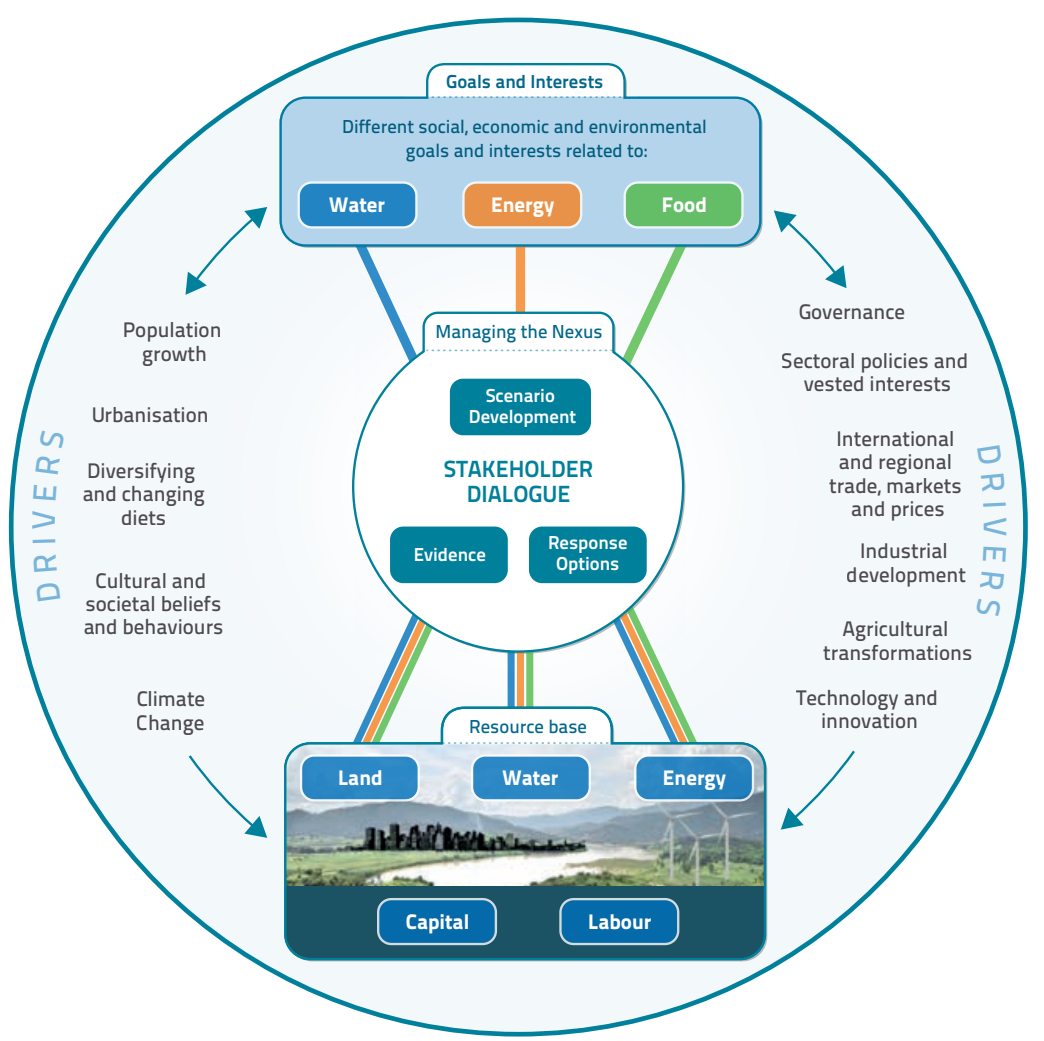

Source: FAO (Food and Agriculture Organization of the United Nations). Water-Energy-Food-Nexus. Accessed June 1, 2017. http://www.fao.org/energy/water-foodenergy-nexus/en/.

food-energy-water systems, assessing technology programme and policy options in terms of their resource use and opportunities for improved environmental, social and economic sustainability.

Implementing a nexus type of assessment requires collaboration among many stakeholders and a strong political economy orientation to understand diverse stakeholder interests and constraints. It may help diverse stakeholders

\section{BOX 6.8 Ireland's Origin Green}

A shining example of a successful effort in this regard is offered by Ireland's Origin Green. Globally, it is the only sustainability program operating "on a national scale, uniting government, the private sector and food producers through Bord Bia, the Irish Food Board", and working with Ireland's farmers and producers to set and achieve measurable sustainability targets_-reducing environmental impact, serving local communities more effectively and protecting Ireland's natural resource base.

Source: Origin Green. 2016. Sustainability report. Accessed June 1, 2017. https://www.origingreen.ie/ sustainabilityreport2016/. 
to see how innovative collaboration can lead to better resource use across activities and sectors. Applied to urban food contexts, a nexus approach may help municipalities and metropolitan districts to identify opportunities for clustering services (e.g. energy, water, food processing) in each area to maximize resource use and enhance sustainability.

\subsubsection{Closed Loop Food System Practices}

Well-planned and executed urban agriculture and agrifood systems can significantly contribute to environmental health and biodiversity conservation, adapting to and even mitigating climate change risks and impacts. Systems such as community farms or gardens and "circular economy" or "closed loop" food system practices can help clean and green cities-for example, by turning vacant or derelict land and cleaned brownfields into green space and safely redeploying organic waste and effluent matter to fuel various aspects of the supply chain. Moreover, UPA provides fresh food close to consumers, thereby reducing energy costs and GHG emissions from transport, cooling or packaging. This benefits the urban microclimate through temperature regulation, higher evapotranspiration, and the provision of shade. ${ }^{325}$ In consequence, the urban heat island effect can be reduced and dust and $\mathrm{CO}_{2}$ can be captured. ${ }^{326}$

As highly managed plant communities, urban agricultural systems can exhibit high biodiversity levels, often exceeding those of other urban green space areas. ${ }^{327}$ In many industrial countries where agricultural land is intensively farmed and agrobiodiversity has drastically declined in consequence, urban areas and agricultural systems can serve as "biodiversity hotspots." ${ }^{328}$ In open green spaces in and around urban areas, food production can be combined with other services like agrotourism or ecological education for children, thereby enhancing people's quality of life and environmental awareness. ${ }^{329}$ Fruit and multipurpose tree plantations (such as citrus or date palms) in and around cities sequester carbon and provide fuelwood, fruits, flowers and other products-enhancing urban food security and biodiversity. ${ }^{330}$ As discussed in other sections, land use planning and management, zoning and property rights are critical issues affecting the ability to implement such interventions. Assuring a certain level of flexibility in future urban plans is important for the development of future urban food systems and cityscapes, particularly with respect to the provision of public space required for these public good investments in the years ahead.

\subsubsection{The Rise of Urban Forests}

Urban forests will play a key role in protecting cities' natural resource base and mitigating diverse effects of climate change. Emerging experiences highlight the positive effect of forests in terms of protecting land and water supply, acting as natural infrastructure to protect soils and absorb rainwater, conserving biodiversity through the creation of green corridors, preventing landslides, mitigating adverse impacts of extreme weather and fighting climate change..$^{331}$ Strategic planting of trees can cool cities by $2^{\circ} \mathrm{C}$ to $8^{\circ} \mathrm{C}$ in addition to helping to filter pollutants and regulate water flow. ${ }^{332}$ Green belt plantations and urban 
forestry on hillsides or surrounding cities, coupled with sustainable practices, can play a vital role in protecting gardens and infrastructure against winds, water runoff and sand encroachment. ${ }^{333}$ They also contribute to attractive living environments and outdoor recreation needs for urban populations.

Numerous cities are green innovators, designing and implementing unique solutions in their urban spaces. They include Milan, Italy, with its vertical forests; Singapore's cooled conservatories and gardens; Manila, in the Philippines, which has established miniature parks along crossroads, railways and old industrial areas; and numerous cities in Latin America and China that have created green belts, comprising forest, agriculture and public exercise space in their urban periphery. Many of these investments are critical to the restoration of the environment and protection of water systems.

China has begun to construct new towns around existing vegetation ${ }^{334}$ and instituted a national forest city scheme that certifies cites as national forest cities, recognizing that forests add to the quality of urban life and attract business.

\subsubsection{Indicative Policy, Investment, Capacity and Knowledge Interventions by City Type}

Table 6.4 presents, by city type, a list of indicative interventions to support this fourth key area: sustainable, resilient agriculture and food systems. Policy, investment and capacity-enhancing interventions may likely differ by city type.

\section{TABLE 6.4 Sustainable, Resilient Agriculture and Food Systems: Indicative Policy,} Investment, Capacity and Knowledge Interventions by City Type

\begin{tabular}{|c|c|c|c|c|}
\hline Base package & $\begin{array}{l}\text { C1: Agrocities: } \\
\text { Agriculture-based } \\
\text { towns or small } \\
\text { cities with under } 1 \\
\text { million inhabitants }\end{array}$ & $\begin{array}{l}\text { C2: Growing } \\
\text { secondary } \\
\text { cities of } \\
1-10 \text { million } \\
\text { inhabitants }\end{array}$ & $\begin{array}{l}\text { C3: Megacities } \\
\text { and } \\
\text { conurbations } \\
\text { with more } \\
\text { than } 10 \text { million } \\
\text { inhabitants }\end{array}$ & $\begin{array}{l}\text { Cn: Food-Smart } \\
\text { cities: Future cities or } \\
\text { neighbourhoods yet to } \\
\text { be built }\end{array}$ \\
\hline $\begin{array}{l}\text { - Food system } \\
\text { resilience, } \\
\text { vulnerability and } \\
\text { climate footprint } \\
\text { assessment } \\
\text { - Land use/zoning } \\
\text { measures for UPA } \\
\text { - Forest policy and } \\
\text { - } \text { scheme } \\
\text { Emission auditing } \\
\text { and reporting } \\
\text { - Treated wastewater/ } \\
\text { UPA integration }\end{array}$ & $\begin{array}{l}\text { - Sustainable land } \\
\text { use planning and } \\
\text { protection } \\
\text { - } \text { Resource recycling } \\
\text { - } \text { Regulations and } \\
\text { incentives to } \\
\text { stimulate recovery } \\
\text { and agricultural } \\
\text { reuse of nutrients } \\
\text { and irrigation } \\
\text { water from urban } \\
\text { organic wastes } \\
\text { and wastewater }\end{array}$ & \multicolumn{2}{|c|}{$\begin{array}{l}\text { - } \text { Multi-use urban green belts } \\
\text { governance (greening the } \\
\text { supply chain, decreasing GHG } \\
\text { emissions) } \\
\text { - Regulations/incentives to } \\
\text { stimulate recovery and reuse } \\
\text { of nutrients and irrigation from } \\
\text { urban organic wastes and } \\
\text { wastewater } \\
\text { - Support for decrease of } \\
\text { GHG emissions related to } \\
\text { food production, processing, } \\
\text { distribution, consumption and } \\
\text { food waste management in } \\
\text { the city region }\end{array}$} & $\begin{array}{l}\text { - Closed loop food system } \\
\text { - Green infrastructure } \\
\text { - Waste/water/energy } \\
\text { efficiencies at scale } \\
\text { - Integrated green housing } \\
\text { developments }\end{array}$ \\
\hline
\end{tabular}

Critical inputs and policy from other sectors required for interventions to be effective:

- Land policy

- Energy policy

- Forestry policy

- Sanitation and water services enhanced

- Emergency preparedness 



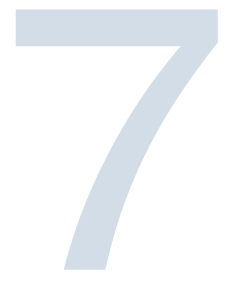

\section{Moving Forward in Support of Urban Food}

\section{Key Messages}

- A number of potential institutional or programmatic entry points exist for initiating work on food system issues, appealing to different clients, offering diverse opportunities to access financial resources and requiring flexibility in response.

- Strengthening institutional mechanisms and incentives is critical for implementing collaborative approaches and multisector programmes and projects, and constituting a critical mass of diverse, experienced professionals and practitioners.

- A future agenda will include: development of an operational toolkit; immediate technical assistance to advance work in the key intervention areas; peer learning for city and country practitioners, leading to a more solid experiential knowledge base; and demand-driven analytical work to assist in project formulation and strengthen advisory services.

- The time is ripe to strengthen engagement on urban food issues. Diverse partnership with city networks, experienced technical partners and diverse private sector and civil society actors can help to advance a transformative, pragmatic food system agenda that is consistent with SDG and World Bank goals.

The issue of how to nourish growing urban populations in the future transcends food and agriculture issues and challenges municipal, district and national governments in four ways: 1) How to foster inclusive economic growth and jobs for youth; 2) How to contribute to improved nutrition and better health for citizens; 3 ) How the growing numbers of urban poor will gain access to food; and 4) How to address multiple manifestations of climate change and become more resilient to the growing number of shocks and extreme weather events. 
This report has presented a narrative and an emerging body of evidence that highlights the centrality of food to the future of cities, countries and the planet-to jobs, human health, food security and climate change. First, regardless of a country's economic development and income level, the food and beverage sector is the largest and most stable source of employment and value-added manufacturing in many countries in the world. The agrifood system is also one of the largest economic sectors in most countries, providing markets for thousands of small- and medium-scale food businesses and service sector jobs for many. Second, an overwhelming number of medical studies conclude that current food consumption trends are bad for people's health. Six of the top 11 risk factors driving the global burden of disease are related to diet. Third, while economic growth has contributed to a growing middle class, rising rates of urbanization and income inequality are contributing to the growth of urban food insecurity and of the urban poor, for whom food access is already problematic and regularly challenged by the next shock. Finally, agriculture and land use changes currently account for 30 percent of global GHG emissions, projected to rise to 70 percent of global GHG emissions under a business-as-usual scenario, largely fueled by diversifying diets and the consumption of animal proteins, for which demand is increasing throughout the world. The growing consumption of processed food and FAFH also increases the food system's climate footprint. The food we eat is not climate-neutral.

The evidence points to both the positive and the negative influences that the current food system has on our lives and the imperative to address the critical issues of Remunerative jobs and better agribusinesses; Affordability and accessibility for food security; Nutritious, diverse, quality and safe food; and Sustainable, resilient agriculture and food systems. Together, the TRANSFORM framework's outcome areas represent the foundation for developing foodsmart cities and can be viewed as goalposts used to achieve poverty reduction and shared prosperity. Achieving these goals will depend on a set of enabling conditions, the most important being a transformation in the institutions for addressing food issues in cities and metropolitan districts.

This final chapter provides a brief recap of the salient findings of the report. It discusses how the TRANSFORM framework could be used in the programme planning and prioritization process. It then segues into a discussion of the way forward including: potential entry points; options and elements of a programmatic approach; potential financial instruments; suggestions on partnership and institutional evolution; and finally, how data, analysis and knowledge are integrated in an operationally oriented phase.

\subsection{A Brief Recap}

To start, this report used a global perspective to examine the trends and driving forces that will shape the food environment, as well as to define the challenges we face today and tomorrow, but it also offered opportunities and options for food systems in the future. Some of the driving forces include: 
- Rapidly growing cities, particularly in Asia and Africa;

- Large numbers of young people looking for jobs;

- Strong food processing value addition and employment for countries at all income levels;

- Increasing competition for land, water and energy;

- Widening income inequality as the numbers of both the middle class and the urban poor rise;

- People eating more diverse diets, processed food and more food outside the home;

- Diets that contribute to the growing prevalence of overweight, obesity, and non-communicable diseases like diabetes and thus to rising health care costs;

- An increasing number of agroclimatic and socio-economic shocks;

- Rapid technological change providing opportunities but requiring capacity and a supportive environment;

- A growing localization of development with a multitude of civil society stakeholders, empowered by instantaneous information flow through social media.

The report identified three overlapping and rapidly evolving segments or channels of the food system: a traditional system featuring urban wholesale markets, open or wet retail markets and small, independent (family-run) retail stores; an informal channel that caters to the urban poor through the use of informal food vendors and restaurants and a variety of formal and informal safety nets; and a modern channel characterized by modernized wholesale and food safety systems, capital-intensive food processing, integrated cold chains and food service firms, state of the art logistics, private branding, labelling and packaging, and modern retail and restaurants.

Urban food systems are challenged to modernize in ways that support consumers' continued preference for open markets, small retail stores, informal vendors and the integration of modern retail and e-commerce into the shopping experience. Investment, updated policy frameworks and institutional reorganization are needed to modernize and transform current critical food systems functions into more competitive and resource-efficient (with low GHG emissions) functions. They include wholesale systems, market information and intelligence, food safety, cold chains, transport and logistics, processing, and waste reuse. Sourcing food from rural production areas and using imports and UPA can strengthen food security and resilience to potential shocks.

The report proposes a preliminary city typology, comprising small cities and towns with under 1 million inhabitants; medium and large secondary cities with 1 to 10 million inhabitants; megacities and conurbations with more than 10 million inhabitants; and Future Cities and new neighbourhoods. We know that the structure and conduct of food systems are strongly influenced by city size and density in addition to the specific characteristics of the food system, including the relative importance of different food subsystems or marketing channels. As the knowledge base is improved, a revised, more nuanced typology will be able to contribute to orienting policy, programmatic 
and investment interventions to the specific socio-economic, demographic and food system characteristics of the city.

Most of the interest in and political momentum for an urban food agenda has occurred, to date, with mayors, city councils and civil society actors at the municipal and metropolitan district level. Given the rapid growth and expansion of cities beyond traditional municipal boundaries, as well as the importance of peri-urban and surrounding rural areas to urban food issues (as articulated in city-region approaches), decision-making at the metropolitan district level (comprising multiple cities, towns or suburbs) will become increasingly important. Yet while municipal and district authorities will likely continue to lead urban food efforts, the determination of the most appropriate level of governance and intervention (e.g. municipal, metropolitan district, national, regional, global) will remain an important question for decision-makers as they engage in these issues.

Stewarding these changes in the evolving urban food space will require significant institutional transformation, creativity and enabling conditions, as set out in the TRANSFORM framework, to address barriers and entrenched interests. Food issues have largely been handled by agriculture ministries, oriented on rural production issues. This report highlights the important roles and contributions of multiple sectors and actors. Stronger roles for municipal and metropolitan governments may augur well for pragmatic, problem-solving approaches that draw the requisite sector expertise and contributions to urban food interventions, most which will be implemented by private sector and civil society actors. National-level ministries may need to consider transformative reforms to more effectively contribute to emerging municipal agendas. Strong governance mechanisms that institutionalize broad stakeholder participation in the prioritization, oversight and accountability of interventions are key to achieving demonstrable results. To better highlight the roles and contributions that multiple sectors and actors can play in delivering on the outcome areas beyond agriculture ministries, Annex 8.1 provides an overview of indicative policy and action points that each sector or actor can utilize to address each outcome area against the backdrop of the enabling conditions. It is important to underline, however, the importance of collaboration and partnership between public, private and civil society actors in many actions, as each stakeholder makes important contributions needed to achieve outcomes.

Four broad programme intervention areas are proposed as an approach to position future food systems to achieve the interlinked outcomes:

- Remunerative jobs and better agrifood businesses

- Affordability and accessibility for food security

- Nutritious, diverse, quality and safe food

- Sustainable, resilient agriculture and food systems

The tables presented by intervention area in Chapter 6 suggest a set of indicative actions for addressing issues and problems within this broad area of urban food. Both a base package of interventions that will be relevant to most cities as well as an indicative set of actions for specific types of cities (i.e. 
the city typology) are proposed. Given the relative newness of the field and the weak analytical and evidence base, these broad intervention areas will naturally need to be refined and improved as additional information is collected, analysis is carried out, and governments and stakeholders are consulted. More in-depth city, country or regional analyses based on empirically driven, primary data collection will be essential to the design and formulation of future interventions.

As articulated in the TRANSFORM framework, future urban food systems need to evolve and be strengthened to achieve results in the set of four interlinked outcome areas supported by the enabling conditions. As governments and diverse stakeholders come together to develop programmes and prioritize actions to address particular problems and achieve the TRANSFORM outcomes that are in line with a vision of a food-smart city, it will be increasingly important to realize that there are multiple angles, entry points and opportunities for addressing aspects of a problem; there is not one silver bullet, one sector, one programme or one level of government to address an issue and attain results. It is also neither a linear process nor a one action-one outcome process; a given intervention can contribute to multiple outcome areas within the TRANSFORM framework.

\subsection{Indicative Policy and Programme Entry Points}

At this stage of development of urban food programmes, prior to the creation of new business lines and corresponding programmes of work, it will be important to maintain a certain degree of flexibility and agility in responding to potential requests for support and assistance, each involving different entry points, programmatic focus and clients.

The city networks that have begun to engage in diverse food system issues, have emphasized the need for technical assistance to municipalities and metropolitan districts, supported by peer learning from existing interventions and programmes already underway. ${ }^{335}$ Responsiveness to the demand and requests from diverse government decision-makers represents a key premise in nascent programme development. Any initiative will also require strong and sustained leadership from informed decision-makers, whether they are dynamic mayors, municipal councils and/or civil society organizations at municipal or metropolitan district levels.

Table 7.1 presents a list of potential institutional or programmatic entry points for initiating work on urban food system issues. It describes various types of interventions and the primary clients who could be interested in leading this work. Each entry point and programme or project approach will offer different opportunities for mobilizing and accessing financial resources. (See Annex 8.2 for additional information on operationalizing food system work).

Municipal and metropolitan district governments may initially be interested in establishing or strengthening the institutional and governance architecture for food system interventions, as presented in the discussion on enabling conditions. This initial work would serve as the basis for a comprehensive urban food 
TABLE 7.1 Urban Food Entry Points by Intervention Type and Main Client/partner

\begin{tabular}{|c|c|c|}
\hline Intervention Type & Description & Institutional client \\
\hline Municipal food programme & $\begin{array}{l}\text { Develop/strengthen urban food component, } \\
\text { initially with focus on institutions and } \\
\text { governance and public finance. }\end{array}$ & $\begin{array}{l}\text { - } \text { Cities } \\
\text { - Civil society }\end{array}$ \\
\hline $\begin{array}{l}\text { Urban component of rural food/ } \\
\text { agriculture project }\end{array}$ & $\begin{array}{l}\text { Upgrade food systems in small agriculture- } \\
\text { based cities and towns as part of rural } \\
\text { agriculture projects to strengthen market } \\
\text { access and develop agro-industries close to } \\
\text { production. }\end{array}$ & $\begin{array}{l}\text { - Small agriculture towns and } \\
\text { cities } \\
\text { - Provincial government }\end{array}$ \\
\hline $\begin{array}{l}\text { Food component of urban } \\
\text { development programme }\end{array}$ & $\begin{array}{l}\text { Develop urban food component within new } \\
\text { or ongoing urban development programme, } \\
\text { focused on food institutions and responsive } \\
\text { to city priorities. }\end{array}$ & $\begin{array}{l}\text { - Cities } \\
\text { - Civil society }\end{array}$ \\
\hline National food policy project & $\begin{array}{l}\text { Conduct analysis and advisory work with } \\
\text { national institutions reviewing and upgrading } \\
\text { national agriculture and food policy or } \\
\text { national food security strategy, to include } \\
\text { urban food dimension. }\end{array}$ & $\begin{array}{l}\text { - } \text { Ministry of Agriculture } \\
\text { - } \text { Food Security Secretariat } \\
\text { - Prime Minister or } \\
\text { Presidential Commission }\end{array}$ \\
\hline Agriculture project & $\begin{array}{l}\text { Collaborate with Ministry of Agriculture to } \\
\text { develop/strengthen urban food component, } \\
\text { focused primarily on UPA, water and } \\
\text { environment. }\end{array}$ & $\begin{array}{l}\text { - Ministries of Agriculture, } \\
\text { Environment, Water } \\
\text { - Cities }\end{array}$ \\
\hline Private sector programmes & $\begin{array}{l}\text { Develop programmes and PPPs in response } \\
\text { to priority focus of private sector groups: } \\
\text { SMEs, jobs, skills, market intelligence. }\end{array}$ & $\begin{array}{l}\text { - Food industry groups } \\
\text { - Chambers of commerce } \\
\text { - PPPs }\end{array}$ \\
\hline $\begin{array}{l}\text { Food-specific projects } \\
\text { - Food safety } \\
\text { - FLW } \\
\text { - Markets } \\
\text { - Nutrition } \\
\text { - Resilience } \\
\text { - Food security } \\
\text { - Climate footprint }\end{array}$ & $\begin{array}{l}\text { Develop projects to address specific } \\
\text { priorities within the proposed intervention } \\
\text { areas (Chapter 6). }\end{array}$ & $\begin{array}{l}\text { - Cities } \\
\text { Diverse Ministries including } \\
\text { Agriculture, Health, } \\
\text { Commerce, Livestock, } \\
\text { Sanitation, Energy, Climate, } \\
\text { Education, Interior. }\end{array}$ \\
\hline $\begin{array}{l}\text { Sector-led projects } \\
\text { - Nutritious food and health } \\
\text { - SMEs/food entrepreneurs/jobs } \\
\text { - Markets and transport } \\
\text { - Waste, water, energy and UPA } \\
\text { - } \quad \text { Displaced people } \\
\text { - Food-friendly housing }\end{array}$ & $\begin{array}{l}\text { Develop projects in other sectors to address } \\
\text { specific urban food-related issues (Chapter } \\
\text { 6). }\end{array}$ & $\begin{array}{l}\text { - } \text { Cities } \\
\text { Diverse Ministries including } \\
\text { Health, Commerce, Labour, } \\
\text { Education, Transport, Public } \\
\text { works, Health, Environment, } \\
\text { Interior, Social Affairs, Urban } \\
\text { Devt., Housing. }\end{array}$ \\
\hline & & \\
\hline
\end{tabular}

programme at the decentralized level. Cities may also be interested in including a food system perspective or programme component in a larger urban development programme. It may be necessary to revisit the adequacy of existing lending instruments needed to support this emerging urban food agenda where municipal and metropolitan district governments are taking the lead.

Agriculture ministries or related projects may be interested in: 1) an urban component to a programme or project centred on market access or value addition, logically leading to interventions in smaller agriculture-oriented cities and towns; or 2) the development or strengthening of an urban and 
peri-urban production programme, probably in collaboration with Ministries of Environment and Water.

National governments, whether in Ministries of Agriculture, Food Security Secretariats or at a higher policy level, may wish to upgrade national food strategies, policies and plans, requiring assistance to effectively incorporate the urban food dimension into new frameworks.

Private sector programmes that support agrifood SMEs, entrepreneurship or financing for urban-based interventions offer many ways to contribute to a food system agenda. In addition to launching new programme initiatives in these areas, there is equal space for contributing to existing programmes, whether through a food dimension to be added to an urban programme or an urban food dimension added to an existing agriculture programme.

Finally, there are a myriad of potential sector entry points for action, whether food-specific or approached from another sector perspective. For example, health sector programmes centred on overweight/obesity or micronutrient deficiencies could integrate some of the food system interventions presented in the following chapter into an existing or new programme or project. Irrespective of the entry point, lead institution or actor, it is important to underscore, once again, the multisector nature of food system issues, and the critical importance of inputs from different sectors.

Although each of these potential programmatic entry points will naturally be shaped by the perspectives and interests of the lead client and the specific programme or project goals, it is important that future work is equally infused with a systems perspective afforded by the interlinked outcome areas articulated in the TRANSFORM framework.

\subsubsection{Incentives for Multisector Approaches}

Strengthening institutional mechanisms and incentives is critical for implementing collaborative approaches and multisector programmes and projects. It is an equally important issue for governments and partner institutions that support them, since it is the institutional incentives and human resource protocols that will determine the feasibility of designing and implementing multisector approaches to address the diverse number of issues related to urban food systems. This issue is particularly important given the lack of a critical mass of experienced professionals to work on these issues. In addition to identifying innovative incentives to reward professionals for multisector collaboration, government and partner institutions alike will need to develop creative ways (e.g. secondments, private and civil society collaboration) for bringing in seasoned professionals and practitioners from diverse backgrounds to infuse programmes with dynamism and the requisite level of competence and experience. Diverse types of partnerships also provide opportunities to benefit from technical skills (e.g. architects) and different perspectives (e.g. civil society urban poverty organizers).

As many of the intervention areas identified in this report will undoubtedly involve contentious issues for which there are different views and interests, it will be important to invest sufficient time to strengthen stakeholder 
awareness and knowledge, to fortify the social capital that will bind stakeholders together and subsequently to develop a common discourse and a consensus vision for moving forward. Working initially on participatory, multistakeholder activities such as joint assessments or developing foodbased dietary guidelines or a food system human resource and skills development plan can achieve two aims. They clarify the goals and basis for future action as well as bind people together through shared experience, forming alliances needed to sustain the process as it moves forward.

\subsection{Next Steps in the Process}

Irrespective of the type of entry point, the level of intervention (i.e. municipal, metropolitan district, national) or the sectors, actors or institutions involved, an agenda to transform food systems for the future will require: 1) more immediate guidance for advancing work in the key intervention areas; 2) greater peer learning through consultation between city and country practitioners, leading to a more solid experiential knowledge base; and 3) demanddriven analytical work that responds to priorities. Technical advisory services, policy analysis work and investment project design to support future food system interventions will all require further guidance and a stronger empirical basis. As is evident in the large number of examples presented in this paper, future food systems work will need to be driven by a diffuse, experiential knowledge agenda in which policy and programme practitioners and private sector and civil society actors contribute more systematically to knowledge generation and reciprocally use it to advance their work.

\subsubsection{Development of a Food System Toolkit}

Towards this goal, the ongoing development of a toolkit will help to guide the delivery of these technical services. The toolkit is envisioned as a living document, building on existing knowledge, updated regularly, with modules emulating this knowledge product's content in a roadmap-like structure, focusing especially on the TRANSFORM framework, with additional modules covering other prerequisite diagnostic assessments. Foremost among the toolkit instruments is an urban food assessment methodology to assist governments and stakeholders in an initial food system diagnosis. A second tool under development consists of an instrument to conduct an urban food poverty assessment that will be used to contribute to an urban poverty and food security profile. A third tool consists of a results and indicator framework and guidance on using diverse data collection systems (including Big Data approaches) for monitoring food system interventions. Other more technical guideline instruments, such as costing and financial analysis of indicative food system interventions, will need to be scheduled and prepared. Among the TRANSFORM framework issues, the module for the institution and governance dimension of urban food systems will be based on other cities' experiences. Likewise, roadmap-like modular guidance will be provided for the other framework aspects. 


\subsubsection{Experiential Learning and City-to-City Exchanges}

Project work will need to be supported by a knowledge agenda driven by experiential learning from cities that have advanced in the design and implementation of food system interventions. Understanding how municipalities and metropolitan districts have strengthened the enabling conditions and addressed the institutional and governance challenges represents an important issue that peer learning approaches can address. Strong partnership with dynamic, global, city-to-city networks and South-South cooperation frameworks and their technical partners will help to ensure continuity, coherence and a demand-driven focus for this empirical learning process.

Although a global learning approach seems to be the most appropriate level for guiding the early stages of this agenda, it will be equally important for regional approaches to focus on analysis and learning about the regional context and particularities of their food systems. As countries within regional groups may share a similar institutional culture in their government institutions and processes, in addition to how their food systems are structured and perform, it may be advantageous to address these issues at a regional level.

Contrary to many other issues addressed in the World Bank, urban food affects almost all cities-rich or poor, large or small. Strengthening information flows, communication and peer learning in decentralized South-South, South-North and East-West networks has the potential to speed up the design and delivery of effective interventions and processes.

\subsubsection{Demand-Driven Analysis}

While many countries and cities wish to receive technical support, policy assistance and investment in a more operationally oriented approach, it is also evident from this report that there is a dearth of data, rigorous analytics and knowledge on the variety of food systems presented in this document. Advancing the urban food agenda towards a more refined operational footing will require a stronger evidence base upon which to design and implement project and programme actions. Strengthening this base and filling the gaps could take place through a two-pronged urban food data, analysis and knowledge agenda consisting of complementary short- and long-term components that concurrently advance low-risk, proven interventions and produce the more detailed information needed for more complex policy and investment actions. In this way, information advances design and implementation without creating a barrier to immediate action.

The short-term data and analytical focus should be centred on what is required to formulate financially, technically and socially valid projects. For example, developing sound urban horticulture projects to produce affordable and nutritious fruits and vegetables needs more detailed information on the agronomics, economics and resource footprints of different production systems. The currently available data are largely based on high-resource systems in high-income countries and largely anecdotal information for other parts of the world.

Medium-term analytical work at country level could also include self-standing spatial food systems diagnostics, country profiles, inclusion in systematic 
country diagnoses and country programming frameworks, and impact evaluations for specific country issues as well as specific components within existing exercises (e.g. urbanization reviews, city development strategies). Specific sector work also provides diverse opportunities for inclusion of a food dimension (e.g. green cities, connecting urban and peri-urban areas, municipal development, infrastructure, land markets, fiscal issues, the urban poor, innovative financing for food systems, spatial food systems metrics). Analytical results could be used to strengthen diverse advisory services such as for food systems curriculum development and approaches to continuous education.

Most interventions at city and metropolitan district levels will need to be preceded by a participatory urban food assessment to provide an initial diagnostic of the urban food system, urban poverty and food insecurity, and other elements related to the intervention areas; these instruments are under preparation (7.3.1). Assessment results can serve as the basis for stakeholder dialogue, prioritization and planning. Focused discussions with a sample of municipal governments, food SMEs and key civil society stakeholders may also help identify priority areas for more detailed analyses and to formulate indicative projects. Similar dialogue with stakeholders and civil society in informal urban settlements may help to crystallize approaches and potential actions for participatory urban development in these priority areas.

Undertaking rapid impact evaluations of promising urban food interventions can produce more rigorous quantitative and qualitative information on project technology, costs, effective institutional arrangements and capacity support needed to produce results, to replicate and to scale up. Providing relatively simple methodological guides, training support and peer reviews could help to quickly build up a scientifically validated evidence base through crowdsourced impact evaluations. Such work could also feed into peer learning using social media and distance learning that involves cities, the private sector, civil society and academia as well as demand-driven capacity building for programme design and delivery (7.3.2).

Collaborative analytical partnerships on issues for which there is a groundswell of interest and commitment-such as: food policy for nutritious, healthy food systems; food-sensitive social protection programmes; rural-urban transformation; and urban zoning-offer great potential for action-oriented policy research that feeds into programme development. Use of crowd-sourcing techniques and citizen science offers opportunities for inclusive, practitioner-based approaches. Exercises to apply the urban food lens to other sector policies and investments (such as transport and sanitation infrastructure, urban resilience, health, education) could help identify opportunities and entry points for joint action. Part of this strategy would entail understanding current and proposed actions of other sectors to identify opportunities for integrating priority urban food actions into these processes.

This broad review of the future of food systems has also raised several questions for which the answers are not immediately evident. Further reflection and more detailed analysis and discussion among stakeholders may help to determine the policy, programmatic, and investment options available to address them: 
- How can the food system create nutrition- and climate-friendly value addition, other than through the production of unhealthy processed and packaged food?

- Do most new technologies result in job loss, or can they contribute to socially inclusive, food system modernization?

- Can labour-intensive food value chains increase productivity sufficiently to compete with capital-intensive global competitors?

- What are the most effective policy options for pricing food to include the long-term climate and resource use externalities?

- How can governments balance the need for appropriate research and development (R\&D) incentives for new technology development and adequate regulatory oversight?

- What is the proper mix of short and longer value chains when considering scale economies, greater resilience to shocks, shared prosperity between rural and urban areas, and nutrition and climate footprints?

- How can countries most effectively reduce the availability of affordable unhealthy foods without affecting food security of urban poor?

- To what extent can knowledge and awareness lead to changes in consumer food preferences that reduce demand for nutrient-poor, highly processed food?

\subsection{Global Leadership and Aligning to the Urban Agenda}

The time is ripe to strengthen engagement on urban food issues. The international space is well primed to include an urban lens in ongoing food discussions and interventions as it merges the food and nutrition focus of SDG 2 with the urban emphasis of SDG 11. SDGs, the climate change Conferences of the Parties, the Second International Conference on Nutrition, and Habitat III provide a favourable global context and overarching results framework for interventions. Ongoing global work streams related to rural-urban transformation (the Global Donor Platform and the Committee on World Food Security), resilient and smart cities, migration and forced displacement represent just a few of the potential areas for urban food systems work. The Milan Urban Food Policy Pact, the C40 Cities network, and the International Council for Local Environmental Initiatives (ICLEI)-RUAF Foundation Cityfood Network represent some of the emerging urban food platforms led by municipal governments.

Advisory services, demand-driven analytical work and investment project design, together with the establishment of a global food systems partnership facility, could help advance a programme of work in this area. A global knowledge function based on city-to-city peer learning, knowledge and capacity development facility and technical assistance could build on and strengthen existing systems in association with these networks and their technical partners. Such a facility would facilitate knowledge management, learning, metrics and evaluation, communications and expert panel support with partners 
for technical advisory services and investment project development. It could serve as a clearinghouse and coordinating entity for a demand-driven analytical agenda in the diverse thematic intervention areas (e.g. governance, UPA research, social protection). An open and Big Data component could infuse existing data systems with a strengthened food systems component in existing standard household surveys (e.g. processed food consumption), business environment measurement surveys or policy monitoring assessments (food systems governance). A global food mentoring facility could facilitate access to critically needed expertise and technical assistance for start-up and mature food businesses. A partnership approach assures continuity, facilitates access to existing technical expertise and experienced practitioners, and keeps the process focused on client needs and priorities.

Stronger engagement by the World Bank in this broad area of work is consistent with its twin goals of ending extreme poverty and promoting shared prosperity. It also provides a unifying thematic topic that cuts across the Global Practices of the Sustainable Development Vice Presidency at the World Bank. It is equally grounded in the Agriculture Global Practice's priorities on Rural Livelihoods and Agriculture, Climate-Smart Agriculture, Value Chains and Agribusiness, and Food Quality and Nutrition-Sensitive Investment, bringing an urban complement to strong rural programmes. It addresses an increasingly important dimension of the World Bank's urban development and resilience agendas. This report has consistently underscored the multisectoral nature and complementarity of diverse urban food-related policies and investments. Modernizing urban food wholesale markets, for example, cannot be completed effectively without efficient transportation infrastructure, regular energy supplies, sanitation systems, effective public-private collaboration and multistakeholder engagement.

This next phase is equally critical for strengthening partnerships and alliances between the diversity of actors involved in issues related to feeding 7 billion urban dwellers in 2050. Tapping into the groundswell of stakeholder momentum, knowledge and local expertise and providing a space for their continued engagement and leadership will help to advance a transformative, pragmatic urban food agenda in support of more sustainable and resilient, more affordable and accessible, safer, nutritious and inclusive urban food systems. 


\section{Epilogue - Lola: Leading Elimudina's Food Future}

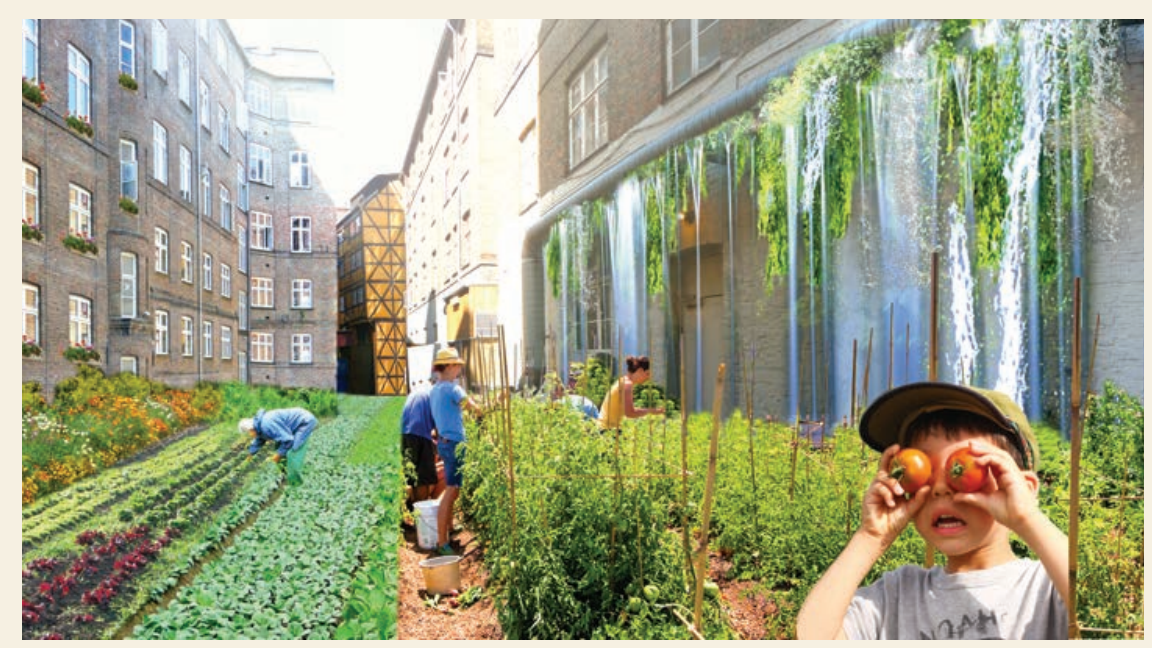

(c) Mark Stevens/Flickr. Further permission required for reuse.

For Lola, food and memories go hand and hand. A certain taste, a smell, or just the presentation of the food evokes visions of family meals, celebrations or special moments. Her life revolves around food. She loves the joy she feels when sharing a meal with friends and family or reaching out to feed the hungry. She truly believes feeding others is a basic, instinctive action that binds people together. Lola grew up experiencing the uniting nature of food daily in the low-income, informal settlement of Elimudina, where she lived with her mother and grandfather who both worked as informal food vendors.

Given her family's business, she logically chose food science as her college major. To earn her degree, she was required to design and implement a food-related project over the four years of studies. Drawing inspiration from her community, Lola designed a project to help formalize the informal food sector vendors, who faced constant harassment from local authorities over issues of quality control, taxes and hygiene.

With participation and co-creation approaches, Lola's first step was to mobilize Elimudina's food vendors to form the Elimudina Food Vendors Association (EFVA). EFVA members agreed to lobby government on a set of priority issues and interventions. They successfully established an alliance with private sector developers and key politicians to push for government recognition as vital economic actors, especially given that most low-income people in Elimudina buy their food from them.

The alliance led to the creation of Urban Chop, a covered outdoor food court with vendor space, public seating, drone food delivery pad, security, and access to clean water and renewable energy from its independent, waste to energy and closed loop water unit. A donation from Lotusleaf Inc. allows vendors to use

(continued on next page) 


\section{Epilogue - Lola: Leading Elimudina's Food Future (continued)}

self-cleaning, cellulose-based dishes with super-hydrophobic coating to repel dirt like a lotus leaf and eliminate washing. Private businesses installed self-assembling solar film to power fee-based, cold chain storage for the vendors. Robots and drones deliver food orders to neighbouring apartments. Lola also worked with NGOs and the food safety agency to organize food hygiene training and food safety certification for vendors, using Urban Chop's integrated on-demand and third-generation holographic television technology.

Lola graduated with high honors in 2050 and became president of EFVA. Degree in hand, she set out to deal with the tougher nutrition challenges facing the community. She mobilized top chefs, TV hosts and a local football star to champion nutritious, safe, local foods at live and virtual events. EFVA even sponsored its own girls and boys teams. Lola formed a partnership with three biorural communities who employ ecological, zero-waste methods all along the value chain to supply Elimudina vendors with the high-quality food that consumers are demanding. Vendors order and pay for their food delivery on the holographic Food Link by 17:00 so producers can harvest and ship to Elimudina for arrival by 04:00 the next morning. A new appreciation for local dishes has sprouted and the once-popular imported chicken and rice dish is now hard to come by and not at all missed.

Lola seized the opportunity to further serve her community by running for and being elected mayor on a platform of eco-smart, safe and nutritious food and jobs. Her flagship initiative is the creation of the Food Institute in partnership with universities, businesses and civil society. The Food Institute, whose motto is "biology to meet needs and enhance opportunities for life," provides formal and informal training for all food system actors. The institute specializes in training in biological sciences to solve food system challenges, design food and agriculture applications and develop job-creating food technologies. A popular, highly praised course on the Ethics of Food Technology, trains students to analyze the multiple tradeoffs in the use of emerging food technologies like nanomaterials and molecular breeding and seek to balance inclusive economic growth, job creation, food safety and ecology. 


\section{Annexes}

\subsection{Indicative Policy and Action Points That Multistakeholders Can Utilize to Address Each Outcome Area}

\section{PUBLIC SECTOR->> INDICATIVE POLICY, INVESTMENT AND KNOWLEDGE INTERVENTIONS BY OUTCOME AREAS}

\begin{tabular}{|c|c|c|c|c|c|}
\hline & $\begin{array}{l}\text { Responsibilities } \\
\text { of different } \\
\text { administrative } \\
\text { levels }\end{array}$ & $\begin{array}{l}\text { Remunerative } \\
\text { jobs and } \\
\text { agribusinesses }\end{array}$ & $\begin{array}{l}\text { Affordability } \\
\text { and } \\
\text { accessibility } \\
\text { for food } \\
\text { security }\end{array}$ & $\begin{array}{l}\text { Nutritious, } \\
\text { diverse, quality } \\
\text { and safe food }\end{array}$ & $\begin{array}{l}\text { Sustainable } \\
\text { and resilient } \\
\text { agriculture and } \\
\text { food systems }\end{array}$ \\
\hline \multirow[t]{2}{*}{$\begin{array}{l}\text { Transformative } \\
\text { institutions }\end{array}$} & National & $\begin{array}{l}\text { Informal } \\
\text { sector policy } \\
\text { development; } \\
\text { mechanism for } \\
\text { line ministry } \\
\text { support to } \\
\text { municipal } \\
\text { governments } \\
\text { Private/public/ } \\
\text { academia } \\
\text { food system } \\
\text { partnerships for } \\
\text { skills, curricula }\end{array}$ & $\begin{array}{l}\text { Food security } \\
\text { interventions } \\
\text { integrated } \\
\text { into slum } \\
\text { development } \\
\text { programmes }\end{array}$ & $\begin{array}{l}\text { Food safety } \\
\text { institutions and } \\
\text { management } \\
\text { systems with } \\
\text { processes, } \\
\text { norms and } \\
\text { standards } \\
\text { developed } \\
\text { Support for } \\
\text { nutritious food } \\
\text { sensitization of } \\
\text { ministries }\end{array}$ & $\begin{array}{l}\text { Food systems } \\
\text { institutionalized } \\
\text { in government } \\
\text { structures }\end{array}$ \\
\hline & $\begin{array}{l}\text { Municipal and } \\
\text { metropolitan } \\
\text { district }\end{array}$ & $\begin{array}{l}\text { Clarification of } \\
\text { jurisdictional } \\
\text { mandates } \\
\text { related to food } \\
\text { systems } \\
\text { Laws to } \\
\text { support local } \\
\text { manufacturing } \\
\text { or sourcing from } \\
\text { smallholders } \\
\text { Private/public } \\
\text { food business/ } \\
\text { entrepreneur } \\
\text { mentoring facility }\end{array}$ & $\begin{array}{l}\text { Public/private } \\
\text { management for } \\
\text { food markets } \\
\text { Functional FLW } \\
\text { agencies } \\
\text { Private/public } \\
\text { structures for } \\
\text { processing } \\
\text { parks, etc. }\end{array}$ & $\begin{array}{l}\text { Strengthened } \\
\text { local food } \\
\text { safety agency } \\
\text { capacities, } \\
\text { procedures and } \\
\text { labs } \\
\text { Nutritious food } \\
\text { programmes } \\
\text { in schools, } \\
\text { military, private } \\
\text { restaurants, etc. }\end{array}$ & $\begin{array}{l}\text { Food } \\
\text { sensitization } \\
\text { in land } \\
\text { administration } \\
\text { and } \\
\text { management }\end{array}$ \\
\hline
\end{tabular}




\section{PUBLIC SECTOR->> INDICATIVE POLICY, INVESTMENT AND KNOWLEDGE INTERVENTIONS BY OUTCOME AREAS}

\begin{tabular}{|c|c|c|c|c|c|}
\hline & $\begin{array}{l}\text { Responsibilities } \\
\text { of different } \\
\text { administrative } \\
\text { levels }\end{array}$ & $\begin{array}{l}\text { Remunerative } \\
\text { jobs and } \\
\text { agribusinesses }\end{array}$ & $\begin{array}{l}\text { Affordability } \\
\text { and } \\
\text { accessibility } \\
\text { for food } \\
\text { security }\end{array}$ & $\begin{array}{l}\text { Nutritious, } \\
\text { diverse, quality } \\
\text { and safe food }\end{array}$ & $\begin{array}{l}\text { Sustainable } \\
\text { and resilient } \\
\text { agriculture and } \\
\text { food systems }\end{array}$ \\
\hline \multirow[t]{2}{*}{$\begin{array}{l}\text { Facilitating and } \\
\text { progressive } \\
\text { policies }\end{array}$} & National & $\begin{array}{l}\text { Policies for } \\
\text { market, trade, } \\
\text { and procurement } \\
\text { facilitation } \\
\text { Elimination } \\
\text { of regulatory } \\
\text { barriers to local } \\
\text { food entry and } \\
\text { expansion }\end{array}$ & $\begin{array}{l}\text { Market } \\
\text { competition } \\
\text { Price policy } \\
\text { FLW standards/ } \\
\text { regulations }\end{array}$ & $\begin{array}{l}\text { Food policy, plan } \\
\text { and review on } \\
\text { nutrition } \\
\text { Dietary } \\
\text { guidelines } \\
\text { and nutrition } \\
\text { standards } \\
\text { Regulations on } \\
\text { sugar, salt, fat }\end{array}$ & $\begin{array}{l}\text { Urban agriculture } \\
\text { land use }\end{array}$ \\
\hline & $\begin{array}{l}\text { Municipal and } \\
\text { metropolitan } \\
\text { district }\end{array}$ & $\begin{array}{l}\text { Approaches } \\
\text { to improve } \\
\text { tenure security } \\
\text { examined; } \\
\text { recognition } \\
\text { by authorities; } \\
\text { protection from } \\
\text { eviction or } \\
\text { exclusion. } \\
\text { Incentives and } \\
\text { regulations for } \\
\text { innovations } \\
\text { Informal sector } \\
\text { regulations } \\
\text { Labour } \\
\text { regulations for } \\
\text { food MSMEs }\end{array}$ & $\begin{array}{l}\text { Agrifood } \\
\text { processing } \\
\text { parks Productive } \\
\text { alliances } \\
\text { Wholesale, retail } \\
\text { food market } \\
\text { regulations }\end{array}$ & $\begin{array}{l}\text { Quality food } \\
\text { institutional } \\
\text { procurement } \\
\text { Promotion of } \\
\text { healthier food } \\
\text { in municipal } \\
\text { buildings, } \\
\text { schools, } \\
\text { community } \\
\text { centres, care } \\
\text { centres and } \\
\text { hospitals }\end{array}$ & $\begin{array}{l}\text { Food system } \\
\text { elements } \\
\text { integrated into } \\
\text { land use plans } \\
\text { and zoning } \\
\text { codes } \\
\text { Forest policy and } \\
\text { scheme }\end{array}$ \\
\hline \multirow[t]{2}{*}{$\begin{array}{l}\text { Open data, } \\
\text { knowledge and } \\
\text { evidence base }\end{array}$} & National & $\begin{array}{l}\text { Food system } \\
\text { data and metrics } \\
\text { Consumer food } \\
\text { demand market } \\
\text { intelligence }\end{array}$ & \multirow{2}{*}{$\begin{array}{l}\text { Food } \\
\text { accessibility and } \\
\text { affordability data } \\
\text { collection and } \\
\text { monitoring } \\
\text { Supply } \\
\text { chain FLW } \\
\text { assessment, } \\
\text { plan and support } \\
\text { facility } \\
\text { FLW accounting } \\
\text { and reporting } \\
\text { Food market } \\
\text { information }\end{array}$} & \multirow{2}{*}{$\begin{array}{l}\text { Food safety } \\
\text { management } \\
\text { systems and } \\
\text { auditing } \\
\text { UPA support } \\
\text { facility } \\
\text { Horticulture } \\
\text { research }\end{array}$} & \multirow{2}{*}{$\begin{array}{l}\text { GHG emissions } \\
\text { auditing and } \\
\text { reporting } \\
\text { Food system } \\
\text { resilience, } \\
\text { vulnerability and } \\
\text { climate footprint } \\
\text { assessment }\end{array}$} \\
\hline & $\begin{array}{l}\text { Municipal and } \\
\text { metropolitan } \\
\text { district }\end{array}$ & $\begin{array}{l}\text { Provision and } \\
\text { support of } \\
\text { agribusiness fairs } \\
\text { Market index } \\
\text { and information } \\
\text { sharing } \\
\text { Employment } \\
\text { information } \\
\text { Knowledge } \\
\text { sharing and } \\
\text { skills training } \\
\text { for women and } \\
\text { youth entering } \\
\text { agribusiness } \\
\text { Food system } \\
\text { data and metrics } \\
\text { generation }\end{array}$ & & & \\
\hline
\end{tabular}




\section{PUBLIC SECTOR->> INDICATIVE POLICY, INVESTMENT AND KNOWLEDGE INTERVENTIONS BY OUTCOME AREAS}

\begin{tabular}{|c|c|c|c|c|c|}
\hline & $\begin{array}{l}\text { Responsibilities } \\
\text { of different } \\
\text { administrative } \\
\text { levels }\end{array}$ & $\begin{array}{l}\text { Remunerative } \\
\text { jobs and } \\
\text { agribusinesses }\end{array}$ & $\begin{array}{l}\text { Affordability } \\
\text { and } \\
\text { accessibility } \\
\text { for food } \\
\text { security }\end{array}$ & $\begin{array}{l}\text { Nutritious, } \\
\text { diverse, quality } \\
\text { and safe food }\end{array}$ & $\begin{array}{l}\text { Sustainable } \\
\text { and resilient } \\
\text { agriculture and } \\
\text { food systems }\end{array}$ \\
\hline \multirow[t]{2}{*}{$\begin{array}{l}\text { Resources for } \\
\text { effective public } \\
\text { and private } \\
\text { financing }\end{array}$} & National & $\begin{array}{l}\text { Government } \\
\text { procurement of } \\
\text { local/regional } \\
\text { food } \\
\text { Smart fiscal } \\
\text { policy }\end{array}$ & \multirow{2}{*}{$\begin{array}{l}\text { Modernized } \\
\text { food market } \\
\text { infrastructure } \\
\text { and cold chain } \\
\text { infrastructure } \\
\text { Joint private- } \\
\text { public financing } \\
\text { for food market } \\
\text { and processing } \\
\text { infrastructure }\end{array}$} & $\begin{array}{l}\text { Collaboration } \\
\text { with SMEs } \\
\text { as financing } \\
\text { partners } \\
\text { Provision of } \\
\text { public seed } \\
\text { funding }\end{array}$ & $\begin{array}{l}\text { Green } \\
\text { infrastructure } \\
\text { development }\end{array}$ \\
\hline & $\begin{array}{l}\text { Municipal and } \\
\text { metropolitan } \\
\text { district }\end{array}$ & $\begin{array}{l}\text { Multicity joint } \\
\text { financing } \\
\text { incentives } \\
\text { for start-up } \\
\text { enterprises } \\
\text { Public seed } \\
\text { funding } \\
\text { UPA financing } \\
\text { Financing } \\
\text { partners for food } \\
\text { SMEs }\end{array}$ & & $\begin{array}{l}\text { Multicity joint } \\
\text { financing } \\
\text { incentives for } \\
\text { nutritious food } \\
\text { programmes }\end{array}$ & $\begin{array}{l}\text { Integrated } \\
\text { green housing } \\
\text { developments } \\
\text { Greening of the } \\
\text { supply chain } \\
\text { Integrated } \\
\text { infrastructure } \\
\text { Urban agriculture } \\
\text { financing }\end{array}$ \\
\hline \multirow[t]{2}{*}{$\begin{array}{l}\text { Multi- } \\
\text { stakeholder } \\
\text { governance } \\
\text { mechanisms } \\
\text { and capacity }\end{array}$} & National & & $\begin{array}{l}\text { Innovative } \\
\text { food-based } \\
\text { social protection } \\
\text { programmes } \\
\text { for urban poor/ } \\
\text { food-insecure } \\
\text { Urban slum food } \\
\text { improvement } \\
\text { committees }\end{array}$ & $\begin{array}{l}\text { National } \\
\text { nutritious food } \\
\text { partnership } \\
\text { Citizen science } \\
\text { programmes }\end{array}$ & \multirow[t]{2}{*}{$\begin{array}{l}\text { Sustainable land } \\
\text { use planning and } \\
\text { protection } \\
\text { Local community } \\
\text { land use } \\
\text { committees }\end{array}$} \\
\hline & $\begin{array}{l}\text { Municipal and } \\
\text { metropolitan } \\
\text { district }\end{array}$ & $\begin{array}{l}\text { Informal sector } \\
\text { food worker } \\
\text { association } \\
\text { Food MSMEs } \\
\text { industry groups } \\
\text { Private sector/ } \\
\text { civil society } \\
\text { engagement } \\
\text { in food-related } \\
\text { curricula }\end{array}$ & $\begin{array}{l}\text { Capacity building } \\
\text { of supply chain } \\
\text { actors } \\
\text { Private sector/ } \\
\text { civil society } \\
\text { FLW committee }\end{array}$ & $\begin{array}{l}\text { Nutritious food } \\
\text { programmes } \\
\text { developed } \\
\text { with other } \\
\text { stakeholders }\end{array}$ & \\
\hline
\end{tabular}

Note: The interventions may vary from country to country and from city to city, and in different situations are overlapped or interlinked. 


\section{PRIVATE SECTOR->> INDICATIVE POLICY, INVESTMENT AND KNOWLEDGE INTERVENTIONS BY OUTCOME AREAS (MANY ARE IN ASSOCIATION WITH PUBLIC AND CIVIL SOCIETY ACTORS)}

\begin{tabular}{|c|c|c|c|c|}
\hline & $\begin{array}{l}\text { Remunerative } \\
\text { jobs and better } \\
\text { agribusinesses }\end{array}$ & $\begin{array}{l}\text { Affordability and } \\
\text { accessibility for } \\
\text { food security }\end{array}$ & $\begin{array}{l}\text { Nutritious, diverse, } \\
\text { quality and safe } \\
\text { food }\end{array}$ & $\begin{array}{l}\text { Sustainable } \\
\text { and resilient } \\
\text { agriculture and } \\
\text { food systems }\end{array}$ \\
\hline $\begin{array}{l}\text { Transformative } \\
\text { institutions }\end{array}$ & $\begin{array}{l}\text { Focus on local } \\
\text { manufacturers, food } \\
\text { processing and } \\
\text { procurement, street } \\
\text { vendors } \\
\text { Food business mentor } \\
\text { programmes } \\
\text { Food innovation } \\
\text { support labs }\end{array}$ & $\begin{array}{l}\text { Accessible and } \\
\text { affordable grocery } \\
\text { stores, local food } \\
\text { markets, street } \\
\text { vendors } \\
\text { Inclusive food market } \\
\text { boards }\end{array}$ & $\begin{array}{l}\text { Food safety } \\
\text { certificates } \\
\text { Support for nutritious } \\
\text { food production }\end{array}$ & $\begin{array}{l}\text { Support for } \\
\text { decrease of GHG } \\
\text { emissions in all food- } \\
\text { related sectors } \\
\text { Food industry } \\
\text { groups reducing } \\
\text { GHG emissions } \\
\text { Vacant land } \\
\text { accessible for urban } \\
\text { agriculture }\end{array}$ \\
\hline $\begin{array}{l}\text { Facilitating and } \\
\text { progressive } \\
\text { policies }\end{array}$ & $\begin{array}{l}\text { Innovations in UPA } \\
\text { Modernized } \\
\text { agribusinesses } \\
\text { Internships, policies } \\
\text { and recruitment for } \\
\text { food system jobs }\end{array}$ & $\begin{array}{l}\text { Agrifood processing } \\
\text { parks Productive } \\
\text { alliances } \\
\text { Provision of healthy } \\
\text { foods promoted at } \\
\text { supermarkets, small } \\
\text { grocery stores and } \\
\text { restaurants }\end{array}$ & $\begin{array}{l}\text { Dietary guidelines at } \\
\text { restaurants } \\
\text { Stimulation for agro- } \\
\text { enterprises in the } \\
\text { region to improve } \\
\text { the nutritious quality } \\
\text { of the food products } \\
\text { they provide }\end{array}$ & $\begin{array}{l}\text { Urban technology } \\
\text { Innovative models } \\
\text { of alternative food } \\
\text { systems }\end{array}$ \\
\hline $\begin{array}{l}\text { Open data, } \\
\text { knowledge and } \\
\text { evidence base }\end{array}$ & $\begin{array}{l}\text { Investment in } \\
\text { timely food system } \\
\text { data Support for } \\
\text { agribusiness fairs } \\
\text { Skills development } \\
\text { and (re)training for } \\
\text { employees } \\
\text { Business incubators } \\
\text { targeting youth and } \\
\text { women }\end{array}$ & $\begin{array}{l}\text { Supply chain FLW } \\
\text { assessment, plan } \\
\text { and support facility } \\
\text { FLW accounting and } \\
\text { reporting }\end{array}$ & $\begin{array}{l}\text { Food safety } \\
\text { management systems } \\
\text { and auditing }\end{array}$ & $\begin{array}{l}\text { Support for } \\
\text { decrease of GHG } \\
\text { emissions related } \\
\text { to food production, } \\
\text { processing, } \\
\text { distribution, } \\
\text { consumption } \\
\text { and food waste } \\
\text { management }\end{array}$ \\
\hline $\begin{array}{l}\text { Resources for } \\
\text { effective public } \\
\text { and private } \\
\text { financing }\end{array}$ & $\begin{array}{l}\text { Private financing for } \\
\text { start-up enterprises } \\
\text { Collaboration with } \\
\text { food SMEs as } \\
\text { financing partners }\end{array}$ & $\begin{array}{l}\text { Modernized food } \\
\text { market infrastructure } \\
\text { including cold chain } \\
\text { infrastructure }\end{array}$ & $\begin{array}{l}\text { Financing partners } \\
\text { for food SMEs Smart } \\
\text { fiscal policy } \\
\text { Multicity joint } \\
\text { financing incentives } \\
\text { for nutritious food } \\
\text { programmes }\end{array}$ & $\begin{array}{l}\text { Green infrastructure } \\
\text { Integrated } \\
\text { green housing } \\
\text { developments } \\
\text { Greening of the } \\
\text { supply chain }\end{array}$ \\
\hline $\begin{array}{l}\text { Multistakeholder } \\
\text { governance } \\
\text { mechanisms and } \\
\text { capacity }\end{array}$ & $\begin{array}{l}\text { Developing agro- } \\
\text { industries close to } \\
\text { production }\end{array}$ & $\begin{array}{l}\text { Capacity building of } \\
\text { supply chain actors } \\
\text { FLW group } \\
\text { Inclusive market } \\
\text { actors }\end{array}$ & $\begin{array}{l}\text { Development of } \\
\text { nutritious food } \\
\text { programmes with } \\
\text { other stakeholders }\end{array}$ & $\begin{array}{l}\text { Multiuse urban green } \\
\text { belts }\end{array}$ \\
\hline
\end{tabular}




\section{CIVIL SOCIETY->> INDICATIVE POLICY, INVESTMENT AND KNOWLEDGE INTERVENTIONS BY OUTCOME AREAS}

\begin{tabular}{|c|c|c|c|c|}
\hline & $\begin{array}{l}\text { Remunerative jobs } \\
\text { and agribusinesses }\end{array}$ & $\begin{array}{l}\text { Affordability and } \\
\text { accessibility for } \\
\text { food security }\end{array}$ & $\begin{array}{l}\text { Nutritious, diverse, } \\
\text { quality and safe } \\
\text { food }\end{array}$ & $\begin{array}{l}\text { Sustainable } \\
\text { and resilient } \\
\text { agriculture and } \\
\text { food systems }\end{array}$ \\
\hline $\begin{array}{l}\text { Transformative } \\
\text { institutions }\end{array}$ & $\begin{array}{l}\text { Development of } \\
\text { food policy councils } \\
\text { providing advisory } \\
\text { services to food } \\
\text { chain actors and } \\
\text { government }\end{array}$ & $\begin{array}{l}\text { Food price oversight } \\
\text { for competitive } \\
\text { markets and } \\
\text { affordable food }\end{array}$ & $\begin{array}{l}\text { Advocacy for food } \\
\text { safety standards and } \\
\text { norms }\end{array}$ & $\begin{array}{l}\text { Building up } \\
\text { community- } \\
\text { supported } \\
\text { agriculture that is } \\
\text { climate-smart }\end{array}$ \\
\hline $\begin{array}{l}\text { Facilitating and } \\
\text { progressive } \\
\text { policies }\end{array}$ & $\begin{array}{l}\text { Engagement in policy } \\
\text { formation and decision } \\
\text { processes } \\
\text { Lobbying for capacity } \\
\text { development for } \\
\text { informal sector } \\
\text { Advocacy for } \\
\text { innovative social } \\
\text { protection for skill } \\
\text { enhancement }\end{array}$ & $\begin{array}{l}\text { Advocacy for } \\
\text { the provision of } \\
\text { affordable healthy } \\
\text { food outlets in } \\
\text { low-income and } \\
\text { underserved areas } \\
\text { Assistance to } \\
\text { households and } \\
\text { individuals at risk } \\
\text { to supplement their } \\
\text { food consumption } \\
\text { needs }\end{array}$ & $\begin{array}{l}\text { Advocacy for } \\
\text { food-based dietary } \\
\text { guidelines at } \\
\text { restaurants } \\
\text { Prevention of over- } \\
\text { concentration of fast } \\
\text { food near schools } \\
\text { Food safety oversight } \\
\text { Support to food } \\
\text { banks/social } \\
\text { protection } \\
\text { Support to nutrition } \\
\text { education in schools }\end{array}$ & $\begin{array}{l}\text { Support for policies, } \\
\text { investments } \\
\text { and capacities } \\
\text { in closed loop } \\
\text { resource systems, } \\
\text { including recovery } \\
\text { and agricultural } \\
\text { reuse of nutrients } \\
\text { and irrigation } \\
\text { water from urban } \\
\text { organic wastes and } \\
\text { wastewater }\end{array}$ \\
\hline $\begin{array}{l}\text { Open data, } \\
\text { knowledge and } \\
\text { evidence base }\end{array}$ & $\begin{array}{l}\text { Provision of incubators } \\
\text { and skills training for } \\
\text { women and youth } \\
\text { Citizen science } \\
\text { initiatives }\end{array}$ & $\begin{array}{l}\text { Advocacy for } \\
\text { supply chain FLW } \\
\text { assessment, plan } \\
\text { and support facility } \\
\text { FLW accounting and } \\
\text { reporting }\end{array}$ & $\begin{array}{l}\text { Food safety and } \\
\text { standards awareness } \\
\text { raising }\end{array}$ & $\begin{array}{l}\text { Advocacy for } \\
\text { emissions auditing } \\
\text { and reporting } \\
\text { as well as food } \\
\text { system resilience } \\
\text { assessment and } \\
\text { climate footprint } \\
\text { assessments }\end{array}$ \\
\hline $\begin{array}{l}\text { Resources for } \\
\text { effective public } \\
\text { and private } \\
\text { financing }\end{array}$ & $\begin{array}{l}\text { Advocacy and } \\
\text { lobbying for public } \\
\text { and private financing } \\
\text { to urban food system } \\
\text { initiatives }\end{array}$ & $\begin{array}{l}\text { Advocacy and } \\
\text { lobbying for public } \\
\text { and private financing } \\
\text { to urban food market } \\
\text { infrastructure } \\
\text { Budget accountability } \\
\text { oversight }\end{array}$ & $\begin{array}{l}\text { Collaborating } \\
\text { with food SMEs } \\
\text { in nutritious food } \\
\text { programmes } \\
\text { Advocacy for public/ } \\
\text { private financing in } \\
\text { support of nutritious } \\
\text { food }\end{array}$ & $\begin{array}{l}\text { Promotion of green } \\
\text { infrastructure } \\
\text { Integrated } \\
\text { green housing } \\
\text { development } \\
\text { Greening of the } \\
\text { supply chain } \\
\text { initiatives }\end{array}$ \\
\hline $\begin{array}{l}\text { Multi- } \\
\text { stakeholder } \\
\text { governance } \\
\text { mechanisms } \\
\text { and capacity }\end{array}$ & $\begin{array}{l}\text { Lobbying for } \\
\text { recognition of informal } \\
\text { sector work rights }\end{array}$ & $\begin{array}{l}\text { Lobbying for small } \\
\text { actor access to } \\
\text { retail and wholesale } \\
\text { markets } \\
\text { Support for } \\
\text { broad community } \\
\text { mobilization for FLW } \\
\text { campaigns. }\end{array}$ & $\begin{array}{l}\text { Collaboration with } \\
\text { other stakeholders } \\
\text { on nutritious food } \\
\text { programmes } \\
\text { Community } \\
\text { mobilization for } \\
\text { nutritious food }\end{array}$ & $\begin{array}{l}\text { Promotion of and } \\
\text { engagement in } \\
\text { multiuse urban green } \\
\text { belts }\end{array}$ \\
\hline
\end{tabular}




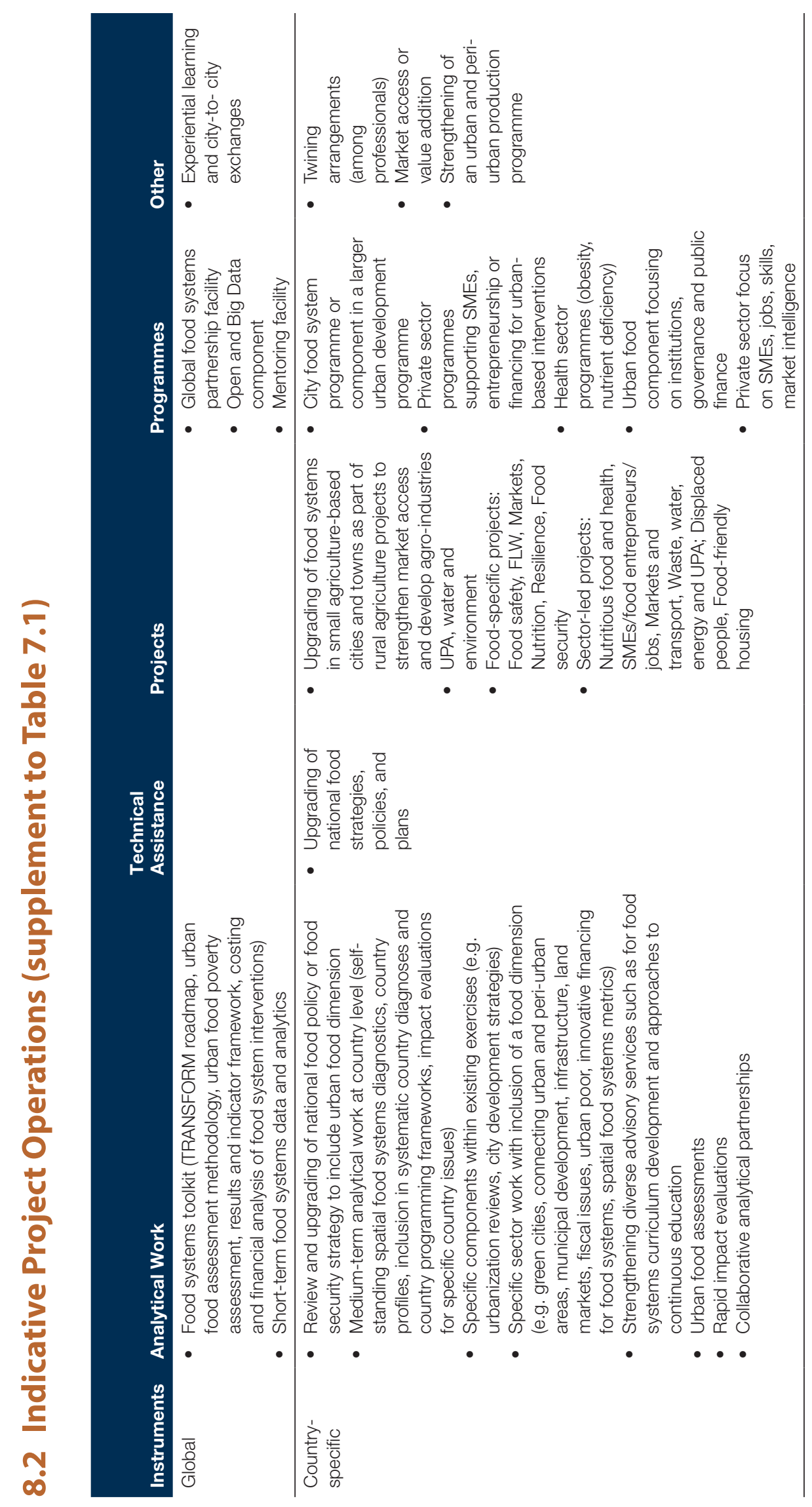




\section{Endnotes}

1. Oehmke, James F, Anwar Naseem, Jock Anderson and Carl Pray. 2016. Comtemporary African structural transformation: An empirical assessment. Food and Agriculture of the United Nations. Accessed June 30, 2017. http:// www.fao.org/3/a-bp141e.pdf.

2. UN DESA Department of Economic and Social Affairs. World's population increasingly urban with more than half living in urban areas. World Urbanization Prospects. Accessed July 10, 2017. http://www.un.org/en/develop$\mathrm{ment} / \mathrm{des}$ /news/population/world-urbanization-prospects-2014.html.

3. United Nations. 2014. World Urbanization Prospects: The 2014 Revision. Accessed July 10, 2017. https://esa.un.org/unpd/wup/publications/files/ wup2014-highlights.Pdf..

4. UN Habitat. Slum Almanac 2015/2016. Accessed June 30, 2017. https:// unhabitat.org/wp-content/uploads/2016/02-old/Slum\%20Almanac\%20 2015-2016_EN.pdf.

5. ILO (International Labor Organization). 2015. Decent and productive work in agriculture. Accessed June 30, 2016. http://www.ilo.org/wcmsp5/groups/public/---ed_emp/---emp_policy/documents/publication/wcms_437173.pdf.

6. UN Sustainable Development Goals. 2015. Accessed June 30, 2016. http://www. un.org/sustainabledevelopment/sustainable-development-goals/.

7. Fonseca Jorge M, Domonkos Oze and Ana Puhac. 2016. Boosting the development of sustainable food systems and postharvest supply chains for feeding cities: Evidence for assessment of interventions in the Global South. Working paper. Food Systems for Cities. Food and Agriculture Organization of the United Nations; Meerman, Janice and Rosa Rolle. 2016. Nutrition, health, and consumer dietary behavior in cities: Current trends and entry points for programmatic action. Background paper for a knowledge product on urban agriculture. FAO World Bank Cooperative Program; Taguchi, Makiko, Caroline Ledant and Jia Ni. 2017. Urban innovative production component for the World Bank Urban Agriculture Knowledge Product. Background paper for a knowledge product on urban agriculture.

8. Bloom, David E. 2016. Demographic upheaval. Finance \& Development. International Monetary Fund; IMF (International Monetary Fund). 2016. The big squeeze: Global population pressures. Accessed July 21, 2017. https://www. imf.org/external/pubs/ft/fandd/2016/03/pdf/fd0316.pdf.

9. United Nations. World Urbanization Prospects

10. United Nations. 2012. World Urbanization Prospects: The 2011 Revision. Retrieved from http://www.un.org/en/development/desa/population/publications/pdf/urbanization/WUP2011_Report.pdf.

11. Bloom, Demographic upheaval.

12. World Health Organization.2015. Ageing and health, Accessed July 13, 2017. http://www.who.int/mediacentre/factsheets/fs404/en/

13. Roberts, Brian H. 2014. Managing systems of secondary cities. Policy Reponses in International; Angel, Shlomo, Alejandro M. Blei, Daniel L. Civco, and Jason Parent. 2012. Atlas of urban expansion. Cambridge, MA: Lincoln Institute of Land Policy; The World Bank. 2016. 6C Central America Urbanization Review: Making Cities Work for Central America. Accessed July 23, 2017. http://documents.worldbank.org/curated/en/134151467994680764/6C-Central-America-urbanization-review-making-cities-work-for-Central-America; Angel, Shlomo, Stephen C. Sheppard, Daniel L. Civco, Robert Buckley, Anna Chabaeva, Lucy Gitlin, Alison Kraley, Jason Parent, and Micah Perlin. 2005. The dynamics of global urban expansion. The World Bank. Accessed May 20, 
2017. http://documents.worldbank.org/curated/en/138671468161635731/pdf/ 355630Global0urban0sept200501PUBLIC1.pdf.

14. Ellis, Peter and Mark Roberts. 2016. Leveraging urbanization in South Asia: Managing spatial transformation for prosperity and livability. Accessed July 23, 2017. http://www.worldbank.org/en/region/sar/publication/leveraging-urbanization-south-asia-managing-spacial-transformation-prosperity-livability; UN Habitat. 2016. Slum Almanac 2015-2016: Tracking improvement in the lives of slum dwellers. Accessed May 20, 2017. https://unhabitat.org/ wp-content/.../02.../Slum\%20Almanac\%202015-2016_EN.pdf.

15. WHO (World Health Organization).2016. Global report on urban health. Accessed May 20, 2017. http://www.who.int/kobe_centre/measuring/urban-global-report/ugr_full_report.pdf.

16. IFPRI (International Food Policy Research Institute). 2017.Global food policy report. International Food Policy Research Institute. Washington, DC: International Food Policy Research Institute. Accessed May 20, 2017. https:// doi.org.10.2499/9780896292529.

17. The World Bank. 2009. Scale economies and agglomeration. Accessed May 20, 2017. http://siteresources.worldbank.org/INTWDR2009/Resources/ 4231006-1225840759068/WDR09_10_Ch04web.pdf; Sri Mulyani Indrawati. 2014. China's New urbanization needs to be inclusive and sustainable. Accessed May 20, 2017. http://www.huffingtonpost.com/sri-mulyani-indrawati/china-urbanization_b_5035433.html; Om Prakash Mathur. 2013. Urban poverty in Asia. Study prepared for the Asian Development Bank; The World Bank. 2014. Speech by World Bank managing director and COO Sri Mulyani Indrawati at the U.S.ASEAN Business Council. Retrieved from: Speech by World Bank Managing Director and COO Sri Mulyani Indrawati at the U.S.-ASEAN Business Council.

18. Ravallion, Martin. 2007. Urban poverty. Finance \& Development, 44(03). Accessed May 20, 2017. http://www.imf.org/external/pubs/ft/fandd/2007/09/ ravalli.htm.

19. The Gini coefficient is a measure of income inequality, which is 0 when everybody has the same income and 1 when one person has all the income.

20. Haggblade, Steven, Peter Hazell and Thomas Reardon. 2007. Strategies for stimulating equitable growth in the rural nonfarm economy. Transforming the rural nonfarm economy: Opportunities and threats in the developing world, 396; Christiaensen, L., Weerdt, J., and Todo, Y. 2013. Urbanization and poverty reduction: The Role of rural diversification and secondary towns. Agricultural Economics, 44(4-5), 435-447.

21. Ortiz, Isabel, and Matthew Cummins. 2012. When the global crisis and youth bulge collide. UNICEF. Accessed May 20, 2017. https://www.unicef.org/socialpolicy/files/Global_Crisis_and_Youth_Bulge_-_FINAL.pdf.

22. 25 The World Bank. 2015. Competitive cities for jobs and growth. Accessed May 20, 2017. https://olc.worldbank.org/sites/default/files/Competitive-Citiesfor-Jobs-and-Growth.pdf;

23. UNIDO.2013. Industrial Development Report. Sustaining employment growth: The role of manufacturing and structural change. Accessed May 20, 2017. https://www.unido.org/fileadmin/user_media/Research_and_Statistics/ UNIDO_IDR_2013_main_report.pdf.

24. Haraguchi, Nobuya. 2016. Patterns of structural change and manufacturing development. Routledge Handbooks Online.

25. Allen, Andrea, Julie Howard, Amy Jamison, Thomas Jayne, J. Snyder, David Tschirley, and Kwame Felix Yeboah. 2016. Agrifood youth employment and engagement study policy brief. Accessed May 20, 2017. http://www.isp.msu. edu/files/6014/7248/3804/AgYees_Policy_Brief_FINAL.pdf. 
26. Tschirley, David, Thomas Reardon, Michael Dolislager, and Jason Snyder. 2015. The rise of a middle class in East and Southern Africa: Implications for food system transformation. Journal of International Development, 27(5), 628-646.

27. Ibid.

28. Pansing, C., A. Wasserman, J. Fisk, M. Muldoon, S. Kiraly, and T. Benjamin. 2013. North American food sector, part one: Program scan and literature review. Wallace Center at Winrock International, Arlington, VA.

29. Masi, Brad, Leslie Schaller, and Michael Shuman. 2010. The 25\% shift: The benefits of food localization for northeast ohio \& how to realize them. Accessed June 1, 2017. http://www. neofoodweb. org/sites/default/files/resources/the25shift-foodlocalizationintheNEOregion.pdf.

30. FAO (Food and Agriculture of the United Nations). 2017. The future of food and agriculture - Trends and challenges. Rome. Urbanization and Rural Transformation Implications for Food Security and Nutrition. (2016, March 14). Accessed June 1, 2017. http://www.fao.org/fsnforum/sites/default/files/ files/126_Urban_Rural_Transformation/UrbRurZeroDraft.pdf.

31. Dong, Fengxia. and Frank Fuller. 2010. Dietary structural change in China’s cities: Empirical fact or urban legend?. Canadian Journal of Agricultural Economics/Revue canadienne d'agroeconomie, 58: 73-91.

32. Anand, Sonia S, Corinna Hawkes, Russell J. de Souza, Andrew Mente, Mahshid Dehghan, Rachel Nugent, Michael A. Zulyniak et al. 2015. Food consumption and its impact on cardiovascular disease: Importance of solutions focused on the globalized food system: A report from the workshop convened by the World Heart Federation. Journal of the American College of Cardiology. 66(14):15901614; Euromonitor. 2015; Gelhar, Mark. and Anita Regmi. 2005. Factors shaping global food markets. In: Regmi, A. and Gelhar, M. (eds). New directions in global food markets, 5-17; Gibbon, Peter, and Stefano Ponte. Trading down: Africa, value chains, and the global economy. Temple University Press, 2005.

33. Tschirley et al., Rise of a middle class; Lançon, F., \& Wade, I. 2016. Urbanisation, changing tastes and rural transformation in West Africa.

34. Tschirley et al., Rise of a middle class.

35. Ali, Jabir, Sanjeev Kapoor, and Janakiraman Moorthy. 2010. Buying behavior of consumers for food products in an emerging economy. British Food Journal, 112(2), 109-124; Neilson. 2015. We are what we eat: Healthy eating trends around the world. Accessed June 2, 2017. https://www.nielsen.com/ content/dam/nielsenglobal/eu/nielseninsights/pdfs/Nielsen\%20Global\%20 Health\%20and\%20Wellness\%20Report\%20-\%20January\%202015.pdf; Nilson.2010. Global trends in healthy eating. Accessed June 2, 2017. http:// www.nielsen.com/us/en/insights/news/2010/global-trends-in-healthy-eating.html; McKinsey \& Company. 2015. Perspectives on retail and consumer goods. Accessed June 2, 2017. http://www.mckinsey.com/industries/retail/ our-insights/perspectives-number-4; Woolverton, A. E., \& Frimpong, S. 2013. Consumer demand for domestic and imported broiler meat in urban Ghana: Bringing non-price effects into the equation. British Journal of Marketing Studies, 1(3), 16-31; Dong et al., Dietary structural change.

36. Ali et al., Buying behavior.

37. Anand, Food consumption; Moodie, Rob, David Stuckler, Carlos Monteiro, Nick Sheron, Bruce Neal, Thaksaphon Thamarangsi, Paul Lincoln, Sally Casswell, and Lancet NCD Action Group. 2013. Profits and pandemics: prevention of harmful effects of tobacco, alcohol, and ultra-processed food and drink industries. The Lancet, 381(9867), 670-679; Stuckler, D., \& Nestle, M. 2012. Big food, food systems, and global health. PLoS medicine, 9(6), e1001242. 
38. Monteiro, C. A., Moubarac, J.-C., Cannon, G., Ng, S. W. and Popkin, B. 2013, Ultra-processed products are becoming dominant in the global food system. Obes Rev, 14: 21-28. doi:10.1111/obr.12107.

39. Allen et al., Agrifood youth employment.

40. Allen et al., Agrifood youth employment.

41. Institute for Health Metrics and Evaluation. 2013. The global burden of disease: Generating evidence, guiding policy. Seattle, WA: IHME; World Cancer Research Fund International. 2010. Preventable and attributable global burden of cancer due to excess body mass index in adults. Accessed June 2, 2017. http:// www.wcrf.org/int/research-we-fund/what-we-re-funding/preventable-andattributable-global-burden-cancer-due-excess.

42. Anand et al., Food consumption.

43. Reddy, K. S. 2002. Cardiovascular diseases in the developing countries: dimensions, determinants, dynamics and directions for public health action. Public Health Nutrition, 5(1a), 231-237; Ibid.

44. Scott, P. 2016. Food systems and diets: facing the challenges of the 21st century. Global Panel on Agriculture and Food Systems for Nutrition. doi:10.1007/ s12571-017-0678-y.

45. Poobalan, Amudha, and Lorna Aucott. 2016. Obesity among young adults in developing countries: A systematic overview. Current Obesity Reports,5(1). doi:10.1007/s13679-016-0187-x.

46. Ng, Marie, Tom Fleming, Margaret Robinson, Blake Thomson, Nicholas Graetz, Christopher Margono, Erin C. Mullany et al. 2014. Global, regional, and national prevalence of overweight and obesity in children and adults during 1980-2013: a systematic analysis for the Global Burden of Disease Study 2013. The Lancet, 384(9945), 766-781.

47. FAO (Food and Agriculture Organization of the United Nations). 2016. The state of food and agriculture. Accessed June 2, 2017. https://www.compassion. $\mathrm{com} /$ multimedia/state-of-food-and-agriculture-fao.pdf; Ibid.

48. WHO (World Health Organization). 2015. WHO's first ever global estimates of foodborne diseases find children under 5 account for almost one third of deaths. Accessed June 2, 2017. http://www.who.int/mediacentre/news/releases/2015/ foodborne-disease-estimates/en/.

49. Grace, D. Food safety in developing countries: an overview. Evidence on Demand, UK (2015) 83 pp. Accessed June 1, 2017. https://dx.doi.org/10.12774/ eod_er.oct2015.graced.

50. The World Bank. 2010. People, Pathogens and Our Plant, Vol 1: Towards a Once Health Approach for Controlling. Zoonotic Diseases Report 50833-GLB; Sustaining Global Surveillance and Response to Emerging Zoonotic Diseases. Washington, DC: National Research Council; 2009.

51. Dobbs, Richard, Corinne Sawers, Fraser Thompson, James Manyika, Jonathan R. Woetzel, Peter Child, Sorcha McKenna, and Angela Spatharou. 2014. Overcoming obesity: An initial economic analysis. McKinsey Global Institute.

52. The Global Panel.2016. The cost of malnutrition: Why policy action is urgent. Technical Brief, 3.

53. Bloom, D.E., Cafiero, E.T., Jané-Llopis, E., Abrahams-Gessel, S., Bloom, L.R., Fathima, S., Feigl, A.B., Gaziano, T., Mowafi, M., Pandya, A., Prettner, K., Rosenberg, L., Seligman, B., Stein, A.Z., \& Weinstein, C. 2011. The global economic burden of noncommunicable diseases. Geneva: World Economic Forum.

54. TechTarget. 2017. Machine learning. Accessed June 1, 2017. http://whatis. techtarget.com/definition/machine-learning.

55. EPA (United States Environmental Protection Agency). 2017. Global Green House Gas emissions data. Accessed June 1, 2017. https://www.epa.gov/ ghgemissions/global-greenhouse-gas-emissions-data. 
56. The World Bank. 2017. Urban development. Accessed June 1, 2017. http:// www.worldbank.org/en/topic/urbandevelopment/overview; The World Bank.2010. Cities and climate change: an urgent agenda. Accessed June 1, 2017. http://siteresources.worldbank.org/INTUWM/Resources/3402321205330656272/4768406-1291309208465/PartIII.pdf.

57. Zhao, Chuang, Bing Liu, Shilong Piao, Xuhui Wang, David B. Lobell, Yao Huang, Mengtian Huang et al. 2017. Temperature increase reduces global yields of major crops in four independent estimates. Proceedings of the National Academy of Sciences (2017): 201701762.

58. Vermeulen, Sonja J., Bruce M. Campbell, and John SI Ingram. 2012. Climate change and food systems. Annual Review of Environment and Resources, 37(1), 195-222. doi:10.1146/annurev-environ-020411-130608; FCRN (Food Climate Research Network) Foodsource. 2017. Food systems \& greenhouse gas emissions. Accessed June 1, 2017. http://www.foodsource.org.uk.

59. Pelletier, Nathan, Eric Audsley, Sonja Brodt, Tara Garnett, Patrik Henriksson, Alissa Kendall, Klaas Jan Kramer, David Murphy, Thomas Nemecek, and Max Troell.2011. Energy intensity of agriculture and food systems. Annual Review of Environment and Resources, 36; Vermeulen, Climate change

60. Mediterra.2016. Zero waste in the Mediterranean. Accessed June 1, 2017. http:// www.ciheam.org/uploads/attachments/333/Mediterra2016_EN_BAT_1_.pdf.

61. Garnett, T. 2011. Where are the best opportunities for reducing greenhouse gas emissions in the food system (including the food chain)? Food Policy,36. doi:10.1016/j.foodpol.2010.10.010.

62. IRENA (International Renewable Energy Agency). 2017. Perspectives for the energy transition: Investment needs for a low-carbon energy system. Accessed June 1, 2017. http://www.irena.org/DocumentDownloads/Publications/ Perspectives_for_the_Energy_Transition_2017.pdf.

63. Kaufmann, Robert K., Karen C. Seto, Annemarie Schneider, Zouting Liu, Liming Zhou, and Weile Wang. 2007. Climate response to rapid urban growth: evidence of a human-induced precipitation deficit. Journal of Climate 20, no. 10 (2007): 2299-2306.

64. The World Bank. 2017. Reducing pollution. Accessed June 1, 2017. http:// www.worldbank.org/en/topic/environment/brief/pollution; AfDB (African Development Bank). 2016. African Economic Outlook 2016: Sustainable cities and structural transformation. Accessed June 1, 2017. https://www.afdb.org/ fileadmin/uploads/afdb/Documents/Publications/AEO_2016_Report_Full_ English.pdf; Zheng, Siqi, and Matthew E. Kahn. 2017. A new Era of pollution progress in urban China?. The Journal of Economic Perspectives 31, no. 1: 71-92; AfDB (African Development Bank). 2016. African Economics Outlook 2016. Sustainable cities and structural transformation.

65. Seto, Karen C., Michail Fragkias, Burak Güneralp, and Michael K. Reilly. 2011. A meta-analysis of global urban land expansion. PloS one 6, no. 8 (2011): e23777.

66. Seto, Karen C., Burak Güneralp, and Lucy R. Hutyra. Global forecasts of urban expansion to 2030 and direct impacts on biodiversity and carbon pools. Proceedings of the National Academy of Sciences 109, no. 40 (2012): 16083-16088.

67. Güneralp, Burak, \& Karen C. Seto. 2008. Environmental impacts of urban growth from an integrated dynamic perspective: A case study of Shenzhen, South China. Global Environmental Change, 18(4), 720-735.

68. Roberts, Eliza. and Brooke Barton. 2015. Feeding Ourselves Thirsty: How the Food Sector is Managing Global Water Risks. Ceres, Boston, MA; World Economic Forum and the Harvard School of Public Health. 2011. The global economics burden of non-communicable diseases. 
69. FAO (Food and Agriculture Organization of the United Nations). 2011. Global food loss and food waste. Accessed June 1, 2017. http://www.fao.org/ docrep/014/mb060e/mb060e.pdf.

70. The High Level Panel of Experts on Food Security and Nutrition. 2014. Food losses and waste in the context of sustainable food systems. Accessed June 1, 2017. http://www.fao.org/3/a-i3901e.pdf.

71. World Resources Institute and United Nations Environment Program. 2013. Reducing food loss and waste. Accessed June 1, 2017. http://pdf.wri.org/reducing_food_loss_and_waste.pdf.

72. Parfitt, Julian, Mark Barthel, and Sarah Macnaughton. 2010. Food waste within food supply chains: quantification and potential for change to 2050 . Philosophical Transactions of the Royal Society of London B: Biological Sciences, 365(1554), 3065-3081; Buzby, Jean. C., and Jeffrey Hyman. 2012. Total and per capita value of food loss in the United States. Food Policy, 37(5), 561-570.

73. FAO (Food and Agriculture Organization of the United Nations). 2015. Food wastage footprint \& climate change. Accessed June 1, 2017. http://www.fao. org/fileadmin/templates/nr/sustainability_pathways/docs/FWF_and_climate_ change.pdf.

74. Kummu, Matti, Hans de Moel, Miina Porkka, Stefan Siebert, Olli Varis, and Philip J. Ward.2012. Lost food, wasted resources: Global food supply chain losses and their impacts on freshwater, cropland, and fertiliser use. Science of the total environment, 438: 477-489.

75. FAO, Food wastage.

76. FAO (Food and Agriculture Organization of the United Nations). 2015. Global Initiative on food loss and waste reduction. Accessed June 1, 2017. http://www. fao.org/3/a-i4068e.pdf.

77. World Bank. 2014. Food loss and waste a barrier poverty reduction. Accessed June 1, 2017. http://www.worldbank.org/en/news/press-release/2014/02/27/ food-loss-waste-barrier-poverty-reduction.

78. Nakicenovic, Nebojsa, Joseph Alcamo, A. Grubler, K. Riahi, R. A. Roehrl, H-H. Rogner, and N. Victor.2000. Special Reporton Emissions Scenarios (SRES), A Special Report of Working Group III of the Intergovernmental Panel on Climate Change. Cambridge University Press; World Bank (2012). What a waste: A global review of solid waste management. Accessed June 1, 2017. https://siteresources.worldbank.org/INTURBANDEVELOPMENT/Resources/336387-1334852610766/ What_a_Waste2012_Final.pdf

79. Goldin, Ian, and Mike Mariathasan. 2014. Future opportunities, future shocks: Key trends shaping the global economy and society. Perspectives. Citi Global.

80. Moragues-Faus, Ana, and Kevin Morgan. 2015. Reframing the foodscape: the emergent world of urban food policy. Environment and Planning A 47(7), $1558-1573$.

81. The World Bank, Urban development

82. Reardon, Thomas, and C. Peter Timmer. 2014. Five inter-linked transformations in the Asian agrifood economy: Food security implications. Global Food Security, 3(2), 108-117; Hollinger, Frank, \& John M. Staatz. 2015. Agricultural growth in West Africa. Market and Policy Drivers. Rome: African Development Bank and the Food and Agriculture Organization of the United Nations.

83. Reardon, Thomas. 2015. The hidden middle: the quiet revolution in the midstream of agrifood value chains in developing countries. Oxford Review of Economic Policy, 31(1), 45-63; Deichmann, Uwe, Forhad Shilpi, and Renos Vakis. 2009. Urban proximity, agricultural potential and rural non-farm employment: Evidence from Bangladesh. World Development, 37(3), 645-660.

84. FAO (Food and Agriculture Organization of the United Nations). 2013. Smallholder integration in changing food markets. Accessed June 1, 2017. http://www.fao.org/docrep/018/i3292e/i3292e.pdf. 
85. Ibid; IFAD (The International Fund for Agricultural Development). 2016. Rural development report 2016. Agrifood markets and value chains. Accessed June 1, 2017. https://www.ifad.org/documents/30600024/8f07f4f9-6a91-496a-89c1d1b120f8de8b; The World Bank. 2008. World Development Report 2008. Bringing agriculture to the market. Accessed June 1, 2017. http://siteresources.worldbank. org/INTWDRS/Resources/477365-1327599046334/8394679-1327606607122/ WDR08_09_ch05.pdf; Armah, Jon, Katie Schneider, Robert Plotnick, and Mary Kay Gugerty. 2010. Smallholder contract farming in Sub-Saharan Africa and South Asia. EPAR Technical Report. Accessed June 1, 2017. https://d7stage.evans. uw.edu/sites/default/files/public/Evans\%20UW_Request\%2060_Contract\%20 farming_5\%20March\%202010.pdf; Das Gupta, S., T. Reardon, B. Minten, and S. Singh. 2010. The transforming potato value chain in India: from a commercialized-agriculture zone (Agra) to Delhi. Report of Value Chains Component of Asian Development Bank RETA (13 th) IFPRI Project on Policies For Ensuring Food Security In South And Southeast Asia.

86. Ibid.

87. Cago, L. 2016. Countries Most Dependent On Others For Food. Accessed June 1, 2017. http://www.worldatlas.com/articles/the-countries-importing-the-mostfood-in-the-world.html.

88. IFPRI, Global food policy report.

89. OECD/FAO.2016. OECD-FAO Agricultural Outlook 2016-2025, OECD Publishing, Paris. Accessed June 1, 2017. http://dx.doi.org/10.1787/agr_ outlook-2016-en.

90. MacDonald, Graham K., Kate A. Brauman, Shipeng Sun, Kimberly M. Carlson, Emily S. Cassidy, James S. Gerber, and Paul C. West. 2015. Rethinking Agricultural Trade Relationships in an Era of Globalization. BioScience 65 (3): 275-289.

91. OECD/FAO, OECD-FAO Agricultural Outlook.

92. Anderson, Kym, and Anna Strutt. 2016. Impacts of emerging Asia on African and Latin American trade: projections to 2030. The World Economy 39(2): 172-194.

93. United Nations Trade Statistics. Accessed June 1, 2017. https://comtrade.un.org/ data/

94. Reardon et al., Five inter-linked transformations

95. National Development and Reform Commission and Ministry of Industry and Information Technology. 2012. 12th Five-Year Plan for the food-processing industry.

96. Proctor, Felicity J., and Julio A. Berdegué.. 2016. Food systems at the rural-urban interface. Working Paper series $\mathrm{N}^{\circ} 194$. Rimisp, Santiago, Chile; Cazzuffi, Chiara, Mariana Pereira-López, and Isidro Soloaga. 2014. Local poverty reduction in Chile and Mexico: The role of food manufacturing growth. Food Policy 68: 160-185; Rankin, Marlo, Siobhan Kelly, Eva Galvez-Nogales, Cora Dankers, Toshi Ono, Massimo Pera, Allison Marie Loconto, David Neven, Florence Tartanac, and Emilie Vandecandelaere.2016. The transformative power of agrifood industry development: policies and tools for restructuring the agricultural sector towards greater added value and sustainable growth. In ESA Conference on Rural Transformation, Agricultural and Food System Transition: Building the evidence base for policies that promote sustainable development, food and nutrition security and poverty reduction, p. $n p$.

97. Berdegué, Julio A., Fernando Carriazo, Benjamín Jara, Félix Modrego, and Isidro Soloaga. 2015. Cities, territories, and inclusive growth: Unraveling urban-rural linkages in Chile, Colombia, and Mexico. World Development 73: $56-71$.

98. Smit, W. (2016). Urban governance and urban food systems in Africa: Examining the linkages. Cities, 58, 80-86; Hollinger and Staatz, Agricultural growth. 
99. Zhao, Miaoxi, Xingjian Liu, Ben Derudder, Ye Zhong, and Wei Shen. 2015. Mapping producer services networks in mainland Chinese cities. Urban Studies 52(16), 3018-3034; Reardon, Thomas, and C. Peter Timmer. 2012. The economics of the food system revolution. Annu. Rev. Resour. Econ. 4(1): 225-264.

100. Zhang, Qian Forrest, and Zi Pan. 2013. The Transformation of Urban Vegetable Retail in China: Wet Markets, Supermarkets, and Informal Markets in Shanghai. Journal of Contemporary Asia 43(3): 497-518.

101. Minot, Nicholas, Randy Stringer, Wendy Umberger, and Wahida. 2013. Urban shopping patterns in Indonesia and implications for food security. Accessed June 1, 2017. https://www.adelaide.edu.au/global-food/documents/ urban-shopping-patterns-indonesia-implications.pdf; Wei, Bo. 2011. The cold chain management in supermarket: Case study on the fresh food logistics in a supermarket. Master's thesis. Univeristy of Gavle.

102. Zhang et al., Transformation of urban.

103. Tsuchiya, Kazuaki, Yuji Hara, and Danai Thaitakoo.2015. Linking food and land systems for sustainable peri-urban agriculture in Bangkok Metropolitan Region. Landscape and Urban Planning 143: 192-204.

104. Hollinger and Staatz, Agricultural growth; Woolverton and Frimpong, Consumer demand

105. Woldu, Thomas, Girum Abebe, Indra Lamoot, and Bart Minten. 2013. Urban food retail in Africa: The case of Addis Ababa, Ethiopia. Ethiopia Strategy Support Program II Working Paper 50; Durkin, Andrea. 2016. Investing to nourish India's cities. The Chicago Council on Global Affairs.

106. Zameer, Asif, and Deepankar Mukherjee. 2011. Food and grocery retail: patronage behavior of Indian urban consumers. South Asian Journal of Management 18(1): 119-134; Panda, Rajesh, and Biranchi Narayan Swar. 2013. Online shopping: An exploratory study to identify the determinants of shopper buying behaviour. International Journal of Business Insights \& Transformation 7(1); Snyder, Jason, Claire Ijumba, David Tschirley, and Thomas Reardon. 2015. Local Response to the Rapid Rise in Demand for Processed and Perishable Foods: Results of an Inventory of Processed Food Products in Dar es Salaam. Feed the Future Innovation Lab for Food Security Policy; Goswami, Paromita, and Mridula S. Mishra. 2009. Would Indian consumers move from kirana stores to organized retailers when shopping for groceries?. Asia Pacific Journal of Marketing and Logistics 21(1): 127-143; Chattopadhyay, Ayan. 2013. Consumer shopping behaviour in the new era of retailing: An empirical study on food and grocery and apparel purchase in East India. Indian Journal of Marketing 43(12): 47-57; Ali, Jabir, Sanjeev Kapoor, and Janakiraman Moorthy. 2010. Buying behaviour of consumers for food products in an emerging economy. British Food Journal 112(2): 109-124; Tschirley et al., Rise of a middle class; Oltmans, Shelley Jayne. 2013. Case study on the food retail environment of Accra, Ghana. Graduate Theses and Dissertations, Iowa State University, Chicago; Woolverton and Frimpong, Consumer demand; Biyani, Shradha. 2011. Urban Poor Food Systems: An Analysis of Food Access in Millennial Delhi.

107. McKinsey \& Company, Perspectives on retail.

108. Stuckler, David, Martin McKee, Shah Ebrahim, and Sanjay Basu. 2012. Manufacturing epidemics: the role of global producers in increased consumption of unhealthy commodities including processed foods, alcohol, and tobacco. PLoS Medicine 9(6): e1001235.

109. Reardon, Thomas. 2016. Growing food for growing cities: Transforming food systems in an urbanizing world. The Chicago Council on Global Affairs.

110. Tschirley et al., Rise of a middle class.

111. Reardon, Growing food 
112. Zheng, Zhihao, Shida R. Henneberry, Yinyu Zhao, and Ying Gao. 2015. Income growth, urbanization, and food demand in China. Agricultural \& Applied Economics Association's 2015 AAEA Annual Meeting, San Francisco, CA, July 26-28.

113. McKinsey \& Company, Perspectives on retail.

114. Berdegué, Julio A., and Felicity J. Proctor. 2014. Cities in the rural transformation. No. 122. working paper series; Reardon, Growing food; Tschirley et al., Rise of a middle class; Berdegue, Cities in the rural; Minten, Bart. 2008. The food retail revolution in poor countries: Is it coming or is it over? Economic Development and Cultural Change 56(4): 767-789; Woolverton and Frimpong, Consumer demand; Ibid.

115. Reardon, Growing food.

116. Gómez, Miguel I., and Katie D. Ricketts. 2013. Food value chain transformations in developing countries: Selected hypotheses on nutritional implications. Food Policy 42: 139-150.

117. Minot, Urban shopping patterns.

118. Hollinger and Staatz, Agricultural growth; Woolverton and Frimpong, Consumer demand.

119. Lançon, Frédéric, and Idrissa Wade. 2016. Urbanisation, changing tastes and rural transformation in West Africa; Rankin, Transformative power

120. Hollinger, F., \& Staatz, J. M. 2015. Agricultural growth in West Africa. Market and Policy Drivers. Rome: African Development Bank and the Food and Agriculture Organization of the United Nations.

121. Staatz, John, and Frank Hollinger. 2016. West African food systems and changing consumer demands. No. 4. OECD Publishing.

122. IGD (The Institute of Grocery Distribution). 2017. Three trends shaping Asian grocery in 2017. Accessed June 1, 2017. https://www.igd.com/articles/article-viewer/t/three-trends-shaping-asian-grocery-in-2017/i/16196; Askew, Katy, 2016. The food industry in 2016-Tapping global growth in e-commerce. Just-Food. Accessed June 1, 2017. https://www.just-food.com/ management-briefing/the-food-industry-in-2016-tapping-global-growth-in-ecommerce_id132013.aspx; FIA (Food Industry Asia). 2017. Singapore Online Grocery to more than triple by 2020. Accessed June 1, 2017. https://foodindustry.asia/singapore-online-grocery-to-more-than-triple-by-2020.

123. Hollinger and Staatz, Agricultural growth.

124. Food Marketing Institute. 2016. U.S. grocery shopping trends in 2016. Accessed June 1, 2017. https://www.fmi.org/forms/store/ProductFormPublic/ u-s-grocery-shopper-trends-2016; Deloitte. 2016. Capitalizing on the shifting consumer food value equation. Accessed June 1, 2017. https://www2.deloitte. $\mathrm{com} /$ content/dam/Deloitte/us/Documents/consumer-business/us-fmi-gmareport.pdf; Nielsen. 2016. What's in our food and on our mind. Accessed June 1, 2017. http://www.nielsen.com/us/en/insights/reports/2016/whats-inour-food-and-on-our-minds.html; Khare, Arpita. 2015. Antecedents to green buying behaviour: a study on consumers in an emerging economy. Marketing Intelligence \& Planning, 33(3), 309-329; Banerjee, S., A. Joglekar, and S. Kundle. 2013. Consumer awareness about convenience food among working and non-working women. IJSR-International Journal of Scientific Research, 2(10): 1-4; Morisset, Michel, and Pramod Kumar. 2008. Trends and pattern of consumption of value added foods in India. Structure and Performance of the Food Processing Industry in India; Indian Statistical Institute: New Delhi, India.

125. Dubbeling, Marielle, Joy Carey, and Katrin Hochberg. 2016. The role of private sector in city region food systems.

126. Tschirley, David. 2010. Opportunities and constraints to increased fresh produce trade in East and Southern Africa. In 4th Video Conference under 
AAACP-funded Series of High Value Agriculture Seminars. Accessed June 1, 2017. http://citeseerx. ist. psu. edu/viewdoc/download; Oltmans, Cast study; Woolverton and Frimpong, Consumer demand.

127. FIES is a direct measurement of people's access to food derived from the widely used and validated experience-based food security scales in the United States of America and in Latin America and the Caribbean.

128. FAO (Food and Agriculture Organization of the United Nations). 2016. FAO's Voices of the Hungry. Accessed June 1, 2017. www.fao.org/in-action/ voices-of-the-hungry/en/.

129. Battersby, Jane. 2010. Beyond the food desert: Finding ways to speak about urban food security in South Africa. Geografiska Annaler: Series B, Human Geography 94, no. 2: 141-159; Frayne, Bruce, W. Pendleton, J. Crush B. Acquah, J. Battersby-lennard, E. Bras, A. Chiweze et al. 2010. The state of urban food insecurity in Southern Africa. Urban Food Security Series 2. Queen's University and AFSUN: Kingston and Cape Town; World Food Program. Adapting to an urban world. Accessed June 1, 2017. http://fscluster.org/sites/default/files/documents/adapting_to_an_urban_world_somalia_urban_assessment_report_ somalia_fsc_0.pdf.

130. Riley, Liam, and Belinda Dodson. 2016. Rapid Urbanisation, Urban Food Deserts and Food Security in Africa. Cham: Springer International Publishing; Raimundo, I., and W. Pendleton. 2016. The state of food insecurity in Maputo, Mozambique. Southern African Migration Programme; Kumar, Naveen, and Suresh Chand Aggarwal. 2003. Patterns of consumption and poverty in Delhi slums. Economic and Political Weekly: 5294-5300.

131. Cannuscio, Carolyn C., Karyn Tappe, Amy Hillier, Alison Buttenheim, Allison Karpyn, and Karen Glanz. 2013. Urban food environments and residents' shopping behaviors. American Journal of Preventive Medicine 45(5): 606-614.

132. Battersby, Beyond the food desert; Crush, Jonathan, Bruce Frayne, and Wade Pendleton. 2012. The Crisis of Food Insecurity in African Cities. Journal of Hunger \& Environmental Nutrition 7.2-3: 271-92.

133. Rudolph, M., Florian Kroll, S. Ruysenaar, and T. Dlamini. 2012. The state of food insecurity in Johannesburg. Urban Food Security Series No. 12. Kingston and Cape Town: AFSUN; Crush, Crisis of food insecurity; OECD (Organization for Economic Co-operation and Development). 2015. Latin American competition forum. Accessed June 1, 2017. http://www. oecd.org/officialdocuments/publicdisplaydocumentpdf/?cote=DAF/COMP/ LACF $/$ A (2015) 1 \&docLanguage $=$ En .

134. Frayne, State of urban food insecurity; Tacoli, C., and B. Vorley. 2015. Reframing the debate on urbanization, rural transformation and food security. International Institute for Environment and Development, United Nations Population Fund.

135. Reid, David McHardy, Eugene H. Fram, and Chi Guotai. 2010. A study of Chinese street vendors: How they operate. Journal of Asia-Pacific Business 11(4): 244-257; Shah, Parth, and Naveen Mandava, eds. 2005. Law, liberty, and livelihood: making a living on the street. Academic Foundation; Patel, Kirit, David Guenther, Kyle Wiebe, and Ruth-Anne Seburn. 2014. Promoting food security and livelihoods for urban poor through the informal sector: a case study of street food vendors in Madurai, Tamil Nadu, India. Food security 6(6): 861-878.

136. Shah and Mandava, Law, liberty, and livelihood.

137. Reid et al., A study of Chinese street vendors.

138. Smit, Urban governance; Patel et al., Promoting food security.

139. IFPRI, Global food policy report.

140. Feeding an Urban World: A Call to Action. 2013. The Chicago Council on Global Affairs. 
141. Crush et al., Crisis of food insecurity; Tacoli and Vorley, Reframing the debate; Pendleton, Crisis of food insecurity.

142. Pendleton, Wade, and Ndeyapo Nickanor. 2016. The State of Food Insecurity in Windhoek, Namibia (No. 14). Southern African Migration Programme.

143. Durkin, Investing to nourish India's cities; Department of Food \& Public Distribution. National Food Security Act (NFSA). 2013. Accessed June 1, 2017. http://dfpd.nic.in/nfsa-act.htm.

144. Frayne, Bruce, and Cameron McCordic. 2015. Planning for food secure cities: Measuring the influence of infrastructure and income on household food security in Southern African cities. Geoforum 65: 1-11.

145. Cohen, Marc J., and James L. Garrett. 2010. The food price crisis and urban food (in)security. Environment and Urbanization 22(2): 467-482; Crush, Jonathan, and Bruce Frayne. 2011. Supermarket expansion and the informal food economy in Southern African cities: implications for urban food security. Journal of Southern African Studies 37(4): 781-807.

146. Minten, Bart, Thomas Reardon, and Rajib Sutradhar. 2010. Food prices and modern retail: The case of Delhi. World Development 38(12): 1775-1787.

147. Minten, Bart. 2008. The food retail revolution in poor countries: Is it coming or is it over? Economic Development and Cultural Change 56(4): 767-789.

148. Waldu, Thomas, Girum Abede, Indra Lamoot, and Bart Minten. 2013. Urban food retail in Africa: The case of Addis Ababa, Ethiopia Strategy Support Program II Working Paper 50.

149. Minten, Bart, and Thomas Reardon. 2008. Food prices, quality, and quality's pricing in supermarkets versus traditional markets in developing countries. Appl Econ Perspect Policy 30 (3): 480-490.

150. United Nations. 2016. World Cities Report 2016. World Cities Report; EuroStata. 2016. Urban Europe: Statistics on cities, towns and suburbs. Accessed June 1, 2017. http://ec.europa.eu/eurostat/documents/3217494/7596823/KS-01-16-691EN-N.pdf.

151. RUAF Foundation, 2015. City region food systems. Urban Agriculture Magazine 29. Leusden, The Netherlands. FAO (Food and Agriculture Organization of United Nations) and RUAF Foundation. 2015. A vision for city region food systems. Rome, Italy. Accessed June 1, 2017. http://www.fao.org/3/a-i4789e.pdf.

152. Wu, Fulong. 2017. Chinas emergent city-region governance: A new form of state spatial selectivity through state-orchestrated rescaling. International Journal of Urban and Regional Research 40 (6): 1134-1151.

153. Si, Zhenzhong, Jonathan Crush, Steffanie Scott, and Taiyang Zhong. 2016. The Urban Food System of Nanjing, China, No. 1. Hungry Cities Partnership Report.

154. Foster, Thomas, Guido Santini, David Edwards, Katie Flanagan, and Makiko Taguchi. 2015. Strengthening Urban Rural Linkages Through City Region Food Systems. Regional Development Dialogue, 35.

155. Adam-Bradford, Andrew, and René van Veenhuizen. 2015. Role of urban agriculture in disasters and emergencies. In: de Zeeuw H. and P. Drechsel (editors). 2015. Cities and Agriculture: Developing Resilient Urban Food Systems. Earthscan Food and Agriculture, Routledge.

156. UNHCR's Strategic Direction 2017-2021. 2017. UNHCR. Accessed July 1, 2017. www.unhcr.org/5894558d4.pdf.

157. United Nations. Percentage of total population living in coastal areas. Accessed July 1, 2017. http://www.un.org/esa/sustdev/natlinfo/indicators/methodology_ sheets/oceans_seas_coasts/pop_coastal_areas.pdf.

158. Ibid.

159. Forster, Milan Urban Food Policy Pact.

160. USDA (United States Department of Agriculture). 2016. Urban agriculture toolkit. Accessed August 1, 2017. https://www.usda.gov/sites/default/files/ 
documents/urban-agriculture-toolkit.pdf; Dubbeling, M., Camelia Bucatariu, Guido Santini, Carmen Vogt, and Katrin Eisenbeiß. 2016. City region food systems and food waste management: Linking urban and rural areas for sustainable and resilient development. GIZ, FAO and RUAF.

161. Rolfes, L., Jr. 2016. Improving Access to Agricultural Land through Leasing for Internally Displaced Persons in Georgia. World Bank Group. Accessed June 1, 2017. http://pubdocs.worldbank.org/en/522311462482847867/Improving-Accessto-Agricultural-Land-through-Leasing-for-Internally-Displaced-Personsin-Georgia-KTF-041916.pdf

162. IFPRI, Global food policy report.

163. Viljoen, André, Johannes Schlesinger, Katrin Bohn and Axel Drescher. In: de Zeeuw H. and P. Drechsel (editors). 2015. Cities and Agriculture: Developing Resilient Urban Food Systems. Earthscan Food and Agriculture, Chapter 4. Agriculture in urban design and spatial planning. Accessed June 1, 2017. http://www.ruaf.org/ agriculture-urban-design-and-spatial-planning; Romer, Paul. (2012, December). Urbanization as opportunity. In presentation to the World Bank's Sixth Urban Research and Knowledge Symposium, October 2012, Washington DC.

164. Ibid.

165. Global Trends 2030: Alternative Worlds. 2012. National Intelligence Council. Accessed June 1,2017.https://www.dni.gov/files/documents/GlobalTrends_2030. pdf.

166. Yeboah, F. K., and Jayne, T. S. 2017. Africa's evolving employment trends: implications for economic transformation. Africagrowth Agenda, 18-22.

167. Vos, Rob. 2017. Unpublished internal comments, FAO (Food and Agriculture Organization of the United Nations); Dubbeling, Marielle. 2017. Unpublished internal comments, RUAF Foundation.

168. As of 2009, the entire World Wide Web was estimated to contain close to one half zettabyte (Wray). By 2020, this will have increased 100-fold.

169. Marr, Bernard. 2015. Big Data: 20 Mind-Boggling Facts Everyone Must Read. Accessed June 1, 2017. https://www.forbes.com/sites/bernardmarr/2015/09/30/ big-data-20-mind-boggling-facts-everyone-must-read/\#444b4d7c17b1.

170. A sensor is a device that detects and responds to some type of input from the physical environment, whether light, heat, motion, moisture, pressure or some other environmental phenomenon. The output is generally a signal that is converted to human-readable display at the sensor location or transmitted electronically over a network for reading or further processing (Rouse 2016).

171. New Jersey Institute of Technology. Big Data and the IoT: The future of the smart city. Accessed August 1, 2017. http://graduatedegrees.online.njit.edu/resources/ $\mathrm{mscs} / \mathrm{mscs}$-infographics/big-data-and-the-iot-the-future-of-the-smart-city/.

172. Koppenol, P., \& Divisional, A. 2016. Open data in a big data world. Chemistry International 38(2): 17.

173. Gurin, J. 2013. Big data vs open data - Mapping it out. Accessed June 1, 2017. http://www.opendatanow.com/2013/11/new-big-data-vs-open-data-mappingit-out/\#.WS2U5WjyuUm.

174. Smit, Urban governance.

175. The World Bank. City creditworthiness initiative: A partnership to deliver municipal finance. Accessed August 1, 2017. http://www.worldbank.org/en/ topic/urbandevelopment/brief/city-creditworthiness-initiative; UN Habitat. 2015. Urban economic development strategies. Accessed August 1, 2017. http://habitat3.org/wp-content/uploads/PU7-HABITAT-III-POLICY-PAPERFRAMEWORK.pdf; UN Habitat. 2011. The economic role of cities. Accessed August 1, 2017. https://unhabitat.org/economic-role-of-cities/.

176. FAO (Food and Agriculture Organization of the United Nations). 2011. The state of food and agriculture 2010-2011: Women in agriculture: Closing the 
gender gap for development. Rome. Italy: FAO. Accessed June 1, 2017. www. fao.org/docrep/013/i2050e/i2050e.pdf.

177. IFC (International Finance Corporation). 2016. Investing in women along agribusiness value chains. Accessed June 1, 2017. http://www.ifc.org/wps/wcm/connect/topics_ext_content/ifc_external_corporate_site/gender+at+ifc/priorities/ entrepreneurship/investing+in+women+along+agribusiness+value+chains.

178. RUAF Foundation. 2014. Urban agriculture: what and why? Accessed June 1, 2017. http://www.ruaf.org/urban-agriculture-what-and-why.

179. UCLG (United Cities and Local Governments)-Capacity and Institution Building. 2015. Financing urban and local development: the missing link in sustainable development finance. Global Taskforce. Accessed June 1, 2017. http://www.cib-uclg.org/cib-library/content/financing-urban-and-local-development-missing-link-sustainable-development.

180. Enabling the Business of Agriculture. 2017. The World Bank Group. doi:10.1596/978-1-4648-1021-3.

181. Sustainable Business Network. Investing in food and farming. (n.d.). Accessed June 1, 2017. http://sustainable.org.nz/sustainability-news/investing-in-foodand-farming\#.WS3E4WjyuUk.

182. The World Bank. 2015. Small and Medium Enterprises (SMEs) finance. Accessed June 1, 2017. http://www.worldbank.org/en/topic/financialsector/brief/ smes-finance.

183. Spatafora, Nikola. 2014. Remittances and Vulnerability in Developing Countries: Results from a new Dataset. Accesed June 1, 2017. http://blogs.worldbank. $\mathrm{org} /$ peoplemove/remittances-and-vulnerability-developing-countries-results-new-dataset.

184. Guiliano, Paola, and Marta Ruiz-Arranz. 2005. Remittances, Financial Development, and Growth. IMF Working Paper.

185. FAO (Food and Agriculture Organization of the United Nations). 2017. Agricultural investment funds for developing countries. 2010. Accessed June 1, 2017. http://www.fao.org/fileadmin/user_upload/ags/publications/investment_ funds.pdf.

186. European Central Bank. 2014. Survey on the access to finance of enterprises (SAFE) in the Euro Area. (2014). ECB. Accessed June 1, 2017. https://www.ecb. europa.eu/stats/ecb_surveys/safe/html/index.en.html.

187. The World Bank. 2016. Doing Business 2016: Measuring regulatory quality and efficiency. World Bank Group. doi:10.1596/978-1-4648-0667-4.

188. Bruhn, Miriam. 2016. Policies for SME growth: what works, what doesn't? Accessed June 1,2017.http://pubdocs.worldbank.org/en/269861478801095302/ Policies-for-SME-Growth.pdf.

189. The World Bank. Doing Business- Getting Credit. (n.d.). Accessed June 1, 2017. http://www.doingbusiness.org/data/exploretopics/getting-credit/.

190. RUAF Foundation. RUAF 10 Years. 2011. Accessed June 1, 2017. http://www. ruaf.org/sites/default/files/UAM_25.pdf.

191. Adam-Bradford and Van Veenhuizen, Role of urban agriculture.

192. RUAF Foundation and ICLEI Local Governments for Sustainability. 2013. Cityfood: Linking cities on urban agriculture and urban food systems. Accessed June 1, 2018. http://resilient-cities.iclei.org/fileadmin/sites/resilient-cities/files/ Full_papers/RUFS_2013_CITYFOOD_12pages_FINAL_hq.pdf.

193. Nwanze, K. F. (n.d.). Viewpoint: Smallholders can feed the world. Accessed June 1, 2017. https://www.ifad.org/documents/10180/ca86ab2d74f0-42a5-b4b6-5e476d321619.

194. Townsend, Robert, Rui Manuel Benfica, Ashesh Prasann, Maria Lee, Parmesh Shah. 2017. Future of Food: Shaping the Food System to Deliver Jobs. World Bank Group. Accessed August 1, 2017. http://documents.worldbank. 
org/curated/en/406511492528621198/Future-of-food-shaping-the-food-systemto-deliver-jobs.

195. Ibid.

196. Yasmeen, Gisèle. 2001. Workers in the urban "informal" food sector: innovative organizing strategies. FAO. Accessed June 1, 2017. http://www.fao.org/3/ay1931m/y1931m04.pdf.

197. Floro, Maria Sagrario, and Ranjula Bali Swain. 2013. Food security, gender, and occupational choice among urban low-income households. World Development 42: 89-99; Patel, Kirit, David Guenther, Kyle Wiebe, and Ruth-Anne Seburn. 2014. Promoting food security and livelihoods for urban poor through the informal sector: a case study of street food vendors in Madurai, Tamil Nadu, India. Food Security 6(6), 861-878.

198. White, Stephanie A. and Michael W Hamm. 2014. Urban Agriculture and a Planning Approach to Urban Food Systems. Center Report Series 4. Global Center for Food Systems Innovation, Michigan State University, East Lansing, Michigan, USA $23 \mathrm{pp}$.

199. ILO (International Labour Office). 2014. Transitioning from the informal to the formal economy. Accessed June 1, 2017. http://www.ilo.org/wcmsp5/groups/ public/---ed_norm/---relconf/documents/meetingdocument/wcms_218128. pdf.

200. The Economist. 2016. Bringing light to the grey economy. Accessed June 1, 2017. http://www.economist.com/news/international/21708675-new-technology-may-persuade-informal-businesses-and-workers-become-formal-bringing-light.

201. Eighth Joint Annual Meetings of the African Union Specialized Technical Committeeon Finance, Monetary Affairs, Economic Planning and Integration and the Economic Commission for Africa Conference of African Ministers of Finance, Planning and Economic Development (2015, March 25). Accessed June 1, 2017. http://www.uneca.org/sites/default/files/uploaded-documents/CoM/com2015/ com2015_overview-economic-social-conditions-africa-e1500193_en.pdf.

202. Fraser, Elizabeth, Malambo Moonga, and Johanna Wilkes. 2014. The role of the informal economy in addressing urban food insecurity in Sub-Saharan Africa. Centre for International Governance Innovation.

203. ILO (International Labour Organization). 2015. Recommendation No. 204 concerning the transition from the informal to the formal economy. Accessed June 1, 2017. http://www.ilo.org/ilc/ILCSessions/104/texts-adopted/ WCMS_377774/lang--en/index.htm.

204. Pansing, Cynthia, John Fisk, Stacia Kiraly, Arlin Wasserman, Michelle Muldoon, and Tavia Benjamin. 2013. A Roadmap for city food sector innovation \& investment. Arlington, VA : Wallace Center at Winrock International.

205. Kabasa, John David, Johann Kirsten, and Isaac Minde. 2015. Implications of changing agri-food system structure for agricultural education and training in Sub-Saharan Africa. Journal of Agribusiness in Developing and Emerging Economies 5(2): 190-199.

206. ILO (International Labour Organization). 2015. Toward solutions for youth employment: A 2015 baseline report. Accessed June 1, 2017. http://www.ilo.org/ wcmsp5/groups/public/---ed_emp/documents/publication/wcms_413826.pdf.

207. Allen et al, Agrifood youth employment.

208. KLab. Accessed June 1, 2017. https://klab.rw/.

209. Townsend et al., Future of Food.

210. Ibid.

211. Lindsay, John, and Sara Babb. 2016. Measuring employment outcomes for workforce development. FHI360. Accessed June 1, 2017. https://www.usaid.gov/sites/ default/files/documents/1865/Measuring_Employment_Outcomes_Briefing_ Paper.pdf. 
212. Townsend et al., Future of Food.

213. The World Bank. 2017. Information \& Communication Technologies Overview. Accessed August 1, 2017. http://www.worldbank.org/en/topic/ict/overview\#1.

214. Kellou, Imene. 2014. Alternative food systems: The case of Agri-food SMEs. Proceedings in Food System Dynamics: 155-160.

215. Tschirley, David. 2017. More and better jobs for youth in agrifood system. 2017. Presentation at the World Bank jointly with Julie Howard and Kwame Yeobah, Washington DC, May 9, 2017.

216. Bruhn, What works, what doesn't?.

217. Ojeka, S. 2011. Tax Policy and the Growth of SMEs: Implications for the Nigerian Economy. Research Journal of Finance and Accounting, 2(2).

218. Bruhn, What works, what doesn't?

219. UNIDO (United Nations Industrial Development Organization). 2017. Integrated agro-industrial parks in Ethiopia. (n.d.). Accessed June 1, 2017. https://isid. unido.org/files/Ethiopia/Integrated-Agro-Industrial-Parks-Overview.pdf.

220. TheWorldBank.2012.Lightmanufacturingin Africa.Accessed June 1,2017.http:// siteresources.worldbank.org/DEC/Resources/LightManufacturingInAfricaFullReport.pdf.

221. Reardon, The hidden middle.

222. Staatz, John M. 1994. The strategic role of food and agricultural systems in fighting hunger through fostering sustainable economic growth. Department of Agricultural Economics, Michigan State University.

223. Estrada-Nora,M.2016.Eurofresh.AccessedJune1,2017.http://www.eurofresh-distribution.com/news/evolution-wholesale-markets-food-logistics-platforms.

224. Hollinger and Staatz, Agricultural growth

225. IFPRI, Global food policy.

226. Dablanc, Laetitia, Genevieve Giuliano, Kevin Holliday, and Thomas O'Brien. 2013. Best practices in urban freight management: Lessons from an international survey. Transportation Research Record: Journal of the Transportation Research Board 2379: 29-38.

227. Hollinger and Staatz, Agricultural growth.

228. Gálvez Nogales, E., and M. Webber. 2017. Territorial tools for agro-industry development. FAO. Accessed June 1, 2017. http://agris.fao.org/agris-search/ search.do? recordID $=$ XF2017003410.

229. Galvez-Nogales, E. (2010). Agro-based clusters in developing countries: staying competitive in a globalized economy. FAO. Accessed June 1, 2017. http:// www.fao.org/docrep/012/i1560e/i1560e.pdf.

230. Iimi, Atsushi, Richard Martin Humphreys, and Sevara Melibaeva. 2015. Firms? locational choice and infrastructure development in Tanzania: instrumental variable spatial autoregressive model; Siba, E., Söderbom, M., Bigsten, A., \& Gebreeyesus, M. (2012). Enterprise agglomeration, output prices, and physical productivity: Firm-level evidence from Ethiopia (No. 2012/85). WIDER working paper.

231. Ali, Merima, and Jack Peerlings. 2012. Farm households and nonfarm activities in Ethiopia: does clustering influence entry and exit?. Agricultural Economics 43: 253-266.

232. Kutcher, Eric, Olivia Nottebohm, and Kara Sprague. 2014. Grow fast or die slow. Accessed June 1, 2017. http://www.mckinsey.com/industries/high-tech/ our-insights/grow-fast-or-die-slow.

233. Nogales and Webber, Territorial tools.

234. Banerjee, Chirantan, and Lucie Adenaeuer. 2014. Up, up and away! The economics of vertical farming. Journal of Agricultural Studies 2(1): 40-60; Townsend, Future of Food. 
235. Thornblad, Mattew. 2017. Tapping into a triple win: Food cold chain for developing countries. Presentation at the World Bank Agriculture Forum Learning Week, Washington D.C.; Global Food Cold Chain Council .2015. Expanding the Food Cold Chain for a Healthier Planet. Accessed June 1, 2017. http://www. foodcoldchain.org/background.

236. Bukeviciute et al., Functioning of the food supply chain and its effect on food prices in the European Union. European Commission. Office for infrastructures and logistics of the European Communities.

237. Baker, Phillip, and Sharon Friel. 2016. Food systems transformations, ultra-processed food markets and the nutrition transition in Asia. Globalization and Health 12(1): 80.

238. Bukeviciute, Functioning of the food supply chain.

239. The World Bank. 2016. Linking farmers to markets through productive alliances: An assessment of the World Bank experience in Latin America. World Bank, Washington, DC. () World Bank. Accessed June 1, 2017. https://openknowledge.worldbank.org/handle/10986/25752 License: CC BY 3.0 IGO."

240. Staatz, John, Andrew Kizito, Michael Weber, and Niama Nango Dembélé. 2014. Challenges in measuring the impact of Market Information Systems. Cahiers Agricultures 23: 317-24.

241. Parfitt et al., Food waste within food supply chains

242. Hanson, Craig and Peter Mitchell. 2017. The business case for reducing food loss and waste. ChaMPioNs 12: 7-8.

243. Buechler, S., and G. D. Mekala. 2006. Wastewater use for urban and peri-urban agriculture. Cities farming for the future: Urban agriculture for green and productive cities, R.v. Veenhuizen. IIRR/RUAF/IDRC. 243-273.

244. The Guardian. 2016. French law forbids food waste by supermarkets. Accessed June 1, 2017. https://www.theguardian.com/world/2016/feb/04/french-lawforbids-food-waste-by-supermarkets.

245. Simone d'Antonio. 2016. Milan leads fight against food waste-with ugly fruit and Michelin-starred soup kitchens. The Guardian. Accessed June 1, 2017. https://www.theguardian.com/cities/2016/oct/16/milan-fight-against-foodwaste-ugly-fruit-grassroots-world-food-day.

246. The Guardian. 2016. French law forbids food waste by supermarkets.

247. Parfitt et al., Food waste within food supply chains.

248. FAO (Food and Agriculture Organization of the United Nations). 2011. Global food losses and food waste - Extent, causes and prevention. Rome; HLPE ( The High Level Panel of Experts) Report. 2014. Food losses and waste in the context of sustainable food systems Extract from the Report: Summary and Recommendations. Committee on World Food Security; Lipinski, Brian, Craig Hanson, James Lomax, Lisa Kitinoja, Richard Waite, and Tim Searchinger. 2013. Reducing food loss and waste. World Resources Institute Working Paper.

249. Hanson, Craig, Brian Lipinski, Kai Robertson, Debora Dias, Ignacio Gavilan et al. 2017. Food Loss and Waste Protocol: Food loss and waste accounting and reporting standard. Accessed August 1, 2017. http://flwprotocol.org/wp-content/uploads/2017/05/FLW_Standard_final_2016.pdf.

250. FAO (Food and Agriculture Organization of United Nations). 2016. Food loss assessments: causes and solutions. Accessed June 1, 2017. http://www.fao.org/ fileadmin/user_upload/save-food/PDF/Kenya_Food_Loss_Studies.pdf.

251. FAO (Food and Agriculture Organization of United Nations). 2016. Social protection in protracted crises, humanitarian and fragile contexts. Accessed June 1, 2017. http://www.fao.org/3/a-i5656e.pdf.

252. Forster et al., Milan Urban Food Policy Pact.

253. Egyptian Food Bank. Experience and achievements. Accessed June 1, 2017. https://www.egyptianfoodbank.com/en/experience-and-achievements. 
254. Global Panel on Agriculture and Food Systems for Nutrition. 2016. Food Systems and Diets. Accessed June 1, 2017. https://www.glopan.org/foresight; IFPRI (International Food Policy Research Institute). 2016. Nourishing Millions: Stories of change in nutrition. Accessed June 1, 2017. http://ebrary. ifpri.org/cdm/ref/collection/p15738coll2/id/130395; World Cancer Research Fund International. Nourishing framework and policy database. Accessed June 1, 2017. http://www.wcrf.org/int/policy/our-publications.

255. Monteiro, Carlos Augusto, Geoffrey Cannon, Jean-Claude Moubarac, Ana Paula Bortoletto Martins, Carla Adriano Martins, Josefa Garzillo, Daniela Silva Canella et al. 2015. Dietary guidelines to nourish humanity and the planet in the twenty-first century. A blueprint from Brazil. Public Health Nutrition 18(13): 2311-2322.

256. Popkin, Barry M. 2006. Global nutrition dynamics: the world is shifting rapidly toward a diet linked with noncommunicable diseases. The American Journal of Clinical Nutrition 84(2): 289-298.

257. Marteau, Theresa M., Gareth J. Hollands, and Paul C. Fletcher. 2012. Changing human behavior to prevent disease: the importance of targeting automatic processes. Science 337(6101): 1492-1495.

258. A food swamp refers to an area or neighbourhood in a city where unhealthy foods are more readily available than healthy foods. Food swamps often exist in food deserts, where there are limited options for purchasing healthy foods. http://mdfoodsystemmap.org/wp-content/uploads/2013/01/Atlas_CLF-FoodSwamp_final.pdf

259. Anand et al., Food consumption.

260. Stuckler et al., Manufacturing epidemics

261. Jolly, Rhonda. 2011. Marketing Obesity?: Junk food, advertising and kids. Parliamentary Library; Hawkes, Corina, J. Jewell, and K. Allen. 2013. A food policy package for healthy diets and the prevention of obesity and diet-related non-communicable diseases: the NOURISHING framework. Obesity Reviews 14(S2): 159-168.

262. Andreyeva, Tatiana, Michael W. Long, and Kelly D. Brownell. 2010. The impact of food prices on consumption: a systematic review of research on the price elasticity of demand for food. American Journal of Public Health, 100(2): 216-222.

263. Hawkes, Corinna, Trenton G. Smith, Jo Jewell, Jane Wardle, Ross A. Hammond, Sharon Friel, Anne Marie Thow, and Juliana Kain. 2015. Smart food policies for obesity prevention. The Lancet, 385(9985): 2410-2421; Global Panel on Agriculture and Food Systems for Nutrition, 2016. Food systems and diets: Facing the challenges of the $21^{\text {st }}$ century. Accessed August 1, 2017. www.glopan. org/foresight; FAO (Food and Agriculture Organization of the United Nations). Toolkit on nutrition-sensitive agriculture and food systems. Accessed August 1 , 2017. http://www.fao.org/nutrition/policies-programmes/toolkit/en/; United Nations System Standing Committee on Nutrition. The ICN2 Framework for Action. Accessed August 1, 2017. https://www.unscn.org/files/cfs/ICN2Framework-for-Action.pdf.

264. Hawkes, Corinna, Sharon Friel, Tim Lobstein, and Tim Lang. Linking agricultural policies with obesity and noncommunicable diseases: a new perspective for a globalising world. Food Policy 37(3): 343-353.

265. Wyness, Laura A., Judith L. Butriss, and Sara A. Stanner. 2012. Reducing the population's sodium intake: the UK Food Standards Agency's salt reduction programme. Public health nutrition 15(2): 254-261; He, F. J., H. C. Brinsden, and G. A. MacGregor. 2014. Salt reduction in the United Kingdom: a successful experiment in public health. Journal of human hypertension 28(6): 345.

266. Masters, William A. 2016. Assessment of current diets: Recent trends by income and region. Global Panel on Agriculture and Food Systems for Nutrition, 2016. Food systems and diets: Facing the challenges of the $21^{\text {st }}$ century. 
267. Trieu, Kathy, Bruce Neal, Corinna Hawkes, Elizabeth Dunford, Norm Campbell, Rodrigo Rodriguez-Fernandez, Branka Legetic, Lindsay McLaren, Amanda Barberio, and Jacqui Webster. 2015. Salt reduction initiatives around the world-a systematic review of progress towards the global target. PloS one 10(7): e0130247.

268. Healthy diets are defined as:

- Adequate, comprising sufficient food for a healthy life.

- Diverse, containing a variety of foods, including plenty of fruits and vegetables, legumes and whole grains.

- Low in food components of public health concern: Sugars and salt consumed in moderation (with all salt iodised) and fats being unsaturated rather than saturated and trans fats.

Additionally, according to the WHO, the hallmarks of a healthy diet are abundant, diverse plant foods, limited or no ultra-processed foods such as sugar-sweetened beverages and processed meats, and appropriate consumption of other nutritious foods aligned with dietary needs for life stage. WHO (World Health Organization). 2015. Healthy diet. Accessed August 1, 2017. http:// www.who.int/mediacentre/factsheets/fs394/en/.

269. Fischer, C. Gonzalez, and Tara Garnett. 2016. Plates, pyramids, planet: Developments in national healthy and sustainable dietary guidelines: a state of play assessment. Rome: Food and Agriculture Organization of the United Nations and The Food Climate Research Network at The University of Oxford.

270. Monteiro et al., Dietary guidelines

271. Morgan, Kevin, and Roberta Sonnino. 2010. The urban foodscape: world cities and the new food equation. Cambridge Journal of Regions, Economy and Society $3(2), 209-224$.

272. Slow Food is a grassroots organization founded in Italy in the 1980s; it now boasts a global presence and seeks to reinvigorate interest in traditional cuisine and local food cultures and encourages sourcing of local fresh produce and livestock products.

273. Bailey, Rob, Antony Froggatt, and Laura Wellesley. 2014. Livestock-climate change's forgotten sector. Chatham House.

274. Zezza, Alberto, and Luca Tasciotti. 2010. Urban agriculture, poverty, and food security: empirical evidence from a sample of developing countries. Food policy $35,265-273$.

275. Poulsen, Melissa N., Philip R. McNab, Megan L. Clayton, and Roni A. Neff. 2015. A systematic review of urban agriculture and food security impacts in low-income countries. Food Policy 55, 131-146.

276. Van Veenhuizen, René. and George Danso. 2007. Profitability and sustainability of urban and peri-urban agriculture. FAO Agricultural Management, Marketing and Finance Occasional Paper 119. Rome: FAO; FAO (Food and Agriculture Organization of the United Nations). 2012. Growing greener cities: Africa. Accessed June 1, 2017. http://www.fao.org/docrep/016/i3002e/i3002e.pdf.

277. Personal communication during a visit to TrueFarms. 2017. http://www.truefarms.com/.

278. Orsini, Francesco, Remi Kahane, Remi Nono-Womdim, and Giorgio Gianquinto. 2013. Urban Agriculture in the developing world: a review. Agronomy for sustainable development 33(4), 695-720.

279. Qian, Wang. 2010. China cracks down on heavy metal pollution. China Daily. Accessed June 1, 2017. http://www.chinadaily.com.cn/china/2010-04/10/content_9711092.htm.

280. Herrle, Peter, Josefine Fokdal, Astrid Ley, and Sonja Nebel. 2016. The New Urban Agenda: The role of partnerships between organised civil society and governments in fostering a sustainable future for all in cities: Cities Alliance: Cities without Slums. 
281. WHO (World Health Organization). 2015. Global burden of foodborne diseases. Accessed June 1, 2017. http://www.who.int/foodsafety/areas_work/ foodborne-diseases/ferg/en/.

282. Food adulteration is the process by which the quality of food is lowered either by the addition of inferior quality material or by extraction of valuable ingredients. It not only includes the intentional addition or substitution of substances but biological and chemical contamination during the period of growth, storage, processing, transport and distribution of food products and is also responsible for the lowering or degradation of the quality of food products.

283. FAO (Food and Agriculture Organization of the United Nations). 2012. Improving food safety and quality along the chain to protect public health, support fair food trade and contribute to food security and economic development. Accessed June 1, 2017. www.fao.org/3/a-i2797e.pdf; FDA (U.S. Food and Drug Administration Center for Food Safety and Applied Nutrition). 2013. FDA's International food safety capacity-building plan. Accessed June 1, 2017. https://www.fda.gov/downloads/food/guidanceregulation/ucm341440.pdf.

284. Jaffee, Steven. 2017. Strengthening the case for food safety investments. Unpublished document at the World Bank.

285. SAI Global. ISO22000 and IFS international food standard, Accessed June 1, 2017. https://www.saiglobal.com/assurance/food-safety/?regid=4.

286. Rahmata, Suharni, Chew Boon Cheongb, Mohd Syaiful Rizal Bin Abd Hamidc. 2016. Challenges of Developing Countries in Complying Quality and Enhancing Standards in Food Industries. Procedia-Social and Behavioral Sciences 224: 445-451.

287. FAO (Food and Agriculture Organization of United Nations). 2005. Codex Alimentarius Commission. Accessed June 1, 2017. ftp://ftp.fao.org/codex/ Publications/ProcManuals/manual_15e.pdf.

288. GS1 (The global language of business). Traceability. Accessed June 1, 2017. http://www.gs1.org/traceability-retail.

289. Aung, Myo Min, and Yoon Seok Chang. 2014. Traceability in a food supply chain: Safety and quality perspectives. Food Control, 39, 172-184.

290. WHO (World Health Organization). Risk assessment. Accessed June 1, 2017. http://www.who.int/foodsafety/micro/riskassessment/en/.

291. Shanghai Press Conference. 2011. Accessed June 1, 2017. http://en.shio.gov.cn/ presscon/2012/01/13/1151771.html.

292. Cornelsen, Laura, Pablo Alarcon, Barbara Häsler, Djesika D. Amendah, Elaine Ferguson, Eric M. Fèvre, Delia Grace, Paula Dominguez-Salas, and Jonathan Rushton. 2016. Cross-sectional study of drivers of animal-source food consumption in low-income urban areas of Nairobi, Kenya. BMC Nutrition 2, no. 1: 70.

293. FAO (Food and Agriculture Organization of United Nations). Street food. Accessed June 1, 2017. http://www.fao.org/fcit/food-processing/street-foods/en/.

294. Ibid.

295. Uyttendaele, Mieke, Elien De Boeck, and Liesbeth Jacxsens. 2016. Challenges in food safety as part of food security: lessons learnt on food safety in a globalized world. Procedia Food Science 6, 16-22.

296. FAO (Food and Agriculture Organization of United Nations). 2011. Guidelines for risk categorization of food and food establishments applicable to ASEAN countries. Accessed June 1, 2017. http://www.fao.org/docrep/015/i2448e/i2448e00. pdf.

297. ILO (International Labor Office). 2016. Policy issues on street vending: An overview of studies in Thailand, Cambodia and Mongolia. Accessed June 1, 2017. http://www.ilo.org/wcmsp5/groups/public/---asia/---ro-Bangkok/documents/ publication/wcms_bk_pb_119_en.pdf. 
298. Von Holy, A., and F.M. Makhoane. 2006. Improving street food vending in South Africa: Achievements and lessons learned. International journal of food microbiology 111, no. 2: 89-92.

299. Hao, Haihong, Guyue Cheng, Zahid Iqbal, Xiaohui Ai, Hafiz I. Hussain, Lingli Huang, Menghong Dai, Yulian Wang, Zhenli Liu and Zonghui Yuan. 2014. Benefits and risks of antimicrobial use in food-producing animals. Frontiers in microbiology 5.

300. De Passillé, A. M., and J. Rushen. 2005. Food safety and environmental issues in animal welfare. Revue scientifique et technique-Office international des épizooties 24, no. 2 (2005): 757.

301. Ibid.

302. Main, D.C.J., S. Mullan, C. Atkinson, M. Cooper, J.H.M. Wrathall, H.J. Blokhuis. 2014. Best practice framework for animal welfare certification schemes. Trends in Food Science \& Technology 37, no. 2: 127-136.

303. Grace, Delia, Florence Mutua, Pamela Ochungo, Russ Kruska, Kate Jones, Liam Brierley, L. Lapar et al. 2012. Mapping of poverty and likely zoonoses hotspots. Zoonoses Project 4. Report to the UK Department for International Development. International Livestock Research Institute, Nairobi, Kenya: ILRI.

304. Berthe, Franck. 2016. One health: let's not have pandemics get in the way. Accessed June 1, 2017. http://blogs.worldbank.org/health/one-health-let-s-nothave-pandemics-get-way.

305. Townsend et al., Future of Food.

306. Secretariat of the Convention on Biological Diversity. 2012. Cities and biodiversity outlook. Accessed June 1, 2017. https://www.cbd.int/doc/health/cbo-action-policy-en.pdf.

307. UN HABITAT. 2011. Hot Cities: battle-ground for climate change. Accessed June 1, 2017. http://mirror.unhabitat.org/downloads/docs/E_Hot_Cities.pdf.

308. Garnett, Tara. 2011. Where are the best opportunities for reducing greenhouse gas emissions in the food system (including the food chain)? Food Policy 36: S23-S32.

309. The World Bank. 2010. Cities and climate change: an urgent agenda. Accessed June 1, 2017. http://siteresources.worldbank.org/INTUWM/ Resources/340232-1205330656272/CitiesandClimateChange.pdf.

310. EPA (United States Environmental Protection Agency). Heat islands. Accessed June 1, 2017. https://www.epa.gov/heat-islands/using-trees-andvegetation-reduce-heat-islands.

311. FAO (Food and Agriculture Organization of the United Nations). Food for the cities. Accessed June 1, 2017. ftp://ftp.fao.org/docrep/fao/011/ak003e/ak003e.pdf.

312. Altenburg, Tilman, Elmar Kulke, Aimée Hampel-Milagrosa, Lisa Peterskovsky, and Caroline Reeg. 2016. Making retail modernisation in developing countries inclusive. German Development Institute Discussion Paper 2: 2016.

313. The Water, energy \& food security resource platform. Nexus Platform. Accessed June 1, 2017. https://www.water-energy-food.org/about/introduction/.

314. Otoo, M. and P. Drechsel. 2015. Resource recovery from waste: Business models for energy, nutrient and water reuse. IWMI and Earthscan (in press) M. Otoo et al 268.

315. Deelstra, T., \& Girardet, H. 2000. Urban agriculture and sustainable cities. Bakker N., Dubbeling M., Gündel S., Sabel-Koshella U., de Zeeuw H. Growing cities, growing food. Urban agriculture on the policy agenda. Feldafing, Germany: Zentralstelle für Ernährung und Landwirtschaft (ZEL), 43-66.

316. FAO (Food and Agriculture Organization of the United Nations). Food for the cities. Accessed June 1, 2017. ftp://ftp.fao.org/docrep/fao/011/ak003e/ak003e05.pdf.

317. The United Nations. 2003. Water for people, water for life, Accessed June 1, 2017. http://www.un.org/esa/sustdev/publications/WWDR_english_129556e.pdf. 
318. Satterthwaite, David. 1999, The links between poverty and the environment in urban areas of Africa, Asia and Latin America. The Annals of the American Academy of Political and Social Science 590, no.1: 73-92.

319. Daigger, Glen T., Joshua P. Newell, Nancy G. Love, Nathan McClintock, Mary Gardiner, Eugene Mohareb, Megan Horst, Jennifer Blesh, and Anu Ramaswami. 2015. Scaling up agriculture in city-regions to mitigate FEW system impacts; Drechsel, Pay, Bernard Keraita, Olufunke O. Cofie, and Josiane Nikiema. 2015. Productive and safe use of urban organic wastes and wastewater in urban food production systems in low-income counties. Cities and Agriculture: Developing Resilient Urban Food Systems, 162.

320. EPA (United States Environmental Protection Agency). Green infrastructure. Accessed June 1, 2017. https://www.epa.gov/green-infrastructure/ what-green-infrastructure\#downspoutdisconnection.

321. De Zeeuw and Drechsel, Role of urban agriculture.

322. Cramer, Jacqueline. 2017. The Raw Materials Transition in the Amsterdam Metropolitan Area: Added Value for the Economy, Well-Being, and the Environment. Environment: Science and Policy for Sustainable Development 59(3), 14-21.

323. Environment. 2017. The raw materials transition in the Amsterdam Metropolitan Area: Added value for the economy, well-being, and the environment. Accessed August 1, 2017. http://www.environmentmagazine.org/ Archives/Back\%20Issues/2017/May-June\%202017/raw_materials_full.html.

324. FAO (Food and Agriculture Organization of the United Nations). Water-EnergyFood-Nexus. Accessed June 1, 2017. http://www.fao.org/energy/water-foodenergy-nexus/en/.

325. RUAF Foundation. Urban agriculture: what and why?. Accessed June 1, 2017. http://www.ruaf.org/urban-agriculture-what-and-why.

326. EPA (United States Environmental Protection Agency). Green infrastructure. Accessed June 1, 2017. https://www.epa.gov/green-infrastructure/reduceurban-heat-island-effect.

327. Lin, Brenda B., Stacy M. Philpott, and Shalene Jha. 2015. The future of urban agriculture and biodiversity-ecosystem services: challenges and next steps. Basic and applied ecology 16(3), 189-201; Jackson, L., K. Bawa, U. Pascual, and C. Perrings. 2012. Agrobiodiversity: a new science agenda for biodiversity in support of sustainable agroecosystems. DIVERSITAS report N 4.

328. Hotspots. Conservation International. Accessed June 1, 2017. http://www.conservation.org/How/Pages/Hotspots.aspx.

329. Barthel, Stephan, John Parker, and Henrik Ernstson. 2013, Food and green space in cities: A resilience lens on gardens and urban environmental movements, Urban Studies 52, no. 7: 1-18.

330. FAO (Food and Agriculture Organization of the United Nations). 2011. Urban and peri-urban agriculture. Accessed June 1, 2017. http://www.fao.org/docs/ eims/upload/215253/briefing_guide.pdf.

331. Salbitano, Fabio, Simone Borelli, M. Conigliaro, and Chen Yujuan. 2016. Guidelines on urban and peri-urban forestry. FAO Forestry Paper (FAO) eng no. 178; Salbitano, Fabio, Simone Borelli, and Giovanni Sanesi. 2015. Urban forestry and agroforestry. Cities and Agriculture: Developing Resilient Urban Food Systems, 285; Bottalico, Francesca, Gherardo Chirici, Francesca Giannetti, Alessandra De Marco, Susanna Nocentini, Elena Paoletti, Fabio Salbitano, Giovanni Sanesi, Chiara Serenelli, and David Travaglini. 2016. Air pollution removal by green infrastructures and urban forests in the city of Florence. Agriculture and Agricultural Science Procedia 8, 243-251. 
332. FAO (Food and Agriculture Organization of the United Nations). 2016. Building greener cities: nine benefits of urban trees. Accessed June 1, 2017. http://www.fao.org/zhc/detail-events/en/c/454543/.

333. Berte, Charles Jacques. 2010. Fighting sand encroachment: lessons from Mauritania. No. 158. Food and Agriculture Organization of the United Nations (FAO) Forestry Paper.

334. Georgia McCafferty. 2017. The rise of the urban jungle. CNN. Accessed August 1, 2017. http://www.cnn.com/style/article/urban-forests-osm/index.html.

335. ICLEI-Local Governments for Sustainability. Cityfood: An ICLEI/RUAF initiative. Accessed June 1, 2017. http://www.iclei.org/index.php?id=1348. 
